\title{
Shadows of traditions:
}

\section{Discourse shifts on the rule of law and China's modernity}

\author{
by \\ Ning Du \\ A thesis submitted to \\ the Faculty of Graduate and Postdoctoral Affairs \\ in partial fulfillment of \\ the requirements for the degree of \\ Doctor of Philosophy \\ in
}

Communication

Carleton University
Ottawa, Ontario

(C) 2010, Ning Du 
Library and Archives

Canada

Published Heritage

Branch

395 Wellington Street Ottawa ON K1A ON4

Canada
Bibliotheqque et

Archives Canada

Direction du

Patrimoine de l'édition

395, rue Wellington

Ottawa ON K1A 0N4

Canada
Your file Votre référence

ISBN: 978-0-494-70549-0

Our file Notre référence

ISBN: 978-0-494-70549-0
NOTICE:

The author has granted a nonexclusive license allowing Library and Archives Canada to reproduce, publish, archive, preserve, conserve, communicate to the public by telecommunication or on the Internet, loan, distribute and sell theses worldwide, for commercial or noncommercial purposes, in microform, paper, electronic and/or any other formats.

The author retains copyright ownership and moral rights in this thesis. Neither the thesis nor substantial extracts from it may be printed or otherwise reproduced without the author's permission.
AVIS:

L'auteur a accordé une licence non exclusive permettant à la Bibliothèque et Archives Canada de reproduire, publier, archiver, sauvegarder, conserver, transmettre au public par télécommunication ou par l'Internet, prêter, distribuer et vendre des thèses partout dans le monde, à des fins commerciales ou autres, sur support microforme, papier, électronique et/ou autres formats.

L'auteur conserve la propriété du droit d'auteur et des droits moraux qui protège cette thèse. $\mathrm{Ni}$ la thèse ni des extraits substantiels de celle-ci ne doivent être imprimés ou autrement reproduits sans son autorisation.
In compliance with the Canadian Privacy Act some supporting forms may have been removed from this thesis.

While these forms may be included in the document page count, their removal does not represent any loss of content from the thesis.
Conformément à la loi canadienne sur la protection de la vie privée, quelques formulaires secondaires ont été enlevés de cette thèse.

Bien que ces formulaires aient inclus dans la pagination, il n'y aura aucun contenu manquant. 


\begin{abstract}
This thesis seeks to define the modernity-tradition problematic from a perspective of epistemology. It argues that traditions are objects of discourses that are constructed under the modern epistemic condition. Under such a condition, the modern West and its world of ideas provide major references of thought when traditions are depicted. This approach to the modernity-tradition problematic has implications for transnational communication studies on two levels. First, it calls for analyses of the specific and diverse ways in which the modern condition orients non-Western narrations of traditions. Second, it requires communication analysts to reflect on the ways in which their own interpretations of traditions, to the extent that they are impacted by the modern epistemic condition, may affect their observations about patterns of communication in cross-cultural phenomena.

The thesis applies the proposed approach to study the changing discourses on "the rule of law"-an idea of Western origin-in socialist China. Employing a model of "discourse shifts" which is developed to study semiotic histories, the thesis analyzes the varying accounts of traditions in the transforming networks of discourses on "the rule of law" in China. It discusses how these accounts, while serving various social agendas, are commonly narrated within the modern epistemic framework. Moreover, it considers how divergent views on Chinese and Western traditions may lead to varied conclusions on the patterns of communication shown by the case. As such, this thesis is an alternative attempt at transnational communication analysis that highlights the importance of an integrated epistemological perspective. It also shows how such a perspective contributes to an understanding of China's modernity which avoids the teleology of the modernization paradigm, yet which does not trivialize Western influences on China.
\end{abstract}




\section{Acknowledgements}

It would be extremely difficult, if not impossible, to produce an exhaustive "thank you" list for such a project as a doctoral dissertation. I would first like to thank my supervisor, Karim Karim, for his indispensable mentorship, support, and encouragement in each phase of my doctoral study, and to thank Michael Dorland and Sheryl Hamilton for their inspiration and critiques without which the dissertation in its current form would have neither been possible. I am grateful to my supervisor and the advisory committee for their invaluable insights and comments from which I have benefited in each stage of the process. Thanks too to other faculty members and the staff in the program of Communication Studies who have made my experience at Carleton an enriching one.

I am also grateful to many friends of mine whose friendship has supported me along the way. I would like to thank particularly the family of Tom Lisi and Elaine Schuetz, the family of Ania Wasilewski and Kevin Murchie, as well as the family of Chengbin Feng and Merlinda Poon, who have made Ottawa a lovely place to live in, and have brought warmth and pleasure to my cross-cultural experience.

Last but not least, I am deeply indebted to my family, for the constant and invigorating encouragement and support from my husband, Nan Feng, my mother, Fan Xiaojing, and my grandparents, Fan Chao and Cao Jingchun. My baby daughter, Yanching, who was born while I was working on the dissertation, is a precious gift that grants new meanings to my life and brings me new strengths. I regret, however, that I have missed forever the chance to present the finalized dissertation to my grandparents, but I always cherish to my heart those moments together with them and am enormously grateful for what they have given to and instilled in me. 


\section{Chapter 1}

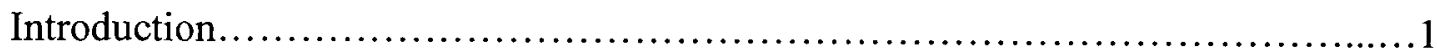

\section{Chapter 2}

"Tradition" revisited: Chinese and Western legal heritages.

\section{Chapter 3}

Discourse shifts

\section{Chapter 4}

The new socialists: Revolution and "the rule of law".

\section{Chapter 5}

Socialism in transformation: Post-revolution (re)emergence of the rule of law.....164

\section{Chapter 6}

Contemporary languaging of the rule of law: New waves in discourse shifts......210

\section{Chapter 7}

Shadows of traditions in China's modernity: Rethinking transnational communication in the discourse shifts on the rule of law.... 


\section{Chapter 1 Introduction}

The relation between modernity and tradition has been defined and reworked in variegated ways in theories of transnational communication. ${ }^{1}$ However, even competing paradigms in the field share common ground in treating the two as disparate and opposed frontiers. This polarization is more evident in accounts of cultural diffusion and confrontation, where global modernity and local tradition are often taken to be in an adversarial relation. In the theories of hybridization, such a dichotomization has been challenged on the basis of evidence of various syncretisms that are said to be combinations of the global and the local. However, there still exists the tendency to conceive of hybridity as that which "highlights the mixtures and discontinuities that have characterized...the encounter between the modern and the traditional in history" (Kraidy, 2005, p. 64; italics added). Marwan Kraidy once noted that "hybridity is a pervasive existential condition" (2004, p. 16; original italics). As celebrated as the approach of hybridization is as a subversion of other paradigms of transnational communication, one may nevertheless wonder: what, then, is the existential condition of hybridities? Are "modernity" and "tradition," if not two opposites, no more than two disparate entities only to be mingled in an epistemic vacuum? I argue that grappling with these issues leads one to the task of re-approaching modernity and tradition from a perspective of

\footnotetext{
' I will conduct a detailed literature review of the various theories of transnational communication later. What is provided here is a brief note of the conceptualization of the modernity-tradition relation in the theories.
} 
epistemology. In such an approach, one may conceptualize "modernity," not as a level of social development achieved in the West, but as a pandemic epistemic condition, under which the modern West and its world of ideas provide major references of thought when social realities are defined, problems are identified, and solutions are sought. Thus, "traditions," rather than being the antithesis of modernity, are a variety of discursive products of the modern condition that are configured to advance social agendas. This alternative approach to the modernity-tradition problematic has implications for transnational communication studies on two levels. First, it calls for analyses of the specific and diverse ways in which the modern condition orients non-Western narrations of traditions. Second, it requires communication analysts to reflect on the ways in which their own interpretations of traditions, to the extent that they are impacted by the modern epistemic condition, may affect their observations about patterns of communication in cross-cultural phenomena. In fact, if modernity and tradition are conceptualized as connected semiotic events, then, "diffusion," "confrontation," and "hybridities" are not so much epistemologically detached descriptions as observations resulting from subjective hermeneutics of traditions.

Applying the above proposed approach, this thesis analyzes the varying accounts of traditions in the transforming networks of discourses on "the rule of law" in socialist China. I will discuss how these accounts, while serving various social agendas, are yet commonly narrated within the modern epistemic framework. Moreover, while critiquing existing theoretical models of transnational communication, this study also seeks to 
rearticulate them based on the approach I propose, and to consider the various interpretations of traditions on the premise of which patterns of diffusion, confrontation, and hybridization may be observed in the case.

In the following parts of this chapter, I will introduce the central research questions of the proposed case study, discuss the main assumptions behind the key terms I employ, and argue the significance of the thesis. I will then present a critical review of related literature in the fields of legal studies, Chinese history, and transnational communication in order to explain further and situate my approach. Then, I will discuss the analytic framework and methodology to be adopted in the analysis of the discourse change of the rule of law in China. Finally, I will outline the structure of the thesis.

\section{Research questions, key terms, and significance}

For scholars of transnational communication, China offers an interesting example as it is both a territory profoundly impacted by the modern West and a land boasting a rich past. How, then, is one to understand the relation between "modernity" and "tradition" in

China? A major challenge therein, I suggest, is to problematize formulations in which the former is seen as what is to replace the latter, yet doing so without trivializing Western influences on China. In fact, the question of how to approach Western impacts on China has been a central concern for many historians, whose discussions of China's recent history, I believe, ultimately point to a question of communication. In a highly regarded work on modern Chinese history, Western influence is taken as a type of revolutionary 
force, under which the "traditional China was torn apart... and changed within the space of three generations" (Teng \& Fairbank, 1954, p. 1). This interpretation is later challenged, exemplarily by Paul Cohen (1984), who argues that Western impacts should not be exaggerated, and who proposes a "China-centered" approach to analyze internal factors that have propelled China's historical change. Cohen's approach, however, is in turn contested. As Prasenjit Duara (1995) points out, the "China-centered" model in effect sustains the essentialist lines of thinking which it is meant to displace. Duara contends that, in the study of modern Chinese history, Western influence should not be marginalized. On the contrary, Duara suggests, one should in particular attend to the question of how Western linear conceptions of history, as a type of discourse, figure as a dominant and repressive force in modern Chinese narrations of the past, the present, and the future. The question raised by Duara, I believe, is essentially a question of communication, one that highlights the centrality of the issue of epistemic hegemony and meaning construction to inquiries about China's modernity.

Recognizing the centrality of this issue, I suggest that theoretical models from the field of transnational communication be articulated with a perspective of epistemology to account for the relation between modernity and tradition in the Chinese context. By "a perspective of epistemology," I mean an approach which takes as its central task the analysis of the epistemic assumption(s) under which ideas are formulated and (or) "phenomena" are "observed." This approach—when applied to investigate the relation between modernity and tradition-requires, first, that one consider the epistemic 
connection between the two. And, as I have suggested, such a connection may be conceptualized as follows: modernity is to be viewed as a socio-epistemic condition under which traditions are configured and mobilized. ${ }^{2}$ Moreover, the approach requires that one review how different interpretations of traditions may form the bases for different observations about patterns of transnational communication. Following such an approach, I suggest that, for the current case, we study the epistemology of traditions in China's modernity. By proposing an examination of the epistemology of traditions, I am attempting a project of transnational communication analysis that not only looks at the ways in which various traditions have been constructed and evaluated in modernity, but also conducts a reflexive review of how diverse observations of communication patterns may emerge out of competing assumptions about traditions held by analysts themselves, who arguably are not exempt from the impact of the modern epistemic condition. Specifically, I will examine the discourse change on "the rule of law" in China from the late $1940 \mathrm{~s}$ - when the Communists came to power - to the present day and ask the following questions: How has "the rule of law"- an idea of Western origin-been discursively constructed in socialist China? How does the modern epistemic condition, or modern epistemology, impact on the depictions of traditions in the discourse? Finally, what patterns of transnational communication can be "observed" in the discourse shifts on the rule of law, and on what bases?

But how is discourse conceptualized in this study and is it a legitimate focus? And

\footnotetext{
${ }^{2}$ I will elaborate later on my assumptions about modernity and tradition.
} 
why choose to examine the discourses on the rule of law, especially those in socialist

China? Furthermore, many have contested linear conceptions of history, and some even avoid using the term "the modern" because of its links to Western-centrism (Cohen, 1984, p. x). ${ }^{3}$ Why, then, is "modernity"- often seen as a notion with Western-centric connotations—-still used as a key term in this study, along with "tradition," and what are the general assumptions underlying the usage? It is necessary to address these questions before moving on to discuss how the proposed study will be implemented.

Some may wonder how analyses of discourse — often seen as mere language rather than real actions - can help one understand China's recent social change. I will devote a section in the thesis to the discussion of my conception of discourse. However, for the purpose of this introduction, it is worth noting that, in this study, discourse is understood not only as a realm of products of semiotic activities, but also as an element/moment of the social. Elements/moments of the social include the material, the semiotic (the discursive), and the mental (including epistemology), which influence each other. As such, discourse is both constituted by, and constitutive of, other elements/moments of the social and, therefore, to analyze discourse change is an effective way to understand epistemological shifts that arise within changing social contexts. To relate this conception of discourse to the case in question, analyzing China's discourses on "the rule of law" means to look at the various ways in which the idea has been articulated and traditions

\footnotetext{
${ }^{3}$ Cohen (1984) points out that there has been "an intellectual bias that equated modern with Western and Western with important" (p. 2; original italics). This bias, it is argued, can be found in conceptualizations in which "Westernized China and modern China [are]...indistinguishable" (ibid.).
} 
have been constructed in the transforming Chinese society under its modern condition, thus to identify patterns of epistemology of traditions shown by the discursive changes.

Why, then, does the study focus on the discourses of the rule of law? This case is chosen, first and foremost, because law is one of the earliest issues that engaged the attention of the modern Chinese, both reformers and intellectuals, who were influenced by their exposure to the West or modern Japan. ${ }^{4}$ Although the discourse change on the rule of law is only one thread of China's highly complex social transformations since the $19^{\text {th }}$ century, it is no doubt one of the most important threads because it constitutes a changing field of reflexive thinking on different modes of social organization. ${ }^{5}$ As the rule of law is often seen as a hallmark of the West (Tamanaha, 2004), a focus on China's discourses on it will allow one to see whether and how Western heritages-in the forms in which they are perceived - are dominating modern Chinese conceptions of law. Further, both institutionally and intellectually speaking, the rule of law remains an area of intriguing ambiguity in contemporary China despite its constitutionalization in 1999. The analysis of its discourses in this thesis is not to undo or suppress the ambiguities, but to make them explicit and to trace the ways in which they have been related to the modern epistemic condition and to contingent social strategies. I particularly examine the

\footnotetext{
${ }^{4}$ The way in which $f a z h i$ (the rule of law) started to figure in the modern Chinese language as a product of Western influence is itself an interesting topic to study. But in this thesis I will focus on the semiotic history of the word in socialist China.

${ }^{5}$ In this study, "modes of social organization" is defined as the ways in which practices in various realms (economic, political, legal, military, familial, communal, cultural, technological, etc.) are organized and sustained in a society.
} 
discourses since the late 1940s and, as will be discussed, the discourses on the rule of law in socialist China - which can be seen as in some ways resembling while in other ways differing from imperial China—have exhibited typically complex relations between Chinese and Western traditions that cannot be reduced to either a relation of replacement or one of confrontation. Rather, one sees a dual hybridity in the case, as I will argue in the conclusion.

As I use the term "China's modernity," one may wonder: does the usage of the term "modernity" - with its connotative links to the history of the West-not subordinate China's history to a Western-centric view? I argue that to refer to China's recent social change as "China's modernity" is not necessarily submitting to Western-centrism. As I have pointed out earlier, in this thesis, modernity is conceived of as an epistemic condition triggered by the recognition of a significant modern West. Four assumptions concerning this conceptualization are particularly noteworthy, which will be discussed in the following paragraphs. They are about, respectively, the time frame of China's modernity, the differentiation of "modernity" from "modernization," the role of the West in China's recent history, and the conception of tradition. ${ }^{6}$

First, how should one identify the beginning time of China's modernity? Some refer to the Opium Wars in the mid-19 $9^{\text {th }}$ century (Fairbank, Reischauer, \& Craig, 1965) when the Chinese troops were defeated by the English and the French who were much better

\footnotetext{
${ }^{6}$ The discussion of these assumptions is developed as a product of literature review. This section will focus on the assumptions only. See the next section for the literature review in detail.
} 
armed, which resulted in humiliating territorial concessions by the Chinese. However, critics point out that this is a Western-centric account of Chinese history in that it tends to over-emphasize the implications of Western impacts while neglecting China's internal social change (Cohen, 1984; Wang Hui, 2004). In fact, other authors reject the OpiumWars definition of China's modernity and, instead, point to the fall of aristocracy, the rise of nationalist ideology, the emergence of a centralized political system, etc., in the early years of the Song Dynasty (960 C.E.-1279 C.E.), suggesting that modernity started in China as early as in the $10^{\text {th }}$ century (Wang Hui, 2004). The problem with this view, however, lies in the fact that it does not explain why the decline of aristocracy, the emergence of nationalism, etc., are necessarily signs of the modern. As some point out, what underlies this narrative is still a Western-centric view of history, which uses the hallmarks of the Western history as the yardsticks to account for the history of others (Wu Guo, 2006). It should be noted that this criticism is highly valuable as it points to the tendency with which the word "modernity" has been used without enough caution against Western-centrism. However, despite the validity of such criticism, one may ask: as the meanings of "the modern" indeed originated in the West, how could one avoid Westerncentrism if the term "modernity" is used? Or, is it just illegitimate to use the term to talk about China's recent change?

I suggest that the term does not need to be discarded and, on the contrary, should be usefully retained for the delineation of historical periods of China. But this is not because I believe that there is a universal stage of history called "modernity" that every country 
must go through at some point; nor is it because this study subscribes to Westerncentrism, arguing that China's modernity is about China following the Western path of development. In this study, China's modernity is defined as beginning in the mid- $19^{\text {th }}$ century. This is a time when the Chinese started to face themselves with an "other" who calls itself —and thus is often referred to as—-the modern; moreover, this is a time when the presence of and the ideas from this "modern other" started to impact on the Chinese in significant ways with significant consequences. ${ }^{7}$ Thus, to refer to the mid- $19^{\text {th }}$ century as the beginning of China's modernity is not nodding to Western-centrism. Rather, it points to the fact that, from then on, "the modern West" has become a major reference of thought - sometimes imagined as a guiding tool while other times portrayed as a devil to avoid—when the Chinese attempt to address social problems. It has been pointed out that, in this study, I will concentrate on socialist China to analyze its discourses on the rule of law. While socialist China only constitutes part of China's experience under its modern condition, I nevertheless choose to look at this historical period because socialist China is itself a product of both Western influence and anti-Western movements (Levenson, 1968a, p. 134; Yu Y., 2004e, pp. 213-214; Wang Hui, 2003, p. 150). Thus, it offers an interesting example for us to think about the relations between Chinese and Western traditions in China's modernity.

\footnotetext{
${ }^{7}$ However, this is not to say that everything that has happened in China since then is simply a consequence of the contact with the West. Furthermore, the West is not a monolithic whole. But "the modern" has been a mark of identity of the Western countries and Japan in their contact with China since the late $19^{\text {th }}$ century.
} 
Some may notice that this periodization of China's modernity overlaps with that of John Fairbank and others (1965) who see the mid-1 $9^{\text {th }}$ century as the starting point of China's "modern transformation," or its modernization. It should be pointed out, however, that I am not using "China’s modernity" as just a synonym of "China’s modernization." On the contrary, I argue that the two terms cannot be conflated--this constitutes my second assumption concerning China's modernity. To be sure, while some see "modernity" and "modernization" as carrying opposing meanings, others use them interchangeably (Pratt, 2002, pp. 34-35). For this study, however, the two need to be differentiated, particularly if "modernization" means following the Western course of development in every aspect of society, or Westernization.

It is also noteworthy that to define China's modernity based on its contact with the West is not to attribute to the West a predominantly decisive role in China's history, which is my third assumption concerning China's modern condition. This assumption is related to the question of how to understand the role of the West in China's history since the mid- $19^{\text {th }}$ century. Debates have been carried out concerning whether China's social change since then was driven externally or internally. For those who emphasize external factors, the impact of West is given tremendous weight that others contest (Cohen, 1984). For those suggesting internal drives, the West does no more than accelerating changes already going on in China (ibid.).

I would suggest that the West should not be seen as the sole precipitator of change in China. At the same time, however, I take the line that Western influences are undeniably a 
significant part of China's recent history, and that they are more than an accelerator of social change because they have an impact on the direction of the change, which, nonetheless, is not teleological but has developed within China's own social contexts. Furthermore, I assume that static dichotomization between the exogenous and the endogenous does not hold as long as cultural or national essentialism (J. Friedman, 1995, pp. 80-81) is to be cautioned against. ${ }^{8}$ In fact, as Lydia Liu notes, "to draw a clear line between the indigenous Chinese and the exogenous Western in the late twentieth century is almost an epistemological impossibility" (L. Liu, 1995, p. 29). Liu's remarks, although made for another context, point to two issues that are of important relevance to this study. On the one hand, it is an issue about the fluidity of ideas. When ideas are seen as dynamically constituted rather than as inherently belonging to any cultures, one is allowed to understand better the interplay of both external and internal factors in the everevolving construction of meanings in any culture. In this study, this can be seen in the way in which articulations of the rule of law have developed neither as an "authentically" indigenous invention nor as a result of external imposition. On the other hand, what is at stake is a hermeneutic issue that analysts need to bring to the foreground. As intensified exchanges between social borders have blurred the boundaries in the world of knowledge and understanding, no claims of epistemological pureness-- essentially Western, Chinese,

\footnotetext{
${ }^{8}$ In the study of cultures, the problem of essentialism is that it "literally flattens out the extremely varied ways in which the production of meaning occurs in the contested field of social existence," and that it "atrociously...conflates the identification of specificity [of certain cultures] by the anthropologist with the creation and institutionalization of semantic schemes by those under study" (J. Friedman, 1995, p. 81).
} 
or objective - can be convincingly made on the part of any "observer" for any "observations" about cross-cultural flows and influences. This has implications for the current study in the sense that, first, being conducted by someone of Chinese origin yet influenced by Western theories, the analysis presented in this thesis is neither "Chinese" nor "Western," or is both Chinese and Western. Second, the necessary existence of epistemological ambiguity points to the need to explore the ways in which seemingly simple and similar "phenomena observed" or "patterns identified" may arise as a result of complex and diverging understandings or perspectives. In the conclusion chapter, I will discuss how this is so when one attempts to capture the general shifts underlying the discourse changes on the rule of law in socialist China.

The fourth assumption about China's modernity is concerned with the conception of tradition. In Western-centric views of history, the traditional is often seen as the opposite of the modern represented by the West, and traditions cannot escape their erasure by modern Western ideas and practices (Lerner, 1962). Even in some studies where the issue of tradition is treated with more sensitivity, the continuity of traditions is deemed as something that comes into place "despite Western influences" (Q. E. Wang, 2001, p. 5). In this study, however, tradition is not defined as simply that which pre-exists and then counters Western modernity, and is not seen as confined to the non-Western. In Chapter 2, I will discuss in detail how tradition is conceptualized in this study. In brief, "tradition" is understood, rather, as the political product of the modern condition, existing in the form of discourse which portrays certain ideas and practices as marks of identities. I suggest 
that modern Chinese constructions of Chinese and Western traditions are predicated on the recognition of a hegemonic West that possesses significant ideas, no matter whether this perceived West is condemned or followed. Moreover, the modern epistemic condition exerts diverse rather than monolithic influences on depictions of traditions, as the latter are involved in various social efforts to maintain, dispute, or reform the status quo of a society.

In sum, I propose to examine the changing Chinese discourses on the rule of law as a case to understand the epistemology of traditions in China's modernity. This study is significant for a number of reasons. First, it is an effort to define the modernity-tradition problematic from a perspective of epistemology. While stressing the impacts of the modern epistemic condition on constructions of traditions, it also attends to the variability of those impacts, the analysis of which highlights the intricate connections between traditions as discourses and changing power relations in a society.

Second, the thesis develops a model of "discourse shifts" to analyze the dynamic relations between epistemology, discourse, and social hegemony over time. This model suggests a way to look at changing networks of social agendas and assumptions in transformations of discourses. As an analytic instrument, it can be applied not only to the current case but also to other studies of semiotic histories. When employed in this thesis, it helps one examine the varying ways in which modern epistemology and contingent social agendas frame articulations of traditions in the shifting Chinese discourses on the 
rule of law. ${ }^{9}$

Third, the thesis points to the indispensability of epistemological reflections in analyses of transnational communication phenomena. It suggests that patterns of crosscultural communication are results of subjective observation and, particularly, are also effects of the modern condition. That is, the body of knowledge that a contemporary communication analyst relies on to offer observations is itself part and parcel of the modern system of ideas which is anything but monolithic. As such, it is necessary to note how different understandings of traditions held by different observers may lead to diverging accounts of analysis of cross-cultural communication phenomena.

Fourth, with the case of the Chinese discourse shifts on the rule of law, I attempt a rearticulation of three existing theoretical models of transnational communication. This rearticulation, which is guided by a perspective of epistemology, shows that the three models are not necessarily opposed to each other, but rather can overlap in ways that have not been sufficiently addressed in existing literature.

Finally, this study attempts a conception of China's modernity that avoids the teleology of the modernization paradigm, yet which draws attention to the diverse ways in which modern epistemology affects China. I argue in this thesis that China's modernity is a historical condition characterized by ongoing and varying reflexive thinking about Western ideas and practices as well as China's own experience. As will be shown,

\footnotetext{
${ }^{9}$ In this study, I use the term "modern epistemology" interchangeably with that of "the modern epistemic condition," and that of "the modern epistemic framework."
} 
modern Chinese discourses are far from a disavowal of the past, yet the continued preoccupation with traditions does not suggest the undisturbed perpetuation of any "heritage" into modernity; neither does it imply the temporary concession of any "true Chinese-ness" which awaits an eventual resurrection. Rather, modern Chinese narrations of traditions are shifting discursive interventions in which historical pieces are extracted from here and there to be reconciled with contemporary needs, yet with the assistance of adapted tools of modern knowledge. As an example of this which I will show in this thesis, the meanings of "the rule of law" under China's modern condition refuse to be stabilized or categorized, but transform as a space of stratagem where modern epistemology defines and embeds various traditions in shifting social contexts, by both repelling them and revering them. If history can be understood as a body of events with indefinite shape, and the modern epistemic condition as constituting variegated sources of light through which images of history are projected, shadows of traditions can then be seen emerging under such lights, or diminishing, or transforming. ${ }^{10}$

\section{Literature review}

As the study focuses on discourse change of the rule of law in China, it is necessary

\footnotetext{
${ }^{10}$ The metaphor of light and shadow is also present in some existing critique of Euro-centrism (Liu H., 2000), which highlights the need to identify possibilities of knowledge outside such a centrism. While acknowledging the indispensable value of such an appeal, I use the word "shadows" in this study not only to discuss the changing shapes of traditions as they are narrated under the modern epistemic condition, but also to note the "embeddedness" of my own analysis of traditions in the modern condition. As such, just as Michel Foucault comments in The Archaeology of Knowledge (1972) that a set of statements may in fact "reactualize others" simply by "commenting on" them (p. 98), my analysis belongs to the same discursive formation of the modern condition as those under study.
} 
to discuss literature in three fields. In this section, I will first look at recent works in legal studies that analyze China's changing discourses of the rule of law. The review of these works will focus on their underlying paradigm and its problems. Given the historical perspective of the study, I will then turn to some major works on recent histories of China. In particular, I will discuss how they address relations of temporality and spatiality in China's history since the mid- $19^{\text {th }}$ century, and will show how this study builds on the existing approaches. ${ }^{11}$ Finally, I will review three theoretical models in transnational communication studies and argue that an epistemological perspective is needed in the field to understand the relation between modernity and tradition. ${ }^{12}$

\section{China's changing discourses on law: The theme of modernization in legal studies}

In the Chinese literature on law, legal modernization is a dominant theme and is often connected to Marxist ideas. While many describe China's legal reforms since the $19^{\text {th }}$ century as part of China's modernization process (Zhang J., 2005; Gong, 2006), this process is also interpreted in Marxist terms. In his review of the recent history of Chinese law and order, Zhang Jinfan, a leading Chinese legal scholar, argues that China's legal modernization has gone through several phases, and that legal reforms in different phases reflected the class interests and political needs of different regimes (2005, p. 426). This

\footnotetext{
"In this study, "relations of temporality" refers to relations between China's past and its present; "relations of spatiality" refers to relations between China and the West.

${ }^{12}$ Given the "discourse" approach of this study, there is another field of literature that should be reviewed, namely, discourse studies. This will be done in a separate chapter on theoretical framework that is specifically devoted to a discussion of existing conceptions of discourse/discursive dynamics and my own conceptualization of "discourse shifts."
} 
Marxist interpretation is also echoed by other authors (Shi, 2006). Moreover, despite the increasingly rare mention of Communism as the final end of social development, many authors still employ Marxist conceptions of historical stages in their discussion of the case of China (Zhang J., 2005; Gong, 2006; Shi, 2006). For them, the recent transformation of Chinese discourses on law and order, as part of China's legal modernization, reflects efforts of the country to rid itself of its feudal past and to embrace modern ideas.

The approach to tradition in the Chinese scholarship is typical of the modernization paradigm, which understands the traditional as the opposite of the modern. To be sure, while some authors lament how old beliefs have obstructed the implementation of "advanced" laws (Shi, 2006), others note the "progressive" elements of traditional values that can be mobilized to promote modern ideas, such as the notion of min gui jun qing (the ordinary people are more important than the monarch), which resembles the modern idea of democracy, and that of you jiao wu lei (education is for all), which fosters the spirit of equality (Zhang J., 2005, pp. 428-429). However, in most writings, the overwhelming tone is one that stresses the gap between tradition and the desired modernization (Zhang J., 2005, pp. 425-439; Gong, 2006, pp. 337; Shi, 2006, p. 53; Jiang L., 2006, p. 41).

The view toward tradition in the Chinese works is related to their understanding of the role of the West in China's legal reforms. For many authors, China's transformation in law is entirely triggered by its contact with the West; furthermore, they argue that, given 
the gap between China's tradition and the modern law exemplified by the West, China needs to "transplant" elements of the "modern legal civilization" in order to realize modernization (Zhang J., 2005, pp. 426-427). As Deng Zhenglai (2006) and Wang Cunhe (2005) point out, Chinese legal scholarship and legal construction have been dominated by "the mindset of modernity" (Wang C., 2005, p. 2) which is predicated on the idea of modernization.

In the English world, the most relevant literature is Randall Peerenboom's voluminous China's Long March Toward Rule of Law (2002) (hereafter referred to as China's Long March), which was written with a critical consideration of preceding works that address similar topics. In this book, as in much of the literature in Chinese, the discourse on law is not the primary concern. ${ }^{13}$ Therefore, the relevance of the book for this review does not lie in its core arguments. It consists, rather, in the language used to talk about issues of the rule of law. When one notes the rhetoric employed in Peerenboom's work, one finds a dilemma of language that any work on the subject of the rule of law—even the truly serious ones—could easily fall into. This dilemma appears when one intends to avoid the modernization paradigm but nonetheless has to fall back on notions typical of it, probably due to the poverty of available conceptual tools. When the use of "paradigmic notions" occurs without qualification or further explanation, it will have counter effects and serve to support rather than challenge the paradigm one

\footnotetext{
${ }^{13}$ To be sure, Peerenboom devotes a portion of his work to debates on the rule of law in China, which is highly valuable. But those discussions can be seen as mainly intended to pave way for the evaluation of China's legal reform.
} 
wishes to caution against.

One can find an example of the dilemma concerning the use of the term "modernity" in Peerenboom's work. In the opening chapter of his book China's Long March, Peerenboom contends that "we need to theorize rule of law in ways that do not assume a liberal democratic framework, and explore alternative conceptions of rule of law that are consistent with China's own circumstances" (p. 5). This statement can be understood as suggesting that analyses of the rule of law in China-either its discourses or related actions - should avoid the teleology of the modernization paradigm which assumes liberal democracy as the end of history. However, in other places of the work, the language employed is strongly reminiscent of the paradigm that is to be avoided. For instance, the rule of law is described as one of the "hallmarks of modernity" (p. 1) and China's legal reforms are viewed as the attempts of the country to "come to grips with modernity" (ibid.). Without further clarification of what is meant by "modernity," such statements may lead to the interpretation that there is a universal and transcendental relationship between modernity and the rule of law, and that China is in a difficult process of emulating the West, the latter having set up a model of modernity - and thus of the rule of law - that is to be pursued by all others. ${ }^{14}$ Or, at the very least, such statements suggest a "modernization frame of understanding" according to which China's recent transformation is essentially a local response to self-evident Western "stimuli," but not a

\footnotetext{
${ }^{14}$ Pereenboom also discusses China in relation to the "East Asian Model" (Pereenboom, 2007). But his ideas are still to a large extent predicated on the modernization paradigm.
} 
process in which the perceived modern both orients and is appropriated in China's attempts to redefine ideals of social organization. ${ }^{15}$

In sum, the modernization paradigm dominates the literature on China's recent change in the realm of law. Marxist and non-Marxist ideas of modernization may diverge on some issues, but they are no more than different branches of the same tree as both reflect the problems of the modernization paradigm, particularly the tendency to dichotomize between China's modernity and its past. In this study, the term "modernity," a notion often related to the modernization paradigm, is employed but with qualifications, as have been discussed. In accounts of China's recent social change, the modernization paradigm in fact has been critiqued by some historians of China and alternative frames of understanding have been proposed.

\section{China's recent history: Dimensions of temporality and spatiality}

As Paul Cohen (1984) points out, historians of China have developed "increasing disenchantment... with respect to modernization theory as a framework for approaching recent Chinese history" (p. 57). In particular, the question of how to address temporal and spatial relations in China's "modern" change has been something that historians are constantly confronted with. The issue of temporality is concerned with the relation between the past and the emerging ideas and practices in China, while the issue of spatiality is about how to understand Western influences in China's history. I have

\footnotetext{
${ }^{15}$ The modernization frame, or the stimulus-response model, of historiography will be discussed later.
} 
discussed related issues in the preceding section, such as those concerning the role of the West in China's recent history and the conception of tradition. In the following review, I will consider how existing historiographies on China have addressed Chinese traditions as well as the role of the West, and how they inform this study.

As has been mentioned, the modernization approach to social change tends to simplify spatial and temporal relations. One of the most influential criticisms of this approach in historical writings on China was put forward by Paul Cohen. In Discovering History in China (1984), Cohen offers a critique of what is called the "impactresponse"-or "stimulus-response"- frame of narration, two synonyms for the modernization approach. Cohen finds the presence of this frame in the works of John Fairbank (Teng \& Fairbank, 1954; Fairbank, Reischauer, \& Craig, 1965) and those of Joseph Levenson (1968a, 1968b), both renowned historians of China. The impactresponse narrative, according to Cohen (1984),

...rested on the assumption that, for much of the nineteenth century, the confrontation with the West was the most significant influence on events in China. A further assumption... was that it was the West that played the truly active role in this period of Chinese history, a much more passive or reactive part being taken by China. (p. 9; original italics)

It is noteworthy that, when introducing his approach to China's recent history, Fairbank himself also recognizes the problems with his narrative model. He admits that notions such as "'response' to foreign stimuli, and of modernization both technological and otherwise" "have their limitations," and that "much has evolved quite naturally from 
within East Asian civilization, not as a response to external stimuli” (Fairbank, Reischauer, \& Craig, 1965, p. 6). Nonetheless, Fairbank is convinced that "the best central theme around which to organize the complicated, many-channeled story presented in this volume [his book on "the modern transformation" in East Asia] is the modernization of the East Asian tradition, primarily as a response to Western stimuli" (ibid.). As Cohen points out, although Fairbank "alluded...to some of the basic flaws of the impact-response framework," "subsequent historians (including Fairbank himself) tended to take over the framework without paying much heed to these qualifications" (1984, p. 200).

Cohen also finds similar problems in the works of Joseph Levenson, despite his appreciation of Levenson as a scholar who "addressed the issues of modernization and cultural change more persistently [and] imaginatively...than perhaps any other American historian of China in the immediate post-war decades" (p. 61). Cohen points out that Levenson's historiography is "essentially an amplification of the impact-response paradigm" (p. 151) and, thus, he takes issue with some of Levenson's "ready assumption[s]" (p. 77) in the handling of both spatial and temporal relations.

In terms of spatial relations, Cohen notes, Levenson overstates the impact of the West as if "the West alone initiated the breakdown [of the Chinese society in the $19^{\text {th }}$ century] and remained its principal (if not exclusive) causal agent" (ibid.; original italics). Levenson's writings, Cohen suggests, attribute two roles to the West in China's recent history: "... first, as a solvent, against which the old [Chinese] culture stood defenseless; 
and second, as a model on which a new Chinese culture was increasingly patterned" (p.

78). Levenson's commentary on the "change of language"--in contrast to what he refers to as mere vocabulary change-in China in the $19^{\text {th }}$ century seems to reflect what Cohen criticizes:

As long as one society is not being conclusively shaken up by another, foreign ideas may be exploited, as additional vocabulary, in a domestic intellectual situation. But when foreign-impelled social subversion is fairly under way (and that has been so in China, not in the West, and in China only in the nineteenth century and after), then foreign ideas begin to displace domestic. This change of language in a society may be described objectively as new choices made under conditions of total invasion. (Levenson, 1968a, pp. 158-159)

This line of narration, Cohen (1984) argues, does not take into account the fact that China's social change since the $19^{\text {th }}$ century has occurred as the result of "indigenous problems of long standing...that might be aggravated by the West but were not its [the West's] exclusive...creations" (p. 79).

Meanwhile, Cohen argues, Levenson's writings reflect an approach to temporal relations that assumes a tradition-modernity dichotomy, which is based on the $19^{\text {th }}$ century Western understanding of the traditional China as essentially "unchanging" over time (pp. 59-61) before its contact with the West in that century. After the contact, according to the Levenson in Cohen's account, the Chinese tradition is gradually displaced by Western ideas, as the metaphor of the change of language indicates. This view of tradition, Cohen suggests, is typical of the impact-response conception of China's recent history, according to which "China as a 'traditional' society, stuck in time, [was] 
capable of being stirred from its eternal repose only by the life-giving force of a dynamic and 'modern' West" (p. 151).

Nonetheless, it needs to be pointed out that, although some of his commentaries may apparently seem similar to those that are based on a tradition-modernity binary, Levenson in fact stresses that in the $20^{\text {th }}$ century the Chinese turned to Communism neither to restore the past nor to follow the West $(1968 \mathrm{a}, \mathrm{pp} .134,141)$. Levenson notes, in the $3^{\text {rd }}$ volume of Confucian China and Its Modern Fate (1968b), that he does not "maintain that China's connection with its past is concluded" (p. v). According to him, the past figures in the present as a remembering that is held onto and thus preserved (pp. 76-77, 124-125), "a national monument" that is "unworshipped...yet also unshattered" (p. 79). By being preserved as items of historical significance, Levenson suggests, the past continues to exist in the contemporary world as old artifacts that are on display in museums (pp. 7682), and as specimens of history that are to be analyzed (pp. 70-71). Levenson also points out other ways in which the past exists as historical milestones that are not idolized any more but are scrutinized and patronized to consolidate new conceptions and practices (pp. 65-75). The question of past-present relation, however, cannot be disconnected with a spatial question, which is in fact raised by Levenson's remarks about language change, that is, the question of "how to explain the 'traumatic choices' made by the Chinese since their violent encounters with Western imperialism" (L. Liu, 1995, p. 30). As a question that "does not easily go away" (ibid.), it leads one to consider how, or the epistemic condition under which, the past is memorized, scrutinized, or patronized. 
Other authors also distance themselves from dichotomizing temporal and spatial relations in China's recent history. Benjamin Schwartz, an influential American historian of China, points out that the past continues to "have an ongoing existence in the present," and that "'Chinese past' and 'modernity' may not confront each other as impenetrable wholes" (1976, pp. 108-109). Similarly, Yu Yingshi, another major scholar of Chinese intellectual history, argues that tradition is not static and that it contains inner contradictions which may help extend certain parts of it into the future (2004b, p. 317). Yu notes that cases of anti-traditionalist iconoclasm existed in China before its contact with the West in the $19^{\text {th }}$ century, and that events and movements in China which are often understood as essentially responses to Western challenges in fact have their own roots in the traditions of the country (2004d, pp. 87-88). Thus, Yu's view allows him to explain social change without falling prey to the Western-centric sense of spatiality which takes the West as the primary and most important propeller for change in China. However, in the temporal dimension, one may still raise a question about the status of traditions: under what condition, or by what criteria, are the contradictory tendencies in China's own traditions detected? One may wonder whether the discovery of the "rebellious" elements of the traditions is not an effect of the recognition of certain traits of the Chinese past as Western-like, and whether the discovery itself is not part of an effort to establish equivalence between China and the West.

Alternative models have also been suggested to replace the modernization approach. In contrast to the approach in which China's recent history collapses into a dualism 
between the modern proactive West and the traditional reactive China, Cohen discusses

"a China-centered history," "the main identifying feature of the new approach" being that "it begins with Chinese problems set in a Chinese context" (1984, p. 154). Moreover, in order to avoid temporal and spatial polarizations, ...the China-centered approach lends itself to a structuring of the Chinese past more in historical than in cultural terms....... its locus of comparison is not the differences between one culture and another (China and the West) but the differences between earlier and later points in time within a single culture (China). The former kind of comparison, by drawing attention to the more stable, ongoing attributes or properties of a culture-a culture's intrinsic nature - encourages a relatively static sense of the past. The latter, by stressing variation over time within one culture, fosters a more dynamic, more change-oriented sense of the past. (p. 190)

In this approach, the focus is on temporal changes within China rather than intercultural comparison. As Duara (1995) notes, Cohen proposes to attend to "the shaping force of the past" by "turning away from the centrality of 'culture' and 'tradition"” (p. 26). Thus, instead of trying to identify the essential differences between cultures - that is, to project China as "the traditional" opposed to the modern West—Cohen aims to map out transformations over time within China.

It is noteworthy, nonetheless, that the China-centered approach is valuable but, if taken to extreme, it will foster conceptions that isolate the past of the country, as if any mention about Western influences would be a contamination of the history of the genuine and authentic China, or all studies of "tradition" would be victims of the modernization paradigm. In fact, Arif Dirlik (1996) criticizes Cohen's China-centered approach as essentialist, which ironically coincides with the impact-response model in terms of 
external/internal isolation and dichotomization (p. 267). ${ }^{16}$ Duara (1995) also points out that, as "pioneering" as it is, Cohen's approach seems to posit that "there is a prefigured narrative to be recovered" from China's past, yet the "history of China can no longer be innocently a history of the West or the history of the true China" (p. 26). Duara instead proposes the conception of "bifurcated history," in which the meanings of the past are seen as "dispersed in space and time" (p. 5; original italics). He argues that, rather than attempting to "recover an uncontaminated, original history of China," one needs to "attend to the politics of narratives" (p. 26), in which "layers of narrative... seek to appropriate or wrestle with the historical real" (p. 27). This approach to China's recent history lends a vision of non-linearity to the issue of tradition. Transposing such an understanding to the context of this study, one should conceive of tradition not as that which precedes and contradicts Western modernity, but as objects of discourses that are politically narrated under the modern condition. In this way, one may better appreciate the variety of ways in which the past connects to the present neither transparently nor innocently but through discursive mediation and mobilization.

Duara defines his approach as guided by "the general framework of postcolonialism," which is "still vaguely defined" (p. 6). As valuable as the postcolonial perspective is, given its vagueness, a few clarifications should be made with respect to

\footnotetext{
${ }^{16}$ Cohen's following comments may be taken as a defense for his model: "My use of the term Chinacentered is not intended to describe an approach to this history that ignores external determinants and treats China in isolation from the rest of the world... Rather, China-centered is intended to delineate an approach to recent China history that strives to understand what is happening in that history in terms that are as free as possible of imported criteria of significance" (1984, p. 196; original italics).
} 
how it is approached in this study to be correspondent with the assumptions taken about

China's modernity. First, Western hegemony as a historical fact and Western centrism as a knowledge framework are interrelated but are also to be differentiated. To critique Western-centric knowledge is not to negate the historical role of Western ideological influences on China - in fact, such a negation would only undermine postcolonial critique as it removes the latter's target of criticism. Second, while the hegemony of Westerncentric knowledge should be critiqued, extremism should be avoided which emphasizes the incommensurability between China and the West. As some observe, the application of postcolonial critique in China has led to a trend of "postism" that has amounted to a new conservatism, or "another version of nationalism" (Sheng, 2007, p. 124). The new conservatism in effect perpetuates the dualism posited between China and the West, selfdefeating its own purpose of critique. Moreover, parochial nationalistic fetishism, which some postcolonial theorists warn against, has in the Chinese context displaced "the criticism of its 'mother country's institutional culture' with the opposition between China and the West, which is, whether politically or culturally, both a compromise with the status quo and a voluntary relinquishment of the responsibilities of the intellectuals" (pp. 124-125). ${ }^{17}$ In this connection, the issue of power emerges and requires critical attention, which has been approached in various ways in transnational communication studies, the

\footnotetext{
${ }^{17}$ As Sheng (2007) explains, the post-1989 rise of postism or new conservatism in China "had to define its first and foremost antagonism in the relationship between the Third World and the First World, because the social conditions for antagonistic cultural criticism [targeting domestic cultural politics] didn't have the social conditions of existence in present China" (p. 125).
} 
major theoretical models of which I will review below.

I argue that the modernity-tradition issue is not one that can simply be avoided or dismissed. As Duara (1995) notes, although his goal is to critique an evolutionary view of history that has created "the false unity of a self-name, national subject over time" (1995, p. 4), it is nevertheless impossible "to radically displace the nation as the locus of history, if for no other reason than that our values...have been intimately shaped by the nationstate" (p. 6). To appropriate Duara's remarks for the context of this study, one may say that, while the hegemonic "modern" is to be contested, one needs to acknowledge at the same time that it has been part of the status of our being. As such, one is not allowed to evade the problematic of "modernity," but needs to come to terms with the question of how "the modern" figures in "traditions." For this, the field of transnational communication studies has provided theoretical frameworks that are worth critical consideration.

\section{Transnational communication: Patterns and power}

As the rule of law is a term of Western origin, the discourse change on this subject in China can be seen as a typical case of transnational communication. It needs to be pointed out that to situate the case within the context of transnational communication is not to revive the impact-response paradigm in which the West is seen as the sole cause of change. I argue that theoretical models of transnational communication should be reviewed if one is to consider how they can be rearticulated to account for the case in a 
way that does not ahistorically prioritize "Western modernity" yet seriously confronts the question of its influence. The review in this section will address two questions: how do existing theories conceptualize patterns of communication across national borders? And how do they approach issues of power? The focus of the review will be on existing studies that analyze the cultural aspects of transnational communication. Admittedly, not all studies applying the examined approaches explicitly address the relation between modernity and tradition. However, they more often than not take as their central concern the relation between the West, with which "modernity" is primarily associated, and other localities in the world, which are comparatively taken as the "traditional." 18 The relation between modernity and tradition has been approached in various ways, yet in which the perspective of epistemology does not seem to have played a central role.

Existing approaches to transnational communication can be divided into three groups in terms of their theorization of patterns of communication and power. ${ }^{19}$ The first can be called the diffusion approach, which has been embraced, ironically, by both critics of

\footnotetext{
${ }^{18}$ Of course, such a dualistic naming has been disputed. The notion of alternative modernity, for example, has been used to talk about the course of development of "traditional" societies. However, the stress on "alternative" itself indicates the association of modernity with the West in the first place. On the other hand, the retention of the term "modernity" suggests that the "traditional" is to be elevated from its original status to become modern.

${ }^{19}$ This does not mean that there are no commonalities across these groups or there are no inner contradictions within each group. David Held and Anthony McGrew have offered in The Global Transformations Reader (2003) a celebrated account of debates of globalization, in which they identify "an emerging fissure between...the globalists... and...the sceptics" (p. 2; original italics). Their criterion of grouping is the difference in viewpoints on the question of whether globalization is real or is an ideological construction. This criterion is valuable but is not taken in this study because the discussions in Held \& McGrew are to a large extent centered on issues of the nation-state, which is related to but is not the main focus of this study. The three approaches differentiated in this study are similar to the "three paradigms of globalization" defined by Jan Nederveen Pieterse (2004). However, Nederveen Pieterse does not elaborate on the theorization of power in the paradigms he discusses.
} 
cultural imperialism and advocates of modernization. Despite many of their differences, authors taking this approach subscribe to what can be called a "hypodermic model of communication," one in which the modern West is more often than not seen as the powerful sender of messages to which other parts of the world have to react. Views may differ among these authors with respect to whether Western influences are desirable or not for non-Western countries. For some, Western impacts mean drives for the modernization of the traditional, whereas for others they imply imperialism. Nonetheless, for both advocates and critics of Western influences, there seems to be a common understanding that the expansion of the West creates in other countries conditions favorable for Western modes of social organization. Thus, those who strive "to identify the many ordinary, everyday ways that life in the South has been affected by the social structures of imperialism" (Sreberny-Mohammadi, 1997, pp. 50-51) may refute the recommendations by others "to modernize traditional societies" by constructing "Western empathic personality types" (Mody, 2003). However, those concerned with the implications of cultural imperialism (Schiller, 2003) are no less convinced about the power of the West than those who believe in the superiority of Western ways of social organization. ${ }^{20}$ To be sure, critics of cultural imperialism also note the resistance to Western cultural industries which has arisen "all around the world" (Schiller, 2003, pp. 330-332). However, the overall emphasis is on the global dominance of Western cultural

${ }^{20}$ See Mody (2003) for accounts of the modernization approach to development. Also see Fukuyama (1995) and T. Friedman (2000). 
conglomerates that has resulted in corporate transnationalism to the detriment of the "disadvantaged societies" (pp. 322-329).

How, then, is "power" understood in this approach? An extremist application of the diffusion approach is most illustrative in this connection. It can be found in a recent innovative attempt by John McNeill and William McNeill (2003) to write a world history from the perspective of communication. In this work, the authors assert that "local languages died out fastest on the world's imperial frontiers," and that local tongues "sometimes vanished...voluntarily, as parents urged children to learn the language that would serve them best in life, the language of power and prestige" (p. 263) ${ }^{21}$ While demonstrating the extreme to which the diffusion approach can be taken at the expense of historical facts, ${ }^{22}$ this example also reveals the way in which "power" is understood in the diffusion approach: in a word, power is something possessed by the intruder-benign or ill-willed — to which the aboriginal has to submit. Admittedly, the works that take the diffusion approach do not necessarily share the same value judgment with regard to the intruding foreigner: some laud the power of the advantaged to help out the backward, whereas others remain highly critical about the conduct of the powerful. But the underlying message is the same-the expansion of the reach of the advantaged.

\footnotetext{
${ }^{21}$ It should be noted that, when referring to the "imperialist languages" (McNeill \& McNeill, 2003, p. 263), the authors use examples such as "Chinese, Arabic, Spanish, Russian, French" as well as "English" (ibid.). However, there still exists a sense of superiority of the powerful in the work.

${ }^{22}$ All local tongues are not destroyed by the so-called "imperialist languages." In the case of Hong Kong, Cantonese, as a local tongue typically "on the world's imperial frontiers" (McNeill \& McNeill, 2003, p. 263), was neither wiped out by English nor replaced by Japanese.
} 
The second approach, in contrast, subscribes to a confrontation model of communication. The authors taking this approach coincide to a large extent with those identified by David Held and Anthony McGrew (2003) as the cultural skeptics of globalization who maintain that transnational communication results in "resurgence of nationalism and national identity" (p. 38). While the diffusion approach lays more emphasis on Western cultural impacts on other countries, those adopting the confrontation model see the revival of regional or national identities as an integral part of globalization:

In the recent period, we have become increasingly aware of the resurgence of national, regional, ethnic and territorial attachments. In Eastern Europe, particularly in the former Yugoslavia, we have witnessed the growth of neo-nationalism in its most militant form, but it has also been a feature of Western Europe, with the assertion of Basque, Breton or Scottish identities. It has now been a journalistic commonplace to describe such regionalist or nationalist reassertion in terms of a reversion or regression to the tribal loyalties. These loyalties and attachments seem to go against the grain of globalization... But we might, at the same time, also see this as itself an expression of globalization process-Anthony Smith...writes of the 'globalization of nationalism'. (Robins, 2003, p. 244)

In the confrontation model, national cultures are often identified as "the traditional," which is understood in an accumulative sense as the sediments of the common historical experience of a community. According to this approach, transnational communication involves processes of "confrontation, contestation and negotiation" as various nationalisms or regionalisms compete for their own position in the global system (p. 245). For example, Anthony Smith, who "provides a most telling challenge" against the envisioning of a global culture (Held \& McGrew, 2003, p. 237), suggests that worldwide 
diffusions of certain cultural images do not guarantee their influences on the receiving end (Smith, 2003, p. 280). He argues, instead, that national cultures "continue to divide our world into discrete cultural blocks, which show little sign of harmonization" (p. 284). Thus, according to Smith, national cultures "have been thrown into conflict," and "culture wars... underline the polycentric nature of our interdependent world" (ibid.).

In the confrontation approach, the analysis of power tends to be centered on the nation-state or regional "cultural blocks" (ibid.). While in the diffusion approach modern Western or imperialist cultures are seen as the powerful, in the confrontation approach power is more often than not related to various nationalisms or traditional cultural identities. Thus, what is emphasized is the power of national symbolism that constructs "the cultural base...for the formation of a modern nation" (p. 282), the legitimization of state power by "nationalist elites" who "actively sought to generate a sense of nationality and a commitment to the nation... a "national community of fate"' (Held \& McGrew, 2003, pp. 14-15), and the "upsurging power of local culture that offers...resistance to the centrifugal force of capitalist globalization" (Tomlinson, 2003, p. 270; original italics). In a word, cultural wars and competitions are the key terms of the confrontation approach, and the local-in opposition to other "locals" some of which have become more global than others-is seen as the locus of power.

The third approach conceptualizes transnational communication as hybridization. Those who employ this approach are often motivated by their dissatisfaction with the diffusion conceptions of communication (Kraidy, 2002; Lull, 2000; Nederveen Pieterse, 
2006). Some draw on Samuel Huntington's idea of clashes between civilizations to dismiss the simplistic understanding of culture in cultural imperialism (Lull, 2000, pp. 230-232), ${ }^{23}$ while others criticize the Western-centricism of modernization theories which they believe have been reinvigorated and masked as theories of globalization (Nederveen Pieterse, 2006). However, these authors do not see transnational communication as necessarily resulting in confrontation. They argue, instead, that the term "hybridization" captures the general characteristics of transnational communication. Noting the early negative connotations of the term hybridity (Kraidy, 2002, p. 319; Nederveen Pieterse, 2006, p. 667), they define hybridization in a more neutral manner as something blurring cultural borders or at the borders. ${ }^{24}$ Taken by some as a synonym of "transculturation," "indigenization," and "glocalization" (Lull, 2000, pp. 242-249), hybridization is conceptualized as "mixing the traditional with the modern," which is "fully reasonable and practical" (p. 242). Others see hybrid cultures as a symbol of "cultural cosmopolitanism," which is "to mediate between national traditions, communities of fate, and alternative styles of life" (Held, 2003, p. 525). As can be seen, in general, hybridization is understood as "a cross category process" (Nederveen Pieterse, 2006, p. 668; original italics), although for some it is a crossing between the modern and the traditional whereas for others it constitutes a site of "dialogue" (Held, 2003, p. 525)

\footnotetext{
${ }^{23}$ In this sense, the hybridization approach shares some common ground with the confrontation approach, as both point to the resilience of the local.

${ }^{24}$ It should be noted that the concept of hybridization is also criticized by some as "employ[ing] an image of the mixing of pure or original strains to produce a new form," the image of which "derives from the notion of race" and objectifies cultures (J. Friedman, 1995, p. 86).
} 
among various national traditions.

But how do these authors approach the question of power? In the hybridization model, the analysis of power contains more nuances than what one can find in the diffusion and the confrontation approaches. Some point out that certain descriptive accounts of cultural hybrids are essentially "power-free" and thus serve existing hegemonic interests in effect (Kraidy, 2002, pp. 324-332; Nederveen Pieterse, 2006, pp. 667-668). But concerns with issues of power are not at all absent in the literature on hybridization, as can be seen in the works of James Lull (2000), Jan Nederveen Pieterse (2006), and Marwan Kraidy (2002). Lull (2000) leads his readers' attention to local innovations in transnational communication, but he also asks critical questions about phenomena of hybridization: "on whose terms, for what purpose, and to whose benefit do cultural hybrids develop?" (p. 252). Nederveen Pieterse conceives of "a continuum of hybridities" that includes "on one end, an assimilationist hybridity that leans over towards the center, adopts the canon and mimics hegemony and, at the other end, a destabilizing hybridity that blurs the canon, reverses the current, [and] subverts the center" (2006, p. 669). Kraidy (2002) notes that "the demise of the cultural imperialism model has left a major theoretical void in international communication," that is, the lack of the questioning of hegemony. Thus, he argues that theories of hybridization should seek to understand "communicative practice of meaning and power" (2002, pp. 332-333; italics added).

If the above are only general suggestions about the need to understand power in 
cultural hybridization, a specific application of a similar line of critical thinking to empirical cases can be found in the work of Néstor García Canclini (1995), who builds on the insights of Michel Foucault to point out that power is not a possession of the elite and is exercised in oblique manners (Foucault, 1997, pp. 291-292, 299; Foucault, 2003b, pp. 29-33; García Canclini, 1995, p. 259). What is called for, accordingly, is the analysis of cultural practices as techniques of power, for example, as legitimacy strategies (García Canclini, 1995, pp. 109-115) and as channels of protestation (pp. 261-262).

As can be seen, the three models have defined transnational communication in different terms. Despite their apparent divergence, however, the three frameworks tend to converge in their view of the modernity-tradition relation, which renders them vulnerable to the pitfalls of the modernization paradigm. That is, they tend to treat modernity as a status of social development represented and spread by the West, and to view tradition as something given and out there to be acted upon. As such, the modernity-tradition question is more often than not framed as one of this kind: in the transaction between modernity and tradition, what is the destiny of the latter, being ruined, returned to, or transformed? I suggest that, rather than taking "tradition" as an unquestioned starting point of analysis, and contemplating on the future it will step into, one should reverse the problematic and ask: how have traditions, in the forms in which they are known, taken shape under the modern condition? If, instead of being static, traditions may assume different forms to different modern observers, what implications does this have for the analysis of patterns of communication in a cross-cultural setting? The posing of these 
questions, I suggest, introduces a dimension of epistemology which has not received enough attention in the literature on transnational communication.

In fact, the existing theoretical models do not seem to have elaborated on this question: what is the hermeneutic standpoint of any analyst when he or she comes to the conclusion of transnational communication as diffusion, confrontation, or hybridization? To put the question within the context of this study: if, in the Chinese discourses on law, one sees the expansion of Western modernity or its clash with China's heritage, what exactly are "the Western" and "the Chinese-ness" that are involved? Or, if an observer sees "cross-category" hybridities in the case, are the categories themselves self-evident? I argue that observers themselves should not presume total epistemic independence, but rather should conduct analysis with a reflexive hermeneutic gesture.

Further, how should one understand the exercise of power in Chinese discursive practices that make use of the foreign term "the rule of law"? As has been mentioned, some critics of the postcolonial critique in China argue that certain studies that attend to tradition-modernity issues are complicit in sustaining the hegemony of the Chinese ruling elite, because these studies, by choosing to analyze Chinese-Western cultural relations, only divert attention away from domestic social problems (Sheng, 2007, pp. 121-122). I argue that the issue of power is of central importance in the construction of traditions under China's modern condition, and that the case offers an opportunity to consider how a term of Western origin may be mobilized in discourses to serve competing domestic social purposes. 


\section{Analytic framework}

How, then, is one to study the specificities of the influence of the modern condition on narrations of traditions? The analytic approach required, I believe, should highlight not only the constitutive relation between epistemology and discourse, but also the fact that epistemological impacts are anything but monolithic. The fluidity-or dispersionof influence, I argue, is both a function of the inner contradictions of epistemologies and a result of the variety of social agendas for which discourses are constructed. In Chapter 3, I will develop a model of "discourse shifts," which studies changing social agendas and assumptions that define transformations of networks of discourses. Specifically, the model builds on Michel Foucault's insights about discursive formation and the episteme, Raymond Williams' ideas about the complexity within the hegemonic, and Norman Fairclough's theory of how intertextuality is connected to social hegemony. The conception of discourse shifts is instrumental for the analysis of the dynamics of epistemology of traditions, as it points to a way to examine how traditions are varyingly constructed in changing networks of ideas. From the shifting configurations of traditions in Chinese discourses on the rule of law, one may then analyze the underlying patterns of transnational communication, and consider how different conclusions may be drawn based on different interpretations of traditions.

\section{Methodology}


I have proposed to analyze the construction of traditions in the discourses on the rule of law in socialist China. In order to do this, I will look at four phases of discourses. The first phase stretches from the early years of the People's Republic to the beginning of the Cultural Revolution; the second and the third being the discourses during the early reform and opening-up period (1979-1985) and those at the beginning of the market economy period respectively (1992-1998); finally, the fourth being the discourses after 1999 (20002006), the year in which the principle of the rule of law was added into China's Constitution. ${ }^{25}$

In terms of sampling, I obtained data from government publications, the mass media (print media), writings of political leaders, as well as academic journals. Data for the first period were from the People's Daily, the mouthpiece of the Communist Party and the most identifiable source of dominant discourses at the time, from writings of Communist leaders and other officials, and from relevant articles by scholars. Those for the openingup period and the early market-economy period were obtained from both the People's Daily and the Economic Daily, two of the most relevant sources of discourses of the state, from documents of the Party and writings by Party leaders of the time, and from articles in both academic and non-academic journals that discuss the rule of law. Data for the

\footnotetext{
${ }^{25}$ Readers may have noticed that the years immediately after the June 4 movement (Tiananmen Square) fall outside of the sample periods. I recognize the significance of discourse analyses focusing on the immediate post-June 4 period. But as Ronald Keith (1994) points out, debates on the rule of law in fact continued among intellectual and political elites between June 4, 1989 and 1992 (pp. 2-3, 210 ), which demonstrated a degree of continuity with the previous period and the one after. On the other hand, one of the political consequences of the June 4 movement is a growing attachment to "Chinese traditions" in dominant discourses, which is shown in the discourses on the rule of law in the 1990 s and the 2000s, as will be discussed.
} 
fourth phase were retrieved from government publications, academic articles in legal studies and in journals of the Central Party School, ${ }^{26}$ and eight newspapers, four of them being major mouthpiece newspapers (People's Daily, Legal Daily, Economic Daily, and Guangming Daily), ${ }^{27}$ the other four including two popular local papers circulating nationwide (Beijing Youth Daily and Guangzhou Daily) and two that target educated readers (China Youth Daily and Nanfang Weekend).

In terms of the method of analysis, for each sample period, I will attempt to identify the major ideas that are brought into the discursive field of the rule of law. ${ }^{28}$ Then, I will analyze the agendas and assumptions with which those ideas are connected to "the rule of law." Specifically, I will ask the following questions: How is "the rule of law" articulated in relation to other ideas? What is the stated rationale behind the promotion (or the critique) of the ideas? What actions have been suggested to realize the rule of law in relation to the other idea(s), if any? What kinds of said or unsaid assumptions can be identified, in terms of the perspective from which the issue of law is approached? How are traditions constructed when realities are defined, actions are suggested, and rationales are stated in the articulations of the rule of law? Finally, how are similar or different meanings conferred to the various traditions that are involved in the networks of discourses on the rule of law, and how do these meanings connect to modern

\footnotetext{
${ }^{26}$ The full name of the school is Party School of the Central Committee of CPC (The Communist Party of China).

${ }^{27}$ Among these four, Guangming Daily is more intellectuals-oriented.

${ }^{28}$ It should be noted that what I identify for each period does not constitute an exhaustive list of the ideas discussed in relation to the rule of law. But I will analyze the most important topics and themes.
} 
epistemology?

\section{Outline}

In the following chapter, I will discuss how this study conceptualizes "tradition," demonstrated by the example of traditions of law in China and the West. Chapter 3 will be a proposal of the analytic framework of discourse shifts for the study of semiotic histories. I will also further explain in this chapter how the conception of discourse shifts can be utilized to analyze the epistemology of traditions. Chapter 4,5 , and 6 will be the analyses of the changing orders of discourses on the rule of law, with chapter 4 on the first sample period, chapter 5 on the second and the third, and chapter 6 on the fourth. I will look at the ways in which traditions were constructed, especially analyzing the social agendas for which and the epistemic condition on which the traditions were articulated. In chapter 7, I will conclude the thesis by reviewing the articulations of traditions in the discourse shifts, and considering how different understandings of traditions may result in different conclusions regarding the patterns of communication shown by the case. Based on this, I will then attempt a way to rearticulate the theoretical models of transnational communication as proposed, and conclude how China's modernity figures as a dual hybridity in which the modern epistemic condition defines the changing shapes of traditions. 


\section{Chapter 2 “Tradition" revisited: Chinese and Western legal heritages}

In this chapter, I aim to show that accounts of traditions are discursive products of the modern condition that are narrated to depict the past and yet to achieve present social agendas. In fact, no entry is found for chuan tong, the Chinese word for "tradition," in the prestigious dictionary Ci Yuan (Sources of Words), an intellectual product of the early $20^{\text {th }}$ century which was meant to collect and explain both "traditional" Chinese terms and modern terminologies that entered the Chinese language. ${ }^{1}$ The Chinese notion of "tradition" itself, I argue, is imbued with an acute awareness of the presence of otherness, particularly that of the West, and with an urge to situate a national self in relation to the other. As such, "tradition" is as much a notion about cultural-spatial engagement as one about temporality. What has been put under the umbrella of "Chinese tradition" is paradoxically a result of China's exposure to the West. Conversely, what has been defined as "the West" for the Chinese audience, or for a Western one interested in China, is similarly often a result of comparison between the two cultural territories. However, articulations of traditions are more than a function of contrast; they are also often a

\footnotetext{
${ }^{1}$ An author points out that, while the emergence of the word "tradition" in Chinese remains to be studied, the usage of it was not commonplace even in the May Fourth period around 1919, when "old ideas, old literature, old ethics, and old cultures" were attacked (Huang, 2009). The term "chuan tong," as a word, was not found in either the 1915 edition or the 1979 edition of the Sources of Words. While the 1915 edition collected both classical Chinese terms and some new neologisms, the 1979 edition claimed to retain only the classical terms, especially those used before 1840 . To be sure, in imperial China the character of chuan and that of tong was indeed sometimes used together, yet the two were juxtaposed to form what is now called a verb phrase, and the phrase means to hand down the throne or learning. In modern Chinese, however, chuan tong, as one word, is instead a noun.
} 
rallying for action, for example, to leave behind the traditional, to reform it, or to hold on to it. This chapter serves three purposes: first, it is an elaboration of my conception of tradition. Second, the chapter reviews various scholarly accounts on Chinese and Western legal heritages to demonstrate how traditions are political discursive consequences of the modern condition. Third, this discussion provides a background for the analyses in following chapters - as will be shown, different views on Chinese and Western legal traditions may lead to different observations about the pattern of cross-cultural communication in the changing discourses on the rule of law in China.

\section{Tradition: Conceptual considerations}

As some point out, despite its extensive use, "tradition" remains "one of the theoretically least well explored concepts" (Wiedenhofer, 2006, p. 376). Nonetheless, while many have used the term without defining it or noting the need to do so (Philips, 2004, p. 3), some have more explicitly explained what is meant by tradition. Edward Shils, the author of Tradition (1981), remarks that "[i]n its barest, most elementary sense, it [tradition] means simply a traditum; it is anything which is transmitted or handed down from the past to the present" (Shils, 1981, p. 12). Luo Zhitian (2003), a Chinese historian, suggests that traditions are the cultures and customs of the past (p. 22). In another definition, "'tradition' refers to a set of practices, a constellation of beliefs, or a mode of thinking that exists in the present, but was inherited from the past" (Gross, 1992, p. 8).

As can be seen, many view "tradition" as something from the past. Such 
conceptualizations immediately require one to explain what counts as tradition or heritage, among the many things handed down from the past, and why. As I have pointed out, "tradition (chuan tong)" is not even a commonly used word before China's encounter with the West in the mid- $19^{\text {th }}$ century. ${ }^{2}$ In the Chinese context, it is a particular phenomenon of modernity to talk about "Chinese tradition" as a mark of the national self, its past, its present, and its future, often as an effort to reorient the self in relation to a newly comprehended world order. I argue that traditions-in the ways in which they are identified and perceived-are located in discourse. That is, in terms of the relation between tradition and discourse, the former is not so much some significant part of the past that contains some permanent meaning which may be reflected in the latter. Rather, traditions are discursively constituted at the moment when something from the past is referred to as such; in terms of how and why they are constituted in certain specific manners, traditions are politically motivated in that they are often part of a yearning for social change or non-change. With these understandings, I define tradition as discursive constructions of self or other which are articulated under the modern condition as both symbols of identity and rationale for action. In this idea of traditions as identification discourses, I share the line of thought that underpins The Invention of Tradition (1983), which according to Edward Said "accentuated the extraordinary influence of today's

\footnotetext{
${ }^{2}$ There were indeed notions used in imperial China to refer to that which should be inherited from the past, such as the notion of $z u z h i$ (ancestral rules). However, the earlier notions did not carry the modern sense of nation-state. The term zu zhi was also not found in the 1915 edition of the Sources of Words, but there were cases of its usage in the Ming Dynasty (1368 C.E.-1644 C.E.).
} 
anxieties and agendas on the...images we construct of a privileged, genealogically useful past, a past in which we exclude unwanted elements, vestiges, narratives" (Said, 1993, p. 15). ${ }^{3}$ In the following paragraphs, I will explain two issues related to this definition of tradition.

First, while modernity constitutes an epistemic condition, this does not suggest that discourses of traditions constructed under such a condition are necessarily uniform. While recognizing the influences of modern epistemology on the narration of traditions, one should also note that the specificities of such influences are defined by contingent social agendas that stand behind various accounts of traditions. The plural form is meant to stress that, under the modern condition, what is being evoked is not just one tradition that stands in contrast to the perceived other. Rather, there may be more than one "self" being "discovered," not just in the sense that multiple sources of heritage may be identified, but that even from the same source numerous versions of self may be established. In the Chinese context, for example, one not only finds the title of tradition being conferred to Confucianism, Legalism, and other less-talked-about aspects of the past, but also sees Confucianism and Legalism themselves being subject to different articulations with regard to what "national character" they represent.

The existence of multiple versions of traditions, however, does not necessarily

\footnotetext{
${ }^{3}$ Some also point out certain problems of the assumptions taken in The Invention of Tradition, such as the "simple opposition between 'genuine' and 'invented' traditions," according to which "genuine...tradition must be involuntary and unconscious" (Phillips, 2004, p. 6). I do not assume such a polarization but define "traditions" as effects of discursive construction.
} 
suggest that some accounts must be truer than others as they uncover those parts of the past that are of real historical significance. To be sure, certain ideas and practices in the past were more widespread or have received more social attention than others and thus they are prone to be documented and seen as traditions; moreover, some accounts are indeed viewed by many as more accurate and convincing than others. Nevertheless, there may be different interpretations concerning the question of what is meant by real historical significance, which bring about different depictions of traditions. One should also note the ways in which certain ideas and practices keep their "status as tradition" once they are branded as traditional. Furthermore, even though something is continually articulated as the traditional, the reason why it is recognized as such and how it is evaluated may change as it connects to various social agendas.

The second issue is about a second layer of relation between modernity and tradition. As I have discussed, in their primary relation, modernity is conceptualized in this study as an epistemic condition under which traditions are symbolically constructed. There does exist, however, a secondary relation, as "modernity" itself, if taken as recent tradition of the West, may also be subject to various interpretations under the modern condition. Thus, there is a relation between modernity as an epistemic condition and itself as a set of traditions. However, even under the modern condition, modernity as Western tradition may not assume the same form in different eyes. In the China case, while the modern condition is triggered by the Chinese recognition of a powerful West which claims itself as the modern, perceptions about this modern West are far from uniform. Thus, as a set of 
traditions, modernity is anything but self-evident, and the ways in which it is approached cannot be separated from contingent social purposes.

In the following two sections, I will present various scholars' accounts of Chinese and Western traditions of law. The discussions show the ways in which what we now know as Chinese and Western traditions have been variably constructed in scholarly narratives, which are often deemed as the most authoritative and elaborate accounts of the past. They will also help demonstrate in the following chapters how different views of what exactly constitutes Chinese and Western traditions may lead to different conclusions about the question of whether or not modern Western ideas of law are taking over domestic ones in China. The following discussion is based on a summary of relevant ideas from a selected number of works that have commented on traditions of law. Therefore, I recognize that what I present here may reinforce rather than challenge certain existing beliefs about what are the traditions in China and in the West. Nonetheless, as I juxtapose ideas from several works which may not have been considered in the same context before, it is hoped that my discussion can help demonstrate the ways in which traditions have been constructed with diverging perspectives. The works chosen to be reviewed include those authored by legal and cultural scholars in both the Chinese and the English worlds. ${ }^{4}$

\footnotetext{
${ }^{4}$ As the thesis is not written from the perspective of legal studies, it will not go into details to review all debates on the subject of law. Only the themes most relevant to this study will be discussed. Further, while strictly speaking the Western scholars whose works are discussed are not necessarily under the direct influence of China's modern condition, their accounts of Chinese traditions are arguably also affected by modern systems of ideas and have contributed —or at least have the potential to do sothe sustaining of the modern condition.
} 


\section{Traditions of law in China}

In this section, I will review existing views about traditions of law in China. I will

first review how the meanings of $f a$ (法), the Chinese term for "law," and their implications have been articulated. Then, I will discuss various views about ideas of law advocated by Legalism and Confucianism, two classical schools of thought that are believed by many to have shaped China's legal traditions. ${ }^{5}$ Finally, I will look at recently emerging studies on "vagabond cultures" (Wang Xuetai, 2007), the notion of which points to certain characteristic aspects of China's social order that are mostly absent in accounts that portray China as a centralized authoritarian society. As will be shown, even in scholarly works, one finds vastly different articulations of what are China's traditions of law. However, they can be seen as belonging to the same spectrum of identification discourses emerging under the modern condition, some to trace the origin of China's distinctiveness, some to discredit its backwardness, others to assert its position in the world.

\section{The meanings of $f a$ (法) and their implications}

In explaining the meanings of $f a$, the Chinese term for law, scholars often refer to Shuo Wen Jie Zi, an early Chinese dictionary that was first compiled in the $2^{\text {nd }}$ century by

\footnotetext{
${ }^{5}$ Daoism is also viewed as a classical school of thought that has influenced China's traditions of law (Peerenboom, 2002; Liang Q., 1922/2003). However, its impact in the realm of law, albeit significant, seems to be minor compared to Confucianism and Legalism. Moreover, thinkers of Legalism also integrated certain ideas from Daoism (Liang Q., 1922/2003). Therefore, this chapter will not discuss the construction of Daoism as a legal tradition. For accounts of the influence of the Daoist school of thought, see Liang Q. (1922/2003) and Peerenboom (2002).
} 
Xu Shen (Liang Q., 1922/2003; Liang Z., 1997a; Zhang J., 2005). Meanwhile, those writing in contemporary China also quote Cai Shuheng (1904-1983), a renowned Chinese legal scholar who studied law in Japan and who explained the meanings of $f a$ differently from Shuo Wen Jie Zi (Liang Z., 1991, 1997a, 1997b; Shi G., 2006). However, for those scholars who cite the ancient dictionary and Cai, they have themselves offered a variety of interpretation regarding what the meanings of $f a$ imply about China's legal tradition. Referring to Shuo Wen Jie Zi, many believe that $f a$ (法) is derived from fei (㵧), an ancient Chinese character no longer in use (Liang Q., 1922/2003, pp. 58, 159, 247; Liang Z., 1997a, p. 25; Zhang J., 2005, p. 54; Shi G., 2006, p. 94). The character of fei is composed of three parts, ; , 廌, and 去. According to Shuo Wen Jie Zi, ; indicates being fair and balanced, 麃 refers to a type of mythical animal that ancient judges relied on to identify the guilty, and 去 means to remove. Thus, it is explained, the character fei refers to punishment; to be specific, it means to be fair and to remove those guilty. However, Cai contests this interpretation of the part of ' (Liang Z., 1997a, p. 25; Shi G., 2006, p. 95). He points out that, as $\xi$ is derived from the Chinese character of water, fei means to ostracize the guilty along rivers to faraway places. With respect to the meaning of $;$ as fair and balanced, Cai concludes that it was added generations later by those who attempted to interpret the meanings of the ancient character fei (ibid.). This view is echoed by others who believe that the meaning of fairness in fact reflects how the word 
$f e i$ was understood at the time when Shuo Wen Jie Zi was compiled (Shi G., 2006, p. 95). ${ }^{6}$

Meanwhile, Cai examines texts that are much older than Shuo Wen Jie Zi to identify other key meanings of $f e i$ and $f a$, which include to abandon, to keep within limits, to ban, and to command obedience (p. 94). Quoting texts of classical Legalism, he also notes that $f a$ refers to measuring instruments and thus metaphorically means rules of social conduct (ibid.).

As has been mentioned, many authors who attempt to explain the meanings of $f a$ cite Shuo Wen Jie $Z i$ and Cai. Nevertheless, a closer review of the texts that cite one or both of the two sources shows that they offer different interpretations regarding what the meanings of $f a$ reflect about China's traditions of law. Some emphasize the positive value of the tradition of $f a$, while others believe that the meanings of $f a$ demonstrate the backwardness of Chinese legal tradition that hinders China's progress toward modernization.

For instance, Liang Qichao (1873-1929), one of the first Chinese intellectuals who reflected on "Chinese legal theories" (Liang Z., 1997c, p. 62), believes that China's tradition should not be entirely rejected but should be carefully re-evaluated and effectively built on to revitalize the nation. He uses the definition of fa provided by Shuo

\footnotetext{
${ }^{6}$ But Shi Guangquan (2006) also insists that there is not enough evidence to refute the interpretation of $;$ as meaning fairness (p. 95).

${ }^{7}$ Before Liang Qichao, there were discussions of classical ideas about law. But Liang Qichao is one of the first intellectuals who used the concept of zhong hua min zu (the Chinese nationality) and reviewed the history of China within the framework of nation-state (Duara, 1995, p. 33). It is also noteworthy that, as Liang Zhiping points out, Liang Qichao is not so much a legal theorist in the strictest sense as an advocate for political reform (Liang Z., 1997c, p. 62).
} 
Wen Jie Zi, emphasizing that, as $f a$ means being balanced and orderly (Liang Q., 1922/2003, pp. 159, 247), it in fact refers to standards of behavior (ibid.). He continues to point out that ancient Chinese thinkers built on this primary meaning of $f a$ to develop ideas of Legalism (p. 160), which advocates public promulgation of law as the sovereign rules of social conduct (pp. 161, 175, 255), and which is a lost tradition that needs to be re-established (pp. 255-256) for the salvation of the Chinese nation. ${ }^{8}$ This positive view of $f a$ is shared by Zhang Jinfan, an influential contemporary Chinese legal historian, who argues that the advocacy of impartiality is one of the major characteristics of China's legal tradition (Zhang J., 2005, pp. 54-67), and that China's ancient legal culture has thus made contribution to the "world legal civilization" (p. 3). Quoting Shuo Wen Jie Zi, Zhang notes that "the etymology of $f a$ shows that the word implies fairness and justice of law in China" (p. 54). To demonstrate this, he refers to the examples of certain imperial dynasties, arguing that the early rulers of these dynasties "were able to maintain a relatively stable legal order, which was inseparable from the impartial protection of the rights of the majority in the feudal society" (p. 56).

However, the meanings of $f a$ are not cast in a positive light by all. Liang Zhiping, a widely cited contemporary Chinese scholar, ${ }^{9}$ uses the interpretations of $f a$ by Shuo Wen Jie $Z i$ and Cai to demonstrate the problems of China's traditional legal cultures. While

\footnotetext{
${ }^{8}$ It should be noted that Liang Qichao also points out several problems of classical Legalism (1922/2003, pp. 177-183). The discursive construction of classical Legalism will be discussed later. ${ }^{9}$ Liang Zhiping's studies on Chinese and Western legal cultures are believed to have constituted a paradigm that "has major impacts on...the entire field of Chinese legal studies" (Deng Z., 2004, pp. 132-133).
} 
citing the ancient dictionary to explain the etymology of the character of $f a$ (Liang Z., 1997a, p. 25), he agrees with Cai that $f a$ does not have the meaning of fairness and balanced (ibid.). He states that jus, the word from which the Western ideas of law are derived, carries the meanings of fairness, justice, and the respect for rights (pp. 24-25). In contrast, he maintains, the character of $f a$ in Chinese does not contain these meanings and thus is hardly an equivalent of jus. Quoting Cai, he notes the repressive nature of the meanings of $f a$ in Chinese such as to ban and to command obedience, the acts of which are realized through the threat of punishment (p. 26). Liang Zhiping concludes that, although $f a$ has taken on new meanings nowadays, many nonetheless continue to understand $f a$ as primarily meaning punishment, as a result of "historical conceptual inertia" (p. 44). This conception of law as tools of control rather than as protection of freedom and rights, Liang Zhiping argues, leads to tragedies such as the Cultural Revolution, resulting in mass destruction of legal authorities and innumerable occurrences of lynching (pp. 44-45). Therefore, he concludes, in order to achieve legal modernization, China has to rid itself entirely of its traditions (Deng Z., 2004, pp. 140$141)^{10}$

The examples given above demonstrate how the ancient meanings of $f a$ have been selectively utilized in the discourses on China's legal traditions. It should be noted that, whether or not the meaning of fairness was added generations later to the word $f a$, this

\footnotetext{
${ }^{10}$ It should be noted that Liang Zhiping later also argues that legal scholars should develop a "sympathetic understanding" of China's legal tradition (Deng Z., 2004, p. 140). I will not elaborate on this, as the intent of the chapter is not to review how Liang Zhiping's ideas have changed over time.
} 
meaning was in existence at least by the time when Shuo Wen Jie Zi was first compiled, as this ancient dictionary indeed interprets $f a$ as such. However, in their evaluation of China's legal tradition, some scholars only takes the old meanings of $f a$ such as punishment, while others emphasize the less authoritarian meanings of $f a$, which may have emerged later than the meaning of punishment but nonetheless did reflect how $f a$ had been understood in the past, at least by the $2^{\text {nd }}$ century. This difference in defining what $f a$ meant in the ancient times can be seen as a result of the differences of the primary intent of these scholars when they comment on China's traditions, some of whom attend to the aspects of China's past that are believed to be "progressive" and preservable for modernization, whereas others casting a doubtful eye on the overall wholesomeness of China's legal heritage for such a cause. As will be shown below, not only the meanings of $f a$, but also the ideas about law in classical Legalism and Confucianism have been constructed in various ways.

\section{Ideas of law in classical Confucianism and Legalism}

Much has been written about the nature of China's legal tradition as the integration of Confucianism and Legalism, which serves to maintain an authoritarian and hierarchical society (Keith, 1994, pp. 46-47; Lubman, 1999, pp. 13-14; Zhang J., 2005, pp. 3-26; Shi G., 2006). ${ }^{11}$ As two classical schools of thought, Confucianism and

\footnotetext{
${ }^{11}$ Confucianism and Legalism were first developed between $6^{\text {th }}$ century B.C.E. and $3^{\text {rd }}$ century B.C.E., a period of time when the Eastern Zhou Dynasty (770 B.C.E.- 256 B.C.E.) gradually disintegrated, the Chinese suffered from wars fought among feudal princes, and numerous schools of thought emerged to offer solutions to ongoing socio-political problems.
} 
Legalism are taken by many as the major sources of influence that define Chinese ideals of law. However, on closer examination, one finds that different claims have been made as to whether or not Confucianism and Legalism indeed value authoritarianism based on hierarchies. Nonetheless, behind these contentious claims about the nature of the two classical schools, there is often a lurking question of "versus": how do the rules of social regulation in China differ from those in the West? One sees a variety of pair-attributes being used as terms of appraisal: hierarchy versus equality, collectivity versus individuality, propriety versus law, self-cultivated rationality versus external containment, and others. Judged by these scales, Confucianism and Legalism are for some enlightening yet for others tyrannical.

For many, the Confucianist idea of $l i$ is evidence that Confucianism suppresses the individual and protects hierarchical social orders (Keith, 1994, p. 43; Lubman, 1999, p. 14; Chen J., 1999, pp. 9, 17; Potter, 2001, p. 8). $L i$ has been translated into English in a number of ways, such as "decorum" (Keith, 1994, p. 43), "propriety" (Potter, 2001, p. 8), "morality" (Chen J., 1999, p. 7), and "rites, traditional customs, mores, and norms" (Peerenboom, 2002, p. 28). Stanley Lubman, the author of Bird in a Cage: Legal Reform in China after Mao (1999), offers a fuller but concise definition, explaining $l i$ as "a variety of moral and customary principles for ceremonial or polite behavior" (p. 14). ${ }^{12}$

\footnotetext{
${ }^{12}$ For a lengthy definition of $l i$, see Chen Jianfu (1999), who explains, " $L i \ldots$ is a set of general rules governing proper conduct and behaviour by which rules can maintain an ideal social order" (p. 8). "It was never a body of detailed rules designed to deal with all situations, but a general instrument for training character and nourishing moral force" (ibid.).
} 
Lubman holds that, as a set of "ethical rules," $l i$ is "differentiated according to status as determined by age and rank in family and society" (ibid.). He writes,

The basic unit of traditional Chinese society was not the individual, but the collectivity. Family, clan, village, gentry, and officials dominated the individual. Most basic of all was the family, whose rules of customary behavior emphasized the precedence and authority of older over younger generations. (p. 17)

Defining the Confucianist $l i$ and the basic characteristic of traditional Chinese society as such, Lubman compares it to "the West's characteristic emphases on rights" (p. 6), so as to stress "the very different paths of legal development in China and the West before the twentieth century" (ibid.). As Pitman Potter also points out, a striking feature of the Chinese traditional norms is that "the Confucian concept of $l i$ (propriety) dominated the regulation of social relationships and held that these were inherently unequal" (Potter, 2001, p. 8). In fact, Chinese legal scholars-even those sympathetic to Confucianismalso note the connections between $l i$ and social hierarchy (Liang Q., 1922/2003, p. 55; Zhang J., 2005, pp. 3-16), ${ }^{13}$ lamenting how $l i$ has impeded China's political reforms (Zhang J., 2005, p. 16).

With respect to how $l i$ is seen in relation to law in ancient China, many stress that the Confucianist idea of $l i$ took precedence over law. Ronald Keith, the author of China's Struggle for the Rule of Law (1994), describes it as follows: "Confucianist content and

\footnotetext{
${ }^{13}$ It should be pointed out that Liang Qichao (1922/2003) gives special notes to the existence of different views within Confucianism as to which hierarchies should be deemed as legitimate (p. 16). As this chapter is not focused on the diversity of views within Confucianism, I will not elaborate on this issue.
} 
attitude dominated legal thinking such that $l i$ was taken as primary and punishment, $x i n g$, as secondary" (p. 47). Similarly, William Alford, Harvard professor of Law, comments that "positive law was meant to buttress, rather than supersede, the more desirable means of guiding society and was to be resorted to only when these other means [the rules of $l i$ ] failed to elicit appropriate behavior" (quoted in Lubman, 1999, p. 14). Scholars also note the way in which the practice of integrating $l i$ and law serves to maintain an authoritarian and hierarchical society (Lubman, 1999, pp. 15-18; Zhang J., 2005, pp. 3-26). Viewing the insertion of $l i$ into law as a primary characteristic of China's legal tradition (Zhang J., 2005 , p. 26), Zhang particularly notes how $l i$ functions to protect the interests of those on higher levels of social hierarchies in legal cases. Lubman (1999) quotes Benjamin Schwartz to conclude that "Chinese political culture was "unambiguously authoritarian,"” and that "codified law in traditional China," influenced by a vision of regulating society based on social status, "emphasized the supremacy of hierarchy over the individual" (p. 16).

Nonetheless, in contrast to those who hold that China's legal tradition was influenced by Confucian ideas and therefore "reflected the subordination of the individual to the collectivity" (p. 18), others have emphasized how Confucianism values the individual (Liang S., 1949/2005; Yu Y., 2004c; Peerenboom, 2002; Zhang J., 2005). Liang Shuming (1893-1988), referred to by Guy Alitto (1979) as "the last Confucian" who sought to revive China's spiritual heritage, argues that what Confucius pays attention to is not so much the organization of society based on relations of ethics as the fulfillment of one's 
self (1949/2005, pp. 106-107, 121). Liang maintains that, in contrast to Westerners who preoccupy themselves with the question of how to control the material world, Confucians attach great importance to understanding the virtue of human beings (p. 116). He criticizes that, even though modern Western psychology utilizes scientific methods to study human beings, it stresses the interplay of incompatible forces within the human body, following the line of religious thought which views the human body as the origin of $\sin$ (ibid.). In contrast, Liang points out, Confucians value human beings instead of divinity and, in particular, have trust in the individual, as Confucius holds that human beings possess rationality (pp. 117, 180), or a harmonious and peaceful mind (p. 117). As for $l i$, or proper relations of ethics, it is the means through which one practices and achieves rationality, which requires respect for others and the harmonious co-existence of all (pp. 79-81, 121). The Chinese live by rationality and self-restraint, Liang argues, while the maintenance of social order in modern Western nations relies on law and enforcement, which is alien to China (pp. 171-182).

Whereas Liang Shuming focuses on explicating what he believes to the true essence of Confucianism, some legal scholars relate a similar interpretation of Confucianism to China's legal tradition (Peerenboom, 2002, pp. 28-33; Zhang J., 2005, pp. 27-38). ${ }^{14}$ Randall Peerenboom (2002) points out that the idea of $l i$ in fact reflects how

\footnotetext{
${ }^{14}$ While Zhang Jinfan (2005) emphasizes how Confucianism protects hierarchy, which has been discussed, he also notes the "humanistic traditions" of the school of thought (p. 28). However, Zhang further comments that Confucianism only reflects a kind of "feudal humanism" (p. 39), which explains why "it is difficult to develop [out of Confucianism] indispensable modern democratic and political foundation in China" (ibid.).
} 
Confucianism values the cultivation, in contrast to mere punishment, of the individual to achieve humanity. He quotes the Confucianist classic Analects: "Lead the people with government regulations and organize them with penal law (xing 刑), and they will avoid punishments but will be without shame. Lead them with virtue and organize them through the $l i$, and the people will have a sense of shame and moreover will become humane people of good character" (p. 28) ${ }^{15}$ Peerenboom goes on to comment on this:

Confucius' goal was not simply a stable political order in which everyone coexists in relative harmony and isolation from each other, with each afraid to interfere with the other for fear of legal punishment. Rather, Confucius set his sights considerably higher. He sought to achieve a harmonious social order in which each person is able to realize his or her full potential as a human being through mutually beneficial relations with others. (ibid.)

Moreover, Peerenboom notes, Confucius's suspicion with respect to the function of law is connected to the "externality" and "generality" of law, which impede the realization of individuality:

Confucius rejects laws as a means for attaining social order because law focuses on external compliance. Since one is merely expected to conform one's behavior to the given legal norm, one is denied the opportunity to fully participate in the creation of a social order more reflective of one's individual character. Laws, as standards of general applicability, do not allow for sufficient individual expression of particularity. (p. 30)

Viewing Confucianism as advocating harmonious human relations built on moral cultivation of the individual, Peerenboom concludes that the ruler of a society envisioned by Confucians is not so much a dictator as "a facilitator of order" (p. 32). To be sure,

\footnotetext{
${ }^{15}$ To be sure, Peerenboom (2002) also notes that "Confucius...did not advocate the complete abandonment of laws" (p. 29). "Nevertheless," he suggests, "the goal is to foster an environment in which laws need to be imposed as little as possible" (ibid.).
} 
Peerenboom acknowledges that, as Confucian literati often assumed that they "possessed superior normative insights" (p. 33) and had the responsibility to interpret $l i$ (p. 31), Confucianism is "decidedly elitist" and "paternalistic" (p. 33). However, the depiction of Confucianism in Peerenboom (2002) — and in Liang Shuming (1949/2005) — is different from the portrayals in which the school of thought is approached as mostly repressive, yet it is no more difficult for one to find the West as a reference of comparison in Peerenboom (2002) than in the accounts disputing Confucianism.

Legalism, another classical school of thought, has also been discursively constructed with varying interpretations. While some point out that the belief in the universal application of law is a key characteristic of Legalism (Liang Q., 1922/2003, p. 175; Potter, 2001, p. 8; Zhang J., 2005, p. 17), particularly in comparison to Confucianism, many maintain that Legalism supports the ruling of society based on social hierarchies (Liang Z., 1997a, p. 40; Chen J., 1999, pp. 11-12; Lubman, 1999, pp. 15-16; Peerenboom, 2002, pp. 33-34; Yu Y., 2004a, 2004b). Among those who share the second viewpoint, there are also different explanations as to how exactly Legalism, unlike Confucianism, serves to buttress hierarchical authoritarianism - all this comparison of the two classical schools, despite the fact that the notion of authoritarianism itself would be a novelty in China before its contact with the West in the $19^{\text {th }}$ century. Compared to the variety of ways in which Legalism is appraised, the criterion used for appraisal which is commonly invoked when China is compared to the West - that is, whether Chinese classical schools support state control-is of less dispute. 
For some, the school of Legalism extols "the objectivity and universality" of law (Potter, 2001, p. 8). Some scholars who hold this view explain that, in comparison to Confucianism that views social hierarchies as permanent and natural (Zhang J., 2005, p. 17), Legalism opposes differentiations between the noble and the commoner and argues that everyone should be judged equally based on law (ibid.). Thus, it is believed, the difference between Confucianism and Legalism is essentially the difference between the idea of differentiated treatment of social relations based on $l i$ and the idea of universal application of law (ibid.). Or, in Liang Qichao's words, it is the difference between the rule of $l i$ and the rule of law (Liang Q., 1922/2003). ${ }^{16}$ Liang even argues that the true spirit of Legalism lies in its respect for the sanctity of law and its belief that no governments should go beyond law (p. 175). Thus, he maintains, Legalism, in particular the stream of it that advocates the rule of law, is the opponent rather than the accomplice of authoritarianism (p. 166). ${ }^{17}$ Some contemporary Chinese scholars contend that Liang has in fact misinterpreted Legalism (Keith, 1994, p. 44). But Liang is not alone in arguing that Legalism believes in the universality of law. His view is shared by other scholars such as Zhang Jinfan (2005) and Karen Turner (Cui Y., 2004).

However, others argue that, although Legalism indeed offered solutions to social

\footnotetext{
${ }^{16}$ It is noteworthy, however, that Liang Qichao's understanding of $l i$ is different from those in which $l i$ is seen as primarily a means to stabilize social hierarchies. Liang views the purpose of $l i$ as the cultivation of character.

${ }^{17}$ To be sure, Liang (1922/2003) also points out the problems of Legalism. For example, he criticizes that Legalism does not clarify who has the right of legislation (p. 177), that law cannot cover the specificity of all social situations (pp. 178-179), and that law tends to be mechanistic and deprives people of their individuality (p. 182).
} 
problems differently from Confucianism, "both schools shared a vision of society in which individual lives were led within hierarchies and social distinctions and proper behavior derived from an individual's status in those hierarchies" (Lubman, 1999, pp. 1516). With respect to the idea of the universality of law that was held by some Legalists, Peerenboom (2002) contests that, "[w]hile advocating the impartial application of publicly codified laws, Legalism was hardly 'a rule of law' which, at minimum, refers to legal limits on the ruling elite" (p. 33). On the contrary, it is argued, "the real objectives of Legalist theory were 'to respect the position and prerogative of the prince and to support authoritarian policies"' (Chen J., 1999, p. 11). Chen Jianfu (1999), influenced by the account of Feng Youlan who authors a widely cited historiography on Chinese philosophy, describes the basic belief of Legalism as follows:

The Legalists believed that law is the order imposed by the state to suppress individuals' desires on the grounds that it is the nature of man to seek profits and avoid harm and that; therefore, rewards and punishments are two effective ways of governing, i.e. to establish interdicts and commands of the state. (p. 11)

As such, for Legalism, "[1]aw was simply a pragmatic tool for obtaining and maintaining political control and social order" (Peerenboom, 2002, p. 33). Specifically, the governing of society is to be achieved by rewarding those who abide by laws that "pleased the ruler" (p. 34) and, more importantly, by heavily punishing those who dare to disobey orders of the state (Chen J., 1999, p. 11; Liang Z., 1997a, p. 39).

In contrast to those who point out the repressive nature of Legalism by emphasizing how the school builds on idea of state reward and punishment, Yu Yingshi suggests 
another oppressive aspect of Legalism that assists not only the harsh governing of social conduct, but also the state control of thought by law. Yu believes that "the impact of Hanfei on the political life of the Chinese goes far beyond what is commonly acknowledged" (Yu Y., 2004a, p. 301). ${ }^{18}$ In particular, he argues that the "antiintellectualism" of Legalism "has exerted long-lasting and profound influence on China's political tradition," in contrast to which the real impact of Confucianism-which advocates political discussions by the literati-has been minimum (2004b, p. 292; 2004c, p. 318). Comparing Confucianism and Legalism, Yu stresses that the former promotes active participation of individual intellectuals in politics, citing Confucius as an example who desired to apply his knowledge to the improvement of society and encouraged his students to play proactive roles in public affairs $(2004 \mathrm{~b}$, p. 279). Legalism, on the other hand, profoundly resents intellectuals and attacks them, who according to the Legalists would only "lead the people to hold the prince in contempt" and "slander the state" (p. 295). For the Legalists, Yu maintains, the ideal situation is one in which the ordinary people stop the pursuit of knowledge other than law, so that they would willingly follow orders of the ruler, the one who possesses real wisdom. Yu quotes Hanfeizi, the bestknown thinker of Legalism:

In the state of a wise prince, there are no books, so only law is used for education; there are no records of the sayings of earlier princes, so people listen to officials of the state.... As such, for all those who live within the boundary of the state, they would regulate their own conduct and speech according to law. (p. 292)

\footnotetext{
${ }^{18}$ Hanfei is believed by many as the most influential Legalist.
} 
Not only advocating strict control domestically, Yu points out, Legalism also recommends that the ruler forbid people—-particularly intellectuals—-from communicating ideas with others outside the state so that there remains only one standard of thought, that is, Legalism, within the state (pp. 294-295). Yu argues that this antiintellectual tendency derives from the Legalist belief in the need for the ruler to establish and maintain the highest authority (2004b, pp. 297, 300; 2004c, p. 318), as intellectuals possess "the most undesirable personality" of "not willing to accept state policies or political lines whole-heartedly" and "even tending to question or criticize them" (2004b, p. 297). This Legalist line against intellectuals which was adopted in the Qin Dynasty (221 B.C.E. - 207 B.C.E.), Yu points out, eventually led to the massive burning of books and the burying-alive of the Confucian literati ordered by Qin Shi Huang (the first Emperor of Qin), who brought into practice the Legalist theory of anti-intellectualism (p. 299).

As has been shown, Confucianism and Legalism have been constructed in various ways as China's traditions. Nonetheless, many believe that the integration of Confucianism and Legalism is the primary characteristic of China's legal tradition (Chen J. 1999; Peerenboom, 2002; Yu Y., 2004a; Zhang J., 2005; Shi G., 2006), and that China's imperial rulers were "Confucianist in appearance but Legalist in reality" (Chen J., 1999, p. 14). That is, "in state practice Legalism continued to provide its methods and solutions for government, while Confucianism was upheld as a desired and ideal order for the society" (ibid.); thus, the two schools of thought combined to foster an authoritarian state. 
However, for some scholars concerned with the lack of respect for law and order among the Chinese and its impact on China's modernization, there are other aspects of China's traditions of law that are more destabilizing and de-centralizing than the notion of authoritarianism can suggest, as will be discussed. Although this interpretation of China diverges from many others, it nonetheless carries a similar presupposition that, for China to become a modern society, obstacles and countercurrents need to be identified and addressed.

\section{Vagabond cultures}

Many see traditional China as "extremely hierarchical" and authoritarian (Potter, 2001, p. 8; Chen J., 1999, p. 17; Wang C., 2005, p. 83). However, Wang Xuetai (2007) contends that, in explicating Chinese traditions, existing accounts often emphasize the social stabilizing functions of state orthodoxy such as Confucianism but neglect "vagabond cultures" (you min wen hua), a type of popular consciousness that emerged among the population who were disengaged from the mainstream familial-clan system, the key social institution in ancient China that sustained Confucian teaching and local loyalty to the state. Wang suggests that, as something opposed to the rule of law, vagabond cultures—which have entered the core of Chinese culture—need to be studied for the advancement of China's development and modernization.

According to Wang, vagabond consciousness, although originating among vagabonds, was later accepted by the majority of the Chinese population, marginalizing the influence 
of elite classics such as the books of Confucianism (pp. 449, 542). Thus, what is urgently needed, Wang suggests, is serious understanding of vagabond cultures, which so far have been an under-explored shaping force of Chinese traditions (p. 2). As a critic points out, Wang's studies on vagabond cultures "uncover another China," not only explaining the prevalence of anti-Confucian values in ancient popular culture, but also revealing the deep cultural roots of "vandalism" and "brutality" that occurred in the more recent peasant uprisings and "mob movements" such as the Cultural Revolution (Li Shenzhi, 2007, pp. 1-7).

But what is meant by "vagabond cultures" and, in particular, how did the vagabonds in ancient China - known as a country dominated by relatively stable Confucian familialclans-come into being? In Wang's definition, the term vagabond refers to those who are disengaged, for various reasons, from the protection and control of their Confucian clans and who live with neither stable vocation nor permanent residency (Wang X., 2007, p. 16). Accordingly, "vagabond cultures" are the consciousness, or the belief systems, of those who live outside the mainstream social institution of Confucian clans (ibid.). While vagabonds have existed from times of remote antiquity (pp. 16, 72), Wang argues that it is in the Song Dynasty (960 C.E. - 1279 C.E.) that they started to constitute a noticeable social group that impacted the social order of ancient China with significant consequences (pp. 114). ${ }^{19}$ Wang identifies a number of social factors which he believes

\footnotetext{
${ }^{19}$ With respect to the time of emergence of vagabonds as a significant social group, Wang (2007) refers to the Song Dynasty, while Li Shenzhi (2007) suggests that large vagabond population were in existence as early as in the Eastern Zhou Dynasty (770 B.C.E.-256 B.C.E.).
} 
explain the rise of the vagabond population: natural disasters coupled with the lack of state relief programs that forced peasants into exile (pp. 72-76), wars and turbulence in the $10^{\text {th }}-13^{\text {th }}$ centuries that disintegrated numerous familial clans (pp. 116, 120), and the growth of population accompanied by massive agricultural land concentration in the hands of the relatively few, which drove rural laborers into cities (pp. 76-68, 120-127). ${ }^{20}$ Wang notes that vagabonds more often than not migrate between cities and towns. "In order to make a living, they had to sell their labor, or to gain fortune through illegal means" (p. 16). However, as a result of high instability in employment and absence of familial-clan support, those without stable income suffered from frequent starvation as well as lack of shelter, and thus they tended to be intolerant and violent (p. 132); some organized themselves into gangs or other forms of private armed forces that were both "not afraid of breaking state laws" (ibid.) and "inclined to pursue gains without sufficient consideration for ordinary civilians" (pp. 116).

For Wang, the rise of vagabonds had profound implications as it came to challenge pre-existing orthodox social norms. Before the formation of vast flowing population, the state relied heavily on local clan-based education and regulation to uphold Confucianism — which protects social hierarchy and advocates a stabilized society—as the orthodox and thereby to maintain social order (pp. 30-31, 55-62). As is also described

\footnotetext{
${ }^{20}$ Citing The History of the Development of the Chinese Population (1992), Wang notes that the population increased fourfold in the Northern Song Dynasty (960 C.E.-1127 C.E.). Wang (2007) also points to the different style of urban landscaping in the Song Dynasty-which allowed for the accommodation of more vagabonds - compared to the preceding dynasty (pp. 132-143). He describes that, while previously the residential and commercial areas of the capital city were isolated from each other, in Song the two merged.
} 
by Lubman (1999), "the Chinese state never penetrated Chinese society to the same degree as royal power did in England and France, and much rule was exercised indirectly through local elites" (p. 16). Specifically, local familial clans "instructed members on Confucian morality, assisted poor and aged members, maintained schools and ancestral halls, and settled disputes among members" (p. 17). However, Wang points out, with the growing number of those who no longer stayed in close connection with their clans, many became detached from the Confucian-oriented order formerly maintained by large familial communities (Wang X., 2007, p. 720). As a consequence of their harsh conditions of life and their loosening tie with Confucian clans, a large number of vagabonds developed anti-social and anti-Confucian consciousness characterized by indiscriminate aggressiveness - they held social order in disregard and were even inclined to generate chaos so as to gain fame and fortune (pp. 292-303). ${ }^{21}$ Moreover, the rise to power of the uneducated vagabonds, who became regional warlords and even emperors during the $10^{\text {th }}$ century, was followed by large-scale destruction of elite aesthetics and pre-existing standards of conduct, henceforth setting the trend of "cultural vulgarization" in the Song Dynasty (pp. 114-119). ${ }^{22}$

In Wang's view, the process of cultural vulgarization that started around the Song Dynasty explains how vagabond cultures not only have challenged pre-existing standards

\footnotetext{
${ }^{21}$ In Wang's interpretation, Confucianism prescribes that every member of society fulfill his or her obligations duly determined by his or her social position, so as to maintain an orderly society (p. 58).

${ }^{22}$ Wang (2007) notes that the first emperor of Song was himself a vagabond before rising to power (p. 119).
} 
of conduct, but also have replaced Confucianism as the effective life philosophy of many non-vagabonds. According to Wang, the symbol of cultural vulgarization is the rise of "popular literature-ism" (p. 449). He notes that, following the growth of the flowing population, "vagabond intellectuals" - the literate vagabonds - composed a large amount of popular literature such as street story-telling (shuo shu), dramas, and novels that "reflected the life and consciousness of vagabonds" (pp. 247-290). The protagonists in much popular literature were vagabonds who rose to power or acquired fame by unconventional means that deviated greatly from Confucian norms which advocate stabilized social hierarchy (pp. 266-272). Wang argues that such literature appealed to many and even gained popularity among the non-vagabond population, as it depicted the possibility of moving up quickly to high social status from the bottom of society (pp. 266, 542). With the spread of influence of "popular literature-ism," Confucian classics were put aside as mere decoration, and many-even among the literati-came to "identify with vagabond consciousness" (ibid.), particularly the desire to gain from instrumentalist opportunism which acknowledged no Confucian moral principles (pp. 273, 544). Thus, the consequence of the rise of vagabonds, Wang suggests, is nothing less than the gradual erosion of orthodox Confucian norms by the flowering centrifugal vagabond cultures (pp. 540-547).

Wang, along with others (Li Shenzhi, 2007), contends that critical understanding of vagabond cultures in China is crucial for the construction of a social order based on the rule of law in the future (Wang X., 2007, p. 726). In contrast to those who describe 
Confucian despotism as China's legal tradition, Wang argues that China's culture contains certain elements of "anomaly" displayed by vagabond cultures, which hinders China's modernization. In particular, he suggests, the devastation of Confucian values and standards of conduct in the Cultural Revolution revived the destructive aspects of vagabond consciousness, such as the unwillingness to bind oneself to any rules of conduct, refusal to take responsibilities, and abandonment of senses of principle (pp. 23, 726). Wang is also alarmed by what he considers to be the reemergence in contemporary China of the social factors that gave rise to vagabonds and vagabond cultures historically, such as socio-economic transition combined with a booming population. In order to realize the rule of law, Wang concludes, one has to be cautious about the negative effects of vagabond cultures as China's tradition of anomaly.

As has been shown, China's traditions of law have been portrayed in a variety of forms. The meanings of $f a$ have been interpreted differently, suggesting different understanding about the nature of China legal traditions. Confucianism and Legalism have been discursively constructed with various evaluations regarding whether and how they support social hierarchies and state control. Further, some point to the unconventional vagabond cultures that have mostly been neglected in portrayals of Chinese legal traditions. All this offers multiple pictures of the traditional China, some depicting the country as being subject to strict authoritarianism, while others articulating it as less so. However, many of the representations, if not all, are centered around the question about China's distinctiveness, with a contrasting West in the background, or 
about what is to blame, among the many sources of heritage, for China's retarded

modernization. The following discussion will show that the Western rule of law tradition has also been constructed in diverse ways, yet many contemporary Chinese accounts on the topic seem to share a "modernization complex" (Xu Zhongming, 2000, p. 84), which leads them to explain "the rule of law" in teleological terms.

\section{"The rule of law" as a Western tradition}

The rule of law, both as a concept and as a set of practice, is often seen as a hallmark of Western legal traditions (Peerenboom, 2002; Tamanaha, 2004). But has it been described consistently in scholarly narratives? In this section, I will discuss how the rule of law as a Western tradition has been constructed differently in Western and Chinese accounts, despite the fact that the former constitutes a major channel through which the Chinese learn about Western legal histories. ${ }^{23}$ To be sure, one should be cautious not to simplify or over-generalize differences between Western and Chinese scholars. The discussion that follows does not presume that there must be some essential differences between the ideas of the two groups. Rather, it is to note the mediation effects of Western references on Chinese narratives. ${ }^{24}$ As will be shown, although many Chinese scholars

\footnotetext{
${ }^{23}$ Some of the texts reviewed may not mention explicitly that the rule of law is a Western tradition. But it is clear that they hold this view, as the majority of sources that they draw upon to describe the rule of law are Western ones.

${ }^{24}$ In this context, "mediation effects" refers to the influence of earlier accounts of tradition on later ones. As Su Li (2004) observes, Chinese scholars tend to cite Western sources uncritically (pp. 41, 59). It would therefore be interesting to examine the extent to which Western views of the rule of law as a tradition have been duplicated in Chinese accounts.
} 
look to Western theories for inspirations, they may however diverge from the sources they rely on, or from other Western authors who reference similar sources. While the rule of law tradition has been critically reflected on in the West, in the Chinese narratives one is more likely to find the argument that Western legal history, being propelled by some transcendental values of law and justice, has followed a teleological course of development. Such an approach to Western legal tradition, which is widely accepted in contemporary China, can be attributed to the ambition of Chinese scholars to build a "rule of law" on their own land. Many legal reformers believe that, to establish the rule of law, one must secure a solid understanding of the immutable essence of law which can be found in Western legal history. The ardent pursuit of a clarified conceptual cornerstone for a rule-of-law China is exemplarily reflected in Xia Yong's comments in his book on the rule of law:

The rule of law is a classical concept in the history of law, and is also an ideal revitalized in contemporary China. As a classical concept, the rule of law has deep and long-lasting meanings, but in the darkness over the years there is not even a commonly accepted definition of it in the West which claims a tradition of the rule of law. As an ideal of law, the rule of law has instilled strong and spirit-nourishing rationality into institutions, has provided clarifications and vitality for learning, yet has also become overloaded and contaminated by excessive political wills and social emotions, and thus is constantly subject to distortion. Therefore, as we hold high the banner of the rule of law over twenty years after we drew a conclusion to the Cultural Revolution and introduced reform and opening-up, why should we not calmly ask: what, indeed, is the rule of law? Asking this question may help us accurately situate the historical and logical position, as well as the contextual particularity, of various contemporary efforts of our nation toward the rule of law, thus providing a good starting point for our rule-of-law theory and practice. (Xia, 1999, p. 3) 
What lays behind an aspiration such as this is often a critique of absolutism, as $\mathrm{Xu}$ Xianming points out in his treatise on the essential components of the rule of law (Xu, 1996). While the category of "the rule of law versus absolutism" is a modern one to the Chinese, Western interpretations of its own tradition have nonetheless not been loyally followed in Chinese accounts. For the latter, "the rule of law" is more than a foreign sign for semantic analysis; in fact, it is nothing less than a disruptor of the status-quo and a propeller for domestic change. Rather than being self-illuminating yet "contaminated by...political wills and social emotions" (Xia, 1999, p. 3), "the rule of law," in the ways in which it is articulated as a tradition, is the product of those wills and emotions.

\section{The meanings of the rule of law: A coherent whole or not}

In Western accounts, the rule of law is sometimes portrayed as containing contradictory component meanings (Kleinfeld, 2005; Tamanaha, 2004). However, in many Chinese works, the inner tensions of the rule of law that are discussed in Western narratives are often downplayed. Admittedly, Chinese scholars on the whole recognize the existence of diverging views concerning the key meanings of the rule of law, as they are exposed to a variety of Western conceptions of the rule of law. Aristotle, Montesquieu, A. V. Dicey, Friedrich Hayek, Lon Fuller, Joseph Raz, and Roberto Unger are among the names frequently quoted when Western ideas on the rule of law are discussed in Chinese accounts, as in Western ones. In fact, Chinese authors also build on the above-mentioned thinkers and theorists to articulate their own understanding of the key elements of the rule 
of law, as contemporary Western scholars do. Nevertheless, although drawing from the ideas of a similar group of legal theorists, Chinese authors are inclined to stress what they believe to be the invariable component meanings of the rule of law, whereas their Western counterparts tend to place relatively more emphasis on the tensions existing among the components.

For example, in "Competing Definitions of the Rule of Law" (2005), Rachel Kleinfeld builds on Aristotle, Montesquieu, Dicey, Hayek, and Raz, among others, to identify five "ends-based definitions" of the rule of law in the West, which are, respectively, "making the state abide by law, ensuring equality before the law, supplying law and governance [law and order], providing efficient and impartial justice, and upholding human rights" (p. 7). However, the author notes, "some of these end goals have become generally accepted in Western legal and political philosophy over the last few thousand years", while others "remain hotly disputed" (ibid.). For instance, "whether human rights is an end of the rule of law—or whether the phrase merely implies technocratic procedures and institutions - has been contested from Aristotle to the present day" (pp. 7-8). Kleinfeld also acutely points out that "rule-of-law ends are in tension" (p. 24):

All good things do not go together. These ends are not part of a unified concept that emerged whole; rather they grew piecemeal in response to different historical needs over a period of millennia. They represent distinct societal goals, and work toward one goal will not necessarily lead to success in the others. (p. 15)

The author goes on to explain how it is so: 
The rule of law is about both limiting the power of the state and empowering it to protect the rights of the citizens against lawbreakers and rebels.

Fostering the judicial independence required to bind the government can work against rooting out corruption within the judiciary. A country with scrupulous human rights norms may have difficulty maintaining law and governance in the face of a heavily armed citizenry and organized gangs without similar scruples. Conversely, citizens wanting social order may demand the weakening of regulations protecting civil and political rights. (p. 24)

Kleinfeld is not alone in emphasizing "the split" (p. 12) among various rule-of-law ends. Brian Tamanaha, the author of On the Rule of Law: History, Politics, Theory (2004), reviews pre-existing conceptions of the rule of law-including those formulated by Aristotle, Dicey, Hayek, Fuller, Raz, Unger, and others - in an attempt to isolate themes that "run through the rule of law tradition" (p. 9). However, he concludes that the rule of law is "an exceedingly elusive notion" (p. 3), and that "it would be facile to suggest that there is an overarching coherence," despite the fact that the rule of law is an "ideal that has survived over two millennia" in the West (p. 114). To be sure, Tamanaha does propose what he believes to be the three "clusters of meanings" of the rule of law, which are "government limited by law," "formal legality" or predictability of ruling, and "not rule of man." Nonetheless, he stresses that these clusters of meanings "revolve around distinct areas, each with its own specific tilt" (ibid.). Moreover, he points out, the three themes of the rule of law may not be equally desirable when considered in the international context.

Chinese authors who seek to describe the rule of law as Western legal tradition also propose various formulations of its key elements, as can be seen in the table below. 
However, although the groups of legal theorists quoted are similar to those referenced in the two Western works discussed above, many Chinese accounts do not seem to be as attentive to the paradoxical relations that may exist among various elements of the rule of law they propose. On the contrary, they tend to create the impression that the rule of law as a Western tradition can be conceived of as a coherent whole rather than as a conglomerate of competing meanings.

\begin{tabular}{|c|c|c|}
\hline $\begin{array}{r}\text { Name of } \\
\text { author(s) }\end{array}$ & $\begin{array}{c}\text { Western authors } \\
\text { quoted (part) }\end{array}$ & $\begin{array}{c}\begin{array}{c}\text { Conceptualization of the key elements } \\
\text { of the rule of law }\end{array} \\
\end{array}$ \\
\hline $\begin{array}{l}\text { Xu } \\
\text { Xianming } \\
\text { (1996) }\end{array}$ & $\begin{array}{l}\text { Aristotle } \\
\text { A. V. Dicey } \\
\text { Joseph Raz } \\
\text { Lon Fuller } \\
\text { Rousseau } \\
\text { John Locke } \\
\text { K. Marx \& F. Engels }\end{array}$ & $\begin{array}{l}\text { Three essential elements: } \\
\text { 1. The spiritual (which requires respect for good laws); } \\
\text { 2. The substantive (which prescribes the principles and } \\
\text { content of law); } \\
\text { 3. The formal (consistency, generality, efficacy of law, } \\
\text { judicial neutrality, professionalism of practitioners, } \\
\text { and others) }\end{array}$ \\
\hline $\begin{array}{l}\text { Xia Yong } \\
\text { (1999) }\end{array}$ & $\begin{array}{l}\text { Harold Berman } \\
\text { Aristotle } \\
\text { Friedrich Hayek } \\
\text { Henry Bracton } \\
\text { M. Tigar \& M. Levy } \\
\text { Roberto Unger } \\
\text { A. V. Dicey } \\
\text { Joseph Raz } \\
\text { Lon Fuller } \\
\text { John Finnis } \\
\text { John Rawls } \\
\text { James Madison } \\
\text { Ronald Dworkin }\end{array}$ & $\begin{array}{l}\text { Ten "admonitions" of the rule of law: } \\
\text { 1. Generality of law; } \\
\text { 2. Public promulgation of law; } \\
\text { 3. Predictability; } \\
\text { 4. Clarity of law; } \\
\text { 5. Consistency of law; } \\
\text { 6. Law can be followed; } \\
\text { 7. Stability of law; } \\
\text { 8. Law higher than government; } \\
\text { 9. Authority of the judiciary; } \\
\text { 10. Judicial justice. }\end{array}$ \\
\hline $\begin{array}{l}\text { Shu } \\
\text { Guoying \& } \\
\text { Cheng } \\
\text { Chunming } \\
(2001)\end{array}$ & $\begin{array}{l}\text { A. V. Dicey } \\
\text { Joseph Raz } \\
\text { Friedrich Hayek } \\
\text { Roberto Unger } \\
\text { Harold Berman } \\
\text { Max Weber } \\
\text { G. W. F. Hegel } \\
\text { Henry S. Maine }\end{array}$ & $\begin{array}{l}\text { Three common goals of the rule of law: } \\
\text { 1. To resist despotism and "wars of man against man"; } \\
\text { 2. To allow the use of rationality in planning personal } \\
\text { affairs; } \\
\text { 3. To prevent the arbitrariness of officials. } \\
\text { Five components of the rule of law: } \\
\text { 1. Law must be understandable and can be followed; }\end{array}$ \\
\hline
\end{tabular}




\begin{tabular}{|c|c|c|}
\hline & $\begin{array}{l}\text { Herbert Marcuse } \\
\text { K. Marx \& F. Engels }\end{array}$ & $\begin{array}{l}\text { 2. Efficacy of law; } \\
\text { 3. Stability of law; } \\
\text { 4. The supremacy of legal authority; } \\
\text { 5. Judicial justice. }\end{array}$ \\
\hline $\begin{array}{l}\text { Wang } \\
\text { Taixian } \\
(2001)\end{array}$ & $\begin{array}{l}\text { Max Weber } \\
\text { Plato } \\
\text { Aristotle } \\
\text { Harold Berman } \\
\text { Roberto Unger } \\
\text { Thomas Aquinas } \\
\text { G. W. F. Hegel } \\
\text { Alexis de Tocqueville } \\
\text { Thomas Hobbes } \\
\text { John Locke }\end{array}$ & $\begin{array}{l}\text { The rule of law "developed out of the infancy of humane } \\
\text { spirits" which provide the following "spiritual } \\
\text { resources" for Western legal tradition: } \\
\text { 1. Rationality; } \\
\text { 2. Belief in law; } \\
\text { 3. The inherent spirits of freedom and equality. }\end{array}$ \\
\hline $\begin{array}{l}\text { Cui } \\
\text { Yongdong } \\
(2004)\end{array}$ & $\begin{array}{l}\text { Aristotle } \\
\text { Henry Maine } \\
\text { Cicero } \\
\text { Augustine } \\
\text { Thomas Aquinas } \\
\text { Friedrich Hayek }\end{array}$ & $\begin{array}{l}\text { Conceptual basis: the evil nature of human beings } \\
\text { Two cores of modern rule of law: } \\
\text { 1. To put limits on government power; } \\
\text { 2. To protect rights of the people. }\end{array}$ \\
\hline
\end{tabular}

Xu Zhongming, a commentator on contemporary Chinese legal studies, once remarks about the works by Zhang Zhongqiu, which are praised as "the most systematic" analysis of Chinese and Western legal cultures (Xu Zhongming, 2000, p. 80): [Zhang's] problematic and research gesture is triggered by a 'Chinese care,' that is, ... an intense 'legal modernization' complex" (p. 84). Xu's comments may not be restricted to Zhang Zhongqiu alone and in fact are applicable to many others in their ardent portrayals of the rule of law as a tradition of the West, which has obtained an aura of immutability and thus is supposed to be able to shed light on China. For example, Zhang remarks that Aristotle's "classical definition...reveals two fundamental characteristics of the rule of law, that is, the universal application of law and the sovereignty of law" (Zhang Z., 1999, pp. 276-277). Commenting on the explications of the rule of law offered by theorists and 
dictionaries after Aristotle, Zhang concludes that they are essentially "consistent with or similar to" the definition offered by the ancient Greek thinker, although there are variations in terms of wording (p. 277). This view is echoed by Wang Taixian and Ai Ming (2001), who stress the "foundational" nature of Aristotle's ideas, which they argue have "consistently" guided the conceptualization of the rule of law by various modern Western theorists (p. 16). Wang and Ai (2001) note that, although the meanings of the rule of law underwent some transformations in the $17^{\text {th }}$ and $18^{\text {th }}$ centuries, its essenceWestern humanism—remains "certain and stable" (p. 21). Shu Guoying and Cheng Chunming (2001) also argue that, although there are different aspects in the manifestation of the rule of law, Western scholars in general acknowledge three core "value goals" and five "elementary components" of the concept (pp. 137-138), which are listed in the table. In a similar token, Cui Yongdong (2004) highlights the conceptual basis and two cores of Western rule of law and, furthermore, suggests that the belief in the evil nature of human beings characterizes the ideas of those who promote the rule of law, among both the Western and the Chinese thinkers (pp. 8-9). To be sure, some scholars also point out the inner tensions of the rule of law (Xia, 1999, p. 49), the discussion of which, however, is far less elaborated. As Xia Yong admits, "[as we] reach a knowledge framework about the rule of law from its origin, admonitions, and values..., this knowledge framework may, for its own purpose, intentionally simplify some issues, and carefully evade some contradictions and differences" (ibid.). That purpose for which contradictions and differences are evaded is, arguably, no other than the contemporary cause of legal 
modernization for China.

The path(s) of development of the rule of law: (Dis)Continuity and crisis

As can be seen, Chinese and Western accounts that build on the ideas of a similar group of legal theorists have nonetheless voiced different views concerning the meanings of the rule of law. This is manifested in the extent to which Chinese accounts, compared to Western ones, are inclined to downplay inner tensions of the rule of law as a concept.

Likewise, in discussing the path of development of Western legal tradition, some Chinese authors also tend to bypass notions of discontinuity and crisis, even though these themes - or at least one of them-are evident in the Western sources they use heavily, such as the works by Harold Berman. ${ }^{25}$ In comparison to the Western sources, the Chinese accounts are more prone to adopt a teleological narrative, indicating that the West has followed a path of linear progression towards the complete realization of the rule of law (Zhang Z., 1999; Shu \& Cheng, 2001; Xia, 1999; Wang T., 2001). Thus, the narrative follows, there is much inspiration in the Western experience for China to harvest from for its own particular context. This emphasis on critical appropriation, however, is ironic in that the legal history of the West has indeed been adapted in many Chinese accounts, yet not as critically as it could have been as the accounts are preoccupied with China's modernization.

In Law and Revolution (1983), a highly respected work on Western legal tradition,

\footnotetext{
${ }^{25} \mathrm{Su} \mathrm{Li}$ conducts an analysis to identify the 20 most frequently quoted foreign works in Chinese scholarly publications in the field of legal studies. His findings show that Harold Berman's Law and Revolution (1983) ranks the $4^{\text {th }}$ (Su L., 2004, p. 66).
} 
Harold Berman notes that, to understand the history of Western legal tradition, one should "dispel common preconceptions" (p. 13) that are "uncritically" accepted in "the conventional historiography that has been generally taught since the sixteenth century" ( $p$. 14). According to Berman,

This [conventional] view simply assumes that Western history is divided into three periods: ancient, medieval, and modern. Ancient history is the history of Greece and Rome. The decline of Rome, due to the barbarian invasions, produced a medieval age, which lasted roughly from the fifth to the fifteenth century. Then modern times began-some would say with the Renaissance, others would say with the Reformation, still others would say with both.... Ancient Israel will be introduced into the picture of the Ancient World. The Middle Ages will be defined by the period between the early Church and Luther's break with Rome. The Protestants, however, will unite with the Humanists in saying that Western art and thought go back to Greece, and Western politics and law go back to Rome. (ibid.)

Berman suggests that the presumed continuities in such a narrative be put under scrutiny.

In terms of the relations between Greece/Rome/Israel and the tradition of the West, he remarks, "[t]he West...is not Greece and Rome and Israel but the peoples of Western Europe turning to the Greek and Roman and Hebrew texts for inspiration, and transforming those texts in ways that would have astonished their authors" (p. 3; original italics). Meanwhile, concerning the continuity within the medieval age, Berman points out that "one who investigates any of the legal systems of Europe first in the period of 1000-1050 and then in the period 1150-1200 finds a tremendous transformation" (p. 15), which "is true, above all, of the law of the church" (ibid.). Based on this observation, Berman argues that the origin of Western legal tradition is to be found in the Papal Revolution of the late eleventh and early twelfth centuries, a great discontinuity within 
the Middle Ages. ${ }^{26}$

To be sure, to say that the notion of discontinuity is visible in Berman's account is not to suggest that the legal historian has dismissed any patterns of regularity in the history of the Western legal tradition. In fact, a major argument of Berman is concerned with the "ongoing character of the tradition" (p. 7). In particular, Berman argues, although the Western legal tradition "has been transformed in the course of its history by six great revolutions"- which were the Russian Revolution, the French Revolution, the American Revolution, the Glorious Revolution, the Protestant Reformation, and the Papal Revolution or the Gregorian Reformation (pp. 18-19)_-"each of the great revolutions made its peace with the pre-revolutionary law and restored many of its elements by including them in a new system that reflected the major goals, values, and beliefs for which the revolution had been fought" (p. 29). "Thus," Berman describes, "the new systems of law established by the great revolutions transformed the legal tradition while remaining within it" (ibid.). Nonetheless, it should be pointed out that Berman's account on Western legal history is not meant to suggest any "deliberate movement toward particular ideal goals" (p. 7). His description of the development of Western legal tradition, Berman notes, "means something less than moral progress, though something more than mere change or accumulation" (ibid.). Moreover, his argument concerning the

\footnotetext{
${ }^{26}$ To be sure, the linear sequence of Greece, Rome, Middle Ages and then the modern still exists in some contemporary Western accounts on the rule of law tradition, as in Tamanaha (2004). However, Tamanaha also points out that "the transition in Europe from the Middles Ages, through the Renaissance and the Enlightenment, to the modern era, was not the uninterrupted flowering of the rule of law" (2004, p. 28).
} 
continuity of tradition is partly aimed to criticize those who believe that "history has no meaning" or that "changes in history are random" (p. 13).

Furthermore, while noting that the Western legal tradition has been sustained despite the impacts of past revolutions, Berman particularly emphasizes that the tradition is confronted with a crisis, the origin of which can be found both within and without the West:

From within, social and economic and political transformations of unprecedented magnitude have put a tremendous strain upon traditional legal institutions, legal values, and legal concepts in virtually all countries of the West. Yet in the past there have been periods of revolutionary upheaval which have also threatened to destroy basic elements of the Western legal tradition, and that tradition has nevertheless survived. What is new today is the challenge to the legal tradition as a whole, and not merely to particular elements or aspects of it; and this is manifested above all in the confrontation with non-Western civilizations and non-Western philosophies. (p. 33)

Berman contends that this "revolutionary crisis" is "greater than any other" in history, "one that some believe has brought it [the Western legal tradition] virtually to an end" (p.

1). This is so because the crisis is not merely about debates on legal philosophies but about the belief in law itself (p. 39). Berman observes that "almost all the nations of the West are threatened today by a cynicism about law, leading to a contempt for law, on the part of all classes of the population" (p. 40). This contempt and cynicism, he suggests, has been "stimulated by the contemporary revolt against...legal formalism, which emphasizes the uniform application of general rules as the central element in legal reasoning and in the idea of justice" (ibid.). In fact, Berman is only one among many who 
"have observed the decline of the rule of law in the West" (Tamanaha, 2004, p. 4). As

Tamanaha points out, the "marked deterioration" of the Western legal tradition has been a widely reiterated theme among Western legal theorists, particularly "in the past three decades" (ibid.). ${ }^{27}$

In contrast to Berman's account which exposes the discontinuities of the Western legal history, and which notes the crisis of the Western rule of law, the Chinese narratives that draw on the legal historian often describe the path of development of the Western tradition in teleological terms, and bypass discussions of the decline of the tradition.

For instance, in recounting the history of West legal tradition, Zhang Zhongqiu (1999) talks of the pre-modern ages as breeding the spirit of the rule of law, and describes the development of the rule of law since the modern era as the perfection of the tradition. ${ }^{28}$ In explaining how theories of the rule of law have been formulated and then gradually perfected in the West, Zhang attributes it to the "consistent and profound understanding of the nature of power among Western thinkers" (1999, p. 303). Meanwhile, although Zhang draws on Berman to demonstrate the religiosity of Western legal culture, when discussing the development of the rule of law in the West, he barely mentions Berman's

\footnotetext{
${ }^{27}$ Of course, this is not to say that there existed no concerns about the Western legal tradition earlier than thirty years ago. Tamanaha notes that the observation of the decline of the rule of law began "with A. V. Dicey over a century ago" and was later "renewed by Friedrich Hayek fifty years ago" $(2004$, p. 4). It should also be pointed out that, although many share the belief that Western legal tradition is in crisis, the reasons why they think so are not always the same.

${ }^{28}$ When talking about the Middle Ages, Zhang does speak of how the spirit of the rule of law was overshadowed by religion (1999, p. 302). However, Zhang argues that "the 'heavy curtain' [of religion] could not block the brightness of the tradition [the spirit of the rule of law]" and that "the idea of law as sacred, authoritative, and inviolable has been circulated in history and among the mass population in the form of an axiom" (ibid.).
} 
comments about the crisis of the tradition. For Zhang, the history of Western legal tradition is "a logical process in which Western theories of the rule of law have reached perfection step by step" (pp. 304-305).

Similarly, Shu and Cheng (2001) also quote Berman to discuss connections between religion and law in the West; however, they again dismiss what Berman has said about the discontinuities within Western legal history or about the challenges faced by Western legal tradition. ${ }^{29}$ Instead, when describing the history of the tradition, the two authors note that theoretical articulations of the rule of law first appeared in ancient Greece and Rome, that relevant institutional bases were later established in the modern age, and that specialized knowledge of the rule of law has come to be enriched since the mid $19^{\text {th }}$ century. "With the unfolding of history," they argue, "the complete picture of the concept of the rule of law gradually becomes clear" (p. 137). The authors at a point do make it clear that one should question linear conceptions of history (p. 139). Nonetheless, their conclusion concerning the pattern of development of the rule of law is strongly reminiscent of what they intend to avoid. "In the West," the authors claim, "the completion of the meanings of the rule of law is manifested as a historical process, one that progresses toward a direction in which emotions of human beings are increasingly brought under control, and in which societies are increasingly integrated" (p. 140).

As can be seen, while in Berman's account of Western legal tradition one finds

\footnotetext{
${ }^{29}$ In Xia (1999) and Wang T. (2001), Berman is also referenced to explain the relations between law and religion in the Western context. But, likewise, Berman's concern about the crisis of Western legal tradition is skipped.
} 
notions of (dis)continuity and decline, in certain, if not many, Chinese works that reference Berman one is offered a picture of the rule of law steadily prospering and being perfected in the West. It is arguable that the tendency to gloss over Western crises of law, coupled with the negligence of inner contradictions of meanings of the rule of law, is connected to scholarly advocacy of the rule of law reform in China. In many contemporary Chinese scholarly accounts, the history of Western legal tradition has been narrated with a teleological twist which is less often seen in contemporaneous Western narratives, and which points to a prospect of the rule of law thriving not only in the West but also in China. However, it is noteworthy that in socialist China "the rule of law" has not always been received as a laudable Western idea. In fact, its meanings have undergone transformations as they are constructed to serve changing social needs. However, the terms in which the meanings are promoted remain within the cognitive framework of the modern condition. In Chapter 4, 5, and 6, I will discuss the narrations of traditions in the discourses on the rule of law, showing the specific and various ways in which they are defined by the modern epistemic condition as they are mobilized for competing social agendas. 


\section{Chapter 3 Discourse shifts}

In the last chapter, I have argued that traditions are discursive products of modernity. I have also proposed to study the accounts of traditions in the Chinese discourses on the rule of law in order to show the specific ways in which they are impacted by the modern epistemic condition. The proposed study, I believe, requires an analytic model which not only approaches semiotic histories from a perspective of epistemology, but also allows the analysis of the varied ways in which the modern condition exerts influences on discourses. Such a model should conceptualize communicative or semiotic practices not as mere acts of transmitting messages, but as efforts to promulgate social definitions, which are dispersed in space and time as they link to varied social causes - modern articulations of traditions are but only one example in this regard. The spatial and temporal dispersion involved requires that semiotic events be theorized as networks of practices which, moreover, are fluctuating as old meanings are contested and new ones promoted. Thus, one needs to look beyond single instances of discourses and consider their interconnections and transformations over time. In particular, for analysts of transnational communication, a long-term perspective provides an advantageous point of observation if they are to discern patterns of diffusion, confrontation, or hybridization in complex communication phenomena. With all this in mind, I conceptualize in this chapter a 
framework of "discourse shifts" to analyze communicative events as changing networks in which social assumptions - a primary and often implicit form of social definitions - are promoted, challenged, remolded, and sustained as they are connected to varying contingent social agendas. Using this framework, one can attempt an understanding of the variety of ways in which traditions are invoked, obscured, contested, and reshaped under the modern epistemic condition. The rest of the chapter contains five sections: (1) an outline of the basic assumptions about "discourse" employed in this study; (2) a critical review of existing conceptions of discourse; (3) an intermediate discussion that explains further my own understanding of discourse; (4) a critique of three existing approaches to theorizing the dynamics of discourse; and (5) based on the preceding discussions, an attempt to propose the model of "discourse shifts" which studies semiotic histories through the analysis of social agendas and assumptions in changing idea-networks. In the last section I will also further discuss how the model helps one examine the epistemology of traditions in modernity.

\section{"Discourse": Basic assumptions}

Given the doubt cast by some on discourse as a legitimate object of inquiry (Palmer, 1990), and given the variety of perspectives that have been adopted in the broad yet ambiguous field called discourse analysis, it is important to explain on what basic assumptions I approach the study of discourse.

First, discourse analysis is central to communication studies as discourse is an 
essential site in which the persuasiveness of communicative practices locates. It is the locus where authority is claimed and refined, passions provoked and suppressed, and rationales enunciated and contended. In a word, it is where semiotics is organized to create meanings that induce consent and actions.

Second, as discourse is essentially related to issues of meaning, one may ask: does studying discourse mean laboring to uncover the deep source of meanings that hides behind specific instances of communication, be it divinity, human reason, or the essential cultural spirit of any social community? Is it to trace the origin of all meanings which, as Foucault argues, remains "ever-receding" if one keeps seeking it (Foucault, 1972, p. 25)? I assume that the purpose of discourse theories is not to reveal the silent, static, and autonomous fountain of meanings, the existence of which is itself doubtful.

Third, instead of seeing everything as composed of nothing but discourse, I assume that there exists a world - whether inherently "structured and stratified" (Joseph \& Roberts, 2004, p. 2) or not-outside of discourse. All is possible to be constructed or represented in discourse but we cannot reduce everything to discourse. At the same time, discourse and other aspects of the social world and are not independent of each other but are entangled. This will be explained immediately.

Fourth, as many others do, I stress the "situatedness" of discourse in "the social" (Mills, 1997, pp. 10-11). Lilie Chouliaraki and Norman Fairclough (1999) see "the social" as composed of "discourse and other, extra-discursive, facets" (p. 6). They 
draw on David Harvey to show that "discourse is one 'moment' among six" in the social process, and that the six moments "internalize" one another (ibid.). I share the understanding about the "social embeddedness" of discourse, and argue that discourse and other dimensions of the social are not separate and independent categories or entities. Nor can we assume any kind of one-way relationship of determination between them.

Furthermore, as Chouliaraki and Fairclough point out, the discursive is "an element/moment of the "social"' (ibid.); thus, the problematic of discourse, in terms of how it relates to social transformation, is not concerned with the question of whether or not discourse change, as something exterior, "brings about" or "determines" social change. In other words, I do not speak of the discursive and the social in a kind of language that attributes to them a relationship as that between an independent variable and a dependent variable. Instead, I assume that the discursive is part of the social and, correspondingly, discourse change is part of social change.

Finally - this is also related to the above assumptions - I treat discourse as historically constituted but not as transcendental. In other words, while I talk about "discourse" in its abstract sense as a dimension of the social, I also recognize the

\footnotetext{
${ }^{1}$ According to Harvey, the six moments of the social process are respectively "discourse/language, power, social relations, material practices, institutions/rituals, and beliefs/values/desires" (Chouliaraki \& Fairclough, 1999, p. 6). Of course, the question of whether this is a good division of "the social" is debatable - for example, Chouliaraki and Fairclough point out that the concept of "material activity" is preferable to that of "material practices" (pp. 28-29); but I agree with the general way in which Harvey defines the relationship between the discursive and the social. My own understanding of how discourse relates to the social will be discussed in further detail in one of the sections that follow.
} 
historical specificities of various concrete discourses. Discourse is not a kind of transcendental and autonomous entity that freely and independently determineswhile not being constrained by - other aspects of the social. ${ }^{2}$ Rather, discourse both influences — by being articulated, circulated, and interpreted — and is influenced by other aspects of the social; at the same time, all elements/moments of the social have effects on the path and scale of social change. As such, the discursive, as a dimension of the social with all its historical specificities, can constitute part of the drive for future social change. While being part of contemporary social change, discourse change also helps to open up possibilities of further change in the future. This and the others discussed above are the primary assumptions about "discourse" employed in this study. Before I further explain my own definition, however, it is necessary to carry out a review of existing conceptions of discourse, which I will turn to in the next section.

\section{Approaches to conceptualizing discourse}

Given the growing corpus on discourse and the variety of approaches, the review

\footnotetext{
${ }^{2}$ In fact, even in The Archaeology of Knowledge (1972) - -hereafter referred to as The Archaeology -which is often seen as representing "structuralist" reflections that give primacy to "discourse" and neglect other social factors, Foucault notes the existence of "primary relations" which "may be described between institutions, techniques, social forms, etc" and which are relatively "independent of all discourse or all object of discourse" (Foucault, 1972, p. 45). In 1968, just before The Archaeology was first published, Foucault also spoke of "the nondiscursive context in which... [a discursive formation] functions" (Foucault, 1996b, p. 35), as well as "extradiscursive dependencies... between different discursive transformations and others which have been produced elsewhere than in the discourse," such as "the correlations... between the medical discourse and a whole play of economic, political and social changes" (p. 38).
} 
conducted in this section would necessarily be selective. Specifically, I will consider how Michel Foucault and authors in the field of critical discourse analysis (CDA) understand "discourse." Foucault is selected as the starting point of the review because he is a seminal author in discourse theory whose ideas have influenced many others. I also choose to examine the field of CDA because, whether seen as a method or a theory, CDA includes various critical perspectives in the conceptual treatments of "discourse." In particular, I will discuss the conceptualizations in the works of Teun A. van Dijk and those of Norman Fairclough. To be sure, apart from CDA, there are also other influential approaches to discourse such as conversation analysis (Hutchby \& Wooffitt, 2008), discursive psychology (Edwards \& Potter, 1992), and systemic functional linguistics (Halliday, 1978) which have their own respective merits. Nonetheless, I choose CDA because it not only incorporates the insight of others about the importance of analyzing the social use of language, ${ }^{3}$ but also contains perspectives that are more relevant to the question of discourse change. In carrying out the review, I will answer two questions in the discussion of each author's ideas: first, what does the author mean by "discourse"? Second, what does the author consider to be the boundary of $a$ discourse? Or, does he or she believe in the fixed boundary of any discourse ${ }^{4}$ As will be shown, addressing these two questions is helpful for the

\footnotetext{
${ }^{3}$ In fact, some conceptions in CDA are built on the basis of a critique of the mentioned approaches to discourse. See Fairclough (1992) as an example.

${ }^{4}$ I ask these two questions just for analytical purposes. I do not assume that, for a certain thing, there must be some static essence or fixed boundaries.
} 
following consideration of discursive dynamics. ${ }^{5}$

\section{Foucault on discourse}

Foucault is seen by many as pioneering the critical study of discourse (Barrett, 1991; Fairclough, 1992; Mills, 1997). As Michèle Barrett (1991) points out, "it is in the work of Foucault that we should look for the most original, monumental, general theory as to why this theoretical lexicon [discourse] is preferable to that of ideology, social formation, class and so on" (p. 126). In this part of the chapter, I will examine Foucault's conception of discourse.

Nonetheless, in attempting to capture a general picture, one may ask: can we really find a consistent conception of discourse in Foucault? Or, is there a consistent Foucault? Does Foucault not plead that "do not ask who I am and do not ask me to remain the same" (1972, p. 17)? In view of these questions, before going into the discussion of Foucault's ideas on discourse, I shall make some clarifications regarding the treatment of the thinker's works and ideas in this chapter. Generally speaking, I believe that it is not always possible to extract a coherent set of ideas from the various works by a same author; or, to take the argument even further and to make it in some way resemble those of Foucault, there is no such thing as a consistent and authoritative authorship that awaits an excavation. ${ }^{6}$ In fact, interesting — and in many cases thought-

\footnotetext{
${ }^{5}$ By "discursive dynamics," I mean the interconnections and transformations of discourses over time.

${ }^{6}$ Nevertheless, I do not subscribe to the structuralistic view that authors do not speak at all but rather are always spoken. Given the limited space, I will not elaborate on this as it is not the central concern here.
} 
provoking - ambiguities emerge at various points in Foucault's works, just as in those of many other great thinkers. As Foucault himself admits, he actually abuses the term "discourse" by using it in different ways (p. 107). Hence, I do not seek to depict a coherent and "flawless" Foucault_-Foucault himself would very likely question the notions of "flaw" and "flawless." Rather, in this section, I will attempt to reflect the richness of his idea of discourse.

However, it should be noted that the existence of ambiguities does not necessarily mean the absence of focused concerns. Despite Foucault's denial of his own works as an organic whole, there are certain central themes that run through the main body of his writings. ${ }^{7}$ As Colin Gordon observes, Foucault's works share an "underlying continuity," that is, "the analysis or examination of the relation between forms of rationality and forms of power" (Smart, 1983, pp. 73-74; italics added). I argue that it is exactly Foucault's vision about the multiplicity of rationalities which underlies his ideas about discourse. The following review shows that Foucault particularly distances himself from the approach that treats discourse as mere linguistic signs; furthermore, Foucault understands discourse as practices that both shape meanings and influence the ways in which people speak or write-this is also connected with his repudiation of the Marxist concept of ideology; finally, Foucault's vision of discursive formations as systems of dispersions contests those views according to which discourses exist in

\footnotetext{
${ }^{7}$ I recognize that Foucault himself questions the approach of grouping discourses by common "themes" (Foucault, 1972, pp. 31-39). But, in fact, even Foucault himself sometimes tries to "thematize" his own research (Foucault, 1983, p. 209; Foucault, 1996b, pp. 33-34).
} 
categories with fixed boundaries or meanings.

As Sara Mills points out, discourse is often "defined by what it is not, what it is set in opposition to" and in contrast to other concepts (Mills, 1997, p. 4). It is arguable that Foucault's approach to discourse is typical in this connection. Nevertheless, in spite of all the vagueness, Foucault does make a clear step to differentiate his conception from a mere "linguistic" understanding of discourse. In the field of linguistics, discourse has been understood mainly as signs (Mills, 1997), being conceptualized as "linguistic communication" (Leech \& Short, quoted in Mills, 1997, p. 4; italics added). For example, Benveniste notes:

Discourse must be understood in its widest sense: every utterance assuming a speaking and a hearer.... It is every variety of oral discourse of every nature from trivial conversation to the most elaborate oration...but it is also the mass of writing that reproduces oral discourses or that borrows its manner of expression and its purposes. (Benveniste, quoted in Mills, 1997, p. 5)

Against such views, Foucault takes great pains to argue that discourse is not just about linguistic signs. In explaining "the statement," the most basic element of discourse, Foucault remarks that "the statement is not the direct projection on to the plane of language (langage) of a particular situation or a group of representations" (1972, p. 99). As such, discourse is not about using words to describe things. Instead, it is a type of formative practice. To capture Foucault's ideas in this connection as a whole, it is worth citing him at length here:

I would like to show that 'discourses', in the form in which they can be heard or read, are not, as one might expect, a mere intersection of 
things and words; an obscure web of things, and a manifest, visible, coloured chain of words; I would like to show that discourse is not a slender surface of contact, or confrontation, between a reality and a language (langue), the intrication of a lexicon and an experience; I would like to show with precise examples that in analyzing discourses themselves, one sees the loosening of the embrace, apparently so tight, of words and things, and the emergence of a group of rules proper to discursive practice. These rules define not the dumb existence of a reality, nor the canonical use of a vocabulary, but the ordering of objects. 'Words and things' [is] a quite different task...that consists of not - of no longer - treating discourse as groups of signs...but as practices that systematically form the objects of which they speak. (pp. 48-49)

As such, rather than reflecting, discourses constitute their objects. To put it differently, discursive practices give meanings. As Fairclough (1992) points out, Foucault advocates a "constitutive view of discourse" that understands discourse as "actively constituting or constructing society on various dimensions" (p. 39).

In Foucault, discourses not only constitute the meanings of the object they speak about, but also "position subjects - those who produce them [and] those they are addressed to" (p. 43). That is, the parameter of thinking of those who speak or write, as well as that of the audience of any talk and texts, is constrained by what is being spoken or written about. In fact, Foucault's comments in this connection impress one with strong structuralist flavor. ${ }^{8}$ When discussing what he refers to as the "enunciative function" of discourse, Foucault remarks:

...the subject of the statement should not be regarded as identical with

\footnotetext{
${ }^{8}$ The question of whether Foucault is structuralist has been widely discussed but I will not join the debates on this issue in this chapter. For some interesting views on this question, see Foucault (1970), Foucault (1972), Foucault (1996a), White (1973), Dreyfus \& Rabinow (1983), Merquior (1985), and Mills (2003).
} 
the author of the formulation-either in substance, or in function... It is [rather] a particular, vacant place that may in fact be filled by different individuals... It is a dimension that characterizes a whole formulation qua statement... To describe a formulation qua statement does not consist in analyzing the relations between the author and what he says (or wanted to say, or said without wanting to); but in determining what position can and must be occupied by any individual if he is to be the subject of it. (1972, pp. 95-96)

Foucault's constitutive view of the object and the subject of discourse seems to be connected with his rejection of the concept of ideology. Unlike those who see discourse as merely the expression of ideology (van Dijk, 1998), Foucault notes in an interview that his conception of discourse is meant to avoid certain presumptions that often accompany the use of the term ideology (1980, p. 118). Foucault criticizes the notion of ideology, first, in terms of its epistemological assumptions. According to him, the Marxist concept of ideology presupposes the existence of "truth" and the possibility of attaining it, whereas "discourses...in themselves are neither true nor false." In fact, what Foucault is concerned with is not so much the distinction between truth and falsehood as the question of "how effects of truth are produced within discourses" (ibid.). Foucault also differentiated the concept of discourse from ideology in their relation to subjectivity. He cautions that the Marxist concept of ideology "cannot be used without circumspection" as it implies "the order of a subject" (ibid.). That is, the usage of the term "ideology" — as it implies that one is capable of stepping out of false consciousness - often presupposes the possible existence of an independent and autonomous mind. Foucault states that, in contrast, 
...discourse is not the majestically unfolding manifestation of a thinking, knowing, speaking subject, but, on the contrary, a totality, in which the dispersion of the subject and his discontinuity with himself may be determined. ... it is neither by recourse to a transcendental subject nor by recourse to a psychology subjectivity that the regulation of its enunciations should be defined. (1972, p. 55; italics added)

As such, when one engages in discursive practice, rather than acting with full sovereignty, he or she is instead circumscribed by what he or she is to speak or write about; that is, he or she must comply with or respond to the rules that define the ways in which a certain topic is to be addressed. It is in this sense that Foucault talks about discourse in relation to "the dispersion of the subject," dissociating it from any idea, such as ideology, that implies the sovereign speaking individual.

In fact, "dispersion" is a key term for Foucault, especially in his analysis of "unities of discourse" which is essentially concerned with the question of how to define the boundary of a discourse. In The Archaeology, Foucault demonstrates that the question of boundary can be answered by using the concept of discursive formation. He notes that discursive formations can be seen as systems of dispersion governed by certain rules of formation. These will be discussed in turn.

First, Foucault maintains that a key characteristic of any statement, as the most basic unit of discourse, is that it always already exists in relation to other statements and, also, "draws upon others in complex ways" (Fairclough, 1992, p. 55)Fairclough notes this as Foucault's emphasis on "the primacy of interdiscursivity and intertextuality" (ibid.). Foucault believes that $a$ discourse should be seen as a 
"discursive formation" that is not composed of any single statement but of groups of them (Foucault, 1972, pp. 38, 97-98). As he states, "generally speaking, one can say that a sequence of linguistic elements is a statement only if it is immersed in an enunciative field, in which it then appears as a unique element" (p. 99). Foucault emphasizes that statements do not exist in isolation. As he points out, "there can be no statement that in one way or another does not reactualize others," "either by repeating them, modifying them, or adapting them, or by opposing them, or by commenting on them" (p. 98).

Foucault insists that, as statements exist in networks, one should consider them not in terms of whether any single utterance reflects some objective truth or not, but in terms of how sets of statements specifically relate to each other to constitute discursive formations that give meanings to what is spoken about. In defining what he means by discursive unities, Foucault rejects four traditional ways of grouping statements that are based on the object, style, concept, or theme of discourse. He comes up with new hypotheses in delineating unities of discourse, which according to him truly reflect the complexity of discourse. For example, Foucault criticizes the traditional manner of defining discursive unities based on the object being talked about, using the discourse on "madness" as an example:

The unity of discourse on madness would not be based upon the existence of the object 'madness', or the constitution of a single horizon of objectivity; it would be the interplay of the rules that make possible the appearance of objects during a given period of time. (pp. 32-33) 
The object of discourse, Foucault maintains, "does not pre-exist itself, held back by some obstacle at the first edges of light" (p. 45); rather, it "exists under the positive conditions of a complex group of relations" (p. 45), which make it possible for the object to take shape. That is, were it not for the discourses on "madness" which emerge under certain conditions, there would be no such thing as "madness"; the meanings of "madness" come into existence only as a result of how "madness" is defined in the discourses that address it. This, again, corresponds with Foucault's view about discourses constituting their own object. Therefore, one may not presume that an object has its own inherent meanings and group discourses based on such an assumption. Foucault also points out that the same "idea" can be predicated on two different series of concepts. For example, what underlay the evolutionist idea in the eighteenth century is different from that in the nineteenth century (Foucault, 2003a, pp. 410-411). Thus, to define the boundary of discourses based on the "idea" being addressed is unreliable, either. Instead, one sees dispersed discursive formations in which "objects" and "ideas" emerge and transform. Foucault then suggests the need to investigate the "rules of formation" that give rise to discursive dispersions (pp. 38-39), that is, the need to examine the various ways of thinking that underpin different discursive formations.

To be sure, Foucault's conception of discourse is not uncontroversial. He is often accused of overemphasizing the one-way influence discourses have on the producer of 
them (Macdonell, 1986; Fairclough, 1992). ${ }^{9}$ He is also criticized for making institutional influences "unintelligible" by attributing autonomy to discourse (Dreyfus \& Rabinow, 1983, p. xxiv). ${ }^{10}$ However, as will be shown later, Foucault's idea that discourses shape meanings and exist in dispersed networks is helpful for my conceptualization of discourse shifts. But before going into that discussion, I will now turn to a review of the conceptions of discourse in the field of critical discourse analysis.

\section{Conceptions of discourse in critical discourse analysis (CDA)}

It can be argued that authors employing the approach of critical discourse analysis share certain theoretical commitments; nonetheless, there does not seem to be a commonly accepted definition of the term discourse (van Dijk, 1997). What follows is a review of the conceptions of discourse in the works of van Dijk and those of Fairclough. van Dijk is chosen because, as the editor of a number of books that offer general reviews of the field of discourse analysis, ${ }^{11}$ he bases his own understanding of discourse on the considerations of a variety of pre-existing definitions of the term. On the other hand, Fairclough is chosen for discussion because he draws upon the works

\footnotetext{
${ }^{9}$ At the same time, however, some scholars express mixed views concerning Foucault's stance on the issue of subjectivity (Barrett, 1991; Mills, 1997).

${ }^{10}$ Interestingly, Foucault does occasionally speak about "autonomous discursive formation" in relation to "institutions, social relations, economic and political circumstances" (Foucault, 1996b, p. 35).

${ }^{11}$ For example, van Dijk is the editor of the 4-volume Handbook of Discourse Analysis (1985) and the 2-volume Discourse Studies: A Multidisciplinary Study (1997).
} 
of a number of influential authors who have written on discourse-for example,

Michel Pêcheux, Ernesto Laclau and Chantal Mouffe, and Foucault. ${ }^{12}$ Fairclough also

integrates these authors' approaches with "a systematic framework of analysis based

on a linguistic analysis of the text" (Mills, 1997, p. 148), which is different not only

from the "non-critical" models of discourse analysis (Fairclough, 1992, p. 141), but

also from Foucault's “abstract approach" (p. 37).

It is worth pointing out that both van Dijk and Fairclough make a point of

distinguishing linguistics models of analysis from those that attend more to the social

aspects of discourse (Fairclough, 1992; van Dijk, 1998). In this respect, they share the

Foucauldian stance that discourse is not the juxtaposition of linguistic signs, and call

for the integration of textual and social perspectives in discourse analysis. Both see

discourse not only as text but also as social practice. ${ }^{13}$

However, unlike Foucault, who seeks to dissociate discourse from ideology, van

Dijk sees the two as intrinsically connected. Defining ideology as "clusters of beliefs

in our minds" that are shared by members of social groups (1998, p. 26), he

\footnotetext{
${ }^{12}$ According to Mills, Fairclough "is one of the few theorists who openly acknowledges his debt to Foucault" (Mills, 1997, p. 150). It is also noteworthy that, although Fairclough agrees with Laclau and Mouffe on the issue of the mechanism of hegemony (Fairclough, 1992, p. 93), he rejects their over-emphasis on the discursive which neglects the influences of the extra-discursive (Fairclough et al., 2004, p. 39).

${ }^{13}$ However, it should be noted that van Dijk understands texts mainly as speech or written texts (van Dijk, 1998), whereas Fairclough has a broader view of text: "texts do not need to be linguistic at all; any cultural artefact - a picture, a building, a piece of music — can be seen as a text" (Fairclough, 1995, p. 4). Nonetheless, Fairclough sometimes also uses text in a more restricted sense. For example, in Discourse and Social Change (1992), Fairclough refers to text "in Halliday's... sense of spoken as well as written language" (p. 71).
} 
understands discourse as the manifestation of those communal beliefs. ${ }^{14} \mathrm{He}$ points out that discourse is particularly important in the expression and reproduction of ideology: ... although discourses are not the only ideologically based social practices, they certainly are the most crucial ones in the formulation of ideologies in their social reproduction. Language use, text, talk and communication (together subsumed here under the overall term of 'discourse') are needed and used by group members to learn, acquire, change, confirm, articulate, as well as to persuasively convey ideologies to other ingroup members.... In sum, if we want to know what ideologies actually look like, how they work, and how they are created, changes and reproduced, we need to look closely at their discursive manifestations. (p. 6$)^{15}$

Fairclough's approach to discourse also combines linguistic and social perspectives. In his seminal work on discourse and social change (1992), Fairclough develops a conceptual model of discourse as simultaneously text, discursive practice, and social practice. Particularly, as social practice, discourse is part of hegemony (pp. 62-100). By this model, Fairclough intends to "integrate a variety of theoretical perspectives and methods" (p. 99). He explains,

I have tried to combine aspects of a Foucauldian view of discourse and a Bakhtinian emphasis on intertextuality: the former includes the vital emphasis upon the socially constructive properties of discourse, the latter emphasizes the 'texture'... of texts and their composition from snatches of other texts, and both point to the way in which orders of discourse structure and are restructured by discourse practice. (pp. 99-100)

\footnotetext{
${ }^{14}$ van Dijk rejects the "polarization between ideology and knowledge" which he believes is "still present in contemporary CDA" (van Dijk et al., 2004, p. xiii), and claims that "once we abandon the negative notion of ideology, the concept becomes theoretically much more useful to describe 'systems of ideas' of any social group or class" (p. xvi). It is also noteworthy that many authors use the term ideology and that of discourse interchangeably (Mills, 1997, p. 46; van Dijk, 2004, p. 5).

${ }^{15}$ Also see van Dijk (1998, p. 191).
} 
Specifically, by the "constructive properties of discourse," Fairclough refers to the functions of discourse in the construction of "subject positions," social relations, and systems of knowledge (pp. 64-65). At the same time, however, Fairclough argues that "constituted social subjects are not merely passively positioned but are capable of acting as agents, and amongst other things of negotiating their relationship with the multifarious types of discourse they are drawn into" (p. 61).

However, while both van Dijk and Fairclough conceptualize discourse as social practice, they consider the issue of the boundary of discourse from different perspectives.van Dijk treats "discourse" as a countable noun (1998, pp. 194-195), which makes it possible for him to speak about $a$ discourse. As van Dijk defines discourse as verbal communication, it is not surprising that he understands the boundary of discourses in terms of spatial or temporal continuity (1998, p. 195). According to him, a dialogue can be treated as a discourse "when it is continuous in time" (ibid.). Likewise, a piece of news report in print is also a discourse because, as something published on paper, it has fixed spatial boundaries. At the same time, van Dijk points out that, for groups of linguistic signs to form $a$ discourse, "we usually further require that they are globally coherent, that is, that they form a meaning unit, and not only a physical unit of continuous expression" (ibid.). However, he also notes exceptions, for example, of "poems... [which] do not seem to have an obviously unitary, global meaning" (ibid.).

Fairclough, in comparison, does not seem to have clearly spelled out what he 
considers to be the boundary of $a$ discourse, although in one occasion, in the form of a footnote, he also refers to discourse as a countable noun (Fairclough et al., 2004, p. 40). Nonetheless, Fairclough stresses intertextuality which he deems as "the source of much of the ambivalence of texts" $(1992$, p. 105). As the distinct property of texts, intertextuality blurs boundaries between discourses. In a following section on discursive dynamics, I will review in detail Fairclough's conception of intertextuality. What is provided here is a preliminary discussion of his definition of the term.

Fairclough develops his idea of intertextuality on the basis of the common ground he discerns in Mikhail Bakhtin (pp. 100-105), Foucault (pp. 39-40), and Pêcheux (pp. 31-35, 68). He identifies in Bakhtin's works the theme of the "translinguistic," which refers to how texts respond to and thus are shaped by both prior and anticipated subsequent texts (p. 101). He also finds in Foucault the emphasis on the "interdependency" between discourses in which statements always "reactualize others" (Foucault, quoted in Fairclough, 1992, p. 101). Finally, in reading Pêcheux, Fairclough highlights the author's analysis of the phenomenon of "interdiscourse" (p. 40), the way in which "any type of discourse practice is generated out of combinations of others, and is defined by its relationship to others" (ibid.). In his own formulation, Fairclough uses the term intertextuality to refer to "the property texts have of being full of snatches of other texts... which the text may assimilate, contradict, ironically echo, and so forth" (p. 84). Moreover, Fairclough makes the distinction between manifest intertextuality, which is characterized by direct text-borrowing, and 
interdiscursivity or constitutive intertextuality, which is characterized by hybridities of genres, discourses, and styles (p. 85; Chouliaraki \& Fairclough, 1999).

\section{Intermediate reflections: Reconsidering the concept of discourse}

Having reviewed various conceptions of discourse, I will now discuss my own understanding of the term by addressing the same two questions of (1) what is discourse and (2) how I approach the issue of the boundary of discourses. Regarding the first question, I will argue that, in its abstract sense and as an uncountable noun, "discourse" refers to an element/moment of the social. In the meantime, as a countable noun, "discourse" refers to products of semiotic practices. For the second question, I argue that discourses exist in fluid networks without stable boundaries. The fluidity and complexity of discourse, I believe, points to the importance of the question of discursive dynamics.

It has been mentioned in the introduction that I agree with Fairclough and others that discourse should be understood as an element/moment of the social. However, instead of seeing the social as the combination of six moments, as is suggested by Harvey who is drawn upon by Chouliaraki and Fairclough (1999), I understand the social as composed of three elements/moments: the material, the discursive (the semiotic), and the mental (including the epistemic). The three combine to form the social in two ways: first, in the social world, one may identify three interrelated composing elements or three sub-realms, the material world, the mental world that 
exists in our mind, and the world of language or semiosis; ${ }^{16}$ correspondingly, one may see the social as composed of three primary yet interpenetrating types of practices: material, mental, and discursive ones. Second, any single instance of human social practice is not simply merely material, mental, or discursive; it at once involves all three moments.

More specifically, the relations between the discursive and the other two aspects of the social can be understood on three levels. First, whenever discursive practices take place, they involve the mobilization of certain material resources as well as certain epistemologies or modes of thinking (the mental). Second, all three elements of the social can be reconstructed in the discursive with infinite possibilities. Not only can the material and the mental be represented in multiple ways in discourse, but any instances of discourse themselves may be reconstituted in subsequent ones, with various extents of misinterpretation or ways of strategic appropriation.

Third - this is related to the above two points-the discursive both influences and is influenced by the material and the mental. On the one hand, discursive practice is constrained by the appropriated material and mental resources. On the other hand, the discursive has impact on the other two; it is noteworthy that the impact of the discursive is exerted through the nexus of the mental. ${ }^{17}$ This happens in the following

\footnotetext{
${ }^{16}$ I adopt the definition by Fairclough and others of semiosis as "the inter-subjective making of meaning" which involves the use of either verbal or non-verbal signs to communicate (Fairclough et al., 2004, p. 40).

${ }^{17}$ It is arguable that the working of the mental almost always involves the discursive, or the use of signs. This is at least true for those who have developed skills to use socially recognizable signs.
} 
ways: acts of language use, guided by certain epistemologies or ways of thinking, produce explanations and interpretations about the material and the mental; also, by inducing change in the mental-a simple example can be that reading may change the way one understands things - discursive practice can indirectly transform the material world if the latter is acted upon with the changed mental. To be sure, the discursive also has influence on itself as earlier discourses may have impacts on later ones, which yet also occurs with the mediation of the mental.

To further clarify on the third point discussed above, it is worth pointing out that, while sharing Foucault's view that discursive practice shapes meanings, the conception of discourse I employ is meant to avoid the one-way determinism of the discursive, which is often associated with Foucault's The Archaeology. If one sees the discursive as always determining the other elements of the social, it becomes difficult to address issues of change without falling prey to some mysterious idealism that grants agency to language or discourse. However, I do not mean that the influence of discursive practice necessarily elapses quickly. In this connection, I share the understanding of "practice" held by Chouliaraki and Fairclough (1999):

A practice can be understood both as a social action, what is done in a particular time and place, and as what has hardened into a relative permanency - a practice in the sense of a habitual way of acting. This ambiguity is helpful in that it points to the intermediate positioning of practices between...structure and agency - practice have partly the character of both. We take a dialectical view of practice, rejecting both a determinism which puts all the emphasis on stabilised structures... and a voluntarism which puts all emphasis on concrete activity. We see social action 
as depending upon and constrained by relative permanencies which it ongoingly reproduces however. (pp. 21-22)

As such, discursive practice, as it is guided by epistemology, has relative endurance yet is open to change.

While I understand "discourse" in its abstract sense as a dimension of the social, it can also be seen as a countable noun referring to the product of specific semiotic practices. However, whenever one speaks of discourse as a countable noun, the question of discourse boundaries emerges. One may ask: what is $a$ discourse? Moreover, what is the difference between text and discourse, if both can be seen as the product of semiotic activities? I use the word text to refer to a body of signs which are characterized by relatively stable physical continuities or boundaries, either temporally or spatially. In this respect, my definition of "text" shares van Dijk's idea about the boundary of discourses. However, in my conception, discourses do not have obvious physical continuities. I argue that discourses are networks of ideas the boundary of which is fluid and re-definable rather than fixed and permanent. Through an analysis of such networks, I believe, one may attempt an understanding of the ways in which social definitions are offered and contested, agendas promoted and challenged, and power relations reproduced and transformed. In the following section, I will discuss how three existing theoretical frameworks which address the interconnections and transformations of discourses may be drawn upon to develop an analytic model to study the relations between semiosis, epistemology, and social hegemony in changing 
networks of discourses.

\section{Approaches to theorizing the dynamics of discourse}

What are reviewed in this section are three theoretical frameworks that address the dynamics of discourse, which are respectively about discourse discontinuity (Foucault, 1970; Foucault, 1972), discourse competition (Williams, 1977), and intertextuality (Fairclough, 1997; Chouliaraki \& Fairclough, 1999). I will evaluate the ways in which they can contribute to an alternative model of "discourse shifts" which I will elaborate on in the next section. It is noteworthy that, although Raymond Williams may not be recognized by all as a major author in critical discourse studies, he is concerned with interconnections between dominant, residual, and emerging cultures, and has also been drawn on by others interested in examining interrelations between groups of contemporaneous discourses (Hall, 1979; Karim, 1993; Karim, 2003). Therefore, I will include Williams in the following review. ${ }^{18}$ As will be shown, further theorization of discursive dynamics can benefit from all of these frameworks.

\section{Discourse discontinuity}

In The Order of Things (1970), Foucault discusses what he sees as "the play of discontinuities in the history of the discourses" (Foucault, 1996b, p. 40; original italics). In fact, Foucault's emphasis on discontinuities represents his revolt against the

\footnotetext{
${ }^{18}$ While van Dijk's works are discussed in my review of existing conceptions of discourse, he is not included in this section. This is because the question of interconnections between discourses over time does not seem to be a major concern of van Dijk.
} 
theme of the sovereign subject and that of the silent origin in traditional histories of thought. Instead of pointing to linear successions or progresses, Foucault highlights two significant ruptures in the history of discourses in the West, or, in his own words, "two great discontinuities in the episteme of Western culture: the first inaugurates the Classical age (roughly half-way through the seventeenth century) and the second, at the beginning of the nineteenth century, marks the beginning of the modern age" (Foucault, 1970, p. xxii).

According to Foucault, discourse discontinuity unfolds in the form of sudden and "enigmatic" (p. 217) change in epistemes, which are to be understood as unconscious positivities of knowledge —or unnoticed a priori ways of thinking that underpin knowledge - that are in and of themselves monolithic. Foucault first argues that discourse ruptures in fact take place at this unconscious epistemological level (p. xi). Then, refuting those who criticize him for not noting change, Foucault stresses that his notion of discontinuity is exactly concerned with the way in which "certain sciences were sometimes reorganized," and especially "the fact that at the same time similar changes occurred in apparently very different disciplines" (p. xii). Moreover, for Foucault, these changes are characterized by "suddenness and thoroughness" (ibid.). Foucault's idea in this connection is evident in his description of one of the ruptures that he discusses in The Order of Things: "It is this configuration [of the Classical age] that, from the nineteenth century onward, changes entirely; the theory of representation disappears as the universal foundation of all possible orders" (p. xxiii; 
italics added). When explaining the overall objective of the book, Foucault also notes that his is "an inquiry whose aim is to rediscover on what basis knowledge and theory became possible; ... within what space of order knowledge was constituted; ... and in the element of what positivity, ideas could appear, ...rationalities be formed, only, perhaps, to dissolve and vanish soon afterwards" (p. xxii; italics added). Furthermore, for Foucault, epistemes are monolithic in the sense that "in any given culture and at any given moment, there is always only one episteme that defines the conditions of possibility of all knowledge, whether expressed in a theory or silently invested in a practice" (p. 168).

Indeed, Foucault's conception of discontinuity in history is what makes his work different from earlier ones in the field of history of ideas. However, it is also the theoretical moment where a major ambiguity arises-Foucault himself admitted that "I didn't make myself sufficiently clear" (Foucault, quoted in Barrett, 1991, p. 128). In view of the possible misunderstanding in reading Foucault, Barrett (1991) explained that, despite his stresses on discontinuities of discourse, Foucault was not championing an understanding of history as total contingency; rather, he was attempting to "redraw different unities and regularities" (p. 128; italics added) across history.

However, this apologia has not yet fully addressed other problems related to the notion of discontinuity. Among various criticisms of Foucault, José Merquior charges that Foucault neglects both inter-epistemic and intra-epistemic realities. With respect 
to the inter-epistemic, Foucault is criticized for overlooking real continuities such as that "between the labors of Copernicus... and the Kepler-Galileo line," "epistemic lags," and "the return of concepts" in discourses (Merquior, 1985, pp. 58-67).

Regarding the intra-epistemic, Merquior points out that, "taken synchronically, ...epistemes - contrary to their allegedly massive unity--seem to encompass a lot of heterogeneity" (p. 67; original italics); taken diachronically, "there may be collapses within an episteme... and intraepistemic breaks" (p. 69; original italics).

In fact, Foucault later notes some of the weaknesses in his earlier works that lead to various criticisms; on the other hand, he seeks to provide further theoretical and methodological supports for his notion of discourse discontinuity-but now focusing more specifically on the idea of discursive dispersions. First, Foucault clarifies that the notion of episteme is in fact not intended for an analysis of the cultural totalities of various historical periods (1972, p. 16). Instead, Foucault argues, [The] epistemic of a period... [is] not the sum of its knowledge, nor the general style of its research, but the deviation, the distances, the oppositions, the differences, the relations of its multiple scientific discourses: the epistemic is not a sort of grand unifying theory, it is a space of dispersion, it is an open field of relationships and no doubt indefinitely describable. (1996b, p. 35; original italics)

Moreover, Foucault notes how the episteme governs networks of heterogeneous discourses as well as their intertwinement and transformation:

What one must characterize and individualize is the coexistence of these dispersed and heterogeneous statements; the system that 
governs their division, the degree to which they depend upon one another, the way in which they interlock or exclude one another, the transformation that they undergo, and the play of their location, arrangement, and replacement. (1972, p. 34)

In particular, Foucault points out that one should try to identify regularities which, nevertheless, are regularities of dispersion, or "systems of dispersion" (pp. 37-38). For Foucault, in these regularities, one can find rules of discursive formation, which are "conditions of existence (but also of coexistence, maintenance, modification, and disappearance) in a given discursive division" (p. 38; italics added).

To summarize, in emphasizing discontinuity, Foucault seeks to stress that the history of discourses is not something which unfolds in a fashion of linear progression. However, Foucault's idea of discontinuity cannot be taken to mean that this history is composed of unrelated and isolated groups of discourses succeeding one another. On the contrary, Foucault points to "dispersion" and "heterogeneity" as the form of existence of discourses which are yet governed by certain rules of formation or episteme. Although Foucault is sometimes seen as idiosyncratic (White, 1979, p. 81), his ideas about discursive formation and the episteme provide a fine foundation for any further theorization of discursive dynamics that is to attend to the complex relations between discourse, meanings, and epistemology.

\section{Discourse competition}

In comparison to Foucault, Raymond Williams more explicitly devotes his attention to the study of hegemony. Emphasizing hegemony as a dynamic social 
process, he notes the tension between dominant, alternative, and oppositional sets of meanings and practices, and at the same time highlights the complex relations between dominant, residual, and emergent cultures. To be sure, Williams does not seem to have used the concept of "discourse" per se; but his ideas about meanings and practices existing in tension have been mobilized by others who seek to demonstrate the mechanism of discourse competition (Hall, 1979; Karim, 1993; Karim, 2003). ${ }^{19}$ Stuart Hall draws on Williams to stress "the plurality of dominant discourses" $(1979$, p. 343), and Karim Karim adopts from Williams the distinction between the dominant, the oppositional, and the alternative in his analysis of discourse competition (Karim, 1993; Karim, 2003) ${ }^{20}$ In this part of the chapter, I focus on the review of Williams' ideas and discuss how they can contribute to further theorization of discursive dynamics. ${ }^{21}$

As has been mentioned, Williams views hegemony as a social process.

Questioning the notion of static hegemony and advocating instead the use of the term "hegemonic" (1977, p. 113) —which for him is a better word that denotes "processes"-Williams introduces the concepts of counter-hegemony and alternative hegemony, and accordingly identifies the coexistence of dominant and effective,

\footnotetext{
${ }^{19}$ It is important to note that by "discourse competition" I do not mean that discourses themselves have agency; rather, I use the term to describe the tension between as well as within various sets of discourses.

${ }^{20}$ However, Karim conceptualizes the three categories differently (1993, pp. 198-202; 2003, pp. 5$6)$.

${ }^{21}$ It is also noteworthy that Williams' Marxist approach stands in sharp contrast to that of Foucault. However, as will be discussed, Williams' conception of hegemony is helpful for this study as it points to the need to note the inner complexity of hegemonic epistemologies.
} 
alternative, and directly oppositional cultures (pp. 108-120). ${ }^{22}$ Williams argues that "in any particular period there is a central system of practices, meanings and values which we can properly call dominant and effective... which are organized and lived" (quoted in Hall, 1979, p. 331). Moreover, he points out that the alternative and the oppositional pose challenge to the dominant: "any hegemonic process must be especially alert and responsive to the alternatives and opposition which question or threaten its dominance" (p. 113); ${ }^{23}$ furthermore, he stresses that these challenges account for not only the tension between the three types of cultures but also the diversity within the dominant:

The reality of cultural process must then always include the efforts and contributions of those who are in one way or another outside or at the edge of the terms of the specific hegemony.... alternative and oppositional initiatives and contributions... are made within or against a specific hegemony (which then sets certain limits to them or which can succeed in neutralizing, changing or actually incorporating them)... (pp. 113-114; italics added)

As can be seen, Williams emphasizes the process of incorporation of the alternatives and opposition by the dominant. He relates this incorporation to the complexity both within and outside the dominant, remarking that, as opposed to "epochal analysis" which tends to emphasize differences while neglecting processes, "authentic historical analysis" should "recognize the complex interrelations between

\footnotetext{
${ }^{22}$ Williams understands culture as "a whole way of life" that expresses meanings and values in social practices (Williams, 1977, pp. 11-20).

${ }^{23}$ But Williams notes that, in comparison to oppositional meanings, alternative meanings pose less significant threats to the dominant because, to some extent, they can be "tolerated within a particular effective and dominant culture" (2001, p. 158).
} 
movements and tendencies both within and beyond a specific and effective dominance" (p. 121).

Williams' distinction between alternative-hegemony and counter-hegemony is similar to while at the same time different from what is distinguished by Michel Pêcheux in his Language, Semantics and Ideology (1982) between "disidentification" and "counter-identification." Their similarities consist in the emphasis on the possibility of resistance and semi-resistance to dominant meanings and values. In Pêcheux, the term "counter-identification" refers to the act of "distancing oneself from existing practices without replacing them with new ones, while the term "disidentification" refers to the situation where a replacement occurs that is characterized by 'the 'overthrow-rearrangement' of the complex of ideological formations (and of the discursive formations which are imbricated with them)" (Pêcheux, quoted in Fairclough, 1992, p. 32). As can be seen, dissimilar to the distinction made in Williams' work between oppositional and alternative practices, "counter-identification" and "disidentification" are distinguished from each other in terms of whether replacement practices are promoted and, thus, in terms of how "revolutionary" the resistance is. As Fairclough observes, Pêcheux "sees the possibility of disidentification as specifically tied to the revolutionary theory and practice of Marxism-Leninism, in the organization form of the Communist Party" (ibid.). In comparison, in Williams' conception, both oppositional and alternative practices offer replacements, although what they offer respectively are predicated on 
different presuppositions - -according to Williams, in comparison to the oppositional, the alternative shares certain common ground with the dominant $(1977$, p. $113 ; 2001$, p. 158).

I argue that further theorization of discursive dynamics can also benefit from Williams' conceptualization of the hegemonic. Emphasizing the diversity of and the tension within the dominant, Williams' ideas raise the following question for theories on discourse and epistemology: if there exists tension within the hegemonic, what does this mean for a dominating epistemology in discourses? If it follows that the hegemonic epistemology may very well contain inner contradictions, then, Williams' insights point to the need to look into the modes in which such contradictions exert influence on the discursive, as well as the manners in which they may be reproduced and transformed along with changing power relations in a society. In fact, by the use of the concept of intertextuality, Norman Fairclough has proposed a way to examine the relation between discourse, epistemic frameworks, and social hegemony.

\section{Intertextuality}

Norman Fairclough's works are also concerned with theories of hegemony. However, unlike Williams, Fairclough is dedicated to incorporating textual analysis into the study of hegemony. As Fairclough remarks, "[the] resulting framework does...allow one to combine social relevance and textual specificity in doing discourse analysis, and to come to grips with change" (1992, p. 100). As will be shown below, 
Fairclough finds the concept of intertextuality particularly useful in bringing together textual analysis and theories of hegemony in the study of social change. In fact, his earlier conceptualization of intertextuality is more textual-oriented while later he understands it more in terms of its relation to power, especially in terms of how it is connected to epistemic frameworks.

As has been discussed earlier, Fairclough sees discourse as part of hegemony. In particular, his conception is influenced by Ernesto Laclau and Chantal Mouffe who offer in Hegemony and Socialist Strategy (1985) an explication of how discourse is connected with hegemonic processes (Fairclough, 1992, p. 93; Howarth et al., 2000, p. 15). In hegemony, Laclau and Mouffe see "the ultimate impossibility of societal closure," manifested by "a social field criss-crossed by antagonisms" and "the presence of elements that can be articulated by opposed political projects" (Howarth $e t$ al., 2000, p. 15). Fairclough argues that this view of hegemony is useful in considering how discourse is connected with change:

Such a conception of hegemonic struggle in terms of the articulation, disarticulation, and rearticulation of elements is in harmony with what I said earlier about discourse: ... seeing discursive structures as orders of discourse conceived as more or less unstable configurations of elements... An order of discourse can be seen as the discursive facet of the contradictory and unstable equilibrium which constitute hegemony... Further, discursive practice...is a facet of hegemonic struggle... (1992, p. 93)

Fairclough points out that, in particular, the concept of intertextuality can be used in the study of discourse in relation to social change. He draws on Bakhtin and Julia 
Kristeva to emphasize that all discourses contain "snatches of" other discourses, that a text "absorbs and is built out of texts from the past," and, thus, that "the text responds to, reaccentuates, and reworks past texts, and in so doing helps to make history and contributes to wider processes of change" (p. 102). Fairclough refers to this as "the inherent historicity of texts" (ibid.). As he points out,

This inherent historicity of texts enables them to take on the major roles they have in contemporary society at the leading edge of social and cultural change. The rapid transformation and restructuring of textual traditions and orders of discourse is a striking contemporary phenomenon, which suggests that intertextuality ought to be a major focus in discourse analysis. (ibid.)

If, in Discourse and Social Change (1992), Fairclough sees "intertextuality" more as an idea to describe "textual" aspects of discourse, which needs to be combined with a focus on hegemony, in a later work of his_-Analysing Discourse (2003)Fairclough applies it more as a concept that directly raises questions about inclusion and exclusion in hegemonic processes. In doing this, he first relates intertextuality to the concept of assumptions, which for him "include types of implicitness" that are "generally distinguished...as presuppositions" (p. 40). Fairclough comments on the connection between assumptions and intertextuality:

Texts inevitably make assumptions. What is 'said' in a text is 'said' against a background of what is 'unsaid', but taken as given. As with intertextuality, assumptions connect one text to other texts, to the 'world of texts' as one might put it. (ibid.)

As such, intertexuality is not simply about quoting or reinterpreting earlier texts, but about the sharing of assumptions across discourses. "In a sense," Fairclough remarks, 
"making assumptions is one way of being intertextual" (p. 17). ${ }^{24}$ Then, Fairclough points out that being intertextual is in fact being "inevitably selective" (p. 55). Thus, intertextuality involves inclusions and exclusions of other texts or voices along with their assumptions (p. 192). This points to how intertextuality in discourses relates to the issue of hegemony or power relations. As Fairclough argues, implicit assumptions in fact constitute a "common ground" of meanings shared by "all forms of fellowship, community and solidarity," and that "the capacity to exercise social power, domination and hegemony includes the capacity to shape to some significant degree the nature and content of this "common ground"' (p. 55). Fairclough distinguishes three types of assumptions, which are respectively existential assumptions that define what exists, propositional assumptions that delineate "what is or can be or will be the case," and value assumptions that draw the boundary of "what is good or desirable" (pp. 55-58).

As such, the notion of assumptions in Fairclough's theory of intertextuality indicates how intertextuality is connected to the establishing of epistemic frameworks. This is so because intertextual assumptions can be seen as constituting both descriptive and prescriptive solutions to social reality: on the one hand, these assumptions frame the understanding of social situations; on the other hand, they prescribe the range within which one can conjure up images of the desirable.

\footnotetext{
${ }^{24}$ Fairclough sometimes speaks of assumptions as part of intertextuality (p. 17), while other times he seems to see assumptions as somewhat different from intertextuality (pp. 40-41). Given the fact that Fairclough puts his discussion of assumptions in the chapter entitled "intertextuality," I treat his view of assumptions as part of his conception of intertextuality.
} 
Thus, Fairclough's approach, influenced by Foucault and others, points to an avenue of studying discourse and hegemony through the analysis of intertextual assumptions or epistemic frameworks. As will be shown below, when combining Fairclough's ideas with Foucault's vision of discursive formation and Williams' insight about the diversity within the dominant, one can attempt a theoretical model that studies the interconnected transformations of discourse, epistemology, and power relations over time.

\section{Discourse shifts: Reconsidering the dynamics of discourse over time}

Based on the preceding reviews, in this part of the chapter, I propose a model of "discourse shifts," which builds on the insights of Foucault, Williams, and Fairclough to study semiotic histories. Specifically, the model considers how epistemologies with inner heterogeneities exert varied impacts on networks of discourses over time and how this connects to changing power relations.

A keyword in my conception of discourse shifts is that of "orders of discourse" (hereafter referred to as $O D$ s) which I adopt from Fairclough. Fairclough in fact borrows this term from Foucault and defines it as "the linguistic elements of networks of social practices" (Fairclough, 2003, p. 24) and "the totality of discursive practices within an institution or society, and the relationships between them" (Fairclough, 1992, p. 43). However, while Fairclough mentions "discourses, genres, and styles" (1992, pp. $124-127 ; 2003$, p. 24) as all related to "orders of discourse," I mainly use the term to 
discuss relations between discourses. ${ }^{25}$ I conceive of an $O D$ as a field of discourses emerging in a certain period of time which address a common subject, be it a thing, a phenomenon, any (groups of) people, an idea, or others. The meanings of the subject, as indicated by Foucault's conception of discursive formation, do not pre-exist its own field of discourses; rather, the meanings emerge from and are sustained by this very field. Moreover, an $O D$ is an idea-network characterized by conceptional intertextuality; or, to coin a term, it is a network of "interconceptionality," in which the meanings of the subject concerned are determined by how the subject is spoken of in relation to the various concepts entangled within. Interconceptional meanings, in turn, are determined by the assumptions or epistemologies, either said or unsaid, and the social agendas that link one concept to another.

In what way, then, can the term "orders of discourse" be used to discuss discourse shifts? I conceptualize discourse shifts as transformations of $O D$ s over time. Such transformations can take several forms: a new concept is brought into the existing $O D$ and discussed in relation to the core subject; no new concept is added but the interconceptional relations between any old concept and the core subject are modified in the discourses; or, an old concept is no longer discussed in relation to the core subject and thus disappears from an $O D$.

\footnotetext{
${ }^{25}$ In fact, it is not clear enough in Fairclough what are the composing elements of an order of discourse. In Language and Power (Fairclough, 2001), he seems to refer to "genre" as the only element (pp. 23-26); in Discourse in Late Modernity (Chouliaraki \& Fairclough, 1999), the authors add "discourses" to the list (pp. 58, 63, 114); but in Discourse and Social Change (Fairclough, 1992) and Analysing Discourse (Fairclough, 2003), Fairclough includes "discourses, genres, and styles" as the elements (1992, pp. 124-127; 2003, p. 24).
} 
It is noteworthy that the sustaining of meanings does not necessarily happen through the retention of the same idea in successive orders of discourses. Sometimes, $O D$ s - either in the same one or in different ones - may contain certain seemingly unrelated ideas, but the interconceptional relations between these ideas and the central subject may be predicated on common assumptions or serve common social purposes. As such, meanings are sustained through different $O D$ s, not because the same idea is repeatedly emphasized, but as a result of the ongoing existence of certain assumptions and social agendas that underlie seemingly different ideas. On the other hand, the appearing of the same term in successive $O D$ s does not necessarily indicate the retaining of a certain meaning; rather, the interconceptional relations between that term and the central subject may vary over time.

While what appears to be a new idea in an order of discourse may be just a comeback of old assumptions and social purposes now being re-packaged, an old notion rejected long ago may reappear yet is reinterpreted. Thus, in discourse shifts, while we may observe the turnarounds of various ideas, that does not necessarily indicate permanent and decisive change; also, the intertwinement between the old and new requires that we pay attention to the issue of intertextuality, that is, the question of whether and how the historical connotations of any old notion which now re-emerges are retained, reinterpreted, or rejected.

Moreover, because an order of discourse is an idea-network and is composed of various interconceptional relations, it may contain contradictory meanings - the 
assumptions and social purposes underlying different interconceptional relations may be in conflict with each other. With discourse shifts, contradictions within an older $O D$ may be carried on into a new one, or be modified, or disappear. However, while the existence of contradictions manifests the co-existence of opposing or potentially opposing assumptions, it also points to the potential of transformations of the ways of thinking that underpin discourses.

Highlighting the contradictions within and the transformations of networks of discourse, the model of discourse shifts helps us consider how discourses relate to shifting hegemony. Fairclough remarks that "hegemonies within particular organizations and institutions and at a societal level are produced, reproduced, contested and transformed in discourse" (1992, pp. 9-10). In other words, "discourse contributes both to the reproduction and to the transformation of societies" (p. 35; italics added), and this is described by Fairclough as the duality of discourse (ibid.). However, reproduction and transformation of hegemony are often referred to as if they were necessarily two separate processes. This stands out clearly, for example, in Fairclough's critique of the Althusserian negligence of transformation processes:

"There is a...tendency in Althusserian theory to overemphasize reproduction-how subjects are positioned within formations and how ideological domination is secured - at the expense of transformation-how subjects may contest and progressively restructure domination and formations" (Fairclough, 1992, pp. 33-34). The concept of discourse shifts indicates, however, that reproduction and 
transformation of hegemony can be one and the same process; that is, the reproduction of orders of discourses can at the same time be their own transformation, because certain interconceptional relations within an older order of discourse may be retained in a new one, while other relations are modified; and because old assumptions and agendas may return with a new appearance. As such, "reproduction" does not necessarily mean the act to replicate the pre-existing condition of hegemony; rather, it can be a "transformative reproduction."

In some way, the concept of discourse shifts may remind one of Kuhn's idea of paradigm shifts. Indeed, both concepts are about "shifts." Kuhn's idea deals with interrelations between old and new paradigms over time, which are characterized by shifts in explanatory models. The concept of discourse shifts, on the other hand, is used to describe transformations in orders of discourses; in such shifts, emerging orders of discourse may manifest the recognition of new sets of standards of human relations which complement and at the same time contest old models of relations.

However, the concept of discourse shifts is different from that of paradigm shifts in at least two ways. First, Kuhn stresses the "incommensurability" between old and new paradigms (1996, pp. 92-94, 103, 148-151); in the concept of discourse shifts, however, new and old orders of discourse are seen not in relation of replacement but in relation of complex reproduction and transformation in which they embody multiple ways of envisioning human relations. Second, Kuhn at some points seems to imply 
that new paradigms are more "objective" than the old one (p. 206), ${ }^{26}$ whereas in the concept of discourse shifts the notion of objectivity is irrelevant.

Some may also wonder: how does the concept of "discourse shifts" connect or not connect with "the dialectic," the Hegelian-inspired idea in Marxism that has been used to summarize the laws that govern the motion of all things including history? ${ }^{27}$ Sean

Sayers remarks that a passage by Mao Zedong captures a principal idea of the dialectic:

Marxist philosophy holds that the law of the unity of opposites is the fundamental law of the universe. This law operates universally, whether in the natural world, in human society, or in man's thinking. Between the opposites in a contradiction there is at once unity and struggle, and it is this that impels things to move and change. (Mao, quoted in Sayers, 1980, p. 1)

As such, the dialectic is referred to as a general law that governs historical

development. In fact, Friedrich Engels also refers to the dialectic as a law (Engels, 1940, pp. 26, 314). When the word "law" is used, it seems to imply that "the dialectic" is about some eternal truth. For the concept of discourse shifts, however, I would not suggest that it unveils any transcendental objective truth. Rather, "discourse shifts" is intended as a model that points to a way of looking at discourse change and thus as a channel to understand epistemological shifts.

To be sure, while sometimes "the dialectic" is taken to be a law, it has in fact also

\footnotetext{
${ }^{26}$ However, Kuhn says at the same time that new paradigms are not necessarily closer to truth even though they replace old ones (p. 170).

${ }^{27}$ This is a large question but it helps to clarify further the perspectives underlying the conception of discourse shifts. However, given the limited space of the chapter, I will only give some brief comments here.
} 
been understood in other ways. I can see certain parallels between my conception of discourse shifts and dialectics as interpreted by Bertell Ollman. In a book where Karl Marx's method of study is explained, Ollman defines dialectics as "a way of thinking that brings into focus the full range of changes and interactions that occur in the world" (2003, p. 12). As such, dialectics is primarily a perspective, an approach of looking at things. Specifically, it is concerned with issues of change. It conceptualizes things in terms of relations rather than as monolithic wholes. Within the relations that constitute things, the dialectic method highlights the existence of opposing tendencies, and suggests that it is the interaction of such tendencies that leads to change in things. The idea of discourse shifts has certain similarities with dialectics interpreted in this way. As a concept that addresses discourse change, it emphasizes the importance of looking at how interconceptional relations shape meanings. In particular, it looks at the ways in which changing relations lead to changing meanings, and how contradictory or conflicting meanings may coexist in an order of discourse and then transform. Nonetheless, I would not suggest that the conflicting meanings within an order of discourse would automatically lead to social change, because such a conclusion would imply that discourses themselves have agency, an argument I would object to. I would argue, instead, that social effects of discourses are brought about through the mediation of human agency, the exercise of which is in turn constrained insofar as the discursive influences the material world and the mental in the ways I 
have discussed earlier. ${ }^{28}$

The model of discourse shifts helps us examine the construction of traditions in China's modernity. Highlighting the influence of epistemology on the construction of meanings, it can be used to analyze how modern epistemology affects the constitution of traditions in discourse. The model emphasizes the importance of examining networks of heterogeneous discourses which diverge from one another in their assumptions or in the purposes they serve. As such, it facilitates the analysis of the diverse manners in which modern epistemology figures in contemporaneous accounts of traditions. Moreover, the idea of discourse shifts is meant to illustrate how transformations of discourses relate to competing epistemologies and evolving power relations. Thus, it points to a way to explore how shifting narrations of traditions, in the transforming Chinese discourses on the rule of law for example, are connected to the fissures within modern Western knowledge-particularly those between Marxism and liberalism - and to the changing face of Chinese Communism. Applying this proposed model, I will show the ways in which traditions are constituted discursively in socialist China as they are varyingly extolled or excoriated, owned or disowned, and the ways in which limits are set and shaken, definitions are given and disputed, and futures are prescribed and re-conjured in modern Chinese articulations of "the rule of law," yet invariably within the constraints of the modern condition.

\footnotetext{
${ }^{28}$ It is arguable that a careful user of the dialectic approach would also agree that the interaction of opposing tendencies within a society involves the exercise of human agency.
} 


\section{Chapter 4 The new socialists: Revolution and "the rule of law"}

How was "the rule of law" approached in Communist China before the reform and opening-up policies were officially announced in 1978? Some believe that by the late 1970s, in "Chinese political and academic commentary," the term "the rule of law" had been "routinely dismissed... as 'bourgeois' propaganda, designed to discredit Chinese socialism and the Chinese justice system" (Keith, 1994, p. 1). This observation indeed points to a dominant view on the rule of law in China before the late 1970s. Nevertheless, it would run the risk of oversimplification if one were then to conclude that the term had been entirely abandoned or denigrated by then. Admittedly, the Communist revolution brought an end to the domination of the Nationalist rule which was said to uphold bourgeois views which included the rule of law. However, while the rejection of those so-called bourgeois viewpoints reached its height in the 1957 anti-rightist movement and in the Cultural Revolution (1966-1976), the idea of the rule of law had nonetheless left its trace as an object of both contention and strategic mobilization.

In the order of discourse on the rule of law from the late 1940s to the 1960s there emerged a variety of themes such as discipline and legality, protecting human rights or "rights of the people," the class nature and inheritability of law, rightist conspiracy, and the hypocritical West. In times during and shortly after the Communist revolution, the languaging of the rule of law appeared in situations where the new elites felt an urgent 
need to consolidate their power, to differentiate themselves from past social systems, and to alienate adversaries. The Communist revolution can be seen as a "peasants" revolution," to use Mao Zedong's words (Mao, 1991, p. 692). At the moment of victory, the Communists were confronted with similar challenges that various peasant uprisings in Chinese history had to face, particularly the need to restore social order and to rein in the unruliness within its own victorious camp. At the same time, however, the Communist movement is a revolution rather than an uprising in the old sense. In fact, ge ming (革命), the Chinese word for revolution, is one of the "return graphic loans", or one of the "classical Chinese-character compounds that were used by the Japanese to translate modern European words and were reintroduced into modern Chinese" (L. Liu, 1995, p. 302). In its classical use, ge ming implies nothing more subversive than the changing of dynasties as a form of compliance with the mandate of the heaven. After being turned into a modern Chinese vocabulary through Japanese, however, ge ming has taken on meanings that are much more radical as to suggest the qualitative change of old social systems. As such, unlike previous grassroots uprisings which eventually returned to imperial modes of governance, the Communist revolution sought to establish something novel, partially guided by Marxist inspirations. Moreover, this revolution was not a geo-politically isolated event but rather took place in a world torn by wars and ideological confrontations. The antagonism associated with the modern ge ming, on both domestic and international levels, factors into the ways in which traditions are articulated in the discourses on the rule of law in the early years of the People's Republic. 


\section{Discipline and legality: Be rid of residues of the feudal past}

Leng Shao-chuan, the author of Justice in Communist China (1967), points out that in the mid-1950s "the question of observing the law was frequently referred to by Communist spokesmen" (p. 51). Indeed, discipline and legality has been a highly noticeable theme in the order of discourse of the rule of law in China from the 1940s to the 1960s. The recurrence of this theme reflected the concern of the senior leaders of the new socialist government that some Communist Party members and state officials, after winning "the liberation war," fell short of abiding by laws and regulations, thus only emulating the old ruling powers and compromising the trust of the masses in the Party as the embodiment of progressive revolution. ${ }^{1}$ In order to differentiate themselves from the old rulers, the leaders of the new government believed, it was necessary for Party members and state officials to demonstrate a high degree of self-discipline in observing laws, thus also serving as a model for the rest of the society.

The necessity for a call for discipline and legality was in fact felt by the socialists before the founding of the People's Republic of China in 1949. In the issue of August $15^{\text {th }}$, 1948, the People's Daily published on its front page an article that criticized a manager of the state-run Marine Bureau in the liberated Northeastern China ${ }^{2}$ - who was also a member of the Communist Party-for illegal detention and punishment of several

\footnotetext{
' In this context, state officials included both government officials and managers of state-run enterprises. The Communists refer to the 1945-1949 civil war as the liberation war.

${ }^{2}$ During the 1945-1949 civil war with the Nationalist, the Communists referred to the regions under their control as the "liberated areas."
} 
workers who had allegedly stolen public property. In its title, the article quoted

Northeastern Daily to call for "the establishment of the spirit of the rule of law." Citing in length the editorial of Northeastern Daily, the article read:

In cities of the people, a good revolutionary social order must be solidified to protect the democratic interests of the people. In order to establish such an order, it is necessary to establish new democratic systems of the rule of law as well as the spirit of the rule of law, [and] to demand discipline.... [State] institutions and groups should in particular become models in executing government policies and laws... If managers and cadres did not rely on the masses...their leadership would be disconnected from the latter... The consequence would be detrimental to the cause of the Party. The origin of the mistake made by Han Sanyou [the Bureau manager]... is that he resorted to intolerably erroneous measures [of management] that should by no means be sought after by any revolutionary. ("Dong bei," 1948, p. 1)

As the article noted, to exercise discipline in governance and to follow the spirit of the rule of law were the key in handling relations between the cadres and the masses.

Moreover, the requirement that Communists serve as models in observing law was seen as part and parcel of a revolutionary system of the rule of law, which was meant to protect "the democratic interests of the people." The extent to which the manager in question—and Communist cadres in general—acted according to law was viewed as having a direct bearing on the success of the Communist Party as the leader of the country. It was necessary, the article suggested, to penalize those acts which demonstrated "a lack of discipline," so as to "realize the spirit of the rule of law and solidify a democratic social order" (ibid.).

It is notable that the People's Daily not only reported this story which had been 
covered by Northeastern Daily, but also republished in part the editorial of the latter. This demonstrates that the Party deemed it vital to stress the importance of Party members abiding by laws. In fact, the notion that Communist cadres and state officials should "heighten the awareness of exercising self-discipline" and "take the lead in observing laws" was a recurring theme mentioned along side with the rule of law in the People's Daily from the late 1940s to the 1950s. Legality, or the observance of laws and regulations, was emphasized as highly important for maintaining healthy relations between the cadres and the masses, and for establishing a new social order based on democratic dictatorship. For example, in another article published on September $26^{\text {th }}$, 1950, the People's Daily reported how the Communist Committee in Anqing, Anhui, set up "rectification classes" (zheng feng ban) for its cadres (Liu H., 1950). The article claimed that, among the first session of the class, $90 \%$ of the 133 cadres were found to have committed illegal detention and battery. These "unhealthy tendencies" were said to be attributable to the fact that the cadres-albeit being activists among the liberated peasants—-had been influenced by the bad mentality of "the old society" that one must gain power through coercion and by producing a feeling of fear and awe among the masses. These cadres, the article stated, lacked a "rule of law" point of view. ${ }^{3}$ Contrary to what they believed in, the masses had become "increasingly enlightened." On the other hand, "in a country of democratic dictatorship, counter-revolutionaries should be handled

\footnotetext{
${ }^{3}$ Du Runsheng (2005), a senior Communist, in his memoir where he recounted how land reforms were carried out in the liberated rural areas in the late 1940s, recalled that some activists in these reforms "could not correct their hooliganism" (p. 15).
} 
by public security institutions and judiciary bodies, and should not be treated with the atrocious measures that had been resorted to by the counter-revolutionary ruling class before" (ibid.).

All this in fact reflected the long held concern among the senior Party leaders that the conduct of the cadres who held law in contempt, the act of which was "a poisonous residue of the past" (Liu Hong, 1950), had negative impacts on the reputation of the Party and on the stability of the new Communist state. For the Communists, what should be primarily guarded against among the "poisonous residues of the past" was the "feudalist ideology" that rulers were in a position to tyrannize (Xie J., 1948/1984, p. 127; Liu Hong, 1950) and had the privilege to remain outside of the rule of law (Dong B., 1954/1984, p. 75). Xie Juezai, a senior Party member and the third President of the Supreme People's Court (1959-1965), wrote the following in his diary on March 20, 1948:

The material aspects of feudalism have been eliminated, but the ideology of feudalism is alive, not only in the mind of peasants, but also among the cadres. Although the cadres are from the good classes of society, with undemocratic conduct, they could become bad cadres and new bullies. $(1948 / 1984, \text { p. 127 })^{4}$

A similar concern was expressed by Dong Biwu, the second President of the Supreme People's Court (1954-1959). In his speech at the eighth National Congress of the Chinese Communist Party in 1956, Dong noted that "there is a serious problem that a handful of Party members and state officials do not pay due regard to state laws and do not abide by

\footnotetext{
${ }^{4}$ The Communists see the imperial dynasties as the period of feudalism. They also argue that the Nationalist Party inherited certain aspects of the feudal ideology.
} 
them" (p. 1956/1984, p. 95). This was later reiterated in another speech of Dong delivered in 1957 , where he remarked,

I have mentioned at the eighth National Congress of our Party that we are confronted with some problems in the legal field, one being that our laws are incomplete, the other being that the laws are not observed. Among these two, which is more severe? I would say it is the latter.... If we do not abide by laws ourselves, how can we expect others to? Nowadays, among those who do not observe laws and do not act according to laws, are they mainly ordinary citizens in society, or mainly state officials and cadres? My observation is that it is the latter... If we have laws and do not abide by them, they will become something hollow and cannot function. (1957/1984, p. 106)

In Dong's view, some cadres dared to neglect law because they believed that "they are the ones unifying the country and creating the new state and, thus, others are subject to the rule of state laws but they are not, and they can stay outside of law and not observe it" (1954/1984, p. 75). In view of the fact that some cadres did not abide by laws, Dong stressed that "for those who break laws...no matter how high their social status is and how much contribution they have made [to the revolution], we must hold them liable" (1956/1984, p. 100). He stated that, "as our state is led by the Communist Party, we Communists must set an example" $(1954 / 1984$, p. 80$)$ and "take the lead in observing the Constitution and laws" (p. 77).

Nonetheless, for Dong, the residue of the past was not simply the feudalist predispositions concerning the legal privilege of those in power; it also included grassroots anti-law propensity inherited from the past. In explaining the reasons why the neglect of law was a widespread phenomenon in the new Republic, Dong contended that 
it was exactly an expression of the feelings of the ordinary people who had developed extreme hatred of and contempt for law because they saw it as a ruthless tool of oppression used by the old feudal regimes (1954/1984, p. 72; 1956/1984, pp. 97-98). Also, Dong suggested, it was exactly through overthrowing the old regimes and the old laws that the Communists came to power; therefore, it was not surprising to observe the prevalence of the mentality that law can be neglected and trampled on (1954/1984, p. 74; 1956/1984, pp. 97-98).

However, in spite of such questioning, the past was not denigrated as a whole. To illustrate the importance of abiding by law, Dong referred to Shang Yang (approx. 390 B.C.E.--338 B.C.E.), a Legalist reformer in the Warring States Period (475 B.C.E. -221 B.C.E.), and recounted how the Legalist emphasized the idea that laws and decrees, once announced, must be observed (1957/1984, pp. 106-107). Dong's view was echoed by Sun Xiaolou (1957), who in an article on classical Legalism published in the scholarly journal of $\mathrm{Fa} \mathrm{Xue} \mathrm{also} \mathrm{invoked} \mathrm{the} \mathrm{story} \mathrm{of} \mathrm{Shang} \mathrm{Yang} \mathrm{to} \mathrm{contend} \mathrm{that} \mathrm{"to} \mathrm{rule} \mathrm{according} \mathrm{to} \mathrm{law}$ brings about constant stability, while the rule of man brings about constant disorder-this is the unwavering theory of the legalists" (p. 27). Sun continued to point out that "in order to rule according to law, one must have the determination and courage to abide by laws and execute them strictly"; otherwise "legality and discipline would be wiped out, and disasters and disorders would follow" (ibid.). A primary reason why ancient China had been a country based on the rule of man rather than the rule of law, Sun explained, was that laws were announced but not abided by, a problem that the ancient Legalists had 
been most concerned about (p. 26). Sun noted that, admittedly, it was not likely for the Legalists to harbor selfless revolutionary spirit which belonged to the working class. However, Sun pointed out, the Legalists were not afraid of holding those in power liable when they broke laws and, thus, although Legalism in the past eventually only served to sustain the rule of feudalist imperial dynasties, one should learn from the Legalists in emphasizing observance of law, thus consolidating the new Communist state.

It is also noteworthy that, along with the criticism of the residues of the past and the praise for classical Legalism, the Russian Soviet was invoked as a useful guide in terms of exercising discipline and legality. For example, with respect to the habitual grassroots contempt for law, Dong conceded that, because of the deep historical and social roots, it was difficult for the Party and the state to eliminate the mentality (1956/1984, p. 98). However, Dong quoted Lenin to argue that to conquer such a mentality was a demanding task that only a Soviet state could fulfill, even though it would take a long period of time and tremendous efforts to achieve the goal $(1954 / 1984$, p. $72 ; 1956 / 1984$, p. 98$)$. The recognition of the value of the Soviet model could also be found in Sun Xiaolou's article on the contemporary relevance of classical Legalism. To strengthen his point that legality was important for the new state in China, Sun quoted Lenin:

In order to eliminate Kolchak and Denikin, we must abide by a very strict revolutionary order as well as the laws and decrees of the Soviet state... Any trivial violation, as a result of either negligence or slackness, would immediately increase the strength of the landlords and capitalists and 
contribute to their success" (p. 27). ${ }^{5}$

As can be seen, what underlay the call for discipline and legality were not only the need to establish social order for the new Communist rule, but also the need to advance the cause against the perceived enemies of the new state. The dominance of these lines of thought can also be found in other themes that appeared in the order of discourse of the rule of law in China from the 1940s to the 1960s. As will be shown, human rights protection was one of these themes mobilized to contest the rule of the Nationalist Party and to build a new image for the Communists.

\section{Rights matter: "Human rights" or "the people's rights"?}

The protection of human rights, or "the people's rights," was another major theme in the order of discourse of the rule of law in the 1940s and the 1950s. In many respects, it was closely related to the theme of discipline and legality, and shared the goal of the latter to gain social support for and thus to solidify the Communist rule. In reviewing the debates on "human rights" in China, some scholars refer to 1957 as a significant moment when the notion re-emerged for a very brief while (Svensson, 2002, pp. 213, 221-222) and when it was invoked mainly by critics of the state. However, one in fact finds the notion appearing in a positive light in the mouthpiece People's Daily in both the 1940s and 1950s, sometimes even relied on to criticize the conduct of individual Communist

\footnotetext{
${ }^{5}$ Kolchak and Denikin led military attacks against the Russian Communists after the October revolution in 1917.
} 
cadres. That is, in the early years of the People's Daily, ${ }^{6}$ the theme "human rights" not only was not wiped out of the picture, but also was used for self-criticism. What is noteworthy, nonetheless, is the phenomenon that "human rights" was mixed with the notions of "the people's rights" and "citizens' rights" without clear definitions. The argument that the protection of "human rights," or "the people's rights," was crucial for the rule of law reflects the desire of the Communist Party, while winning the civil war, to justify its cause against the Nationalist rule, to condemn the Western capitalists, to bring the unruliness of some cadres into constraint, and to promote the idea that the Party intended to establish a social order based on law, one in which rights are protected but with a guideline of class struggle.

In fact, even before the civil war broke out in the mid-1940s, the idea of human rights-although it is rarely thought of as in congruence with Communist ideologies - had not been alien to the Communists in China. On the contrary, the Communist Party was well aware of the power of the notion in helping it establishing legitimacy. At the eve of World War II, after forming a united front with the Nationalist Party to fight against the Japanese, the Communists set as their goal to found "the people's government" in the "anti-Japanese base regions." In order to establish

\footnotetext{
6 The People's Daily, as the official newspaper of the Central Committee of the Chinese Communist Party, was founded in 1948, when the Jin Cha Ji Daily (founded in 1937) and the People's Daily of the jin ji lu yu region (founded in 1946) were combined into one.

7 The united front was formed in 1937. In the decade before that, the Communist Party was not recognized as a legitimate party by the Nationalist government in Nanjing. Communist troops were under attack by the army of the government, and were forced out of the isolated Chinese Soviet regions where they gathered, eventually embarking on the Long March (1934-1936).
} 
themselves in these regions, the Communists put forward the slogan of "protecting human rights" to call for an end to anarchism and reign of terror (Du R., 2005, p. 11) which prevailed in the previous Chinese Soviet regions. With the slogan as well as other contemporaneous policies under which the Party shared power with non-Communists, "enlightened local gentries," and intellectuals in the base regions, it was hoped that the general public could rest assured that the lawless popular terror that had been resorted to by the Party in the Soviet regions (Tay, 1986, p. 9) before the anti-Japanese War would now be replaced by a pursuit of social order based on law (Du R., 2005, p. 11).

After WWII and while fighting the Nationalist Party in the civil war, the language of rights was again invoked, but this time mobilized to question the righteousness of the Nationalist rule, and to reveal the deceptiveness of the Nationalist capitalist tradition of rule of law. An article published on December $5^{\text {th }}, 1946$, on the front page of the People's Daily reported "the tragedy of Shanghai peddlers" which, according to the article, demonstrated the anti-democracy nature of the Nationalist:

Peddlers in Shanghai took to the street to petition to the Nationalist authorities, demanding to preserve their most basic rights to do business and thereby to feed themselves - [the peddler had to demonstrate because] the four families of Jiang, Song, Kong, Chen, in order to monopolize every market, have banned the peddlers from doing business and have made it impossible for them to make a living. The demonstration of the peddlers was entirely justified and lawful. But the government controlled by the four families resorted to relentless measures. It deployed military police and secret agents, and used weapons provided by the American imperialists-rifles, machine guns and tear gas were used to butcher and slaughter the fellowmen who suffered from hunger and cold. Jiang Jieshi and a handful used the rhetoric of "the rule of law" to cheat the people. But if one looks at [this tragedy]... what law can one speak of under the rule of 
Jiang Jieshi? Jiang Jieshi has only one law, that is, only the four families are allowed to make money, while the people are not allowed to feed themselves; only the autocratic government is allowed to kill at will, while the people is not allowed the most basic citizen rights of assembly, association, and demonstration. ("Shanghai," 1946)

The article concluded that "the tragedy of the Shanghai peddlers again reflected the severity of the crisis of the autocracy of Jiang Jieshi," and that "the great movement in which the people fight for freedom and rights for livelihood will flourish regardless of any oppression" (ibid.).

During the civil war, while the Nationalist Party was criticized for encroachment upon rights, in the liberated zones controlled by the Communists, programs were announced which were intended "to safeguard the democratic rights of the people" (Dong, 1956, p. 90). For example, in July 1946, in the Harbin city of Northeastern China, a municipal policy platform was unanimously approved by the senators of the city, which claimed that the city would "establish social order based on democracy and the rule of law, protect human rights and property, safeguard the freedom of assembly, association, publication, speech, and belief, and safeguard the rights of the people to condemn traitors and secret agents [of the Nationalist Party]" ("Ha'erbin," 1946). Similar provisions of rights protection also appeared in "the proclamation of the People's Liberation Army signed by Mao Tse-tung and Chu The in April 1949" and "a policy directive issued in 1949 by the North China People's Government" (Leng, 1967, pp. 23-24). Reviewing the

\footnotetext{
8 Jiang Jieshi (1887-1975), whose name is sometimes romanized as Chiang Kai-shek, was then the chairman of the Nationalist government.
} 
Communist moves in the legal realm in this period of time, Alice Tay (1986) remarks that "in the hour of victory [over the Nationalist], moderation and the rule of law were re-emphasized" (p. 12). As Leng (1967) also explains, the moves were to "allay many people's fears," to "check the revolutionary excesses and [to get] reoriented...toward moderation" (p. 23). However, on the side of the Communists, the emphasis on rights protection was interpreted not as expediency but as a tradition of theirs. As an author wrote in the People's Daily, the socialist legal system, as the most revolutionary and the most progressive system of law which protected the democratic rights of citizens, was a legacy of the socialist struggles led by the Communist Party (Li Q., 1956).

The language of rights was not only relied on to condemn the Nationalist and to portray the Communist as respecting rights, but was also used to criticize the misconduct of certain Communist cadres. A case of this is the coverage of an incident of human rights violation in the People's Daily in 1950. On July $12^{\text {th }}$ of that year, the People's Daily published a letter to the editor from the correspondents of a local Party committee, who reported that some cadres in the Rong county of the Hebei province committed illegal corporal punishment against a villager for the alleged offences of pilferage and attacking armed officers. Entitled "Cadres in Rong Violated Human Rights," the letter reported the court conviction of the cadres involved, and called for the government and the Party committee of the county, who had shielded the abusers, to conduct self-criticism openly for their behavior ("Rong cheng," 1950). Then, on August 11 $1^{\text {th }}$, the People's Daily published another letter, this time written by the government and the Party committee of 
the Rong county, which reviewed the incident and apologized for "not having fully appreciated the policies on human rights protection and the spirit of the rule of law" ("Guan yu," 1950). The authors of the letter acknowledged that they had not paid enough attention to human rights abuses which had compromised the trust of the people in the Party and in the government.

In fact, the discourses on human rights and the rule of law in the early years of Communist China were closely connected to the promotion of discipline and legality, that is, to the call for Communist cadres to observe law. In tracing the origin of the tendency of the Communist cadres to belittle law and encroach on rights, what was blamed was "the feudalist and capitalist ideology" which granted legal privilege to those in power ( $\mathrm{Li}$ Q., 1956, p. 7). In order to perfect socialist law, an author claimed, it was necessary both to fight the traditional feudal mindset that "looked down upon the rule of law," and to oppose capitalist ideas of law that were "detached from the masses" (ibid.). To give an example of the "hypocrisy" and "absurdity" of the capitalist "great tradition of democracy and freedom," an article in the People's Daily pointed to the United States, criticizing that the American Constitution, when first drafted, did not even contain any clause of human rights protection, or any mention of the freedom of speech, publication and assembly which the capitalists claimed to advocate (Yi, 1962, p. 3).

As can be seen, even in the talk on human rights, the notion of "class" occupied a central spot. It is noteworthy that the Communist promotion of rights protection was often accompanied by the argument that dictatorship was to be exercised over class 
enemies. "Traitors and secret agents," "war criminals," and "those controlled by "the bureaucratic capital"" ("Ha'erbin," 1946; Leng, 1967, p. 24) were excluded from the protected. Zhou Enlai, the first Premier of the People's Republic of China, remarked that Chinese capitalists and landlords were "nationals" of China but not part of "the people" (1949/1980, pp. 368-369) and, therefore, they did not have the rights that belonged only to the people. Liu Shaoqi, the second President of Communist China, also made a point of polarizing between the people and the counter-revolutionaries, noting that only after depriving the latter of freedom and rights could the people gain their true freedom and rights (1954/1984, pp. 52-53). In fact, the rhetoric of struggles between the people and the "counter-revolutionaries," as another expression for class struggle, also dominated other topics and themes discussed in relation to the rule of law in this period, such as the class nature and inheritability of law as well as the conspiracy of the rightists, which will now be turned to. As will be shown, these ideas were brought up to consolidate the Communist rule by repudiating the legal tradition of the Nationalist Party and attacking "the fallacious arguments" of the rightist legal scholars.

\section{The class nature of law, the inheritability of law, and conspiracy of the rightists}

The class nature of law, the inheritability of old laws, and rightist conspiracy-these were also the key terms associated with the idea of the rule of law in the early decades of the People's Republic, especially during the anti-rightist movement in 1957. The anti-rightist movement, in Leng Shao-chuan's words, was a campaign by the new 
Communist government "to counter-attack its outspoken critics" (1967, p. 55), who were labeled as conspirators seeking to restore the legal tradition of the Nationalist Party that represented the interests of the old ruling elites. While the Communists insisted on "the political nature of law" and questioned the rule of law tradition under the Nationalist rule, the "conspirators" contended that legal heritage from the old regime, or at least part of it, was still valuable despite its class nature.

A major origin of the contention can be found in the instructions for legal work issued by the Communist government in 1949, which claimed that the Nationalist legal tradition must be abolished before new laws could be established. The instructions clearly stated a theory with regard to the class nature of law and applied it to analyze the laws under the Nationalist rule:

Law is the state ideology that the ruling class openly enforces through the use of force. Just as the state, law is a tool to protect the interests of the ruling class. The six codes of the Nationalist Party, as all other capitalist laws, appear in a form that covers up their class nature. However, just as there can be no states that go beyond all classes, there can be no laws that go beyond all classes.... All laws of the Nationalist Party are no more than tools to protect the reactionary rule of landlords, comprador bureaucrats and capitalists, and are weapons to suppress and control the people. ("Zhong gong zhong yang guan yu fei chu," 1949/1984, p. 1) ${ }^{9}$

The instructions stipulated that one should "constantly hold in disdain and criticize...all reactionary laws and regulations of the Nationalist Party," "hold in disdain and criticize...all laws and regulations in the capitalist states [such as those in] Europe, the

9 The six codes of the Nationalist included the Organic Law, the Commercial Law, the Civil Code, the Criminal Code, the Civil Code of Procedure, and the Criminal Code of Procedure. 
United States, and Japan," and use Marxism to "educate and transform" practitioners of law (p. 3). That is, the opposing class natures of the new Communist state and the old Nationalist state meant that the legal tradition of the latter was not to be inherited.

These key points of the instructions were later echoed in several articles published in the People's Daily. On August $22^{\text {nd }}, 1952$, an article in the newspaper called for the elimination of "the viewpoints of the old laws" (Li G. \& Li J., 1952). The authors asserted that "the viewpoints of the old laws" were "the six codes and all other reactionary legal conceptions of the Nationalist reactionaries, including...their whole anti-people system of the rule of law" (ibid.). Specifically, the reactionary ideas included the following: to claim the principle of equality before law so as to treat the people and the enemies of the people indiscriminately; to insist on following complicated, inefficient, and inflexible procedures, and thus alienating the masses from judicial work; to emphasize the so-called judicial independence, etc. It was argued that, instead of inheriting these old viewpoints, legal cadres in the new Communist China should "suppress the enemies of the people ruthlessly" so as to protect the interests of the people, should stay close to the masses and de-bureaucratize judicial procedures, and should uncover the deceitfulness of the capitalist judicial independence while supporting the leadership of the revolutionary government (ibid.). Even Shen Junru, a non-Communist advocate of democracy and the first President of the Supreme People's Court of the People's Republic, remarked that law should stay in close connection with class struggle and with the masses:

It is not right to separate law from politics. [It is true that] After the laws are 
formulated, they have their own independent functions and it is not right to negate these functions either.... But...the people's judicial work must actively serve politics and integrate with the central political tasks [of class struggle] and the mass movements at present. (Shen J., 1951/1994, pp. 660-661)

On the other hand, a work report by Shi Liang, the first Minister of Justice of Communist China, spelled out the importance of constructing the people's rule of law for the continued success of the Communist revolution. Shi stated that one of the notable achievements of the legal work in the first three years of the new China was the judicial reform movement (1952-1953), the purpose of which was to liquidate the viewpoints of the old laws by reeducating practitioners of law, particularly those who used to work under the Nationalist rule (Shi L., 1952). Other contemporaneous articles took these practitioners as their particular target of criticism, and argued that a new rule of law must be built based on the repudiation of the mindset of the old legal experts. An author wrote,

Some comrades boast of their "many years of practice of the old laws" and see themselves as the legal "authority" in China. Deep in their mind is a kingdom of old legal traditions ruled by feudal landlords, comprador bureaucrats and capitalists, which is fraught with a variety of reactionary and rotten laws used by the reactionary imperial dynasties as well as Jiang Jieshi's Nationalist Party to suppress the people. These laws are seen and consecrated [by the old legal experts] as the orthodox. They [the old experts] look down upon the laws created by the people in revolutions...; they do not understand that the people's laws are only to be created in class struggles. Lenin said that the new government creates new rule of law and new order...but those who hold the above viewpoints [the old practitioners] would not understand this. (Ye L., 1952)

In fact, the judicial reform movement praised by Shi Liang, which was predicated on the assumption that old practitioners of law should be reeducated, later sparked criticism 
among scholars, who not only questioned the treatment of legal experts in the movement, but also challenged the notion of the "un-inheritability" of old laws. According to the critics, the judicial reform has thrown scholars specialized in law into positions where they could not apply their expertise-some were sent to be transcribers in administrative agencies, some were dispatched to hospitals to be registrars, and some had to stay at home with nothing to do (Lu \& Tie, 1998, p. 19). Yang Zhaolong, a professor of law with international reputation who was later condemned as a rightist, attributed the problems of the reform to the simplistic understanding of the class nature of law and to the underestimation of the value of old laws and their practitioners (Yang Z., 1957a, p. 109).

Such criticism was most vehemently voiced in the spring of 1957 , after the Communist leaders encouraged intellectuals in all circles to criticize the Party and to "help the Party to rectify itself." On May $1^{\text {st }}, 1957$, the People's Daily published on its front page "The Instruction of the Central Committee of the Communist Party about the Rectification Movement" ("Zhong gong zhong yang guan yu zheng feng," 1957). This instruction was based on an earlier report by Mao Zedong, in which the chairman articulated his theory of "correctly handling contradictions within the people," and asked non-Communists to help improve the Party by critiquing it. ${ }^{10}$ Following the instruction, the People's Daily published an editorial the next day entitled "why the rectification

\footnotetext{
${ }^{10}$ The period of this rectification movement (zheng feng yun dong) was also called the period of "Hundred Flowers," the metaphor of which Mao used to encourage intellectuals to voice their own opinion on a variety of issues, no matter how deviated their viewpoints were from the Party lines. Some see the movement as a strategic move of Mao to entice the "counter-revolutionary rightists" to expose themselves (Ye Y., 2000).
} 
movement," which stated that contradictions within the people had replaced contradictions between the people and their enemies as the main challenge for the new state ("Wei shen me," 1957). At the same time, the editorial claimed, in order to find timely and correct solutions to contradictions within the people, it was necessary to let the people express their opinion freely to help the ruling Party criticize its own work, thereby improving relations between the Party and the rest of the society (ibid.). Emboldened by these messages, many in the circle of legal studies began to raise their concerns about legal work in the new China.

Yang Zhaolong and Wang Zaoshi, two leading scholars in the field, particularly noted the importance of establishing the rule of law in the new socialist state of China (Yang Z., 1957b; Wang Z., 1957). Among the many related issues debated, those of class struggle, the inheritability of law, and the usefulness of the practitioners of old laws stood out prominently. Wang suggested that, as class struggles had come to an end in China and now the focus was on resolving conflicts within the people, it would be necessary to emphasize democracy which could not be realized without the rule of law. In particular, he contended, knowledge about the rule of law should be widely promulgated, as the Chinese people had been immersed in the tradition of the rule of man (ren zhi) for thousands of years (Wang Z., 1957, pp. 31-32). The rule of man, Wang pointed out, was a feudal residue and, in order to eliminate it, there must be laws which once enacted should not be disregarded. Wang also argued that, once the importance of the rule of law was widely understood, there would be more who wanted to study law and, therefore, old 
experts and practitioners of law should be given a chance to contribute to the education cause of the new state (pp. 32-33).

On the other hand, in two of his famous essays later labeled as revisionist and rightist, Yang Zhaolong pointed out that the class nature of law in a state was not static (Yang Z., 1956, pp. 26-30), and that the socialist rule of law should be applicable to both members of the people and the "class enemies" of the people, even if only the former but not the latter could have democratic rights (Yang Z., 1957b, p. 86). In terms of the inheritability of law, Yang noted that, due to heightened "revolutionary vigilance," there existed simplistic and impractical views about the value of old laws (Yang Z., 1956, p. 32). He argued that, as the class nature of law does not consist in the legal norms themselves but in the way in which law is mobilized, and as the norms themselves are embodiments of justice of humanity, old laws should not be abandoned but rather should be made good use of (p. 33). With respect to those who practiced or studied law when the Nationalist Party was in power, Yang contended that law was a body of specialized knowledge despite its political nature, and that legal specialists, even if they were not members of the Communist Party, should not be discriminated against (Yang Z., 1957a).

However, such ideas were later attacked as revisionist and rightist, and those who voiced them were deemed conspirators who intended to overthrow the revolutionary government and to resurrect the reactionary capitalist rule. From the mid-1957 on to the 1960s, numerous treatises appeared in the People's Daily and in academic journals to denounce those who reviewed critically the issues of the class nature and inheritability of 
law. Thus, the rectification movement for the Communist Party was turned into the anti-rightist movement against the outspoken intellectuals. The notion of the rule of law was frequently related to the idea of "rightist conspiracy" against the Communist Party (Han Y., 1957; Wu Defeng, 1957; Zhu X., 1957; Ding, 1957). Critique of the Party solicited from legal scholars was interpreted as evidence that the conspirators attempted to "revive the ghost of old laws" (Rui, 1957; Ke, 1957). Viewpoints of intellectuals that did not resonate with Party lines were no longer seen as representing contradictions within the people, but rather as demonstrating why class struggle between the people and their enemies — or the rightists in this context—needed to be continued. The most typical rhetoric of the attack against the intellectuals can be found in an article entitled "struggles in the legal circle," where the author wrote,

At present the legal circle in the whole nation is in the anti-rightist movement - this is a struggle in national legal construction between the two lines of socialism and capitalism, a struggle in legal thought between the revolutionaries and the reactionaries.... The plot of the capitalist rightists is to abolish proletarian dictatorship and to resurrect the capitalist and, therefore, the socialist legal system has become the main target of their attack... The general slogan of their attack is that of "the rule of law".... As we all know, the capitalist rule of law is just the banner of capitalist dictatorship.... The rightists opposed the leadership of the Party in legal work... and used the slogan of "the rule of law" to stir up discontent with the Party viciously. (Tao X., 1957)

This article, along with many others, not only repudiated the viewpoints concerning the class nature and inheritability of law proposed by the intellectuals, but also refuted the criticism by legal scholars of the treatment of experts of old laws in the judicial reform. Thus, the rule of law as an idea, endorsed by the intellectuals under attack, increasingly 
became a synonym for reactionary ideology. The negation of the rule of law was also evident as the notion became more frequently referred to as a camouflage of the West in pursuing imperialism overseas and fascism domestically.

\section{The West: The face of hypocrisy}

Not only the Nationalist Party and the rightist, but also some Western countries were criticized in the dominant discourses in the early decades of the People Republic. For the Chinese Communists, the alleged "the rule of law" in the Western countries-except those in the Soviet bloc - was nothing more than rhetoric. It was argued that the West utilized the banner of the rule of law as a pretense for domestic fascism as well as overseas expansion, and a number of issues and cases that allegedly betrayed Western hypocrisy in this respect were reported in the People's Daily. The coverage of the cases and issues echoed the Party lines that the rule of the capitalist elites was repressive and imperialistic, and that it was necessary to advance the revolutionary cause of Communism.

For example, stories about the Communist Party in Western countries were reported by the People's Daily and were seen as examples demonstrating the fascist nature of the rule of law promoted by the West domestically. An article authored by the Chinese New Legal Studies Institute was published on October $31^{\text {st }}, 1949$, in the People's Daily, which was meant "to protest against the illegal convictions of revolutionary leaders by the counter-revolutionary governments of the United States and Australia" ("Kang yi," 1949). 
This article was written in response to two legal cases, one regarding "11 Communists convicted of plot" (Porter, 1949) in the United States, the other about the general-secretary of the Communist Party in Australia who was found guilty for "having uttered seditious words" ("Red secretary," 1949). According to the New York Times, the "top leaders of the Communist Party of the United States were found guilty... of criminal conspiracy...for secretly teaching and advocating, on secret orders from Moscow, overthrow of the United States Government and destruction of American democracy by force and violence" (Porter, 1949). For the other case, it was reported by the Toronto Daily Star that the general secretary of the Australian Communist Party "was convicted of saying during a telephone interview that 'if Soviet forces in pursuit of aggressors entered Australia, Australian workers would welcome them"” ("Red secretary,"1949).

In response to the convictions, the article in the People's Daily stated that the cases demonstrated that "the people's rights in ideas, speech, association, assembly, and personal liberty protected by the basic law of the Anglo-Saxon states" were "severely encroached on" ("Kang yi," 1949, p. 1). Describing the charges against the Communists in the two countries as a "humiliation for democratic laws and human justice," the article commented,

The value of law consists in its protection of the rights and interests of the largest majority of the people. If law is only to serve the financial oligarchy in its suppression of ideas and speech of the people, to serve to oppress calls for peace and justice, and to serve to persecute the true leaders of the working people, as demonstrated by the two cases, then, it completely exposes the true character of the so-called "the rule of law" under the rule of financial oligarchy, and announces the bankruptcy of the so-called 
democracy and the spirit of the rule of law in capitalist states. (ibid.)

Such questioning of the nature of "the rule of law" in some Western countries was a continuing theme from the 1940 s to the 1960 s. A common charge was that the governments of the West persecuted the Communists by various means with the use of grand slogans. As an article published on March $24^{\text {th }}, 1962$, claimed, the way in which the American Communists were treated revealed the fascism of the rule of law in the United States, which was even worse and meaner than Hitler's anti-Communist crimes (“Ken ni di," 1962).

Similar rhetoric also appeared in the People's Daily to applaud the black riots taking place in the United States in the 1960s, to support the anti-Vietnam-war demonstrations, and to accuse the Johnson administration of using "the rule of law" to pacify the people. African Americans were praised for their bravery in despising the hypocritical order of the rule of law and in counter-striking the fascist police force, whereas the government was criticized for advocating the peaceful rule of law while ordering crackdown of uprisings and anti-war protests ("Dou zheng," 1964; "Quan shi jie," 1967; "Yue han xun," 1967). Referring to the comments, voiced by the Johnson administration, that the anti-war demonstrations were to be blamed for irresponsible violence and unlawfulness, an article rebutted,

Such comments exposed the ferocity of Johnson and his followers.... What is "unlawfulness"? The Johnson administration betrays the will of the American people...insists on the invasion of Vietnam, and suppresses the demonstrators with the use of force. How can the American people bear with this? The American people want to rise up to resist the "law" which 
the American ruling class utilizes to send the people to perish in the battlefield.... The American people just want to use revolutionary violence to counter-act against the counter-revolutionary violence of the American reactionaries. Let "the rule of law" and "order" of the Washington nobles go to hell! ("Yue han xun," 1967, p. 5)

According to this article and other similar ones, the struggles carried out by the African Americans and the anti-war demonstrators in the United States were part of a world-wide revolution that sought to resist and "bury" the old ruling elites ("Quan shi jie," 1967; "Yue han xun," 1967), and to overthrow the hypocritical "rule of law."

While "the rule of law" was described as a tool to deceive the people in the domestic affairs of Western countries, it was also denounced as a pretense for American imperialism. A number of news reports and commentaries in the People's Daily from the 1940s to the 1960s followed this line of argumentation, using cases such as the Korean War, the Taiwan issue, the Vietnam War, and others as examples. This is a period of time in which the Cold War unfolded and the government of the United States continued to provide military assistance to the Nationalist government, which had to retreat to Taiwan but sought to take back the mainland of China from the Communists. At the same time, given their disadvantage in marine and air forces, the Communists were also evaluating different prospective ways of unifying China including the region of Taiwan. Under such circumstances, the Communist government was particularly vigilant about any military actions taken by the United States along the border of China, which might in effect help the Nationalist Party in carrying out counter-strikes and restoring its rule. In an article entitled "Truman clamored for continued invasion of Korea and China," the author wrote, 
"Truman explains that to invade Korea and China is to "fight for the restoration of international rule of law and order'; that is, the Truman administration is prepared to continue its war of invasion so as to force... China to accept 'the rule of law and order' of Jiang Jieshi" ("Du lu men," 1951, p. 1).

With respect to the Taiwan issue, in the coverage of Dwight Eisenhower's visit to Taiwan in June 1960, an article quoted the President as saying that "the United States does not acknowledge the right of the belligerent and despotic Peking Communist regime to speak for the Chinese people... and will seek effective solutions to stop wars and promote international rule of law regardless of any setbacks" (“Ai sen hao wei er," 1960 , p. 4). Refuting such remarks, the article charged that Eisenhower was attacking the new China viciously, and that the President was in Asia to sell the phony peace of rule of law, but in fact only to create regional tensions and thus advancing imperialism (ibid.).

Similarly, the Vietnam War was viewed as an example of imperialist attempts camouflaged with the slogans of peace and the rule of law. While praising the victories of the Vietnamese troops, some commented, "in the American imperialists' own words, 'the peace strategy' is just a supplementary means for the war strategy..., the purpose of which is to "subject' the whole world to American 'rule of law"" (Yuan, Qiu, Wang, \& Pan, 1966, p. 6). On the other hand, the Vietnamese, just as the black revolts and the anti-Vietnam-War protests, were seen as engaging in revolutionary struggles with capitalist hypocrites. 


\section{"The rule of law" in revolution ferment: Traditions in the politics of antagonism}

The early years of Communist China were immersed in the sentimentalities and politics of revolution. As the Communist revolution symbolizes for the Chinese a farewell to the feudal past as well as confrontation with the imperial West and its representatives in China, the Chinese discourses on "the rule of law" in these years were permeated by an ethos of division and struggle. The politics of antagonism dominated the discourses, where the new Communist rulers spared no efforts in distancing themselves from feudal and bourgeois elites in the past, drawing a line between "the people" and "the counter-revolutionaries," and throwing criticism at the West as a perceived ideological enemy. "The rule of law," representing a social ideal yet originating from the West, was thus both applauded and chastised, being tugged into a war of division between "ours" and "theirs." As "ours," the rule of law was to be pursued for the consolidation of the new socialist state; as "theirs" - either of the home capitalists or of the West - the rule of law was repressive and hypocritical. Eventually, the advocacy of "ours" was overwhelmed by the animosity towards "theirs."

As has been pointed out, the notion of ge ming, or revolution, is a modern Chinese transmutation (via Japanese) of an ancient word which in its new usage stands for a call for the radical overthrowing of the past. As an epitome of China's modernity in an antagonistic form, the revolutionary spirit defined the ways in which traditions were constructed and evaluated in the first few decades of the People's Republic. For China's 
own past, the major target of attack was feudalism, viewed as the social system under which the Chinese people had suffered oppression for thousands of years. The term often used to characterize feudalism was that of “人治 (the rule of man)," the notion of which, however, was popularized in China only after Liang Qichao's History of Political Thought in the Pre-Qin Period (1922), a modern monograph in which "the rule of man" and "the rule of law" were contrasted as the ideas in two of the four major streams of classical Chinese political thought. The conceptual category of the rule of man versus the rule of law was also adopted in the young Communist China, yet the rationales of critique varied. For some, the rule of man was at fault because of its lack of resolution in strictly implementing laws and, thus, its incompatibility with the need for revolutionary discipline in obeying rules and decrees, without which the Communist state could not stand up to its enemies. Along with this, there was also another type of criticism, albeit marginal, against the rule of man, which hinged on an issue other than discipline. As can be seen in the condemned "rightist" arguments by Wang Zaoshi which appeared in his proposal on how to handle contradictions within the people, the rule of man was despotic and thus a post-class-struggle socialist state should reject it and embrace the rule of law to bring about democracy. It is interesting to note that Wang's comments - as well as those of some other "rightists"- are a typical example in which liberal themes were brought to be reconciled with Marxist ones. In fact, the need to bring together the two streams of modern Western ideas was more acutely felt in the post-Cultural-Revolution China, as will be shown in the following chapters. 
Within the feudal tradition, two sub-tendencies were also taken as the opposites of the rule of law, one from the above concerning legal privilege of those in power, the other from below about the grassroots disregard for law. Neither of the two, it was believed, was beneficial for the new revolutionary order that was to be established in the new socialist China. However, although most from the feudal past was held suspicious and dangerous, classical Legalism was lauded for its emphasis on a social order based on law, which was appraised as in line with what the consolidation of the new state required. Yet the praise for Legalism was qualified by the Marxist-inspired critique that the ancient school of thought was a product of feudalism. Feudalism was also found, blended with capitalist interests, in the legal tradition of the Nationalist Party. Although this tradition, also claimed as the rule of law, was described by a few as containing elements of justice and thus inheritable, it was officially denounced as deceitful for its reactionary class nature. What was to replace the Nationalist repressive rule of law, according to the Communists, was a revolutionary type of rights protection in which the interests of the people were to be distinguished from those of state enemies. As such, ideas and practices from China's own past were still being remembered, yet only as something to be discarded or at least cautioned against in the construction of socialist rule of law.

In fact, when "the rule of law" was articulated in positive lights in the discourse - that is, when it was qualified as "socialist" or "revolutionary"—it was rarely explicitly identified as a Western concept or tradition. Thus, except in some marginalized alternative voices, "the rule of law" somehow became a notion without histories, its 
origin and past being at best evaded or even erased. On the other hand, however, when "the rule of law" was discussed as an ideal advocated by the West, it was often denigrated and seen as demonstrating the double standards of Western capitalist countries, which talked about peace and law while in actions only pursuing fascism and imperialism.

What was proposed to counter the "-isms" of the hypocritical West and the domestic feudalism, however, was another "-ism" that was anything but indigenous Chinese. The once foreignness of the notion of she hui zhu yi (社会主义), or socialism, can be seen in the component parts of the character compound. Zhu yi is a suffix that arrived in modern Chinese from Japanese; regarding she hui, it was used in imperial China to refer to social gatherings that offered sacrifice to the god of the earth, the meaning of which was at best remote from what the term later indicated in she hui zhu yi. In fact, in the discourses on the rule of law, both the identification of social problems - that is, the critique of the reactive legal ideologies of the West and the past—and the proposal of solutions, or the promotion of socialist rule of law, bore a mark of Western influence.

In particular, the confrontational identification of feudalism and capitalism versus socialism was underpinned by Marxist lines of thought, one of the modern streams of Western ideas adapted by the Chinese. The idea of feudalism and capitalism as both undesirable stages of the past was borrowed from Marxist views of historical progress and radical revolution. The mark of Marxism can also be readily found in other instances. For example, "human rights" was equated with the rights of the people, who should be protected as opposed to class enemies. As another example, the criticism of Western 
imperialism and fascism was situated within a larger framework of understanding predicated on the belief that worldwide revolution was taking place to overthrow the rule of the capitalist. As such, although the West is often explicitly critiqued in the discourses, Western influence is not at all absent. If seen as a modern Western tradition, Marxism as Communist China's official ideology offered instruments by which other Western ideas and China's own past were gauged.

However, some may argue, the prevalence of Marxist lines of thought does not necessarily mean total repudiation of China's own heritages. They may point out that the gesture of distancing from the past was ironically accompanied by the implicit nodding towards practices employed in imperial China. For those who believe that the non-differentiation between politics and law is an imperial tradition of China, the modern Chinese idea of the class nature-or the political nature - of law, although cloaked in Marxist terms, was just an extension of China's own heritage. Also, for those who take Confucian rule-of-man as the mainstream Chinese tradition, they may note that the call for the Communists to take the lead in observing laws is very similar to the Confucian notion that "the ruler is... to turn disorder into order, and to persuade others to join in the realization of that harmonious social order by virtue of his moral vision, character, and the example he sets" (Peerenboom, 2002, p. 33). Thus, they may conclude, the call for discipline within the Party sustained the Confucian assumption that "political order was... largely dependent on the quality of those in power" (ibid.). However, others may stress the legacy of Legalism as a mode of thinking. They may refer to the attacks against 
intellectuals in the anti-rightist movement as a type of absolutist anti-intellectualism -as has been discussed in chapter 2, some believe that Legalist anti-intellectualism is aimed at unifying social thought and removing ideas that do not resonate with state orthodoxy (Yu Y., 2004a, 2004b). Despite these different evaluations of how China's past extends to the present, one needs to note that the bases on which the observations are made, such as the merging of politics and law, Confucianism as a tradition of the rule of man, or Legalism as undemocratic, are respectively only one way of reading China's past, which yet is provoked by China's exposure to the West and its knowledge.

One may also find the disregard for law among both revolutionary cadres and the ordinary people strongly reminiscent of the contempt for law underlying the centrifugal vagabond cultures. If one agrees with Wang Xuetai (2004) that vagabond culture is a key characteristic of China's tradition, he or she may argue that the advocacy for discipline and legality was a measure to counteract traditional anti-establishment tendencies. In fact, later developments in the legal field showed a curious combination of both totalitarian and anti-establishment tendencies, which culminated in the Cultural Revolution when the authorities of the country dictated that legal institutions be "smashed." The chaos generated by decades of mass movements eventually led to a trend of revisionism, in which the importance of law in social governance was re-evaluated. If from the 1940s to the 1960s the articulations of "the rule of law" were early attempts at solidifying the Communist state, what followed were more experiments that sought to re-orient the Party's leadership and redefine "the rule of law" in a changing society. 


\section{Chapter 5 Socialism in transformation: Post-revolution (re)emergence of the rule}

\section{of law}

If the discourses in the early decades of Communist China can be said to have been dominated by antagonistic mentalities, then, the years from the late 1970 s on have witnessed a retreat from this revolution mindset in the languaging of the rule of law. Nonetheless, the apparent easing of the confrontational tone did not at all indicate the disappearance of the sense of urgency either on the part of the Communist leadership or among the ordinary Chinese. On the contrary, "the rule of law" resurfaced in many respects as an idea drawn upon to address old and new problems. If the primary challenge for the Communist Party from the late 1940s to the 1960s was to establish its rule in China, the Party found itself stranded in another legitimacy crisis in the late 1970s (Tsou, 1994), this time not resulting from conflicts with the Nationalist Party, but rather as a consequence of the devastation generated by the Cultural revolution, which was triggered by the Communists themselves. Meanwhile, many were led to reconsider the path of development for China to pursue. Ironically, the Cultural Revolution with its mass mobilizational nature had cultivated a generation who became articulate in expressing political viewpoints, and who "periodically in the following decades continued the efforts" to contest "the abuses of political power" (Goldman, 2005, p. 50).

To address the crises brought about by the Cultural Revolution, the Party 
introduced the policy of reform and opening-up in the late 1970s. The following decade witnessed economic growth, relative loosening of ideological control (Tsou, 1994, pp. 149-153), and the rise of corruption among officials and Party cadres. In the late 1980s and early 1990s, however, in the wake of domestic political turbulence and the collapse of Communist rule in Eastern Europe, ${ }^{1}$ the Party was once again confronted with the daunting task of resituating itself as the leader of the country (Tsou, 1994, p. 137). Deng Xiaoping's 1992 tour to Southern China re-affirmed the direction of reform, and a "market economy with Chinese characteristics" was announced as a major objective to work toward for the Party and for the country as a whole. On the other hand, as an observer points out, the post-1989 China saw the "de-politicalization" of criticism and the "keynote of the time" was shifted to the enhancement of national heritage, "which becomes the top melody of politics and culture" (Sheng, 2007, p. 124). However, it was not clearly defined what exactly was meant by either "Chinese characteristics" or "national heritage."

As a product of all this, a number of topics and themes appeared in the orders of discourse on the rule of law in China in the 1980s and the 1990s. The rule of law was extolled as the antithesis of the rule of man, the latter being viewed as what had brought about the disaster of the Cultural Revolution. Moreover, in the discourses in these two periods one sees debates on class struggle and human rights, the former being

\footnotetext{
1 The political turbulence in 1989 was a result of both the success and the failure of the reform pursued in the 1980 s (p. 145; Lieberthal, 2004, p. 146). This will be further explained in the section on economic reform.
} 
increasingly questioned whereas the latter being emphasized more often than before.

Further, the rule of law was described as the guardian of economic reform which could be relied on to combat corruption, to rein in local protectionism, and to protect consumer rights and intellectual property rights. Meanwhile, one also finds the call for a socialist spiritual civilization, which stressed the need to supplement law with virtue in governance. As will be shown, after being labeled and excluded as reactionary in the revolutionary ferment from the mid 1950s to the 1970s, "the rule of law" (re)emerged as a keyword of discussion, this time no longer as a target of attack, yet barely embodying any unified views of law. This ambiguity is manifested in the narrations of traditions in the discourses, which, however, remained to be oriented by the modern epistemic condition.

\section{Rule of law, not rule of man}

From the late 1970s on, the rule of man was more extensively critiqued as the opposite of the rule of law than previously. The frequent contrast between the two was a product of critical reflections on the Cultural Revolution. As Randall Peerenboom observes, the Cultural Revolution was seen by "rule-of-law proponents" as a period characterized by arbitrariness "where the views of top leaders and CCP policies trumped laws" (Peerenboom, 2002, p. 56). It is noteworthy that, although this revolution was branded as being led by the proletariat, what was blamed in the post-revolutionary critique was not such a leadership but rather the "fascist feudalism" pursued by the 
Gang of Four, the chief culprits of the Cultural Revolution. The conduct of the Gang was described as typical of the rule of man, a residue of feudalism. Following this line of argument, much criticism in the periodicals from the 1980 s to the 1990 s pointed to China's weak legal tradition, questioned the legal privilege of those in power, and called for the strengthening of the rule of law.

The problems of the Cultural Revolution, in terms of its destructive consequences in the realm of law and order, were famously critiqued in a manifesto authored by three former Red Guards. On November 10, 1974, this manifesto entitled "On Socialist Democracy and the Legal System" was posted in one of the busiest streets in Guangzhou, a major city in southern China. As some observers point out, "the central theme of the essay is...the rule of law and popular participation in politics" (Chan, Rosen, \& Unger, 1985, p. 10). In this essay which was soon declared by the authorities as "counter-revolutionary" and "the most reactionary article yet since Liberation" (p. 12), ${ }^{2}$ the authors charged that some "inside the Party [attempt] to practice a feudalistic despotism of socialist-fascism" (Li Yizhe, 1974/1985, p. 62). They condemned the rampaging legal nihilism seen in the Cultural Revolution:

...the main task of the Great Proletarian Cultural Revolution is to forge the revolutionary democratic spirit of the masses for self-liberation.... However, ... [the revolution] has not completed its task. ...the rule of law under socialism "suddenly did not operate," and what operated in its stead was "political power is the power to suppress." Across the length and breadth of the land, everywhere there were arrests, everywhere there was

2 The Communists called the 1945-1949 civil war as "the liberation war," and 1949 as the year of "liberation." 
suppression and imprisonment of the innocent.... It was a time of sheer lawlessness! This was a rehearsal for socialist-fascism in our country. (p. 63)

In tracing the roots of the tragedy, however, instead of blaming Party lines or the Marxist ideology of the state, the authors denounced "feudal rule," which was said to have "perpetuated for more than two thousand years" and "left its ideology firmly embedded in society." They then went on to state that "the vicious practices of the dictatorial arbitrariness of the feudal era were fixed firmly in the minds of the people as well as in those of the average members of the Communist Party" (p. 42). To learn from the lessons of the Cultural Revolution, the authors contended, yet in typical Marxist fashion, that "we must suppress those who suppress the people," "punish the 'mandarins' who have committed monstrous crimes, who violate the law while knowing the law" (p. 81), and eliminate any class of special privilege which "itself is fundamentally in opposition to the interests of the people" (p. 78).

In fact, the themes contained in this once counter-revolutionary essay later emerged in most post-Cultural-Revolution critique of the rule of man. An article in the People's Daily stated that legal nihilism prevailed in the 1960s and the 1970s, thanks to the dominance of the rule of man (Cui, 1981). A scholar maintained that the rule of man in the Cultural Revolution was essentially a product of the influence of feudalism, which fostered the cult of personality and commanded unconditional loyalty (Liu Shike, 1985). To eliminate the residual poisons of feudalism, it was argued, the ordinary people must be allowed to exercise oversight so as to contain the rule of man (Liu Shike, 1985; "Ba 
fa lü," 1985). Others stressed that, to be rid of the bad influence of the Cultural

Revolution and to march from the rule of man to the rule of law, Party members should take the lead in observing laws and no one should enjoy any legal privilege ("Ren da dai biao," 1982).

Similar themes also appeared in important post-Cultural-Revolution documents and speeches of the Communists, where the advocacy for "the rule of law," or "legal systems," was framed by the question of how to maintain Communist rule, the legitimacy of which was under question in the late 1970 s. $^{3}$ Senior Party leaders at the time even used phrases such as "the survival of the Party" to indicate the severity of the problem (Deng X., 1980b/1983, p. 358; Tsou, 1994, p. 115). To address this crisis, Deng Xiaoping focused on re-adjusting the way in which the Party ruled. Reflecting on the Cultural Revolution, Deng deplored the weakness of China's legal tradition and the influence of feudalism:

The privilege we are opposed to today is the right to...go beyond law.... The exercise of privilege [in the Cultural Revolution] is a phenomenon which shows us that the residual influence of feudalism has not been eliminated. The old China has left a lot of feudal and dictatorial traditions with very little heritage of democracy and legal systems.... Nobody should be allowed to interfere with the enforcement of law. (1980a/1983, p. 332)

To establish a stable and healthy leadership, Deng suggested, legal systems must be

\footnotetext{
3 To be sure, in the Communist documents, the term "legal systems" appeared much more frequently than "the rule of law." However, in the 1980s and the 1990s, many used the two interchangeably, although some did differentiate between them (Yu H., 1981; Xie B., 1994). And one can find an early usage of "the rule of law" in a 1979 Communist document (Xia, 1999, p. 143).
} 
strengthened which would not change simply as any leaders changed their viewpoints or switched their attention (1978/1984, p. 146); otherwise, Deng warned, failure to correct the style of leadership will "change the color of the Party and of the country" (1980a/1983, p. 333).

While Party leaders were preoccupied with maintaining Communist rule through a reform of leadership style, others contested autocracy on various grounds, yet the terms of critique remained aligned with Marxist conceptions. This can be seen in some articles published in the People's Daily between 1979 and 1980. Wang Liming (1979), the author of an early critique of "the rule of man," argued that this notion as a "reactionary" Confucian idea meant to act not according to law but in accordance with the will of one's superior, and thus was dangerous as it relied on the wisdom or the will of the state ruler. According to Wang, a major negative implication of this was that those who catered to the personal desire of the ruler would be easily put into positions of importance. Wang argued that classical Legalism, instead, was insightful in pointing out that the rule of law should be relied on to promote people with real talent, and to remove those who were only skilled at flattering. Wang's comments, in fact, were targeted at the Gang of Four, who had "trampled on the legal system" and "truly inherited the reactionary [rule of man of] Confucianism." In this context, the opposition between the rule of law and the rule of man was depicted as one between classical Legalism and Confucianism, one progressive while the other a pernicious influence of feudalism. 
The rule of law was also contrasted to the rule of man in more radical ways in the critique of autocratic rule, but the critics made a point of referencing Marxism in their comments. For example, Wu Daying and Liu Han (1980) suggested that "the theoretical basis" of Confucian rule of man was a type of "idealism that believes in the creation of history by heroes." The rule of law, on the other hand, was something that "could not be possibly accomplished in the feudal society," and was instead "one of the great historical achievements of the capitalist class," its constituent ideas including "natural rights, popular sovereignty, the separation of powers, universal suffrage, parliamentarism, and equality in front of law." As such, according to Wu and Liu, the rule of law was not so much a legacy of China's own as one imported. Wu and Liu were also quick to clarify, however, that the rule of law promoted by the capitalists only served bourgeois dictatorship; further, and to object to the rule of man was not to ignore the indispensable function of the Party; instead, laws in the system of the rule of law they advocated were to be drafted under the leadership of the Party. However, the authors emphasized, the rule of law in its nature rejected autocratic arbitrariness, which should be repudiated as Marx had long ago questioned the manner of governance in which the king was the system.

It is noteworthy that, in the articles examined for the 1980s, many discussed "the rule of law" as a heritage of China's classical school of Legalism, which was said to advocate sovereignty of law (Gu A., 1980; Liu Shike, 1985; Yu R., 1984), and fewer elaborated on the concept as a Western one (Wang Hongfu, 1983; Yu R., 1984). 
However, in the review of the rule of law, seen either as Legalist or as Western, Marxist terms of analysis were frequently employed. A typical phenomenon in this connection is the use of class analysis. It was often argued that neither the rule of law nor the rule of man ever transcended class politics (Wu W., 1980, p. 5). Thus, various conclusions were drawn concerning what specific classes the Legalist rule of law and the Confucian rule of man respectively served in ancient China (Wu W., 1980; Wang J., 1981). On the other hand, Western rule of law was as usual referred to as capitalist (Wu W., 1980; Guo H., 1980), but this time its "progressive" aspects recognized such as its repudiation of feudal despotism.

In fact, the attribution of the rule of man to Confucianism and the rule of law to Legalism was questioned by some who argued that such a categorization was an indiscriminate transposition of Western ideas onto Chinese reality. Yu Ronggen, a legal studies scholar, pointed out that the difference between "the rule of man" and "the rule of law" was initially articulated by ancient Greek thinkers and, thus, understandings of the two concepts needed to be based on the ways in which they were explicated in the West (1984). Regarding China's own traditions, Yu noted, Confucianism itself contained elements that were anti-rule-of-man. In contrast, Legalist ideas, by advocating strict enforcement of law, in fact only justified the imposition of repressive rule through law. Just as the ideas of democracy and science, Yu remarked, the rule of law was foreign to China. However, he stressed, the proletariat was the inheritor of all fine cultures of the mankind and, thus, socialist rule of law should learn from the 
"positive" aspects of ideas from the past (p. 22). It is interesting to note that, although Yu insisted that the Western categories of the rule of man and the rule of law should not be transposed to Confucianism and Legalism in China, he could not but return to these categories in his own evaluation of the two classical schools. In the meantime, just as Wu Daying and Liu Han (1980), while extolling Western rule of law, Yu felt obliged to declare the compatibility between his views and Marxism.

In the 1990s, reflections on the Cultural Revolution continued, with its lessons summarized as the prevalence of the rule of man and the abandonment of the rule of law (Bo, 1993; Peng C., 1994). In the discussions of the rule of man in this period, "feudal residues" remained a target of criticism (Ou, 1993; Wang \& Wang, 1994), and the method of class analysis continued to be used (Qiu, 1992). At the same time, one finds more explicit mention than in the 1980s of themes associated with Western liberalism. However, in this connection, one also sees various efforts to reconcile liberal conceptions with Marxist ideology.

For example, an author contended that both the Legalist rule of law and the Confucian rule of man served despotism, and that neither placed any limit on the power of the monarch. In contrast, socialist rule of law was to build a "check mechanism" to ensure the proper use of state power (Liu J., 1993, p. 8). In other articles, a similar argument about limiting state power was made in relation to the development of market economy which was set as a goal of the Party in the 1990s. It was claimed that the idea of the rule of man stood at the core of planned economy, which honored the supremacy 
of state power in coordinating resource allocation, production, distribution, and consumption; however, socialist market economy had the internal requirement that all economic activities be regulated by law and that the supremacy of law be respected (Jin, 1994, pp. 79-80; Xie B., 1994). Moreover, some argued that rights and the rule of law were the cornerstone of market economy (Xie B., 1994, p. 6), and that those engaged in market exchange should be granted ownership of the commodity being exchanged (Jin, 1994, p. 80).

Meanwhile, one finds the presence of Marxism in these talks on check-and-balance, the supremacy of law, and the ownership of commodities. In terms of the arguments about relying on the rule of law to limit state power, they were qualified by the critique that capitalist countries offered helpful experience in this regard but were hypocritical because they only served the rule of the bourgeois (Liu J., 1993, p. 8). Regarding rights and law in market economy, an author quoted Marx to justify his argument: "From the point of view of law, the sole condition of this type of [market] exchange is that everyone has the rights of ownership and disposal for his own products" (quoted in Jin, 1994, p. 80).

As Tsou Tang (1986) points out, the Cultural Revolution led many Chinese to the realization that the rule of man as a mode of governance must be rejected or disasters would follow (pp. 248-249). However, as can be seen, while the rule of law was promoted and other Western concepts were discussed, Marxist lines of thought were not at all abandoned. How, then, was "class struggle"-once the Marxist guideline of legal 
work-approached in the 1980s and the 1990s? I will turn to this question in the next section.

\section{Rights matter (II): Class struggle and/or human rights}

For many, the unlawful state of the "proletarian dictatorship" in the Cultural Revolution raised the questions of whether class struggle should be the line to follow and what was to be done to prevent large-scale infringement of rights from happening again. In the 1980s, the themes of both class struggle and human rights stood out in the discussions of the rule of law. In the 1990s, however, the notion of the class nature of law, or law as a tool of class dictatorship, came to be challenged more explicitly. At the same time, human rights protection was more often than before described as what should be pursued in order to realize the rule of law. The discourses on these apparently opposing themes - that is, class struggle and rights protection-hinged on questions of this type: How should Marxism and its practice be resituated in a society which is now increasingly disenchanted with "revolutionary" agendas? The need for reorientation, then, directed the ways in which various traditions were articulated, including those of the Communists, of the Nationalists, and of China's imperial past.

As has been discussed in the last chapter, in the early decades of Communist China, "the people" whose rights should be protected was meant to be distinguished from "class enemies"; at the same time, the occasional use of the term "human rights" was mixed with those of "the people's rights" and "citizens' rights" without clarifications. 
This ambiguity was carried on into the immediate post-Cultural-Revolution years in the mouthpiece People's Daily. While the use of "human rights" was limited, ${ }^{4}$ both of the other two terms were referred to, sometimes to justify the need to promote solidarity among the people as well as to strike against counter-revolutionaries (Wang G., 1981), sometimes to criticize "feudal consciousness of legal privilege" (Feng, 1982), other times to emphasize the supremacy of law ("Ren ren xue xi," 1982). In the circle of legal studies, it was also debated whether "equality before law" should be applicable to "the people" or to "citizens" (You, 1985). The lack of clear definitions may have in part stemmed from the ambiguity of the language on rights in several official documents and leaders' speeches of the time, where both "the people's rights" and "citizens' rights" continued to be talked about, but often without sufficient explications of what the two meant, whether they differed from each other, and how they stood respectively in relation to "class struggle." For example, Ye Jianying, the Chairman of the Standing Committee of the National People's Congress (1978-1983), avowed that the people's rights needed to be ensured to correct the wrongs of the Cultural Revolution which was carried out with the banner of proletarian dictatorship (Ye J., 1978/1984). However, an important Communist document of the time maintained that, in order not to repeat the chaos of the Cultural Revolution, socialist laws must become a tool both to protect the people's rights and to fight against class enemies ("Zhongguo gong chan dang zhong

\footnotetext{
4 The reference to "human rights" in the People's Daily will be discussed later.
} 
yang," 1981/1984). Other times, it was simply stated that citizens' rights protected by laws must be defended and not be encroached on ("Zhongguo gong chan dang di shi yi jie," 1978/1984; Deng, 1978/1983).

To a certain extent, this ambiguity reflected renewed thinking about the guideline of class struggle, and about the nature and purpose of law. While within the academia there were heated debates on whether or not law should be merely a tool for class struggle (Cui \& $\mathrm{Li}, 1998$ ), in a landmark Communist document which reflected on the problems and issues confronted by the Party since the founding of the People's Republic, it was explicitly pointed out that class struggle was no longer the priority concern although it would persist for a long time ("Zhongguo gong chan dang," 1981, p. 10). To be sure, the same document also claimed that one must remain vigilant against those hostile towards socialism (pp. 10-11); however, it clearly replaced class struggle with national economic development as the primary task of the Party (p. 9).

With the status of "class struggle" as the guideline for social development being relegated, the notion of human rights resurfaced as a laudable concept after the Cultural Revolution. Its reemergence, as some observed, was met by doubt and resistance of those who believed that class enemies should not be granted rights, and that socialist legality and the people's dictatorship should go hand in hand (Xu \& Min, 1998, p. 178). However, in most of the examined periodicals of the 1980s, the notion of "human rights" was not much challenged, but rather was cast as something that was worth pursuing or should be protected. For example, the People's Daily published two articles 
that made direct reference to "human rights." These articles were meant to inform mainland readers of the political situation in Taiwan, in particular to let them know how the spirit of the rule of law and human rights was violated by the Nationalist Party who controlled the island. They reported that the Taiwan authorities were criticized locally for the Curfew Law which severely restricted freedom of the public ("Zai Taiwan," 1982), and for expanding at will the power of the police ("Fei guo min dang ji," 1982). While the human rights condition in Taiwan was reported in the People's Daily as evidence of the repressiveness of the Nationalist rule, some also pointed to cases of human rights offences by police officers and Party cadres in the mainland of China (Jia, 1985; Tao Z., 1985). However, in certain instances, the protection of human rights was depicted as part of the Communist revolutionary tradition which accounted for the success of the Party and which should be "cherished and inherited" (Zhang J., 1984, p. 126). For example, Yang Yonghua and Fang Keqin (1984) pointed out how, during the Second World War, progressive "landlords, wealthy peasants, and capitalists" were "no longer indiscriminately treated as the target of [the people's] dictatorship," and were "granted the same rights as the working people" (p. 70). Such a practice, it was argued, helped the Party build its United Front into a stronghold in the fight against the Japanese.

To be sure, the theme of law as a tool for class struggle was not entirely absent in the 1980s. For example, when interpreting the relation between the rule of law and economic reform, both of which were viewed as new directions of Party work, an 
author cited the "Marxist legal theory" of the class nature of law to emphasize that law would be the most effective tool to fight against economic criminals (Gao, 1985, pp. 60-61). Other times, although "the class nature of law" was not directly referred to, certain notions reminiscent of the guideline of class struggle - such as to strike against "the enemies" or "the bad guys"- -were used to explain why socialist legality needed to be strengthened (Cui, 1981; "Dang yuan," 1983). In fact, the slogan of the day to promote "legal systems" or "the rule of law" was that "there must be laws to rely on; laws must be observed; laws must be strictly enforced; and violation of laws must be punished" ("Zhongguo gong chan dang di shi yi jie," 1978/1984, pp. 7-8). In an interpretation of the slogan, Deng Xiaoping (1980c/1984) pointed out that it was to stress the importance of not tolerating any counter-revolutionaries and holding onto proletarian dictatorship.

In the 1990s, however, the affirmation of "law as a means for class dictatorship" became increasingly rare, in both the mouthpiece newspapers and other journals. As the Party guideline of class struggle came under more explicit criticism, the rule of man tradition was again pointed to as the historical burden that had hindered the establishment of the rule of law in China. In a review on the development of China's legal construction, an author of the Chinese Academy of Social Sciences lamented the overemphasis on the class nature of law, which he believed resulted in the trampling of human rights in the Cultural Revolution (Chen C., 1994). Meanwhile, quoting Deng Xiaoping's critique of China's feudal legacy, the author suggested that only in a society 
which already had a good legal tradition could the rule of law be realized, and that China, however, was for long governed by the rule of man and thus lacked a fine foundation of law.

Similarly, Xie Hui (1995), a professor of law, unequivocally stated that while the rule of law had been a central preoccupation of Chinese legal studies, it was precisely the instrumentalist view of law that had obstructed the fulfillment of what was aspired. What stood at the core of this mentality of instrumentality, according to Xie, was the notion that law should be a tool for class struggle (p. 50). In explaining the danger of instrumentalist views that underlay the idea of the class nature of law, Xie remarked that,

Legal instrumentalism, in its essence, is a theory that strengthens the rule of man.... [It] on the one hand critiques the reversed social order in pre-capitalist societies, [where]...laborers who should enjoy the right to rule did not gain legal privilege but rather became the ruled, while...those who did not work...became the ruler. But, on the other hand, it [legal instrumentalism] is still constrained by the traditional mindset. What it has achieved is just to follow the traditional logic and to turn upside down the originally reversed world, thus creating...new social hierarchies.... In a sense, this is a theory tinted with feelings of revenge.... [As such, state] power is not subject to any limits... and rights are of little significance. ... unconstrained honoring of state power would only serve to popularize the rule of man. (p. 53)

This view was echoed by others (Cai D., 1996) and, in explaining the cultural roots of legal instrumentalism, Xie pointed to classical Legalism, which he believed promoted "rule by law" and attached importance to law as a tool but not to the supremacy of law (1995, p. 54). Xie maintained that Legalism should not be taken as an advocate for the 
rule of law, which requires the strengthening of the awareness of rights. ${ }^{5}$ Others, however, blamed the long-lasting influence of Confucianism (Zhao M., 1992). Contemplating on the question of why Confucianism had not given rise to the rule of law which was "required in the modern age," Zhao Ming noted that the classical school lacked critical considerations of rights as the ultimate value of law. Zhao argued that this Confucian legacy could be seen in the $20^{\text {th }}$-century China where "the theory of humanity was a taboo for the academia," being overshadowed by the theory of class (p. 99).

On the other hand, as the idea of class struggle became obsolete, the advocacy for rights protection grew stronger in the 1990s. While legal instrumentalism was challenged, many argued that the rule of law itself was an end to pursue, of which "rights" was an essential element (Zhu P., 1995; Xie H., 1995; Zhang G., 1995). However, the affirmation of the idea of human rights sparked contention over the nature of Marxism and its practice. Some argued that Marxism was in line with the idea of human rights (Guo D., 1994; Xie P., 1996), whereas others charged that it was Marxist conceptions that had turned Eastern European countries into dictatorship (Du G., 1994). Commenting on China's case, an author from the People's University remarked that Communist rule in fact inherited the despotism of its Nationalist predecessor (Du G., 1993), who atrociously trampled on human rights under the banner of "the dictatorship

\footnotetext{
${ }^{5}$ Xie's argument was a refutation of the widely accepted view, propagated by Liang Qichao in the 1920 s, that classical Legalism stood for the rule of law. For a brief discussion of Liang's view in this regard, see the section in Chapter 2 on China's legal tradition.
} 
of the majority" (p. 21).

While views varied on the question of whether or not Marxism supported liberal approaches to rights, some invoked China's past to defend the importance of rights protection and the rule of law (Guo D., 1994). In this connection, China's own traditions were portrayed, not as the pernicious feudal, but as something commensurable with Western liberal conceptions of rights. On the one hand, it was contended that the requirement of human rights was compatible with China's traditional emphasis on benevolence and universal harmony. It was pointed out that, although the ideal type of interpersonal relations in the Chinese conception of harmony was remote from the spirit of antagonism embodied in the Western idea of human rights, the two were in line with each other in their ultimate pursuit, that is, the general harmony of the human society. On the other hand, it was acknowledged that China's tradition lacked conceptions of individual independence and freedom, and thus should be supplemented by the spirits of human rights and the rule of law.

Despite the increased advocacy of human rights and the rule of law, however, some critics deplored that "the [Party] leadership's repeated emphasis on introducing the rule of law was primarily to promote economic development and business procedures, not political and civil rights" (Goldman, 2005, p. 179). In the next section I will turn to the ways in which the rule of law was articulated in relation to economic reform in China from the 1980s to the 1990 s. 


\section{Economic reform: The rule of law as the guardian}

Economic reform was twice a major part of the Party's proposed solution in the wake of political turbulence. In the late 1970s after the Cultural Revolution, apart from widespread social grievance against legal nihilism, China faced a series of problems such as low productivity and shortage of food resulting from the planned economy, as well as social disenchantment with the state ideology (Du R., 2005, pp. 97-98; Lieberthal, 2004, p. 246). Many started to cast doubt on the validity of Marxism, and on the superiority of socialism in comparison to capitalism (Tsou, 1994, p. 115). Reflecting on the history of the Republic, the Party declared that the "primary contradiction" of China's socialism was the increasing gap between the backward productive force and the growing material needs of the society. Economic development was thus taken as a new priority of the Party ("Zhongguo gong chan dang,"1981, p. 9). By the late 1980s, economic reform had raised the living standards of the Chinese, opened up the country to the world, and resulted in a less centrally controlled economy. At the same time, it had also given rise to corruption, inflation, as well as greater space for freedom of thought, all of which contributed to the outburst of discontent and the demonstrations in the spring of 1989 (Lieberthal, 2004, pp. 140-143, 146; Tsou, 1994, pp. 144-146, 149-153). The protests of 1989 finally led to military crackdown, which in turn cost the Communists their image as reformers, and threw further doubt on the viability of China's social system under the Party's leadership. The turbulence was also followed by 
international sanctions as well as the collapse of Communist rule in Eastern Europe. All this led the Chinese Communists to re-orient themselves, yet again mainly in economic terms (Lieberthal, 2004, p. 147). Thus, after a three-year standstill, economic reform was renewed by Deng Xiaoping's visit to Southern China in 1992, this time with the aim to establish a market economy with Chinese characteristics. The continued reform again brought about stunning economic growth, while also leading to extensive corruption, local protectionism, ${ }^{6}$ as well as growing awareness of rights.

When the rule of law was articulated in relation to economic development, a theme frequently appeared that the former was the guardian of the latter. However, what was to be specifically "guarded" for or against by the rule of law in fact followed several agendas which, albeit interrelated, reflected a variety of concerns. One finds a theme running through from the 1980s to the 1990s with respect to the importance of the rule of law for the fight against corruption and, thus, for the building of a favorable image of the Party and the government. In the 1990s, "the rule of law" was also drawn upon by some to promote the protection of rights in market economy, and by others to call for strengthened regulations over regional governments which developed local protectionism and undermined the Party's central leadership. In the various advocacies, one sees a range of efforts to define or redefine traditions, in either Marxist or other modern terms, some to reaffirm legitimacy or authority, some to cheer enlightening cases of rights protection, some to reclaim the relevance of lost heritage, and others to

"The problem of "local protectionism" encountered in reform will be briefly explained below. 
bemoan conservatism of the past.

As Lin Ruo, former Party secretary of the Guangdong province, points out, after economic reform was launched, corruption among officials and Party members emerged as a significant problem in the 1980s and grew even wilder in the 1990s, causing widespread discontent among the ordinary Chinese (Lin, 1993). Types of corruption ranged from illegal profiteering that took advantage of the dual-track price system, most active in the $1980 \mathrm{~s},{ }^{7}$ to bribery, embezzlement, and others that ran rampant in both the 1980s and the 1990s (Sun Y., 2004, p. 39). ${ }^{8}$ In the battle against corruption, however, the Communists sought to "class-ify" the problem, by referring to capitalism as the origin of the sin, and by portraying hardworking and thriftiness as the Communist tradition. According to them, corruption was one of "the rotten things that entered [China] after opening-up" (Deng X., 1993, p. 379). It was pointed out that, from the time it was founded, the Communist Party had laid great emphasis on fighting the influence of the exploitative class and corruption (Research Office of CCP Central Committee Documents, 1993, p. 185). However, it was lamented, after reform and opening-up, "some comrades...became indifferent to the good tradition of hardworking," and were "eroded by the outlook on life and the worldview of the

\footnotetext{
${ }^{7}$ The dual-track price system is "a part-plan and part-market system in which firms could price and sell their products in the market after fulfilling state output quotas" (Sun, 2004, p. 24). As Yan Sun explains, "corruption occurred...in sectors that manufactured or retailed goods and services on the two-track system, as [state-owned enterprise] managers now had discretionary power over the above-plan portions of those goods and services... [and] exploited price differentials and supply shortages as the primary means to acquire illicit wealth" (pp. 43-44).

${ }^{8}$ For detailed accounts of corruption in China's economic reform, see Sun (2004), Lieberthal (2004, pp. 202-203), and Lubman (1999, pp. 120-121).
} 
exploitative class," such as "the worship of money, hedonism, and extremist individualism" (p. 190). Deng Xiaoping warned that, if not paid enough attention to, corruption might "change the face" of the Party and of the country (1982/1983, p. 403). Interpreting Deng's words, some noted that anti-corruption was a key feature of "socialism with Chinese characteristics," its major difference from capitalism being that it aimed at not only economic prosperity but also social progress in all aspects (Research Office of CCP Central Committee Documents, 1993, p. 184). It was believed that whether corruption could be curbed had great influence on the degree of public trust in the Party (Gong C., 1981; Li G., 1993; Qing, 1996), and "socialist" rule of law was proposed as the solution.

Apart from corruption, trends of local protectionism also developed in economic reform, the curbing of which, some argued, also required the strengthening of the rule of law. As Tsou (1986) observes, the retreat of planned economy means "a much larger autonomy than before to respond to economic incentives", with which "individuals, collective units... and state-owned enterprises are encouraged to play a more active role and to take greater initiative in increasing their own earnings and thus in promoting economic development of the society" (p. 168). However, this enlarged autonomy had some by-products many found unpleasant (Lubman, 1999, p. 110). As local-level officials across regions competed more intensely to spur economic development in their respective jurisdictions, local protectionism took stronger hold. Such protectionism took many forms, such as alliances between regional governments and enterprises that 
obstructed nationwide cooperation (p. 104), local violations of national laws to attract investment (Shen G., 1995), and the protection of regional interests by local courts as a result of the influence of local governments (Lieberthal, 2004, p. 266; Han B., 1994). As some point out, centrifugal practices were in existence even before the reform (Du R., 2005, pp. 83-95), but by the 1990s they had become even more popular, epitomized by notions such as "policies from the above can be countered by tactics from below" and "economy needs developing while laws need loosening" (Tao W., 1994, p. 4; Hong, 1996). A deep cultural root of local protectionism, an author remarked, was the prevalence of the rule of man over the rule of law, that is, the tendency in which the will of those in office rather than law was taken as the guidance of work (Wu Jie, 1994). Under the influence of the feudal tradition of the rule of man, it was believed, professionalism was abandoned in favor of personal connections, which constituted the basis of unfairness. It seems ironic, however, that although the rule of man was identified as the fault, the power of the state and the Party was resorted to in the attempt to solve local protectionism. Some pointed out that fair competition could not be guaranteed by market itself but could only be ensured by a powerful state relying on law (Hong, 1996). Others related the authority of law to that of the Party, arguing that disrespect for the rule of law in fact weakened the Party, as state laws represented the will of the people and of the Party leadership; therefore, to strengthen the rule of law in economic development was to strengthen the authority of the Party at the center (Tao W., 1994). 
The rule of law was seen as essential not only for the combat against corruption and local protectionism, but also for the protection of the rights of "market subjects." Many pointed out the indispensability of the rule of law for the promotion of consumer rights (Zhu Y., 1993; Zhang Y., 1993; Xiao, 1996). An author introduced how the rule of law was implemented in the United States and Poland to protect consumers (Zhang Y., 1993). In response to China's enactment of the Consumer Rights Protection Act in 1993, a scholar argued that, while the direct objective of socialist market economy was economic development, the economic system also meant something deeper, that is, the rationalization of "rights structure." Thus, the promulgation of laws protecting consumer rights would be important for the speedy construction of socialist market economy (Li Songling, 1993).

Many lauded the action of Wang Hai, an ordinary Chinese who from 1995 on resorted to the newly enacted Act to protect his own rights as a consumer (Xiao, 1996; "Xiao fei zhe," 1996; Liu Yuanlongtao, 1997). Wang was most well known for purchasing counterfeit commodities and then suing department stores for selling them. He was once praised as the "protector of Chinese consumers" by Bill Clinton and "market scavenger" by Wu Jinglian, an eminent Chinese economist ("Wang Hai da jia," 2008). Some also argued that the "Wang Hai phenomenon" was a reversal of China's tradition of legal nihilism (Li C., 1998) or indifference toward law (Hu, 1996), and that Wang's defense for his own rights should be encouraged to "strengthen public belief in law" and "foster rights consciousness" (Li C., 1998, p. 5). 
While some saw Wang Hai's action as a subversion of the deplorable tradition which neglected law and rights, others believed that what Wang had done was only a betrayal of China's moral tradition, and was also an irony for the advocates of "modernization of the rule of law" (Liu M., 1998). Liu Muyan, a legal scholar, contended that, by intentionally purchasing counterfeit commodities and then filing lawsuits, Wang turned rights protection into a means of personal gain and social retaliation. He argued,

We should recognize that our nation's moral tradition is so rich that for thousands of years law was only a handmaid to morality. However, in the modern times, the [positions of] two have been switched..., creating a "legitimation crisis" for the moral order that had long dominated China. The social vacuum in which indifference towards law abounds and morality loses authority is the breeding ground of the Wang Hai phenomenon.... From a state instrument of the rule of virtue, law has shifted to another extreme, having fallen into or been vulgarized as a tool to satisfy personal material desire. $(1998$, p. 81$)$

Liu concluded that the Wang Hai phenomenon, albeit centered around rights protection, was a blow to those promoters of modernization who took the falling of traditional morality as the premise of the rule of law, and that, if the issue of morality was not addressed, the rule of law could only be an ideal the realization of which had to be postponed (p. 82). However, despite his charge that legal modernization was pursued without regard to the question of morality, Liu was not remote from those who he challenged, in taking the rule of virtue and the rule of law as respectively what stood for the traditional and the modern.

On the other hand, in the 1990s, property rights also became a focus of concern 
when the rule of law was discussed in relation to market economy. Admittedly, as Ronald Keith and Zhiqin Lin (2001) observe, in the Chinese context, "property law is one of the most confusing and disappointing chapters of contemporary legal development as it relates to the creation of a 'rule of law economy"' (p. 138). However, the call for the protection of property rights was more than sporadic, in which the mention of Marxism — which contests private ownership — was almost nowhere to be found. Many contended that market economy is an economy of property rights, which needed to be recognized and protected by laws (Chen S., 1992; Zhou X., 1993; Hong, 1996). Some focused specifically on intellectual property rights. For example, in an article in the People's Daily, Tian Jingzhao, former deputy mayor of the Hefei city, argued that legal protection of local brand names could not only help develop regional economy, but also benefit China's march into the international market (Tian J., 1995). In another case, Wu Jun, general manager of a regional trading company, authored an article published on the front page of the Economic Daily, in which he refuted those who blamed his company's act of registering numerous trademarks as speculation and unfair competition. Wu contended that market economy was an economy of the rule of law and, therefore, companies needed to protect their trademarks by law (Wu Jun, 1995). In addition, the need for the protection of intellectual property rights of foreign products was also noted. The People's Daily once published an article authored by Tsunao Hashimoto, former vice chairman of the Sony Corporation, who offered several suggestions for China's economic reform, including a call for more respect and 
recognition of intellectual property rights such as those of software technologies (Hashimoto, 1995). The foreign practice of protecting intellectual property rights, such as those in the United States, was also introduced (Wang D., 1995).

In explaining the lack of respect for intellectual property rights, legal scholars reflected on China's history and provided a list of reasons. They referred to imperial control of intellectual production (Xia \& Cai, 1997; Wei \& Lei, 1997; Li Y., 1998), the tradition of despising profit-seeking, and the "natural economy" in China's past which was thought to be an unfavorable condition for the cultivation of rights consciousness (Wang Q., 1997; Wei \& Lei, 1997). It is notable that, in articulating these traditions, the scholars did not agree with each other on all fronts. For example, some referenced Marxism to argue that rights consciousness was a product of the economic conditions of a society and, therefore, that the protection of intellectual property rights would be an impossibility in China until market economy was developed (Wei \& Lei, 1997); others, however, approached the state ideology critically and suggested that it coincided with the Confucian tradition of strict ideational regulation, leading the Communists in China to confer intellectual rights only to the state for purposes of control (Li Y., 1998). Nonetheless, one finds a common pathos behind the various arguments, that is, an urge for liberation from traditions and for the march toward modernization. As a legal scholar commented on the transplantation of "advanced" intellectual property laws in China as "a backward country that lacks legal traditions":

China has an old culture, but it lacks modern legal consciousness and 
institutions. However, modern market economy, according to Weber, must be regulated by rationalized laws. China is in an age which witnesses the surge of globalization or internationalization, as well as the omnipresence of modern science, technology, and market power, and it therefore needs to understand and use modern legal systems to regulate its society. This is a lesson that was already learnt at the time of the Opium Wars. (Li Y., 1998, p. 115)

Another author, on the other hand, rejoiced at the growth of "market economy consciousness"-including that of property rights-among Chinese intellectuals. He claimed that, as "a deepening and enrichment of the sense of subjectivity of the intellectuals," the new consciousness "spurts as the intellectuals broke away from the conservatism, parochialism and isolation of natural economy, and changed their historical bias that the literati should not be engaged in business" (Wang Q., 1997, p. 91). However, "despite the favorable domestic and international environment for the legal protection of copyrights in our country," others pointed out, "we must cool-mindedly recognize that, as we are burdened by traditional cultures, more hard work and efforts are required on the road of socialist market economy and modernization!" (Wei \& Lei, 1997, p. 58).

However, although the rule of law was taken as the guardian of economic reform, some questioned the sufficiency of the rule of law in addressing all problems that occur in a market economy (Peng, H., 1994). The concern about the limits of law, for example, can be seen in some discourses on rights protection, where attention was drawn to the issue of morality and traditional rule of virtue. In the next section, I will discuss how, in the call for a socialist spiritual civilization, merits and problems of the rule of law and 
those of the rule of virtue were articulated.

\section{The construction of socialist spiritual civilization: The rule of law and/or the rule}

\section{of virtue}

The call for the construction of a socialist spiritual civilization can be traced back to the late 1970 s and the early 1980s, when the Party leadership stated that both material development and the promotion of virtue were to be pursued in the project of socialist modernization ("She hui zhu yi jing shen wen ming," 2003). The advocacy of spiritual construction, along with the economic success of the East Asian countries and regions influenced by Confucianism, also renewed interest in China's ancient schools of thought (Chen Bohai, 1986; Chen Z., 1988). In the 1980s, intellectuals' views about the merits of "the rule of virtue," taken as a Confucian idea in contrast to the rule of law, ${ }^{9}$ were at best mixed - this was so partly because, as has been discussed, reflections on Cultural Revolution had produced vast doubt and critique of "the rule of man," which was often seen as a synonym of the rule of virtue $(\mathrm{Ni}, 1986 ; \mathrm{Wu} \mathrm{S} ., 1989)$. However, as some observe, the Cultural Revolution and the economic reform launched afterwards have also led to social disenchantment with the Communist ideology, a growing vacuum of faith, as well as the a society-wide pursuit of material wealth and personal gain (Lubman, 1999, p. 121; Liu \& Zhang, 1994). As a result, the term "the rule of virtue"

\footnotetext{
9 According to Yang Liuqiao (1983), Confucian "rule of virtue" emphasizes benevolence, which implies that the ruler of a society should care about the people, and that moral cultivation instead of legal punishment should be the primary tool of governance.
} 
enjoyed a revival in the 1990s, this time almost standing on an equal footing with "the rule of law" and often viewed as an integral part of socialist spirituality. ${ }^{10}$ However, it is noteworthy that the term "the rule of virtue," which is thought to be Confucian, is in fact not even found in the Ci Yuan (Sources of Words) which collects classical words. Just as "the rule of man," "the rule of virtue" is a modern conceptual construct that has been used to depict Confucianism in particular and China's imperial governance in general. As such, the discussions on the rule of virtue in Communist China were not so much nostalgic moves to return to the past as a continuation of the modern construction of China's traditions.

Although the advocacy of the rule of virtue was quite explicit in the 1990s, the Party's call in the 1980 s for socialist spirituality was not so much praise for Confucianism. Rather, one finds Marxist ideas underlying the Party's conceptions of law and virtue in the promotion of spiritual construction. In the "Resolution of the Central Committee of the Party on the Guidelines of Constructing Socialist Spiritual Civilization," the basic task of the spirituality project was defined as "to cultivate socialist citizens with ideals, virtue, knowledge, and discipline" ("Zhong gong zhong yang guan yu she hui zhu yi," 1986). For the Resolution, the term "discipline" explained the linkage between law and socialist spirituality. The document claimed that socialist spiritual civilization sought to realize a high level of democracy, but that such a

\footnotetext{
${ }^{10}$ To avoid repetition in wording, "socialist spiritual civilization" and "socialist spirituality" will be used interchangeably.
} 
democracy could not be separated from law and discipline. As it stated, laws must be known and observed, and the people's dictatorship must be upheld so that law was relied on to combat enemies who sought to undermine the socialist system.

On the other hand, for the "virtue" mentioned, the 1986 Resolution explained it as "socialist" or "Communist." Specifically, it meant "to serve the people whole-heartedly," "to obey orders of the organization one belongs to," "to be devoted to serving others without pursuing personal interests," and others (Deng X., 1980b/1983, p. 367). For the construction of socialist spirituality, the promotion of such "revolutionary traditions" was meant to resist the harmful influence of not only the feudal residues such as those supporting despotism and legal privilege, but also "capitalist rotten ideas and social systems" the beliefs in which had crept into China after its reform and opening-up ("Zhong gong zhong yang guan yu she hui zhu yi," 1986). ${ }^{11}$ As Deng Xiaoping (1980b/1983) saw it, Party members, in particular senior cadres, should take the lead in practicing Communist virtue; otherwise, "if we disarmed ourselves spiritually, how were we to educate the youth, to lead the country and to guide the people in the construction of socialism!"' (p. 367).

The Party leadership's call for spiritual construction and socialist/Communist virtue, although not meant to revitalize Confucianism, nonetheless aroused intellectual interest in the study of China's classical schools of thought in the 1980s. Just as the 1986

\footnotetext{
11 The Resolution did not specify what was exactly meant by "capitalist rotten ideas." But it did state that, to support China's economic reform, socialist virtue stood in opposition to the worship of material wealth and to any behavior that benefited oneself to the detriment of others.
} 
Resolution, many intellectuals considered the issues of both law and virtue in their discussion of socialist spirituality. Comparative evaluation of the rule of law and the rule of virtue in academic journals was mainly carried out along two lines. The first was about the relations between classical Confucianism and Legalism (Yang L., 1983; Zhang H., 1983; Li S., 1988), the second about those between Confucianism and what was called "modern rule of law," including both capitalist and socialist ones (Ma N., 1984; Chen Z., 1988). In these discussions, views varied with respect to the value of the rule of virtue. However, Marxist class analysis was intertwined with the Western liberal contrast between the rule of man and the rule of law in most accounts. In terms of the relations between Confucian rule of virtue and Legalist rule of law, some stressed the similar nature of the two as both serving feudal despotism or "the rule of man" (Xie B., 1982; Ni, 1986), which others contested (Chen Bohai, 1986). Regarding the relations between the rule of virtue and modern rule of law, some cast a doubtful eye on the former in particular and on Confucianism in general, contending that the classical school of thought was incompatible with modern rule of law because it supported social hierarchies and the supremacy of the power of the feudal monarch (Ni, 1986; Chen Z., 1988). However, others suggested a more "critical approach" that looked at both the "backward" and the "progressive" aspects of the Confucian idea of governance by virtue (Ma N., 1984; Chen Bohai, 1986). ${ }^{12}$ While being viewed as serving the feudal ruling class in the past, Confucianism was praised for its insight about how to avoid

12 The notions of "the rule of virtue" and "governance by virtue" were often used interchangeably. 
tyranny, that is, the Confucian advice that virtue should be taken as the primary means of governance whereas law and punishment as a supplementary one (Ma N., 1984, pp. 103-104).

In the 1980s, although the Party Resolution promoted socialist/Communist virtue, it made no mention of "the rule of virtue." Meanwhile, some academic journal articles echoed what was said about "Communist virtue" in the Resolution (Zhang Hao, 1983). However, in the 1990s, while the notion of Communist virtue again appeared in a new Resolution of the Party on socialist spirituality passed in 1996, it was not to be found in most of the journal or newspaper articles on related topics. ${ }^{13}$ The new 1996 Resolution repeated the basic definitions of socialist spiritual civilization provided in the 1986 Resolution, reiterating that Party members should be moral examples, and at the same time affirming the relevance of socialist spiritual construction in China's market economy ("Zhong gong zhong yang guan yu jia qiang," 1996). The 1996 Resolution did not specifically mention "the rule of virtue," just as in the old Resolution. However, the term became a buzzword frequently talked about along with the rule of law in both the mouthpiece People's Daily and academic journals.

It should be noted that concerns about moral degradation pervaded the discourses on virtue, law, and socialist spirituality in the 1990s. The 1996 Party Resolution deplored that moral cultivation was not paid enough attention to in the $1980 \mathrm{~s}$ and, thus,

13 This is so for the sample articles analyzed. Also, this does not mean that the mentioning of upholding Communist beliefs in general in spiritual construction was absent. See (Jiang L., 1996; Su T., 1996). 
in economic reform, there arose the worship of money, hedonism, selfish individualism, and dishonest business practices; meanwhile, it was stated that the spread of corruption within the Party had done great harm and would undermine the sustainability of the Party’s leadership ("Zhong gong zhong yang guan yu jia qiang," 1996). A deputy of a municipal People's Congress stressed that market economy should not only be an economy based on the rule of law, but also be an "economy of virtue," which required "public morals" (Yuan Y., 1995, p. 5). The fellow citizens of this deputy made the appeal that market economy should not be a breeding ground for shoddy-counterfeit products, vandalism, and pollution. A scholar lamented that, after Confucianism had been overthrown as "a tool for feudal rule," no other new "moral mansion" had since been established and Marxist views of ethics had not yet reached into the heart of the Chinese; as a result, a whole generation who lost their spiritual home developed a sense of moral nihilism (Zhang Hua, 1994, p. 7). Similar outcry could also be found in other academic journal articles (Liu \& Zhang, 1994; Zhang, D. 1994a).

With respect to what to do to counteract moral degradation, many pointed to the importance of relying on the cultivation of virtue in addition to the rule of law. General mention was made about the necessity of combining the rule of virtue, or moral cultivation, with the rule of law (Chi, 1996; Jiang L., 1996; Shen Z., 1996), with some referring to Singapore as an example of success (Cheng, 1994). At the same time, however, some authors stressed the value of the rule of virtue in particular. It was argued that the rule of law had not succeeded in establishing moral values and thus 
Confucianism, with its emphasis on virtue, should be "critically inherited" (Zhang, Hua, 1994, p. 7). Zhang Dainian, a professor of philosophy, contended that the classical schools of Confucianism and Legalism one-sidedly emphasized the function of virtue and law respectively but in fact the two should be combined (Zhang, D., 1994b). Nonetheless, Zhang continued to point out, although it was known to all that market economy needed law, law itself needed the aid of moral cultivation. As he explained, virtue was about discipline from within, whereas observation of law was about discipline from without; "if one does not have the spirit of self-discipline but only relies on discipline from outside, that discipline would not last long" (p. 5). Another author even took such arguments further, stating that "the rule of virtue is a wiser strategy of governance than the rule of law," because the former "disciplines one's mind" and "treats the deep root" of social problems, whereas the latter merely "disciplines one's conduct" and thus "only treats the symptom" of problems (Peng, H., 1994, p. 94). In fact, it is striking how these comments, which appeared in contemporary Communist China, were reminiscent of the remarks by Liang Shuming-a "counter-revolutionary" named by Mao Zedong - who argued about half a century ago that the difference between internal and external control was an essential difference between the Chinese and the Western modes of social regulation.

This way of contrasting virtue and law, which was earlier used to compare China with the West, was ironically also followed by those who expressed reservation about the rule of virtue in particular and about Confucianism in general. A list of concerns 
behind the doubt about the rule of virtue can be found in an article authored by Guo Fengzhi (1994) published in an academic journal. Guo agreed that Singapore was a good example in terms of the combination of the rule of law and the rule of virtue; however, he contended, what Singapore put more emphasis on was in fact the former rather than the latter and China should follow suit. According to Guo, this was so primarily because the rule of law represented "the iron fist" whereas the rule of virtue, relying on self-discipline, stood for "the soft hand" (p. 18). Thus, the former had better enforceability and effectiveness for the construction of spirituality. In particular, the rule of law was of greater importance because of the following: social disorder resulting from moral nihilism could only be corrected with something enforceable; the population of China was large but "of low quality," especially lacking respect for law, and, thus, the governance of such a population required enlightenment about "law consciousness"; finally, the growing migrating population with the accompanying rise in crime rate in economic reform meant the necessity of resort to the heavy hand of law (pp. 19-20).

On the other hand, in terms of the critique of Confucianism in general in contrast to the rule of law, Hao Tiechuan, a professor of law, argued that Confucian pan-moralism should be cautioned against in that it was characterized by the naïve belief that a society with mere selfless virtue but without external discipline of conduct could possibly exist (Hao, 1996). According to Hao, the rule of law could not be based on the conception of benign human nature because "law essentially is the representation of the will of the ruling class" and, "given that class is the product of the system of private ownership," 
human nature thus developed "cannot be entirely benign" (p. 26). The function of the rule of law, according to Hao, was to reward human good by ensuring civil rights, and to guard against human evil by punishment. Hao pointed out that the rule of law and Confucian pan-moralism stood in opposition to each other also because the former believed in the supremacy of law and the protection of rights, especially political rights, while the latter primarily honored "economic rights of subsistence," which in effect granted privilege to the ruler (pp. 26-27). As can be seen, apart from the "internal versus external" approach of contrast, Marxist terms such as class and other Western concepts such as rights were also mixed with each other in the critique of Confucian moralism.

\section{Traditions in post-revolution reorientations of "the rule of law"}

Compared to the first few decades of the People's Republic, "the rule of law" in the 1980 s and the 1990s was not as politically controversial, yet the talk about it not any less polemical, serving a variety of potentially competing agendas. In the $1980 \mathrm{~s}$, the rule of law surfaced as an important concept in the critique of the Cultural Revolution and of the rule of man. It was thought to be indispensable for establishing a healthy political order and for sustaining the legitimacy of the Party. At the same time, as the Party promoted economic reform, the argument for class struggle continued on as a noticeable theme in the discourses on law but gradually lost currency, its relation with the talk about rights protection remaining ambiguous. In contrast to class struggle which was less emphasized, corruption within the Party that arose in the reform became a major 
concern, and the rule of law was taken as a solution to the problem. Furthermore, the Party advocated the construction of socialist spirituality in parallel with economic development, requiring that laws be observed and that Party members practice Communist virtues. The call for spirituality also generated discussions among intellectuals with varying conclusions about the merits of rule of virtue in contrast to those of the rule of law.

Some themes were carried on into the 1990s, such as the criticism of the Cultural Revolution and of the rule of man, the call for the rule of law to fight corruption, and the advocacy for the combination of law and virtue in the construction of socialist spirituality. Meanwhile, in the 1990s, the idea of law as a tool for class struggle came to be challenged as instrumentalist; on the other hand, the rule of law was more explicitly lauded as an end itself. At the same time, when articulated in relation to market economy, the rule of law was also seen as important for countering local protectionism and ensuring consumer and property rights. On the level of spiritual construction, while it was widely argued that the rule of law should be supplemented with the rule of virtue, such an advocacy was also questioned.

While the revolutionary flavor in the first few Communist decades stands in stark contrast to the moderation and revisionism in these later periods, both are evidence of how traditions are contingently constructed as a measure of China's reorientation under the modern condition. Although "the rule of law" re-emerged after the Cultural Revolution as a legitimate notion, the purposes for which it was invoked were anything 
but unified, leading to reformulations of traditions on various fronts.

It can be seen that the rule of man, a mode of governance attributed to China's past only in its modernity, remained an object of critique, yet one finds different interpretations of it which were driven by different agendas. Unlike previously when it was viewed as incongruent with revolutionary discipline and thus detrimental to the consolidation of the new state, the rule of man was taken in the 1980s and the 1990s as a tradition to be blamed for the Cultural Revolution, legal instrumentalism in Marxism, and local protectionism in China's socialist economy. In these accusations, while the rule of man tradition was still seen as one that promoted feudal privilege, it was also depicted as one that fostered unconditional loyalty to despotism and honored state control, one that did not grant any rights to commoners in a society, or one that functioned in favor of personal connections instead of according to law. Thus, while earlier the rule of man was condemned for not being amenable for establishing a socialist state, later it was again criticized as the root of many problems that arose in socialist China, even for the movements, policies, and ideologies that were once upheld by the new state. As such, the rule of man stood as a classical target commonly pointed at when it was believed that "historical reasons" should be blamed for social illnesses. This, of course, did not happen without reasons, one of which, arguably, was that "the rule of man tradition" long bore a stamp of backwardness as a modern conceptual construct opposed to the rule of law. 
Although the rule of man was often thought of as a Confucian idea, ${ }^{14}$

Confucianism itself was not unanimously censured, especially due to the "revival" of the notion of the rule of virtue. However, the terms in which "the rule of virtue" was appraised were by no means without Western influence, as the widely followed distinction between virtue as inner control and law as external control had long been a way to differentiate China from the West.

To give another example of the impact of the modern epistemic condition, while many came to acknowledge the importance of protecting rights, the legacy of Confucianism in this connection stood as an object of contention, the debate about which was yet based on a foreign idea. In the critique of legal instrumentalism, some raised the question of why Confucianism had not given rise to the rule of law, and an answer was offered that it was a tradition that lacked recognition of rights. Similarly, pan-moralism void of rights was ascribed to Confucianism when the latter was portrayed as the embodiment of the rule of virtue; the classical school was also thought to be a cultural origin of poor protection of intellectual property rights as it advocated state ideological control. On other fronts, however, Confucianism or its emphasis on morality took on a progressive face: its ultimate goal was stated as commensurable with that of Western confrontational conception of rights, both being the pursuit of social harmony; also, others reminded that, as China's traditional law was an instrument

${ }^{14}$ As has been discussed, some also associated the rule of man with Legalism, but in the main it was more often taken as a Confucian tradition. 
subordinated to the rule of virtue, modern Chinese rule of law and rights protection should no longer be demoted into a means of personal material gains and, therefore, morality should not be pushed aside as the foundation of law. Despite their differences, however, these views share a common basis on which evaluations of Confucianism were made, that is, the idea of rights, which yet was once alien to the Chinese. In fact, the origin of quan $l i$, the Chinese term for "rights," bears witness to the once extraterritoriality of the notion. As Lydia Liu (2004) points out, as an "invented neologism" (p. 125) in the Chinese translation of Henry Wheaton's Elements of International Law, quan li emerged in the $19^{\text {th }}$-century China as an "unwieldy coinage" (p. 126) yet "the best of necessity" according to the translators (p. 128). The characters of quan, standing for power and domination, and $l i$, meaning profits, were "purged" of their "earlier connotations" and combined to introduce a novel word with "positive meanings" and "a very new concept into Chinese political discourse" (ibid.).

Classical Legalism was also approached with a Western reference when it was discussed whether this school of thought upheld the rule of law. This has been a question long debated since Liang Qichao's monumental Western-inspired thesis which, as has been mentioned, used the conceptual categories of "the rule of man" and "the rule of law" to classify classical Chinese thought. In the 1980s and the 1990s, the discussion about the essence of Legalism was involved in various critiques of Communist practices. For some, ancient Legalists possessed insights about the benefits of ruling according to law, and Legalism was the opposite of Confucian rule of man 
which led to tyrannical arbitrariness in the Cultural Revolution. As such, to adopt the rule of law while discarding the rule of man was less an embracing of foreign concepts than a gesture of re-affirming one indigenous tradition against another. Such a positive reading of Legalism was disputed by others, who argued, for example, that Legalism featured instrumentalism which was inherited in the idea of law as a tool for class struggle. In this interpretation, Legalism was an accomplice, rather than a challenger, of the rule of man.

The salience of ideas of Western origin as evaluative criteria can also be seen in the ways in which more recent traditions were portrayed. The issue of rights was prominent when the Nationalists were denounced and the Communists extolled: the People's Daily reported the human rights condition in Taiwan to uncover the repressiveness of the Nationalist regime, while some mainland scholars praised the Communist policy of respecting rights, such as that adopted in the anti-Japanese war, as a cherishable revolutionary tradition. Others, nevertheless, remained critical toward the political movements and slogans in the early decades of the People's Republic, comparing the Communists to the Nationalists in their tyrannical approaches to rights. On a different level, Marxist ideas as another stream of Western conceptions were employed when the Chinese revolutionary tradition was distinguished from the capitalist one, the latter being depicted as decadent in its avaricious pursuit of profits; thereby, the root of corruption in China's socialist economy was identified as "theirs", and legitimacy was extended to the building of a socialist spiritual civilization. In a reverse trend, however, 
while Marxism remained the official ideology, notions associated with it such as the class nature of law and Communist virtues came to be less applauded in the 1990s than before.

However, although the idea of class struggle was questioned, Marxism underlay the discourses about several other themes related to the rule of law from the 1980s and 1990s. Many arguments about the rule of man versus the rule of law were made with the support of Marxist ideas, such as the class nature of the feudal rule of man, the critique of capitalist rule of law, and others. Class analysis was also employed in the criticism by some of the rule of virtue in comparison to the rule of law. Even the promotion of concepts often viewed as liberal democratic, such as limiting state power and property rights, was articulated with Marxism in the background. However, it is also noteworthy that, in the accounts where Western liberal concepts were referenced or affirmed, reconciliation efforts were often attempted in order to show that Marxist lines were equally relevant or important.

Some may contend that the Marxist ideas embedded in these discourses did not reflect the true beliefs of those who referenced them, or that Marxism was simply cited as a strategic choice to ensure the "political correctness" of one's comments. Such a statement, in fact, is not easy either to be disputed or to be vindicated. However, it needs to be recognized that, even if Marxist lines of argumentation merely served rhetorical purposes, their presence demonstrates the dominance, although vitiated to some extent, of Marxism in the discursive field as the orthodox. 
Others may argue that, despite the domination of Marxism, the legacy of China's past can be seen in certain discourses which apparently relate either to Marxism or to liberal democracy. For example, they may point out, the requirement that Party members take the lead in practicing Communist virtues resembled the Confucian call that the ruler be a moral example for the society in general. Moreover, some may argue that much that was said to compare the rule of virtue with the rule of law-even for certain arguments that valued the rule of law-showed the Confucian understanding of law as punishment and coercive social control. They may contend that, even though the contrast between internal and external control was one made to distinguish China from the West, it was made only because Confucianism indeed and unequivocally advocated moral cultivation more than law and punishment as the means to regulate social conduct. Although the validity of these arguments should not be denied, however, one should also note their epistemic foundation. While Confucianism did contain teachings about virtue and moral leadership, the idea that the essence of Confucianism is "the rule of virtue," as opposed to the rule of law, is but one among the many readings of the classical school that only emerged in modern China.

In fact, the idea that Confucianism is the tradition of China would be challenged by those who see Legalism as what truly dominated China's imperial era. Those in this latter camp may identify the continued existence of Legalist lines of thought, instead of Confucianism, in socialist China. For instance, they may point out that the slogan in the 1980s for legal construction, "there must be laws to rely on; laws must be observed; 
laws must be strictly enforced; and violation of laws must be punished," can be seen as showing the Legalist belief in the effectiveness of law as a tool for social control. In the anti-corruption discourses, some stated that the rule of law was superior to self-discipline as the former offered more enforceability--this may then be read as a Legalist argument against the Confucian idea of moral cultivation as the primary tool for social governance. Or, some may conclude, in terms of seeing law as a means of social control while neglecting to explore any internal value of law itself, the Legalist legacy converged with that of Confucianism, both of which can be seen in the legal instrumentalism in socialist China. Despite all these observations, however, it is noteworthy that the idea of instrumentalism itself, whether ascribed to Confucianism or Legalism, would be unfamiliar to both ancient Confucians and Legalists. Many such modern ideas, which took shape under China's modern condition, continue to underlie the depictions of traditions in the $21^{\text {st }}$ century, yet for varied purposes and in diverse fashions. 


\section{Chapter 6 Contemporary languaging of the rule of law: New waves in discourse}

\section{shifts}

In the first few years of the $21^{\text {st }}$ century, the semiotics of "the rule of law" in China was complicated by its official endorsement. In 1997 , the $15^{\text {th }}$ National Party Congress announced that China was to pursue the rule of law under the leadership of the Party. In 1999, China's Constitution was amended to add the national goal of building a socialist rule-of-law state. ${ }^{1}$ Then, another Constitutional amendment in 2004 declared that the state respects and safeguards human rights, which was seen as a major development for the rule of law in China. The popularization of "the rule of law" in this period can be attributed to a number of causes. These include, first of all, concerns about widespread corruption among officials and Party cadres in China's transition towards a "socialist market economy." While it increased social autonomy, China's economic reform also created opportunities of "rent-seeking" for those in office. In addition, uneven development resulted in marked social inequality by the late 1990s: the rural areas were far less developed than the cities; in the urban areas, disparity in income and social

\footnotetext{
${ }^{1}$ The first paragraph of Article 5 of the Constitution now reads, "the People's Republic of China governs the country according to law and makes it a socialist country under rule of law," as is translated by Chinalawinfo, a legal information service affiliated with the Law School of Peking University. It is noteworthy that one of the official translations of the provision reads, "the People's Republic of China governs the country according to law and makes it a socialist country ruled by law" (The Constitution, 2003; italics added). But in China Daily and Beijing Review, both state-run mouthpiece media in English that are seen as official sources of information about China, the term "rule of law" is used in translation. Numerous scholars also see fa zhi (the original Chinese term used in the Constitution and in various discussions) as the linguistic equivalent of the rule of law in English (Peerenboom, 2002; Xu X. \& Song, 2005). The difference in translation indicates nothing less than the complexity of the connotations of $f a z h i$ in China.
} 
benefits also struck some hard, especially those from the countryside who rushed into cities to sell their labor, and those who suffered from the restructuring of state-owned enterprises. Unbalanced development, coupled with the public perception of a corrupted officialdom, led to social tensions which posed threats to social stability. It was under such circumstances that many turned to the rule of law as a solution. Further, as the development of market economy encouraged the pursuit of material gain and thus created a spiritual vacuum, social belief in Marxism as the state ideology was undermined, which pushed the Party to seek new ground for legitimacy of its leadership. Ideological diversity among Chinese intellectuals was also noteworthy. As Merle Goldman (2005) observes, “diverse ideological groups within the establishment...not only debated relatively freely among themselves, but also challenged the party's policies" (p. 95), particularly on issues concerning "serious social dislocations, increasing inequalities, and rampant corruption unleashed by China's economic reforms" (p. 96). Moreover, as its economic achievements grasped the attention of the international community, China also attempted to build a positive image in the world, one that would present China as a peaceful country advocating harmony and standards of a good society that the world recognized. All this created networks of discourses in which "the rule of law," despite its constitutionalization, was debated for both old and new agendas.

As Randall Peerenboom (2002) points out, the official advocacy for the rule of law was in part an effort at legitimizing the rule of the Party (p. 60). At the same time, "the public endorsement of the rule of law fosters new norms that provide the basis for 
challenging the Party and the government" (p. 111). As will be shown, in the 2000 s, the order of discourse on the rule of law in China contained ideas such as anti-rule-of-man and upholding the rule of virtue, oversight, rights protection, and building a "socialist harmonious society." In the articulations of the rule of law in relation to these topics and themes, some were oriented toward sustaining the legitimacy of Party rule, while others championed ideas in ways that either explicitly or potentially contested the existing social system. The complexity was translated into the ways in which traditions were constructed in this period.

\section{The rule of virtue}

The rule of virtue was officially endorsed by the Party in the 2000 s as a mode of governance parallel to the rule of law. On the one hand, this can be seen as part of the effort of Jiang Zemin, General Secretary of the Party (1989-2002), to establish his personal political legacy (p. 224). On the other hand, as Peerenboom observes, "the ruleof-virtue policy is another in a long string of campaigns to change the moral character of citizens and officials" (p. 237), especially to address problems such as growing corruption and rising moral nihilism. However, while the promulgation of the rule of virtue as a supplement of the rule of law suggested that the state be the primary entity to correct wrongs by the use of both law and virtue, such a view was also contested and the rule of virtue was seen as being dangerously close to the rule of man.

The advocacy of the rule of virtue in the 2000 s displayed a degree of continuity with 
the discourses in the 1990s. One sees in the advocacy the promotion of

Communist/socialist virtue (Luo G., 2001; Wu G., 2001), the emphasis on Party members and cadres to behave as moral examples (Hou, 2001; Jiang G., 2001), and the significance attached to virtue which was promoted to address perceived moral degradation in market economy ("Fa zhi," 2001; Liu Yuchun, 2002; Wang Zhongfu, 2001). However, it was at a meeting in 2000 on improving the "ideological and political work" of the Party that Jiang Zemin, then General Secretary of the Party, formally addressed the relations between "the rule of law" and "the rule of virtue" and described the latter as a priority for the Party. As Jiang states,

Law and ethics, as parts of the superstructure, are both important means to maintain social order and to regulate people's thought and conduct. They relate to and supplement each other. The rule of law regulates the conduct of social members through its authoritativeness and by enforcement, while the rule of virtue relies on the power of persuasion and inculcation to heighten the level of thought and ethics of social members. Standards of ethics and law should be combined to function together. To build a socialist system of virtue that adapts to the development of socialist market economy is extremely important and should be worked on as a priority. The construction of socialist virtue must be guided by Marxism-Leninism, Mao Zedong's thought, and Deng Xiaoping's theories... The whole Party and the whole society must work together...to make it [socialist virtue] the standard of conduct that is recognized and voluntarily observed by all in the country. (Jiang Z., 2000)

Jiang identified several factors which he believed pointed to the necessity of strengthening the ideological and political work of the Party, of which the rule of virtue was to be an integral part. These factors included the "crisis in the belief system" among both ordinary Chinese and Party members that was triggered by the disintegration of the 
East European socialist block, the volatility and diversity of people's ideas that intensified as a result of economic reform, as well as the libertarianism, centrifugalism, and hedonism that emerged in the pursuit of a market economy. Jiang noted that, in the process of reform, more solid work had been done in the development of economy while less had been achieved in "ideological and political work." As a result, "now it is not so easy to unify solidly the ideas of both the cadres and the masses." To address the issue, Jiang pointed out, it was important to supplement the rule of law with the rule of virtue. As he stated in another occasion, "in our construction of a socialism with Chinese characteristics and our development of a socialist market economy, we must unremittingly strengthen the building of socialist legality...[and] socialist morality." "The rule of law is about political construction, being part of political civilization, whereas the rule of virtue is about thought construction, being part of spiritual civilization. While the two belong to different realms, their respective roles and functions are very important" (“Quan guo," 2001).

In fact, the rule of virtue was far more enthusiastically discussed in the mouthpiece newspapers and the Party School journals than in other mass media. With respect to how specifically the rule of law and the rule of virtue relate to each other, many articles in the mouthpiece media and Party School journals echoed what Jiang remarked in the 2000 speech about the enforceability of the former as opposed to the "soft power" of the latter. A typical argument can be found in an article in the People's Daily: "Law...represents the requirement of the state for the conduct of the members of the country in political, 
economic, and social realms, and represents the requirements for social stability, for the security of people's lives and property, and for national security." "The state relies on courts, the police, and other repressive state apparatuses to ensure the implementation of law." Virtue, in contrast, "albeit also being an important part of the superstructure, is different from law; the implement of virtue does not rely on measures of enforcement but uses methods of moral education...to have people abide by standards of conduct voluntarily." "Virtue resorts to people's 'conscience' and their inner 'moral beliefs." For the author, while the rule of law was important, it was also necessary to "strengthen people's sense of honor and disgrace" (Luo G., 2001). In a similar vein, another author pointed out that the rule of virtue was about exercising self-discipline, whereas the rule of law was more about "hard standards" of discipline, that without the rule of law the society would sink into disorder, and that further social development required further discipline (Wang H., 2000). In an article in the Guangming Daily it was also argued that, in comparison with the rule of virtue which relied on public opinion and the power of tradition, socialist rule of law was meant to punish evil and promote good by state force (Xu J., 2003). As can be seen, when discussed in relation to the rule of virtue, the rule of law was frequently connected to the idea of resorting to penal punishment and the coercive power of the state in regulating conducts (Lei, 2001; Zhu J. \& Chen, 2001).

Such a definition of the rule of law versus the rule of virtue reminded many of the differentiation made between the two in Confucianism, which equated law with penal punishment and argued that morality was far more important because it reached into 
people's heart and cultivated a sense of shame which would keep people away from evil doings (Luo G., 2001). In fact, in the discussion of socialist rule of virtue, many turned to a review of the Confucian idea of rule of virtue. Some particularly noted what they believed to be the positive roles that the Confucian rule of virtue played in the ancient times, their arguments often emphasizing the role of the state as the moral leader and educator versus the ordinary people as subjects to be supervised and controlled. For example, an article contended that, as a major political tradition of China, Confucian rule of virtue sought to build a society which was not to be governed by "cold-faced" laws but was characterized by good social morality, benevolence, and the care of the state for the people. In such a society, it was the responsibility of the state to "motivate the people to work hard, correct their wrongs, seek justice for them...[and] make them aware of their dignity" through moral cultivation ("Lun de zhi," 2001). Some argued that the construction of socialist rule of virtue would benefit from a recognition of the "progressive aspects" of the Confucian rule of virtue, even though the latter had its own "historical limits" because it mainly served the interest of the ancient ruling class (Luo G., 2001; Jiang G., 2001; Tian Y., 2001). Such progressive aspects included the requirement that state officials practice good morals themselves to set a standard for the rest of the society (Luo G., 2001; Tian Y., 2001), as well as the role that the advocacy of virtue played in maintaining social stability (Jiang G., 2001). It is notable that all this praise for Confucian teachings on morality formed an interesting contrast to the cynicism—or at least reservation — expressed toward Confucianism in early modern China, when 
Confucian advocacy of virtue was blamed for China's backwardness, and was deemed too out-dated to guide China's competition in the world (Pusey, 1983, pp. 222-225).

However, just as in early modern China when Confucianism was read and appropriated in varied ways (pp. 216-235), the classical school was an object of dividing political interpretations in the 2000 s. As the rule of virtue and the rule of man were both taken as Confucian ideas and were often associated with each other, the relation between the two stood out as a thorny issue for those exalting the official promotion of socialist virtue. In fact, for the idea of the rule of man itself, it continued to be critiqued as the opposite of the rule of law in the 2000s. Reflecting on the history of the Party, an author commented that, when the Party came to power, it did not have a clear idea regarding the specific way to govern the country (Yin Zhen, 2004). What characterized the Party rule from the 1940s till the end of the Cultural Revolution, according to the author, was a model of authoritarianism, which was adopted as a result of the influence of the feudal rule of man tradition; it was not until the fifteenth Congress of the Party held in 1997 that the rule of law was formally recognized as a superior mode of governance. This recognition, according to the author, indicated that the Party had stepped out of the fallacious idea that whoever gained power through military force would be entitled to rule at will. Another article that commented on the achievements of the fifteenth Party Congress reviewed Deng Xiaoping's ideas of rule of law, highlighting how Deng pointed out the peril of the rule of man in undermining social stability and threatening the sustainability of Party rule (Zhou H., 2002). In order to make a transition from the rule of 
man, as three other authors argued, the key was to handle correctly the relation between Party leadership and the rule of law, especially to get rid of feudal influence and to heighten the "legal consciousness" of both the masses and Party cadres (Gu, Gu, \& Dong, 2003).

Given the widespread skepticism toward the rule of man, some made a point of differentiating between the rule of virtue and the rule of man. In some occasions, this was done to justify the official advocacy of supplementing the rule of law with the rule of virtue. For example, Wang Qianhua pointed out that, although in the ancient times there were debates between Confucianism and Legalism about the merits of the rule of virtue and the rule of law, the advocates on both sides shared common ground in their support of the rule of man, that is, the support for monarchical rule. Modern rule of law, however, was different from the rule of man in its nature, viewing law not just as "limits of freedom" but also as a "protection for freedom" (Wang Q., 2001, p. 93). It was argued that, in contemporary China, modern rule of law and modern rule of virtue were both oriented towards freedom and equality. Modern rule of law emphasized the legitimacy of the acts of the state, the protection of rights, as well as the reliance of the state on enforceable methods to regulate social conduct, whereas modern rule of virtue was about establishing public morals in order to have people, including state officials, regulate their own behavior themselves (p. 96).

In other occasions, however, while the value of the official advocacy for rule of virtue was recognized, the danger of falling prey to traditional rule of man-and thus 
undermining the rule of law-in the promotion of the idea of "ruling the country by virtue" was warned against. As Zhou Yongkun suggested in an academic journal, if the traditional rule of virtue was followed, the core of which was the culture of the rule of man, it would necessarily reduce the modern constitutional principle of the rule of law to the Legalist rule of law, the core of which was the use of state violence (Zhou Y., 2002, p. 5). Thus, the rule of virtue tradition, if it was to be inherited, must be transformed to be aligned with the requirements of the modern rule of law, including respect for equality, the rejection of the cult of personality that encouraged unconditional loyalty, as well as the recognition of the diversity of moral beliefs.

While the rule of man was in the main the embodiment of the backwardness of China's feudal past, some were apologetic in reconciling its relation with the rule of virtue. Conceding that the ideas about rule of man had dragged China behind the modern West, two authors from the Chinese Academy of Social Sciences then proceeded to claim that many Chinese had been accustomed to valuing the Western culture while disparaging China's own heritage, and that as a result certain fine elements of Chinese traditions were driven out of view, their potential contribution to the rule of law being erased:

In fact, the spirit of modern rule of law is built on the basis of human morality and rationality, and morality is necessary for the development of the rule of law... Although the idea of "governance by virtue" led to that of "the rule of man" [in the feudal past] which had negative effects..., it had its strengths in stressing the need for the ruler to exercise self-discipline. For a long time people have mistaken "the rule of man" for..."someone's words taking precedence over law" or "power taking precedence over law." In fact... what "the rule of man" emphasizes, as an idea growing out of "governance by virtue," is that the ruler must have achievements in 
legislation and be a model in abiding by laws. Moreover, a good ruler must also be a moral model.... What is enlightening of the Chinese traditional culture is precisely its resort to the criterion of morality in the appraisal of governors and their governing. (Ma \& Yu, 2002, p. 19)

Meanwhile, the authors pointed out, as Western scholars have turned their attention to the weaknesses of their own rule of law, China's five-thousand-year-old traditions, once renewed and remolded, would have a role to play in the modern and future development of the rule of law (ibid.).

As can be seen, in the advocacy of combining the rule of law and the rule of virtue many emphasized the reliance on the moral and the coercive power of the state, but some remained cautious about the extent to which "ruling the country by virtue" should be pursued. In fact, in the discourses on the rule of law in the 2000s, limiting rather than strengthening state power was a highly noticeable theme, which will be discussed now.

\section{Oversight}

Oversight appeared as a prominent theme in the order of discourse on the rule of law in the 2000s. To be sure, oversight was already made general reference to in the $1980 \mathrm{~s}$ ("Ba fa lü," 1985; Liu Shike, 1985); it was also mentioned as a means to limit state power in the 1990s (Gong, 1994). However, in the 2000s, overseeing the act of state agencies became more widely talked about as an integral part of the rule of law. Meanwhile, China's lack of rule-of-law traditions was extensively critiqued, taken as simultaneously the reason why oversight had long been absent, why a strong government was needed, and why the Party should be applauded rather than blamed for its level of oversight 
awareness.

Much discussion of the rule of law in relation to oversight in this period was concerned with limiting state power in general. Many argued that the transition from a state based on the rule of man to one based on the rule of law meant containing or preventing the abuse of administrative power (Li \& Lin, 2000; Zhao \& Xu, 2001; Yuan S., 2002). An author particularly noted what made a modern society of rule of law different from a feudal one:

The primary objective of modern rule of law is to emphasize that state organs and their officials abide by laws.... The type of "rule of law" that only imposes restraints on the ordinary people already existed in the feudal society, and is not what we now refer to as the rule of law... The "rule of law" that cannot put restraints on state organs is not the true rule of law. (Wang Zhenmin, 2003, pp. 23, 24)

The most important means to limit state power, according to the author, was to establish constitutional oversight, which was "the highest form" as well as the "cornerstone and core" of the rule of law (p. 24). This was echoed in an article by a member of the standing committee of a municipal People's Congress in the Shandong province, who argued that "the tradition that gives weight to leaders' words and belittles constitutional rights still enjoys a great deal of currency" in contemporary China. The author pointed out that,

In real life, the authority of the Constitution is challenged from time to time.... While the Constitution of our country stipulates that all state organs treat the Constitution as the highest code of conduct, and while the Constitution of the Party has it that Party organizations at all levels must act within the range allowed by the state Constitution and laws..., some go beyond law to exercise personal power, treat their own words as laws, and use their power to trample on law.... Therefore... it is necessary and urgent to implement constitutional oversight. (Ge, 2003) 
In the explanation of the lack of constitutional oversight in China, both external and internal reasons were identified. Ai Guo noted, in a thesis on "The Evolution and Development of the CCP's Ideas about the Constitution," that the absence of a functional system of constitutional oversight can be attributed to the fact that the Chinese Communists had not developed "mature constitutional conceptions," which would take a long while to nurture given the "backwardness of both the economy and the culture of our nation," "the deeply seated influence of historical feudal despotism," and "the lack of traditions of democracy and legality" (Ai, 2004). Meanwhile, Ai commented, the idea of constitution was one originating in the West and not intrinsic to China's political legal tradition. Rather, the constitution was for the Chinese only a tool to empower the nation when confronted with Western impact, which also explained why the constitution was approached less from the perspective of legality than from political points of view. Ai admitted that the Chinese Communists had gone astray in their understanding about the constitution. However, it was then pointed out, the Party had gone through profound change and come to emphasize oversight in its $16^{\text {th }}$ National Congress. Such progress, Ai commented, could only be made step by step because of the constraints of tradition. It is notable that the view that China lacked a tradition of oversight was in fact contested by others. For example, Liang Cong, a judge and a professor of law, claimed that Huang Zongxi, as one of China's earliest "enlightenment thinkers," was an ardent advocate of oversight of state officials and agencies by the literati. However, Liang noted, the tyranny of feudalism and the absence of a civil society rendered Huang's idea about the rule of 
law an impossible ideal (Liang C., 2007).

In contemporary China, the emphasis on limiting state power was particularly prominent in the discussions which suggested that the oversight by the People's Congress be improved to strengthen the rule of law (Zhao \& Xu, 2001; Fu, 2002; Yuan S., 2002). According to Chinese law, the People's Congress is the supreme organ of authority in the People's Republic of China. The Constitution has it that "all administrative, judicial, and procuratorial organs of the state are created by the people's congresses to which they are responsible and by which they are supervised." Many stressed that oversight by the people's congresses and their standing committees was an important part of the construction of socialist rule of law (Zheng, 2001; Xiong, 2003; Yin Zhongqing, 2004). Some applauded the Congressional Oversight Bill which was submitted to the National People's Congress for its first reading in 2002, arguing that the core of modern oversight was to use citizens' rights to restrain state power (Fu, 2002), and that the introduction of the Bill would further the progress of building a nation of the rule of law (Kan, 2002). A director of the research office of the standing committee of the National People's Congress wrote that the Congress must "solidly" take up its responsibility of supervision, not only reviewing regulatory instruments drafted by state organs, but also correcting the unconstitutional conduct of state officials (Yin Zhongqing, 2004, p. 43). Against the view that congressional oversight would only bring trouble to the government, some authors pointed out in the People's Daily that congressional work was not to seek unprincipled "harmony," and that congresses must be confident and feel in the right to conduct 
supervision without fear (Zhao W. \& Xu, 2001; Zheng, 2001). Many others emphasized that congressional oversight should resort to substantial and "hard-line" measures such as interpellation and removal from office (Zhao \& Xu, 2001; Shen \& Zhou, 2003; Xiong, 2003).

In spite of the call for stronger congressional oversight, some maintained that the authority of the state not be undermined, the reasons cited coinciding with those stated to explain China's necessarily slow development in constitutional oversight. A professor of a provincial Party school wrote that China's rule of law was one propelled by the government, differing from the Western one which emerged as a result of "natural evolution." Being a country lacking traditional rule-of-law resources and institutions, an advanced civil society, and a mature commodity economy, China was not able to develop a "naturally-born" rule of law speedily. Nor did China have the time to wait for the automatic emergence of such a type of rule of law, as it had been pushed to a project of national survival since the Opium War in 1840. Since "the development of world history would not grant spare time to the Chinese nation alone to let you slowly have "natural social evolution,'... China must choose the path of government-propelled rule of law," which in turn required a government that was "centralized and unified, relatively stable, and had relatively good reputation." Thus, in the process of building the rule of law, while state power should be restrained, its authority should also be strengthened so as to maximize the "control capacity" of the government, to alleviate political conflicts, and to maintain social stability (Guo X., 2001). 
Another issue that remained controversial was about the relation between Party rule and the oversight by the People's Congress, despite the official stress on the consistency between the rule of law, the leadership of the Party, and the principle that the People are the master of the country (Jiang W., 2003). Some insisted that, while congressional oversight was an important part of the rule of law, it should be exercised in ways that upheld the leadership of the Party (Zha, 2002), or should be aligned with what the Party or the government aimed to focus on (Xiong, 2003). Some particularly noted the cases in which effective congressional oversight relied on the support of key Party officials. For example, a feature article published in the China Youth Daily reported how the proactive facilitation of Party leaders helped the people's congresses in the Guangdong province exercise oversight rights (Li \& Lin, 2000). The article especially highlighted the "express route" maintained by the provincial Party leaders, a channel of communication opened up for the congressional deputies to reach top provincial officials directly. Normally, deputies need to submit their opinion to the congress of their level, which will then forward the opinion voiced to related government agencies. However, as the article quoted an officer in the provincial congress, such procedures were inefficient and could not guarantee the solving of problems. In view of this, the provincial Party committee created an "express route," which allowed deputies to hand in their suggestions directly to provincial leaders and to catch the leaders' attention to the issues deemed important by the deputies. According to the article, the case demonstrated that support from Party leaders was essential in encouraging deputies to voice their concerns and in bringing 
about effective congressional oversight.

However, there also existed questioning about the way in which Party rule had obstructed congressional oversight. As has been mentioned, some authors urged that the congresses should resort to more "hard-line" measures of supervision. In doing so, some discussed the reasons why such measures had not been mobilized sufficiently. An author alluded to Party rule as a major factor therein:

What has led to the rare exercising of interpellation rights in local people's congresses and their standing committees? ...it is related to the political system [of our country]. In the present condition, there exists in our country the phenomenon of Party work not separated from government work, and Party work substituting government work, in various degrees. Therefore... what is formed is a model of political operation in which Party committees make policy decisions which are then executed by the government, or in which Party committees and the government jointly make policy decisions. Under such circumstances, the question of how the people's congresses are to exercise their oversight rights needs to be explored in practice. (Dou, 2001, p. 9)

Two other authors also noted how Party rule had negative impacts on the effectiveness of congressional oversight. As they stated, the Constitution stipulates that local people's congresses and their standing committees have the responsibility and the right to conduct supervision over the work of the government. However, the Party committee in some places distributed administrative work between local governmental officials and the chairs of the standing committee of the local people's congress, making it difficult for the congresses to conduct oversight (Zhao W. \& Xu, 2001). In stating the necessity of oversight over the Party, a professor of the Central Party school pointed out that the Party had been accustomed to a type of "unitary leadership," which was indispensable in times 
of revolution yet was unsuitable for the rule of law. However, the author then turned apologetic, "due to the fact that China had a history of feudal despotism for over two thousand years, and that the tradition of the rule of man was so deeply rooted whereas the idea of the rule of law was so weak, it was very difficult to be rid of the influence of the rule of man"; thus, the advocacy of socialist rule of law was already a step of "immense political audacity and theoretical courage" on the part of the Party (Zhang Xiaoyan, 2000).

Despite areas of ambiguity and controversy, however, limiting the power of state organs remained a key idea in the discourses on the rule of law in this period. In fact, it also appeared in the discussions of the rule of law in relation to rights protection. Yet, in the talk about rights, one finds a noticeable difference between the People's Daily and other periodicals, the former often condemning the United States for using human rights issues to attack China, while the latter highlighting a variety of other themes. But both show how Chinese discourses on rights and the rule of law are preoccupied with the Western, their threats, or their teachings.

\section{Rights matter (III)}

Rights protection continued to be a major theme in the discourses on the rule of law in the 2000 s and, in 2004, the notion of "human rights" was added to China's Constitution. For some, this constitutional amendment marked a profound change from the years before the late 1970s, when the term "was a taboo" (Chen Dingding, 2005, p. 156). In explaining China's change in this regard, some pointed to Western pressure, 
while others argued that it was a result of the cognitive change on the part of the Chinese themselves (pp. 156-157). However, although both external and internal factors have played their roles, the term quan li (rights), ever since its genesis in the $19^{\text {th }}$ century (L. Liu, 2004, pp. 124-131), has been an integral part of China's dealing with the modern world. And it is Western conceptual instruments that define the ways in which China's (or its lack of) traditions of rights are constructed.

A prominent theme in the People's Daily was that the criticism of China's human rights record was an example of American hegemony neglecting the efforts that China had made toward the rule of law ("Jie ren quan," 2001; Dong Yunhu, 2003; "Zhongguo ren quan yan jiu hui," 2004). A typical argument in this regard can be found in a commentary article:

It is already nothing novel for the United States and other Western countries to attempt to push forward anti-China motions at the UN Commission on Human Rights.... China has strived to construct a socialist country of rule of law, taking a series of proactive measures in strengthening legislation, promoting strict law enforcement, punishing corruption, and enhancing local-level democracy. For all this...the international community has sung high praise [for China]. However, the United States neglected these basic facts entirely and put forward anti-China motions again and again, which only betrayed its own diabolical intentions. In the final analysis, what the United States attempts to achieve is to use human rights issues to ruin China's international image, to exert political pressure on China, to undermine the stability of China, and, thus, to contain and obstruct China's development. Such acts of hegemony that politicize human rights issues would necessarily be condemned by the Chinese government and the people. ("Jie ren quan," p. 4)

In fact, the People's Daily published a number of articles by Dong Yunhu, Associate Director of the China Society for Human Rights Studies, who argued that American 
criticism of China's human rights conditions was an act of demonizing China (Dong Yunhu, 2003), which demonstrated a type of "cold war mentality" of the American government (Dong Yunhu, 2004b, p. 7), especially its political prejudice against China and its evil political motive of overthrowing Communist rule in China (Dong Yunhu, 2003, 2004a). In contrast to what the American government depicted, according to many articles in the People's Daily, China had seen substantial improvement in the rule of law and human rights, which was acknowledged by both the Chinese people and the international community (“Jie ren quan," 2001; Li P., 2002; “Ji ji ping jia," 2003); furthermore, all this was about China's internal affairs that the United States should not interfere with (Li P., 2002; Dong Yunhu, 2003; "Zhongguo ren quan yan jiu hui," 2004). ${ }^{2}$

It is noteworthy that the articles in the People's Daily, albeit keen on criticizing the West for using human rights issues to demonize China, also pointed out that the idea of rights should not be seen as merely belonging to the capitalist. In an article that commented on the significance of the incorporation of the notion of human rights into the Constitution, the author noted that, although since the late 1980s and the early 1990 s "the international adversaries" had more actively used "human rights" to launch attacks on China, socialist China should not abandon the banner of human rights in the struggle against anti-China forces. In contrast to the leftist approach which viewed "human rights" as a taboo and a "patented" slogan of the capitalist, socialist China should uphold the

\footnotetext{
${ }^{2}$ To be sure, criticism of the act of interfering with China's domestic affairs with the use of "human rights" already existed in a 1991 document issued by the State Council of China. However, in this document the issue was not explicitly discussed in relation to "the rule of law."
} 
banner of human rights and articulate its own viewpoints on the issue (Dong Yunhu, 2004c). ${ }^{3}$ Li Buyun, an eminent professor of law in China, also suggested in the People's Daily that the 2004 Constitution amendment was a good reminder to everyone that "human rights" was not a notion solely belonging to the capitalist, and that socialist countries should be the ones that attached the greatest importance to human rights. According to $\mathrm{Li}$, the amendment not only helped enhance knowledge about human rights among Chinese officials and ordinary citizens, but also was beneficial for the promotion of China's image in the international community (Pei, 2004).

While many articles in the People's Daily focused on the issues of rights from the perspective of international relations, others instead noted the importance of learning from the West, their comments often bearing the mark of the mindset of modernization or evolutionism. Xu Aiguo offered a typical account in the mouthpiece Legal Daily on the necessity of looking to the West for inspirations about the rule of law. As Xu noted, human rights was one of the ideals of the rule of law, which "strictly speaking" originated in the West and should be used to measure the "degree of civilization" of societies, all of which stood at a certain point on a continuum that stretched from the status of no law to that of rule of law. It should be admitted, Xu stated, that Western developed countries had a higher level of the rule of law compared to China. As for China's path of development, Xu remarked that since "there existed insoluble contradictions between a modernized

\footnotetext{
${ }^{3}$ As Dong pointed out, the need to interpret human rights from China's perspective was already noted by the Party leadership in the late 1980s and the early 1990s. However, at that time the issue was not explicitly related to the rule of law.
} 
industrial society [under the rule of law] and a traditional agricultural society," China's "traditional feudal society cannot possibly evolve by itself into a commercial society." "If we believe in the evolution of the human race...we then have reason to believe in the necessity of learning from the Western legal systems" and "aligning our law in accordance with international practice" (Xu A., 2002).

Such arguments were echoed by those who turned to China's past to review the degree to which it could cultivate rights awareness. In this connection, it was highlighted that China's tradition valued the collective while belittling the individual (Liu H., 2002; Wang T., 2001), or that it honored state power yet neglected rights (Wang T., 2001; Xie P., 2007). Wang Taixian (2001), a professor of law, offered a detailed discussion of these "Chinese characteristics" by reflecting on China's "traditional humanism." According to Wang, the ultimate goal of the China's traditional humanism was an idealized society but not individual fulfillment. Based on such a principle, human beings were only the means for certain socio-political purposes; they belonged to the collectivity but were not independent individuals. Under such humanism, the spirit of freedom and rights could not be formed and fostered, and, thus, the rule of law which took the protection of freedom and rights as its goal could not come into existence. Regarding state power and rights, Wang noted, China's tradition valued the former yet did little to protect the latter. In Wang's view, as the philosophers and thinkers in ancient China were dependent on the secular political authority, this dependency extended to the relation between China's traditional humanism and the state. As such, while occasionally it emphasized the value 
of the individual, Chinese humanism would not come into conflict with the authorities if the latter trampled on humanity. As a result of this lack of independence, China's humanism could not foster the rule of law that put limits on state power and protected rights.

To be sure, all this critique does not mean that China's traditions were entirely rejected in the talk on the rule of law and human rights. As an author suggested, "on cultural issues, we should not underestimate ourselves... and sink into pessimism and despair; nor should we be self-conceited and not seeking improvement.... While we inherit China's good culture, we should also... absorb the essence of Western and other types of cultures" (Liu H., 2002). Similarly, Wang Taixian advocated the combination of Chinese and Western "humanist spirits," or the pursuit of harmony of the former and rationality and liberalism of the latter, to reconstruct the spiritual foundation of the rule of law in China (Wang T., 2001, pp. 16-19). Another legal scholar also pointed to the "humanist care" of the Chinese tradition, claiming that the Confucian idea of benevolence was a "sparkle of human rights consciousness" in China's heritage of legal culture (Qi, 2006, p. 170). At the same time, these authors pointed out that it was in the West that human rights protection first developed, and that Western cultures should be seen as part of the fine traditions of human beings which China should learn from (Liu H., 2002; Wang T., 2001). Despite the deep understandings of rights reflected by Confucianism, it was argued, the human rights consciousness in China's tradition was merely aimed at reducing social conflict and thereby maintaining the rule of autocracy 
(Qi, 2006, p. 171).

As has been shown, in the discussion about China's traditions, some lamented the tradition of honoring state power and neglecting rights. In fact, limiting state power was also a key theme when the rule of law was discussed in relation to issues of rights. Commenting on the significance of the 2004 Constitutional amendment which proclaimed that the state of China respects and protects human rights, Xu Xianming, a law professor, remarked that the amendment meant that limits were set for state power and that human rights protection would become a code of conduct for all state agencies and their staff (Wang F. \& Zhang, 2004). Another author pointed out that the highest form of the rule of law was constitutionalism (Li Jinyan, 2004). However, she argued, the existence of the Constitution did not necessarily mean the existence of constitutionalism; for China, there remained the need to consider how to handle the relation between state power and citizens' rights based on the spirit of the Constitution. It was suggested that, as constitutionalism required putting limits on state power and protecting individual rights, government officials and cadres should accordingly establish the understanding that their power came from the people and should serve to protect rights. The need to resituate the relation between state administrative organs and citizens was also emphasized by others. For example, Zhu Q. and Tong argued in a Party School Journal that socialist China had long followed a model of governance characterized by the domination of state power, or a political system of "totalism" in which all social organizations and individuals were dependent on the state. According to the authors, the objective of such a "pyramid" 
tradition of governance was not to ensure that citizens were free from the abuse of power, but to provide codes of conduct to citizens and make them submit to state organs (Zhu Q. \& Tong, 2001, pp. 120-121). Such a situation needed to be changed if China was to establish the rule of law, because the core of the rule of law was individual rights, or the dignity and freedom of human beings. Ignoring these ethical values of the rule of law would lead to legal instrumentalism, the tragedy of which was seen in German fascism during the Second World War. In order to foster rights and freedom, the authors argued, state power must be subject to restraint.

As can be seen, in the discourses on the rule of law, "human rights" was not only a concept of the enemy's camp or a means to build China's international image, but also a guideline for China's course of development. However, in the efforts to define China's future, not only the themes originally thought of as Western but also those from China's own past were mobilized, as in the case of the promotion of a "socialist harmonious society."

\section{Building a socialist harmonious society}

While "human rights" was no longer seen as an "alien" notion in the discourses on the rule of law, one also finds the deployment of China's own past to advance the socialist cause. As has been discussed, the rule of virtue was one of the slogans that pointed to a "progressive" past. In fact, another one of a similar nature was promoted after Hu Jintao, Jiang's successor, came in office, namely, that of building a socialist 
harmonious society. Harmony, as that of virtue, is also taken as an important theme in Confucianism. As has been mentioned earlier, for Jiang's endorsement of the rule of virtue notion, some pointed out that it was part of Jiang's attempt to "solidify his legacy" (Peerenboom, 2002, p. 224). Regarding Hu's promotion of a "socialist harmonious society," however, it remains debatable to what extent this was also an attempt at establishing personal political legacy. ${ }^{4}$ But it stands out clearly that the concept of harmony was advocated as the Party felt the need to address growing corruption and social inequality ("Zhong gong zhong yang guan yu gou jian," 2006), both of which posed a challenge for the legitimacy basis of the Party that branded itself as representing the working class and the interests of the people. As will be shown, in the discourses on the rule of law--which was described by the Party as an integral part of a socialist harmonious society - the notion of harmony does not so much indicate victorious return of Confucianism. Rather, one sees attempts to resituate Chinese socialism, for the purpose of which Marxism and China's own past were brought together by being rearticulated.

The slogan of building a socialist harmonious society was first formally put forward in 2004 in a resolution of the Central Committee of the Party on improving the Party's governing capacity. According to the resolution, it was necessary to mobilize all "positive

\footnotetext{
${ }^{4}$ As Alice Miller (2007) notes, "from the standpoint of leadership politics," it is interesting to note that in the Party's "resolution and the commentary" on building a socialist harmonious society, "in no place do they credit the concept... as a product of Hu Jintao's personal insight or initiative." "Hu is frequently depicted as playing important roles in the process of formulating the concept of "socialist harmonious society,' but he is not credited as its author nor is it described as his exclusive intellectual property" (p. 10).
} 
factors" in the society to build a harmonious society and to solidify the social basis of Party rule ("Zhong gong zhong yang guan yu jia qiang," 2004). However, the 2004 resolution did not explicitly mention social harmony in relation to the rule of law. Another Party resolution, which was passed in 2006, was particularly about the construction of a harmonious society. While reiterating the need to enhance the governing capacity of the Party, the new resolution also explicitly referred to the rule of law as one of the primary principles of social harmony. In fact, "building a socialist harmonious society" appears to be an official buzzword in the 2000s which is used to describe the overarching objective of the Party for the years to come and, thus, the 2006 resolution on the issue reads as a general directive for Party work that touches on many areas. The resolution first stated that social harmony had always been the goal of the Party, and then pointed out that, in the development of socialism led by the Party, China had achieved a status of harmony yet there remained many "contradictions and problems," among which the resolution highlighted issues about social inequality, moral degradation, corruption, and threats to national security posed by international adversaries. The rule of law stood out as a rather noticeable theme in the resolution. It was articulated as one of the "general requirements" and "principles" of a socialist harmonious society, as well as one of the "major tasks" to work on. More specifically, in the discussion of the rule of law, the 2006 resolution stated the need to protect the integrity and the authority of socialist legal system, to ensure equality before law, to respect and safeguard human rights, to strengthen oversight and restraints on power, as well as the need to build a "culture of 
harmony" which was the core value system of socialism and which required the combination of the rule of law with the rule of virtue.

The official slogan of "socialist harmonious society" again opened up a space for scholars to re-evaluate China's past, many pointing to the potentials of traditions for the envisaging of China's future while noting their "backwardness." Zhao Ming, a professor at the Southwestern University of Political Science and Law, suggested that the reality of China as a transitional society entailed a "rational redefinition and grasping of the meanings of the past," the practice of which was followed by the Confucian thinkers who, based on their reflections, proposed the idea of harmony to address the social change they were facing in the pre-Qin times (Zhao M., 2006, p. 31). The harmonious society these thinkers envisioned, according to Zhao, called for "noble spirituality" on the part of those in rule, whose insatiable desire for power had triggered profound social turmoil. On the other hand, the idea of harmony was also for the Confucians an appeal for the reestablishment of the older social order based on $l i$. Thus, what stood at the core of the Confucian advocacy of harmony, in Zhao's interpretation, was a proposal for both selfcultivation and institutional arrangement. However, Zhao noted, such an idea did not incorporate the end value of individual-centered rights, and therefore had its limits when applied to contemporary China. But Zhang continued to point out that the ancient Confucian advocacy of harmony was inspirational in that it highlighted the importance of reflecting on one's traditions, rather than "irrationally negating" them, in order to look for solutions to practical problems. Besides, the Confucians also taught the lesson that 
healthy economy and rational state power needed to be ensured by effective institution arrangements. While such arrangements meant for the Confucians social regulation through $l i$, for contemporary China they required nothing less than the building of a ruleof-law society the premise of which was respect for rights and freedom (Zhao M., 2006, pp. 31-32). This line of thought that traditions needed to be both inherited and transcended was widely shared among the scholars who approached "harmony" as the essence of Chinese humanism (Wang T., 2001; Tao Y., 2006). As an author argued, although Confucius' political theory only served to perpetuate the privilege the powerful, the idea of harmony as its "humanistic core" offered a moral orientation for socialist rule of law (Tao Y., 2006, pp. 5-6, 18).

Others, however, took the re-emphasis on harmony as a way for China to distance itself from Western-centered knowledge. In a thesis on the construction of a culture of the rule of law for a socialist harmonious society, Sun Yuwei contended, In our ardent pursuit of modernization, we have paid more attention to, introduced, and absorbed many things from the Western culture including its legal theories. This indeed is important and necessary; however, we have at the same time to a large extent either consciously or unconsciously fallen into a "paradigm of Western modernity" (in Deng Zhenglai's words) that takes as its blueprint Western paths of development and theories. Comparatively speaking, we have not done enough work on the research of the progressive resources of Chinese traditional legal culture. (Sun Y., 2006, pp. 23-24)

A "precious spiritual treasure" of that tradition, according to Sun, was the advocacy of harmony, without which the populous Chinese nation could not have survived given the difficulty and the turbulence it had gone through. Sun also argued that the promotion of 
the idea of "harmonious society" in socialism pointed to the need for theoretical renovation in China, especially the need to take into account the non-conservative and progressive aspects of national traditions for the building of a modern rule-of-law culture.

In fact, the slogan of "socialist harmony" raised questions about the ideological basis of Communist rule in China. It is noteworthy that the 2006 Party resolution repeatedly stated that the construction of a socialist harmonious society with the rule of law must be guided by Marxism, which must be held onto as China's state ideology. However, some may find the official advocacy of social harmony a deviation from the pursuits of Mao Zedong and Deng Xiaoping. Mao is known for his insistence on class struggle and his revolutionary approach to development. For Deng Xiaoping, while he was oriented toward reform, "at no point in the Deng era did authoritative Party statements endorse a 'harmonious society' as the overarching goal of the Party" (Miller, 2007, p. 6). In fact, as Miller observes, the 2006 resolution displayed "defensiveness" about the legitimacy of the concept of a harmonious society and "[has] taken pains to assert the ideological orthodoxy of the goal" (ibid.). In an article in the People's Daily that stressed the significance of the resolution and reiterated its major themes, Wu Bangguo, chairman of the standing committee of the tenth National People's Congress (2003-2008), pointed out that the envisioning of a socialist harmonious society was the product of the combination of China's reality with Marx's thought about harmony, and thus was different from "the world of great harmony" envisaged by thinkers in China's past (Wu B., 2006, p. 2). Similar defense was also voiced in a special editorial published in a journal of the Party 
school, authored by the Vice President of the school, which argued that Marx and Engels themselves affirmed the advocacy of social harmony which they believed could only be achieved in Communism where there would be no more class confrontations. Therefore, according to the author, "to struggle for the ideal of Communism is in a sense to fight for a harmonious society" (Li Junru, 2006, p. 7).

In the same journal, other authors also went to extra length to argue for the connections between Marxism, the rule of law, and the notion of social harmony. In an article on "power civilization," the author noted that a socialist harmonious society required the harmony between the ruler and other members of the society, or fairness and justice of state power. Thus, it should be a society of the rule of law, which required oversight and checks on power. The author suggested that such requirements were in line with Marx's critique of "power fetishism," an evil tendency in which state power became the object of worship, a means for personal gain, and a tool for officials to act at will. For the author, the essence of a "power civilization" was the oversight of power. Oversight, it was said, was a task Marx had envisioned and was especially relevant for contemporary China due to widespread corruption, which was a manifestation of power fetishism and a legacy of the feudal tradition (Ma Z., 2005). Marxism was also invoked to explain the relation between the rule of law and social harmony from the perspective of social stability. An author pointed out that Marxist theory had it that the superstructure of a society served its economic base and at the same time was a counter force that acted on the base. Therefore, without a stable "socio-political environment" and a "core political 
authority" to handle complex political issues, the economic development of a society would be affected. This, according to the author, indicated that the rule of law was important for social harmony in that law was the basic tool to maintain social stability and could be relied on to eliminate unnecessary social conflicts (Xue, 2006, p. 14).

\section{Traditions in the prospering "the rule of law"}

The Constitutional amendment in 1999 formally granted legitimacy to the rule of law as a mode of social organization. However, the prospering of the idea was not simply an indication of the successful diffusion of Western liberal views of law, as Marxist and Chinese indigenous conceptions were also assembled to define socialist rule of law. However, such an assembling is more than a simple combination of self-evident Western and Chinese elements. Rather, one finds a reciprocal intelligibility between them, as knowledge of the West prescribes the terms in which the indigenous is approached, and as domestic agendas in turn qualify the ways in which the West is articulated. ${ }^{5}$

The Western-inspired binary concepts of the rule of man and the rule of law, widely used in earlier decades, remained popular theoretical tools in the evaluation of practices and ideas from China's past. Thus, although the promotion of the rule of virtue and that of oversight grant different statuses to the state-in the former the state being the moral educator whereas in the latter being the entity to be monitored-they shared common ground as they are preoccupied with the issue of their own relation with the rule of man

${ }^{5}$ However, even if domestic agendas framed narrations about the West, the West - either the perceived threats from it or the admiration of it —often stood behind those agendas. 
or the Legalist rule of law as feudal residues. However, these residues themselves were neither self-illuminating but malleable enough to take different shapes even under the same agenda: in the call for the rule of virtue, while for some the rule of man was what to keep distance from, for others its "enlightening" emphasis on moral modeling constituted the legitimacy foundation of the Communist promotion of the rule of virtue.

The advocacy of the rule of virtue and socialist harmony may seem to be a trend opposing the contemporaneous urging for oversight and human rights protection, since the purpose of the former was to ease social tension, whereas the latter gave power to the individual as opposed to the state. However, these seemingly conflicting appeals were not too remote from each other in their modeling on modern conceptual instruments. The impact of modern epistemology can be found not only in the orientation of the questions that were posed to investigate China's past, but also in how those questions were addressed.

A question frequently asked in the promotion of oversight and rights was whether there existed the rule of law in Chinese traditions. In the search for answers, feudal despotism and the under-development of capitalist economy were commonly blamed for the absence of locally-born and "naturally-evolved" rule of law, which was then cited as the reason behind the unavoidability of government-propelled legal reform and slowpaced establishment of oversight system. Even for those who believed that there were elements of rule of law and oversight in China's traditions, the failure of these elements to turn into modern rule of law was similarly explained in terms of limited development 
of capitalism. Thus, on the one hand, the question asked about China's past was permeated with an anxiety about whether and how well the country had achieved what the West had accomplished. On the other hand, the answers offered were also guided by Western-derived explanatory frameworks, such as that about social evolution, that about the historical logic of development (from feudalism and capitalism), or that about the deciding influence the economic base has on the superstructure.

Meanwhile, in the attempt to identify local traditions that are beneficial for socialist rule of law, many were preoccupied with the question of whether any type of humanism can be uncovered in China's classical schools of ideas. As soon as humanism was found, for example, in the Confucian idea of harmony, it was then argued that the tradition itself needed to be transcended for the construction of socialist harmony. However, neither the notion of humanism nor the idea of transcending traditions can be convincingly branded as indigenous Chinese. While the talk about critically learning from the past typically adopted the rhetoric of Marxist dialectics, contemporary attempts to situate humanist spirit in China's classical learning were strongly reminiscent of the early- $20^{\text {th }}$-century intellectual efforts to revive China's national essence, which were inspired by Western discourses in their claiming of an on-par Chinese humanism (L. Liu, 1995, pp. 239-256).

In fact, Western notions were also appropriated in contradicting manners for a variety of domestic social agendas. On one level, the idea of human rights was taken as a component part of the Western hegemonic machinery the function of which was to demonize other nations. In this reading, the rule of law and human rights were no more 
than instruments for international relations management. The strategy for China to follow, it was suggested, should be to co-opt this instrumentalism and turn "rights protection" into a weapon of "ours" against the scathing from "them." On another level, and conversely, others argued that constitutionalism was conceptualized as something of supremacy in the West, unlike in China where it was from the start a tool for nation strengthening. This nature of constitutionalism in China, which differed from the noninstrumentalism in the West, was then pointed to as the reason why the Communists could not but be constrained in building the rule of law.

Some may note that in the discourses that apparently relate more to the Western traditions, there were in fact underlying modes of thought that were reminiscent of ideas from China's past. For instance, some may point out, certain discourses on oversight contained Confucian lines of thought rather than Western views of rule of law because they emphasized the need to align oversight with the agenda of the Party and the government. As such, the discourses on the rule of law and oversight in China followed an authoritarian mindset that consolidated the power of the ruler. However, it is noteworthy that such an observation is based on an interpretation in which Confucianism was seen as a rule-of-man tradition, which is but only one of the many modern views about the school. For those who approach Confucianism in other ways, the conclusion drawn may be different. As has been discussed in Chapter 2, some see Confucianism as a school of thought that encouraged public discussions of political affairs. Wang Yi, a prominent Chinese intellectual, once argued that the advocacy and establishment of 
Confucianism as the state ideology in the Han Dynasty (202 B.C.E.-220 C.E.) was in fact an effort of the Han intellectuals — who reflected on the lessons of the preceding Qin Dynasty which was known for its cruelty based on Legalist absolutism-to subject the emperor to the supervision of the Confucian literati (Wang Y., n.d.). Following such an interpretation of Confucianism, one may suggest that contemporary discourses on oversight, which stressed restraints on state power, can be seen as Confucianism renewed.

Conversely, in the discourses on the rule of virtue and socialist harmony which seem to connect to Confucianism, some may instead detect the insistence on Marxism. Some may argue that these discourses reflect the Communist struggle to keep Marxism as the dominant ideology of the state. Apparently, the notion of socialist harmony does not contain much Marxist flavor except for the adjective "socialist"; but, ironically, Marxism is cited to justify the validity of the notion. This seems to indicate that the Party on the one hand is aware of the lack of appeal of Marxism to the society but on the other hand feel the need to insist on the ideology because it has long constituted part of the legitimacy basis of the Party as a party of the people. Moreover, some may point out, the talk on virtue in fact reflects attempts to unify social ideas. While some may view this as a continuity of the Legalist tradition of thought control, others may contend that it is a Marxist-Maoist mindset - the necessity to secure ideological leadership - that underlies such attempts. As Jiang Zemin once quoted Mao Zedong, "to gain leadership over people's ideas is paramount among the leadership over everything" (Jiang Z., 2000). Thus, some may argue that the emphasis on virtue in the discourses on the rule of law indicates 
that the Party finds the rule of law alone - as an external mode of control that regulates conducts but not ideas—-to be insufficient for the sustaining of the Party's ideological leadership. Therefore, they may contend, in the discourses on the rule of law, the advocacy for virtue and socialist harmony serves to teach Marxist principles about ideological control with the use of notions with a Confucian outlook, yet such teachings also carry with them some real Confucian twist, that is, law is to be seen as supplementary to the regulation of ideas but not as the supreme mode of governance. Despite all these different readings of how Chinese traditional modes of thinking underlie contemporary discourses on law, however, as soon as China's past is gauged with Western-inspired instruments of "the rule of man," "the rule of virtue," "the rule of law," or "state control," among many others, it is taken over by a modern epistemic condition, no matter whether it is judged to be reactionary, progressive, or worth critical inheritance. 


\section{Chapter 7 Shadows of traditions in China's modernity: Rethinking transnational communication in the discourse shifts on the rule of law}

In the last three chapters, I have analyzed the construction of traditions in the Chinese discourses on the rule of law since the advent of Communist rule. What, then, is the underlying pattern of change shown by the case? Some may argue that, although one finds in the discourses the insistence on Marxism, the reaffirmation of Confucianism, and varied understandings about the rule of law, the discourse shifts on the whole show the diffusion of Western constitutionalism in China. One has reason, indeed, to reach such a conclusion. Yet, from the perspective of communication studies, to stop at this would be an oversimplification of the case at hand. By saying so, however, I do not mean to suggest that phenomena of diffusion do not exist in the case. On the contrary, I believe that the diffusion or dominance of the modern epistemic condition, is that which underlies the Chinese articulations of the rule of law. Specifically, the effects of this diffusion can be found on two related levels. First, modern epistemology significantly influences the construction of traditions, and its impacts are far from uniform. The diversity of influence not only can be seen within any single order of discourse, but also can be found across different orders of discourses. Second, the fact that there may arise different understandings of traditions under the modern condition suggests that the following two phenomena may simultaneously emerge, in intriguing ways, when communication researchers analyze the current case. On the one hand, different interpretations of traditions may lead to varied observations of the case; on the other hand, apparently similar analyses may in fact be based on dissimilar perceptions of traditions. 
In the following parts of this conclusion chapter, I will review the influence of modern epistemology on the two levels above-mentioned, and then consider what this case study has to offer for further thinking about transnational communication and China's modernity.

\section{The changing shapes of traditions in Chinese socialism}

In the preceding chapters I have discussed the impact of modern epistemology within four orders of discourse respectively. In this chapter, I will review how the modern epistemic condition orients, in varied ways, the narrations of traditions across different orders of discourse. Specifically, I will highlight the ways in which traditions have been varyingly interpreted within changing social contexts. It is notable that, in the Chinese discourses on the rule of law, there are discussions about two pairs of ideas both of which are major conceptual constructs that emerged in China's modernity. The first is "the rule of man" versus "the rule of law," both of which are believed to be traceable to the remote past; the second pair is yet used to talk about far more recent history or envisions of history, namely, "Communism" (or socialism) versus "capitalism." In the following paragraphs, I will discuss how the rule of man, the rule of law, socialism, and capitalism, when described respectively as a tradition, have been articulated in China's changing discourses on the rule of law. As will be shown, as the discursive products of the modern condition, the four have been defined and then reconstructed to meet various social needs.

In Chapter 3, I have pointed out a number of forms in which meanings may change in discourse shifts. One of the forms is that, while the same concept may appear in several orders of discourse, its interconceptional relations with the core idea of the orders 
of discourse may transform. This can be seen, for example, in the wavering meanings of "the rule of man" in relation to the rule of law. When it appeared in the discourses on discipline and legality in the first two decades of the People's Republic, the rule of man was depicted as a tradition which had minimal respect for law and discipline and, therefore, had negative impacts on the Communist Revolution. Later in the post-CulturalRevolution years, however, it was instead portrayed as a residue of the past that fostered not only legal nihilism but also despotism and irrational loyalty to monarchy, which were thought to have been inherited in the post-1949 Communist political movements in China. Then, after the rule of virtue was officially promoted, the rule of man was salvaged as an "enlightening" heritage for its emphasis on moral modeling, and thereby legitimacy was granted to the advocacy of socialist virtue among Communist cadres, which was meant to combat the vicious impact of the imported market economy. As such, "the rule of man" has been caught between the aspiration for revolutionary victory, reflections on revolutionary arbitrariness, and an apologia for the indigenous leaning toward morality, yet all of which being moments under the modern condition where a national past emerges, either as an evil burden on the new China, or as a piece of treasure to repossess for its power to counter foreign threats.

Another way through which traditions take different shapes in discourse shifts is the re-summoning of ideas repudiated before, which can be seen in the changing articulations of "the rule of law" tradition. Once treated as a symbol of hypocrisy of both the domestic capitalists and the West, it has become an acclaimed part of the capitalists' struggle with feudalism, a social ideal rightfully upholding human rights, and an inspiring model for China to look to despite its "historical limits." As Western rule of law is touted as an 
advanced mode of governance, socialist legality is relegated from a status of superiority to one of inferiority. Thus, a new "evolutionary hierarchy" is curiously formed, one in which the socialist self, seen as overshadowed by a feudal past, is placed below the capitalist other. This contrasts sharply to the class-based historical linearity prescribed in the Marxist-inspired official ideology where socialism is undisputedly above both feudalism and capitalism.

"Socialism" and "capitalism" as two traditions have also been objects of transformative reconstruction. As I have discussed in Chapter 3, in discourse shifts, there may be cross-cutting agendas that stand behind seemingly unrelated—or remotely related-topics which appear in various orders of discourse. However, even for a crosscutting agenda, traditions may well still be constructed in varied ways, as are the cases of socialism and capitalism. In the discourse shifts on the rule of law, a typical agenda of this kind is that of maintaining Party rule, which can be found in the talk about the class nature of law, rightist conspiracy, combating corruption, socialist spirituality and the rule of virtue, oversight, as well as socialist harmony. In these various discourses which serve the same social purpose,${ }^{1}$ the depiction of the socialist and the capitalist traditions took drastic turns. In the talk about the class nature of law and rightist conspiracy, socialism was portrayed as one defined by revolutionary antagonism, and thus the socialist rule of law was to displace the hypocritical capitalist one, since everything old should be rejected for its association with the interests of past reactionary classes. In the 2000s, however, it is contended that the socialist cause led by the Party has been one that seeks to resolve

\footnotetext{
${ }^{1}$ It should be noted that these discourses also served other social purposes, but they do share common ground in rendering legitimacy to Communist rule.
} 
conflicts by building non-confrontational social relations, and thus a "socialist harmonious society" is conceivable, which is to inherit the spirit of traditional Chinese humanism critically. On the other front, in the talk on anti-corruption and socialist spirituality, Western capitalism was identified as something insidious that spread the seeds of avarice, which the Party was to resist through supplementing the rule of law with the rule of virtue, so as to protect its reputation and integrity in a seducing market economy. This adversarial view, however, was overthrown by those who contended that the capitalist tradition was what nurtured the rule of law in the West, and that, considering China's limited development of capitalism, the Party is condonable for not having formed mature understanding of constitutionalism and oversight.

In fact, the changing articulations of "socialism" and "capitalism" are only two examples which reflect the transformation of domestic power relations in socialist China. If power can be defined as that which enables the exercise of human agency, one may argue that "the rule of law" has constituted a resource of power, one that enables various quarters of the society to pursue their respective agenda, which has potential impact on the changing balance of social hegemony. The ruling elites may use "the rule of law" in different ways under different circumstances—sometimes denigrating while other times extolling it-to pursue different objectives such as to sustain legitimacy, to spur economic growth, to maintain social order, and to gain international recognition. However, others may also mobilize "the rule of law" to serve purposes and address concerns in ways that either run parallel to or contradict what those in office would be willing to see. While the official definitions of "the rule of law"-which mainly buttresses state power-were often echoed in the mass media, other meanings were also 
promoted to contest the absolute dominance of the state, such as those that emerged in the critique of the rule of man, in the advocacy of rights protection, and in the critical reading of the rule of virtue. In response, the ruling elites were compelled to reconfigure state orthodoxy and seek new ground for legitimacy. From a guideline for adversarial class struggle, Marxism has been re-aligned into one that also highlights rights protection and social harmony. Thus, even though apparently the Party is to be Marxist, it has been retuning its approach of governance which now bears the mark of both Western liberalism and China's own imperial past. These latter two, albeit alien to Marxism in the eyes of many, have also been molded to suit the mandate of Communist rule. As such, power relations have gone through transformative reproductions, "the rule of law" not a vocabulary solely belonging to the state yet constantly being re-articulated by the state to refine its basis of legitimation.

\section{Patterns of communication in the discourse shifts on the rule of law}

What patterns of transnational communication, then, can be observed in the shifting discourses on the rule of law in socialist China? Do the changing articulations of traditions reflect a leaning towards Western conceptions of social organization? Or do they demonstrate the clash between Chinese and Western ideas?

It is arguable that China's modernity, of which Chinese socialism has been a major part, is about the nation re-envisaging and re-situating itself in relation to the "modern West" including the latter's world of ideas about social organization. In the efforts of reenvisioning the ideal, both the foreign and the native have been discursively constructed by the Chinese to meet the needs of contingent social agendas. As has been discussed, as 
China's own past was reoriented to meet "socialist" needs, Marxism itself as the official state ideology was also subject to re-articulation, both by those to sustain and those to contest Party rule. Meanwhile, Western liberal conceptions of law and governance were redeemed as the influence of the guideline of class struggle was diminished and as China was opened up to the world. In all this redefinition of the native and the foreign, what one finds is not any teleological modernization that dictates the fate of traditions, but rather a tendency in which a changing society pushes both "the self" and "the other" to be reknown and re-appraised, which are sometimes drawn closer while other times dragged apart.

However, some may ask, even though various traditions-and "the rule of law" itself-have been defined in diverse ways, is there any latent meaning underlying the discourse shifts on the rule of law, in terms of the diffusion of the Western or the resurrection of the native? Does the increased emphasis on notions such as rights and oversight in the discourses not indicate the diffusion of Western liberal views of law which hold state power in suspicion? And are the newly re-emerging notions associated with Confucianism not a sign of the revival of the indigenous to confront foreign threats? Some may even point out that, although apparently the explicit lines between various traditions have been blurred, what underlies such a hybridity is a tendency to reaffirm only one set of traditions but not the others, and the answer is to be chosen between Chinese ones and Western ones.

Such assertions, however, tend to polarize between "the Chinese" and "the Western," approaching them as if they were immutable and incompatible. While I argue, for the current case, that a pattern of diffusion can be seen in terms of the impact of modern 
epistemology on the construction of traditions, I also believe that under the modern condition it is possible to form diverse rather than uniform interpretations of "the Chinese" and "the Western," some noting the common ground between the two whereas others highlighting their differences. Based on a vast variety of interpretations, then, both similar and dissimilar conclusions can be drawn with regard to the patterns of communication shown by the case. In this section, I will attempt a review of a number of scenarios (summarized in the table below) in which various patterns may be observed in the Chinese discourse shifts on the rule of law, based on different understandings of traditions. For the purpose of analysis, we need to consider the interpretation of traditions on three fronts: those about Western rule of law, those about imperial China, and those about Marxism. As will be shown, a variety of observations may arise, which respectively highlight the pattern of diffusion, confrontation, hybridization, or their combinations in the case. However, these observations are arguably also products of the modern condition, as soon as they are based on reflections on China where the nation is understood in terms of its differences from or parallels with the West. While the diversity of observations is attributable to varied interpretations of Western rule of law, imperial China, and Marxism (as is shown throughout the table), similar observations may nevertheless also be based on diverging views of traditions (as can be seen between scenario 3 and 5, or between 4 and 6).

\begin{tabular}{l|l|l|l|l}
\hline & $\begin{array}{l}\text { Views on } \\
\text { Western } \\
\text { rule of law }\end{array}$ & $\begin{array}{l}\text { Views on } \\
\text { imperial China }\end{array}$ & $\begin{array}{l}\text { Views on } \\
\text { Marxism }\end{array}$ & $\begin{array}{l}\text { Pattern of } \\
\text { communication } \\
\text { observed in socialist } \\
\text { China }\end{array}$ \\
\hline Scenario & Sovereignty & $\begin{array}{l}\text { Discretionary } \\
\text { power in the }\end{array}$ & $\begin{array}{l}\text { legal } \\
\text { instrumentalism }\end{array}$ & $\begin{array}{l}\text { Hybridization } \text { the rule of } \\
\text { man hybridized with }\end{array}$ \\
\hline
\end{tabular}




\begin{tabular}{|c|c|c|c|c|}
\hline 1 & of law & $\begin{array}{l}\text { rule of man } \\
\text { neglecting the } \\
\text { supremacy of } \\
\text { law }\end{array}$ & $\begin{array}{l}\text { for the purpose } \\
\text { of revolution }\end{array}$ & $\begin{array}{l}\text { Marxist banner), } \\
\text { followed by the diffusion } \\
\text { of Western beliefs } \\
\text { (supremacy of law } \\
\text { qualified by Marxist } \\
\text { ideology) }\end{array}$ \\
\hline $\begin{array}{l}\text { Scenario } \\
2\end{array}$ & $\begin{array}{l}\text { Both } \\
\text { restraining } \\
\text { and } \\
\text { empowering } \\
\text { government }\end{array}$ & $\begin{array}{l}\text { Arbitrary rule; } \\
\text { authoritarianism }\end{array}$ & Arbitrary rule & $\begin{array}{l}\text { Diffusion (of the Western } \\
\text { idea of limiting the state), } \\
\text { AND hybridization } \\
\text { (reinforcement of the } \\
\text { indigenous with the } \\
\text { banner of Marxism) }\end{array}$ \\
\hline $\begin{array}{l}\text { Scenario } \\
3\end{array}$ & $\begin{array}{l}\text { Oversight } \\
\text { and human } \\
\text { rights }\end{array}$ & Autocracy & -- & $\begin{array}{l}\text { Diffusion of Western } \\
\text { ideas }\end{array}$ \\
\hline $\begin{array}{l}\text { Scenario } \\
4\end{array}$ & $\begin{array}{l}\text { Limiting the } \\
\text { state }\end{array}$ & $\begin{array}{l}\text { Non-total } \\
\text { control by the } \\
\text { state, } \\
\text { encouraging } \\
\text { intellectual } \\
\text { engagement in } \\
\text { politics }\end{array}$ & -- & $\begin{array}{l}\text { Hybridization (continuity } \\
\text { of the indigenous with a } \\
\text { foreign outlook) }\end{array}$ \\
\hline $\begin{array}{l}\text { Scenario } \\
5\end{array}$ & $\begin{array}{l}\text { Supremacy } \\
\text { of law }\end{array}$ & $\begin{array}{l}\text { Loose state } \\
\text { control, } \\
\text { vagabond } \\
\text { culture } \\
\text { disregarding law }\end{array}$ & -- & $\begin{array}{l}\text { Diffusion of Western } \\
\text { respect for law }\end{array}$ \\
\hline $\begin{array}{l}\text { Scenario } \\
6\end{array}$ & -- & $\begin{array}{l}\text { The importance } \\
\text { of regulating } \\
\text { social ideas }\end{array}$ & $\begin{array}{l}\text { The emphasis on } \\
\text { ideological } \\
\text { leadership }\end{array}$ & $\begin{array}{l}\text { Hybridization (of } \\
\text { traditional and Western } \\
\text { modes of thought) }\end{array}$ \\
\hline $\begin{array}{l}\text { Scenario } \\
7\end{array}$ & $\begin{array}{l}\text { Oversight } \\
\text { and human } \\
\text { rights }\end{array}$ & $\begin{array}{l}\text { The state not } \\
\text { penetrating into } \\
\text { every sector of } \\
\text { society }\end{array}$ & $\begin{array}{l}\text { Total control of } \\
\text { society by the } \\
\text { state }\end{array}$ & $\begin{array}{l}\text { Confrontation between } \\
\text { Marxism and Western } \\
\text { liberalism }\end{array}$ \\
\hline
\end{tabular}




\begin{tabular}{l|l|l|l|l}
\hline $\begin{array}{l}\text { Scenario } \\
8\end{array}$ & -- & $\begin{array}{l}\text { The advocacy of } \\
\text { harmony as } \\
\text { constructive } \\
\text { care for life }\end{array}$ & Antagonism & $\begin{array}{l}\text { Diffusion (of Western } \\
\text { antagonism), and then } \\
\text { hybridization } \\
\text { (resurrection of the } \\
\text { native qualified by the } \\
\text { insistence on Marxism) }\end{array}$ \\
\hline
\end{tabular}

As I have discussed in Chapter 2, in certain accounts the tensions and crises of the rule of law as a Western tradition are highlighted, while in others they are downplayed. More specifically, contemporary Chinese authors tend to describe the rule of law as something that has a set of unified meanings, the essence of which is often summarized as the supremacy of law. It is arguable that such an understanding of the rule of law is partly a result of the reflections on the political movements in the early Communist decades - especially the Cultural Revolution - when discretionary power triumphed over law, which was thought to be a typical feature of Chinese traditional rule of man inherited in Communist legal instrumentalism. Viewing the rule of law as a Western tradition that upholds the supremacy of law, one may argue that, from the early decades of Communist China to the post-Cultural-Revolution years, what is observable is first the prevalence of traditional rule of man hybridized with the Marxist banner of revolution, and then the dominance of Western beliefs, in the form of the popularization of the supremacy of law qualified by the insistence on Marxism.

However, instead of seeing the rule of law as something with coherent meanings, some highlight the potential incompatibility among various elements of the rule of law, which I have discussed in Chapter 2. For instance, for the five ends of the rule of law she identifies, Rachel Kleinfeld notes that they are "distinct, likely to meet different support 
and resistance within countries under reform, and often in tension with one another in practice" $(2005$, p. 3), and, as an example, Kleinfeld explains how the rule of law may both restrain and empower the state (p. 24). If one sees such tensions within the rule of law, then, he or she may observe the co-existence of opposing patterns in the postCultural-Revolution call for legal construction. On the one hand, one may suggest that the rise of "the rule of law," with its emphasis on restraining the government, challenges the pre-existing mode of governance adopted by the Communists which resembled imperial arbitrary rule. As such, what can be observed is the diffusion of the Western idea of limiting the state. On the other hand, one may also identify a pattern of reinforcement of the Chinese tradition: the rule of law emphasizes the need to maintain social order, thus justifying the authority of the state. In fact, some advocated the rule of law in China because they believed it could help rein in destabilizing centrifugal practices that threatened the central rule of the Party. Therefore, one may argue, the emphasis on the rule of law, an idea from the West, in fact sustains China's imperial tradition which stressed the importance of honoring the authority of the ruler. Of course, one may add, this reinforcement has another hybrid twist because what is now supposed to be strengthened by the rule of law is not imperial rule but that of a Communist Party.

Yet some may ask: if the term "the indigenous Chinese tradition" means the perceived key characteristics of imperial China, is this traditional imperial China a polity in which the monarch possessed absolute and total power? It is arguable that different views on this issue may lead analysts to different conclusions about the question of whether contemporary popularization of "the rule of law" is a trend that erases the autocratic tradition, or a reinvigoration of some "pro-liberal" tendencies in imperial 
China. We need to keep in mind that "imperial China" and "the Western" may not always be opposed to each other in the eyes of those who emphasize the parallels between the two.

To be specific, if one believes that imperial China was based on autocracy, in which the power of the monarchy reached every sector of society whereas the society did not possess any meaningful degree of autonomy (Xie D., 1995; Ma, 2005), this view may lead one to conclude that the discourses on the rule of law, with their increased emphasis on human rights and on congressional oversight, offer an example of the rise of Western ideas and the decline of traditional Chinese conceptions. However, some have pointed out that imperial China was not a society characterized by the total power of the monarch. For example, Kenneth Lieberthal (2004) argues that "the imperial government restricted its actual efforts to a few rather circumscribed spheres," which were limited to "propagating ideology, suppressing rebellion (in other words, protecting its own power), maintaining national defense, gathering revenues to sustain itself, selecting its successors, and constructing public works" (p. 19). Tsou Tang (1986) offers similar observations, suggesting that imperial China may be said to be authoritarian but not totalitarian, as the monarchy did not have total control over the society (pp. xxii-xxiii). Scholars have cited evidence of this absence of total control in several social areas. For the economic realm, Helen Dunstan (2006) points out that anti-state-interventionism discourses were not new to imperial China at all and can be found in at least the Song and the Qing dynasties. Tsou also observes that "in the countryside, there was what can be called a system of precapitalist 'free enterprise' in agricultural production, landownership, and rural trade," and that "local-level associations were quite strong vis-à-vis the formal bureaucracy" 
(1986, p. xxiii). For the political realm, both Yu Yingshi (2004a) and Wang Yi (n.d.) in their analysis of Confucianism in imperial China highlight how the Confucian literati advocated intellectual engagement in political affairs. Wang particularly notes that the literati had the imperial state honor Confucianism because they believed such honoring would boost their social status and help them restrict the power of the emperor. Lastly, in the area of culture, some note that the Chinese long honored moral self-cultivation or self-discipline (Liang S., 1949/2005), which disproves the perception that everything was supposed to be controlled by the state in imperial China. Arguably, such views of imperial China as a not-so-autocratic polity would lead one to conclude instead that the modern Chinese discourses on "the rule of law," for its emphasis on limiting state power, demonstrate not so much the pure diffusion of Western beliefs. Rather, they show the sustaining of traditional patterns of social organization or indigenous Confucian ideas, the continuity of which nonetheless assumes a hybrid form as the old ideas are now expressed with a notion from the West (which also suggests restraining state power), and as the limits imposed on government are now supposed to be facilitated through law but not through the public opinion of the Confucian literati.

Meanwhile, the view of a non-autocratic China may also lead one to observe the diffusion of Western ideas. As has been discussed in Chapter 2, some contend that Confucianism was not the effective dominant ideology in imperial China, and that traditional China was in fact a society dominated by "vagabond culture," which did not respect any laws or rules but rather encouraged centrifugal practices that undermined' central state power (Wang Xuetai, 2007). As Wang Xuetai argues, vagabond culture is characterized by anomaly, and thus is entirely incompatible with the rule of law (p. 726). 
He also points out that many social factors that gave rise to vagabond culture in imperial China can be found in contemporary China, particularly the co-phenomena of socioeconomic change and population growth which disrupts orderly life. If one follows Wang's interpretation and believes that the essence of Western legal tradition lies in the supremacy of law, he or she may suggest that the rising popularity in China of "the rule of law"-as a notion from the West that advocates respect for law-reflects the diffusion of Western ideas; or more specifically it reflects the efforts of some Chinese to mobilize a concept from outside to address internal problems such as centrifugal practices and social conflicts that emerge in China's reform.

As we are looking at a case in socialist China, we also need to consider a third issue: if we see Marxism or socialism itself as a somewhat established tradition in China-the Communists having been in power for more than half a century-is this newly established tradition Chinese or Western? For the thriving discourses on the rule of law in socialist China, are they demonstrating a Western tradition replacing indigenous values in the mask of Marxism? Or are they showing one Western tradition taking over another in China? Chen Pingyuan, a renowned Chinese intellectual, once commented:

The Western culture we have accepted for more than a century-from notions of equality or evolution introduced by missionaries, to the advocacy of science and democracy by the May Fourth Movement, or the widespread adoption - and later national implementation—of Marxism, has accumulated so many meanings in our daily life that it has itself become a new cultural tradition. While criticizing Eurocentrism, how should we regard these now inseparable components of our own heritage?" (Chen P., 2003, p. 119)

In fact, the notion that Marxism has merged into China's heritage brings up a question about the differences and similarities between imperial China and socialist China. Some note that the two are both known for their legal instrumentalism (Xie H., 
1995; Chen J., 1999). It is argued that such instrumentalism stresses the supremacy of the will of the state or of the ruler rather than that of law. As such, the notion of the class nature of law, or law as a tool for class struggle, constitutes the foundation of "a modern rule-of-man system" in socialist China (Xie H., 1995, p. 50). If one follows this view that socialism in China -albeit having Marxism rather than Confucianism as the state ideology — features a modern form of the imperial model of governance, one may then suggest that the discourse shifts on the rule of law, with the decreased emphasis on the class nature of law, in fact indicates the erosion of the instrumental conception of law prevalent in imperial China, although apparently it rather seem to reflect the decline of Marxist ideas. As evidence, one may refer to the continued critique of "the rule of man" in the post-Cultural-Revolution decades, which coincided in time with the decreasing mention of law as a tool for class struggle. The identification of parallels between imperial China and socialist China may yet also lead one to observe the continuity of both foreign and indigenous legacies in the form of hybridity. For example, one may note how both in the ancient times and in Communist China the importance of regulating social ideas is stressed. Thus, the contemporary revival of the notion of the rule of virtue, with which the Party intended to reclaim its ideological leadership, may be interpreted as evidence of the sustained vitality of both traditional and Marxist modes of thought.

However, although certain affinities are observable between imperial China and socialist China, their differences are more prominent in the eyes of some. Tsou particularly points out that, although "the substantive content of some Chinese traditions...facilitated the acceptance of Marxism and the Leninist party and affected later developments under the Communist regime," and despite the fact that "the form of 
sociopoliticalcutural system developed under the Chinese Communist movement and regime paralleled that of traditional China," "there was a change in content" $(1986, p$. xxxiv). This change in content, according to Tsou, consists in the degree to which the state penetrates the society. Tsou argues that, in actual fact, in imperial China the state "lacks the capability of penetrating very deeply" (p. xxii): "the formal, centralized bureaucracy of the [traditional] Chinese state extended downward only to the xian [county] level" (p. xxiii); the state regulated ideas and education through a civil exam system but normally did not engage in direct interference; civil society groups-although not as powerful as those in Europe - such as familial clans and secret societies could exert their own influence locally; and popular culture enjoyed a certain degree of independence (1994, p. 238). In contrast, in socialist China, the organizations of a Leninist party penetrate into every sector and every level of social life, "almost occupying the entire social space with the Party claiming leadership over everything" (pp. 238-239), and such a tendency reached its height in China during the Cultural Revolution (1986, pp. xxiii-xxiv), which was branded as a movement to push forward the "proletarian dictatorship" led by the Communist Party. With this imperialist-socialist contrast in mind, the retreat of the language of total dictatorship and the rise of liberal themes such as oversight and human rights in contemporary Chinese discourses would seem to be not so much a confrontation between the old China and the modern West as a clash between the declining Marxist orthodoxy and the rising Western liberal ideas.

Although Marxism may be opposed to certain other Western ideas, some may point out that it represents the Western cultural spirit in the most full-fledged form. As some argue, a major difference between Chinese and Western cultures lies in the fact that the 
Chinese honor harmony, whereas Westerners tend to resort to intense struggle as a solution to social problems, and tend to form adversarial blocks in the process (Liang S., 1949/2005). Taking a similar view and indicating that Marxism inherits the Western spirit of antagonism, Yu Dunkang, a scholar of Chinese philosophy, noted in a series of public lectures that after the Communists came to power the life of the Chinese was for a long time dominated by the mindset of struggle and revolution. According to him, this trend was reversed in recent decades as the Chinese came back to what they had long believed in, that is, the idea of harmony. This traditional Chinese idea represents a type of "constructive care for life" that differs from the potentially destructive Western antagonism, the extremist form of which can be found in the idea of revolution (Yu D., 2006, 2009). Following this interpretation of the path of development of Chinese socialism, one may identify in the discourses of law, first, a diffusion of Western antagonism and, afterwards, the resurrection of traditional Chinese ideas of harmony. One may argue that this resurrection, albeit with a hybrid outlook as "harmony" is now qualified as "socialist," is in essence a return to the core Chinese spirit.

\section{Rethinking transnational communication and China's modernity}

Considering the variety of observations that may be yielded, can one then argue that all three models of transnational communication-diffusion, confrontation, and hybridization—are valid? As I have discussed in Chapter 1, current theories in the field tend to treat traditions as self-evident. I believe that the current case study can help us explore a way to reorient the conceptions of diffusion, confrontation, and hybridization, in a manner that highlights the "genealogy" of traditions. 
I argue that, with a perspective of epistemology, the validity of the diffusion model should be recognized when it is rid of "modernization biases" and used instead to consider the diverse impacts that modern epistemology exerts on modern constructions of traditions. However, as a result of the inner tension of modern Western knowledge, within the diffusion there may emerge confrontations, for example, between Marxist and liberal lines of thought. Yet confrontation also takes place on another level, that is, the rise of the non-Western in face of Western hegemony. In this connection, confrontation is not a counter-current of diffusion. Rather, it is a product of the modern epistemic condition which reinvigorates the native in face of the intruding foreign yet also in terms of the foreign. As such, confrontation may also be read as a hybridization in which the continuity of the native features a foreign twist. It is noteworthy that, while emphasizing the impact of the hegemony of modern epistemology, I do not mean that this hegemony is permanent. Although it remains difficult to foresee what type of alternative epistemology may effectively challenge the modern epistemic framework and eventually form a new hegemony, one has reason to believe that the dominance of modern epistemology, or at least its forms of dominance, will be transformed in the long run. Lastly, the current case also corroborates the model of hybridization, yet it shows that hybridization occurs within the larger framework of diffusion. On the one hand, hybridity consists in the diverse constructions of traditions in the discourses on law, where "the Chinese" and "the Western" are aligned with each other under the modern condition; on the other hand, it is about the plurality of possibilities in which the patterns underlying the discourse shifts may be interpreted-or, it is a hybridity of observations yielded on the basis of divergent interpretations of traditions. 
In fact, it is arguable that Chinese socialism, an important episode of China's modernity where various indigenous and foreign ideological resources are mobilized, is a typical case of such a dual hybridity. In explaining the appeal of Communism to the Chinese, Joseph Levenson (1968a) suggests that it lies in the way in which Communism is at once both a critic of the "pre-Communist West" that "impinged on China," and a pointer to the possibility that the Chinese "need not fall back on a desperate traditionalism" to establish "the equivalence of China and the West" (p. 134). Despite the profound transformations of Chinese socialism since then, Levenson's observation arguably still holds true today. As the Chinese continue to deploy discursive resources of various types to advance varying social agendas, the fashions in which Chinese socialism figures as a hybridity will persist. The discourse shifts on the rule of law do not substantiate the view that the traditional China is being revitalized, or the view that China is taking steps to reach a known destination exemplified by the West. Rather, they show a picture in which China's destination is not so clear, and in which we see efforts to search for a way. However, the Chinese attempts to re-envisage social ideals are nevertheless mediated by modern epistemology. As such, there emerged, in the discourses on the rule of law, shadows of Chinese and Western traditions that are cast in the light of the modern epistemic condition. As these traditions acquire parallel or opposing meanings, they become part of the social efforts to sustain or contest existing modes of social organization. Thus, in the Chinese discourses, the meanings of "the rule of law" remain an object of contention and strategic articulation, as they have long been after the modern West became, for China, what is to be reckoned with. 


\section{References}

Alitto, G. S. (1979). The last Confucian: Liang Shu-ming and the Chinese dilemma of modernity. Berkeley: University of California Press.

Barrett, M. (1991). The politics of truth: From Marx to Foucault. Stanford: Stanford University Press.

Berman, H. (1983). Law and revolution: The formation of the Western legal tradition. Cambridge: Harvard University Press.

Chan, A., Rosen, S., \& Unger, J. (Eds.). (1985). On socialist democracy and the Chinese legal system: The Li Yizhe debates. Armonk: M. E. Sharpe Inc.

Chen, Dingding (2005). Explaining China's changing discourse on human rights, 19782004. Asian Perspective, 29(3), 155-182.

Chen, J. (1999). Chinese law: Towards an understanding of Chinese law, its nature and development. Cambridge, MA: Kluwer Law International.

Chen, Pingyuan (2003). Scholarship, ideas, politics. In Wang, Chaohua (Ed.), One China, many paths (pp. 108-127). London: Verso.

Chouliaraki, L., \& Fairclough, N. (1999). Discourse in late modernity: Rethinking critical discourse analysis. Edinburgh: Edinburgh University Press.

Cohen, P. (1984). Discovering history in China: American historical writing on the recent China past. New York: Columbia University Press.

The Constitution of the People's Republic of China. (2003). Beijing: Fa Lü Chu ban she.

Cui, Min, \& Li, Kefa (1998). Fa de jie ji xing yu she hui xing de lun zheng (The debates on the class nature and the social nature of law). In Guo Daohui, Li Buyun, \& Hao Tiechuan (Eds.), Zhongguo dang dai fa xue zheng ming shi lu (A record of contentions in contemporary Chinese legal studies) (pp. 203-213). Changsha: Hunan ren min chu ban she.

Cui, Yongdong (2004). Zhong xi fa lü wen hua bi jiao (Comparatives studies on Chinese and Western legal cultures). Beijing: Peking University Press.

Deng, Zhenglai (2006). Zhong guo fa xue xiang he chu qu (Where should Chinese legal studies go). Beijing: Shang wu yin shu guan.

Dirlik, A. (1996). Reversals, ironies, hegemonies: Notes on the contemporary historiography of modern China. Modern China, 22, 243-284.

Dreyfus, H., \& Rabinow, P. (1983). Michel Foucault: Beyond structuralism and hermeneutics. Chicago: University of Chicago Press. 
Du, Runsheng (2005). Du Runsheng zi shu: zhongguo nong cun ti zhi bian ge zhong da jue ce ji shi (Du Runsheng's memoir: Documenting major policies in China's rural reforms). Beijing: Ren min chu ban she.

Duara, P. (1995). Rescuing history from the nation: Questioning narratives of modern China. Chicago: The University of Chicago Press.

Dunstan, H. (2006). State or merchant? Political economy and political process in 1740s China. Cambridge: Harvard University Press.

Edwards, D., \& Potter, J. (1992). Discursive psychology. London: Sage.

Engels, F. (1940). Dialectics of nature (Clemens Dutt, Trans.). New York: International Publishers.

Fairbank, J. K., Reischauer, E. O., \& Craig, A. M. (1965). East Asia: The modern transformation. Boston: Houghton Mifflin Company.

Fairclough, N. (1992). Discourse and social change. Cambridge: Polity Press.

Fairclough, N. (1995). Critical discourse analysis. London: Longman.

Fairclough, N. (2001). Language and power. Harlow: Longman.

Fairclough, N. (2003). Analysing discourse: Textual analysis for social research. London: Routledge.

Fairclough, N., et al. (2004). Critical realism and semiosis. In J. Joseph, \& J. M. Roberts (Eds.), Realism, discourse and deconstruction (pp. 23-42). London: Routledge.

Foucault, M. (1970). The order of things: An archaeology of the human sciences. New York: Pantheon Books.

Foucault, M. (1972). The archaeology of knowledge (A. M. Sheridan Smith, Trans.). London: Tavistock.

Foucault, M. (1980). Truth and power. In Colin Gordon (Ed.), Power/knowledge:

Selected interviews and other writings, 1972-1977 (pp. 109-133). Brighton: Harvester.

Foucault, M. (1983). The subject and power [Afterword]. In H. Dreyfus, \& P. Rabinow, Michel Foucault: Beyond structuralism and hermeneutics (pp. 208-228). Chicago: University of Chicago Press.

Foucault, M. (1996a). Foucault responds to Sartre. In Sylvère Lotringer (Ed.), Foucault live (Lysa Hochroth \& John Johnston, Trans.) (pp. 51-56). New York: Semiotext(e).

Foucault, M. (1996b). History, discourse and discontinuity. In Sylvère Lotringer (Ed.), Foucault live (Lysa Hochroth \& John Johnston, Trans.) (pp. 33-50). New York: Semiotext(e). 
Foucault, M. (1997). The ethics of the concern for self as a practice of freedom. In P. Rabinow (Ed.), Ethics: Subjectivity and truth (R. Hurley et al, Trans.) (pp. 281-301). New York: The New Press.

Foucault, M. (2003a). On the archaeology of the sciences: Response to the epistemology circle. In P. Rabinow, \& N. Rose (Eds.), The essential Foucault (pp. 392-422). London: The New Press.

Foucault, M. (2003b). "Society must be defended": Lectures at the Collège de France, 1975-76 (David Macey, Trans.). New York: Picador.

Friedman, J. (1995). Global system, globalization and the parameters of modernity. In M. Featherstone, S. Lash \& R. Robertson (Eds.), Global modernities (pp. 69-90). London: Sage.

Friedman, T. L. (2000). The Lexus and the olive tree: Understanding globalization. New York: Anchor Books.

Fukuyama, F. (1995). Reflections on the end of history, five years later. History and Theory, 34(2), 27-43.

García Canclini, N. (1995). Hybrid cultures: Strategies for entering and leaving modernity (C. L. Chiappari \& S. L. López, Trans.). Minneapolis: University of Minnesota Press.

Goldman, M. (2005). From comrade to citizen: The struggle for political rights in China. Cambridge: Harvard University Press.

Gong, Pixiang (2006). Fa zhi xian dai hua de tiao zhan (The challenge of legal modernization). Wuhan: Wuhan da xue chu ban she.

Gross, D. (1992). The past in ruins: Tradition and the critique of modernity. Amherst: The University of Massachusetts Press.

Hall, S. (1979). Culture, the media and the "ideological effect." In James Curran, et al. (Eds.), Mass communication and society (pp. 315-348). Beverly Hills: Sage.

Halliday, M. A. K. (1978). Language as social semiotic: The social interpretation of language and meaning. London: Edward Arnold.

Held, D. (2003). Cosmopolitanism: Taming globalization. In D. Held \& A. McGrew (Eds.), The global transformations reader: An introduction to the globalization debate (pp. 514-529). Cambridge: Polity.

Held, D., \& McGrew, A. (2003). The global transformations reader: An introduction to the globalization debate. Cambridge: Polity.

Huang, Xingtao (2009). "Gai nian shi" shi ye yu wu si yan jiu (The horizon of "the 
history of ideas" and May Fourth studies). Chinese Academy of Social Sciences Review, 52. Retrieved April 27, 2010, from http://qk.cass.cn/zgskb/wqhg/20090416/200904/t20090420_7946.htm

Hutchby, I., \& Wooffitt, R. (2008). Conversation analysis. Cambridge: Polity Press.

Jiang, Lishan (2006). Fa lü xian dai hua: Zhongguo fa zhi dao lu wen ti yan jiu (The modernization of law: A study on China's path of the rule of law). Beijing: Zhongguo fa zhi chu ban she.

Joseph, J., \& Roberts, J. M. (2004). Introduction: Realism, discourse and deconstruction. In J. Joseph, \& J. M. Roberts (Eds.), Realism, discourse and deconstruction (pp. 119). London: Routledge.

Karim, Karim H. (1993). Constructions, deconstructions, and reconstructions: Competing Canadian discourses on ethnocultural terminology. Canadian Journal of Communication, 18, 197-218.

Karim, Karim H. (2003). Islamic peril: Media and global violence. Montreal: Black Rose Books.

Keith, R. C. (1994). China's struggle for the rule of law. New York: St Martin's Press.

Keith, R. C., \& Lin, Z. (2001). Law and justice in China's new marketplace. New York: Palgrave.

Kleinfeld, R. (2005). Competing definitions of the rule of law: Implications for practitioners. Carnegie Papers, no. 55. Washington, D.C.: Carnegie Endowment for International Peace.

Kraidy, M. M. (2002). Hybridity in cultural globalization. Communication Theory, 12(3), 316-339.

Kraidy, M. M. (2004). International communication from culture to hybridity. Conference Papers -- International Communication Association, 1. Retrieved September 25, 2008, from Communication \& Mass Media Complete database.

Kraidy, M. M. (2005). Hybridity, or the cultural logic of globalization. Philadelphia: Temple University Press.

Kuhn, T. (1996). The structure of scientific revolutions. Chicago: The University of Chicago Press.

Leng, Shao-chuan (1967). Justice in Communist China: A survey of the judicial system of the Chinese People's Republic. Dobbs Ferry: Oceana Publications, Inc.

Lerner, D. (1962). The passing of traditional society: Modernizing the Middle East. Glencoe: Free Press. 
Levenson, J. R. (1968a). Confucian China and its modern fate: The problem of intellectual continuity. Berkeley: University of California Press.

Levenson, J. R. (1968b). Confucian China and its modern fate: The problem of historical significance. London: Routledge and Kegan Paul.

Li, Shenzhi (2007). Introduction: Uncovering another China. In Wang Xuetai, You min wen hua yu zhongguo she hui (Vagabond cultures and Chinese society) (pp. 1-11). Beijing: Tong xin chu ban she.

Liang, Qichao (1922/2003). Xian qin zheng zhi si xiang shi (History of political thought in the pre-Qin period). Tianjin: Tianjin gu ji chu ban she.

Liang, Shuming (1949/2005). Zhongguo wen hua yao yi (The essence of Chinese culture). Shanghai: Shanghai ren min chu ban she.

Liang, Zhiping (1991). Xun qiu zi ran zhi xu zhong de he xie (In search of harmony within the natural order). Shanghai: Shanghai ren min chu ban she.

Liang, Zhiping (1997a). "Fa" bian (Explicating "law"). In Liang Zhiping (Ed.), Liang Zhiping zi xuan ji (Self-selected works of Liang Zhiping) (pp. 23-45). Guilin: Guangxi shi fan da xue chu ban she.

Liang, Zhiping (1997b). Zhongguo fa de guo qu, xian zai yu wei lai: yi ge wen hua de jian tao (The past, present and future of Chinese law: A cultural perspective). In Liang Zhiping (Ed.), Liang Zhiping zi xuan ji (Self-selected works of Liang Zhiping) (pp. 46-68). Guilin: Guangxi shi fan da xue chu ban she.

Liang, Zhiping (1997c). Fa lü shi zheng zhu yi zai zhongguo (legal positivism in China). In Liang Zhiping (Ed.), Liang Zhiping zi xuan ji (Self-selected works of Liang Zhiping) (pp. 69-100). Guilin: Guangxi shi fan da xue chu ban she.

Lieberthal, K. (2004). Governing China: From revolution through reform. New York: W. W. \& Norton Company.

Liu, Lydia H. (1995). Translingual practice: Literature, national culture, and translated modernity - China, 1900-1937. Stanford: Stanford University Press.

Liu, Lydia H. (2000). Ouzhou lu deng guang ying yi wai de shi jie: zai tan xi fang xue shu xin jin de zhong da bian ge (The world outside of the light of the European street lamp: More on the recent major changes in the Western scholarship). Dushu, 2000(5), 66-74.

Liu, Lydia H. (2004). The clash of empires: The invention of China in modern world making. Cambridge: Harvard University Press.

Lu, Jinbi, \& Tie, Li (1998). Jian guo chu qi si fa gai ge de de shi (The gains and problems of the judicial reform in the early years of the Repubilc). In Guo Daohui, Li Buyun, 
\& Hao Tiechuan (Eds.), Zhongguo dang dai fa xue zheng ming shi lu (A record of the contention on the science of law in contemporary China) (pp. 18-29). Changsha: Hunan ren min chu ban she.

Lubman, S. B. (1999). Bird in a cage: Legal reform in China after Mao. Stanford: Stanford University Press.

Lull, J. (2000). Media, communication, culture: A global approach. New York: Columbia University Press.

Luo, Zhitian (2003). Lie bian zhong de chuan cheng: Er shi shi ji qian qi de zhongguo wen hua yu xue shu (Inheritance within rupture: Chinese culture and learning in the early $20^{\text {th }}$ century). Beijing: Zhong hua shu ju.

Macdonell, D. (1986). Theories of discourse. Oxford: Blackwell.

Mao, Zedong (1991). Mao Zedong xuan ji (The selected works of Mao Zedong). Beijing: Ren min chu ban she.

McNeill, J. R., \& McNeill, W. H. (2003). The human web: A bird's-eye view of world history. New York: W. W. Norton \& Company.

Merquior, J. G. (1985). Foucault. London: Fontana, Press/Collins.

Miller, A. (2007). Hu Jintao and the sixth plenum. China Leadership Report, 20, 1-12.

Mills, S. (1997). Discourse. London: Routledge.

Mills, S. (2003). Michel Foucault. London: Routledge.

Mody, B. (Ed.). (2003). International and development communication: $A 21^{\text {st }}$ century perspective. Thousand Oaks: Sage.

Nederveen Pieterse, J. N. (2004). Globalization \& culture: Global mélange. Lanham: Rowman \& Littlefield.

Nederveen Pieterse, J. N. (2006). Globalization as hybridization. In M. G. Durham \& D. M. Kellner (Eds.), Media and cultural studies: Keyworks (pp. 658-680). Malden: Blackwell Publishing.

Palmer, B. D. (1990). Descent into discourse: The reification of language and the writing of social history. Philadelphia: Temple University Press.

Peerenboom, R. (2002). China's long march toward rule of law. New York: Cambridge University Press.

Peerenboom, R. (2007). China modernizes: Threat to the West or model for the rest? Oxford: Oxford University Press.

Philips, M. S. (2004). What is tradition when it is not 'invented'? A historiographical 
introduction. In M. S. Philips, \& G. Schochet (Eds.), Questions of tradition (pp. 329). Toronto: University of Toronto Press.

Porter, R. (1949, October 15). 11 Communists convicted of plot; Medina to sentence them Friday; 6 of counsel jailed in contempt. New York Times, pp. 1, 8. Retrieved October 3, 2008, from ProQuest.

Potter, P. B. (2001). The Chinese legal system: Globalization and local legal culture. London: Routledge.

Pratt, M. L. (2002). Modernity and periphery: Toward a global and relational analysis. In E. Mudimbe-boyi (Ed.), Beyond dichotomies: Histories, identities, cultures, and the challenge of globalization (pp. 21-47). Albany: State University of New York Press.

Pusey, J. R. (1983). China and Charles Darwin. Cambridge: Council on East Asian Studies, Harvard University.

Red secretary in Australia gets 3 years. (1949, October 17). Toronto Daily Star, p. 1. Retrieved October 3, 2008, from ProQuest.

Robins, K. (2003). Encountering globalization. In D. Held \& A. McGrew (Eds.), The global transformations reader (pp. 239-245). Cambridge: Polity.

Said, E. W. (1993). Culture and imperialism. New York: Vintage Books.

Sayers, S. (1980). On the Marxist dialectic. In R. Norman, \& S. Sayers (Eds.), Hegel, Marx and dialectic: A debate (pp. 1-24). Brighton: Harvester Press.

Schiller, H. (2003). Not yet the post-imperialist era. In M. G. Durham \& D. M Kellner (Eds.), Media and cultural studies: Keyworks (pp. 318-333). Malden: Blackwell Publishing.

Schwartz, B. (1976). History and culture in Levenson's thought. In M. Meisner \& R. Murphey (Eds.), The Mozartian historian: Essays on the works of Joseph $R$. Levenson (pp. 100-112). Berkeley: University of California Press.

She hui zhu yi jing shen wen ming jian she de ti chu yu fa zhan (The advocacy for and the development of the construction of socialist spiritual civilization). (2003). Retrieved March 9, 2009, from http://news.xinhuanet.com/ziliao/200301/20/content_697927.htm

Sheng, Anfeng (2007). Traveling theory, or, transforming theory: Metamorphosis of postcolonialism in China. Neohelicon, XXXIV(2), 115-136.

Shi, Guangquan (2006). Li fa rong he yu zhongguo chuan tong fa lï wen hua de li shi yan jin (The compromise of li and law and historical changes of Chinese traditional 
legal culture). Beijing: Fa lü chu ban she.

Shu Guoying, \& Cheng Chunming (2001). Xi fang fa zhi de wen hua she hui xue jie shi kuang jia (A cultural-sociological explanatory framework for Western rule of law). Tribune of Social Sciences and Law, 2001(4), 135-148.

Smart, B. (1983). Foucault, Marxism and critique. London: Routledge.

Smith, A. (2003). Towards a global culture? In D. Held \& A. McGrew (Eds.), The global transformations reader (pp. 278-286). Cambridge: Polity.

Sreberny-Mohammadi, A. (1997). The many cultural faces of imperialism. In P. Golding \& P. Harris (Eds.), Beyond cultural imperialism: Globalization, communication and the new international order (pp. 49-68). London: Sage.

$\mathrm{Su} \mathrm{Li}$ (2004). Ye xu zheng zai fa sheng: Zhuan xing zhongguo de fa xue (Perhaps it is happening: Legal studies in a transitional China). Beijing: Fa lü chu ban she.

Sun, Yan (2004). Corruption and market in contemporary China. Ithaca: Cornell University Press.

Svensson, M. (2002). Debating human rights in China: A conceptual and political history. Lanham: Rowman \& Littlefield Publishers, Inc.

Tamanaha, B. (2004). On the rule of law: History, politics, theory. Cambridge: Cambridge University Press.

Tay, A. (1986). Law in China: Imperial, Republican, Communist. Sydney: The Centre for Asian Studies, University of Sydney.

Teng, Ssu-yü, \& Fairbank, J. K. (1954). China's response to the West: A documentary survey, 1839-1923. Cambridge: Harvard University Press.

Tomlinson, J. (2003). Globalization and cultural identity. In D. Held \& A. McGrew (Eds.), The global transformations reader (pp. 269-277). Cambridge: Polity.

Tsou, Tang (1986). The Cultural Revolution and post-Mao reforms: $A$ historical perspective. Chicago: The University of Chicago Press.

Tsou, Tang (1994). Er shi shi ji zhongguo zheng zhi: Cong hong guan li shi yu wei guan xing dong de jiao du kan (Twentieth century Chinese politics: From the perspectives of macro-history and micro-mechanism analysis). Hong Kong: Oxford University Press.

van Dijk, Teun A. (1997). Discourse as interaction in society. In T. A. van Dijk (Ed.), Discourse as social interaction (pp. 1-37). London: Sage.

van Dijk, Teun A. (1998). Ideology: A multidisciplinary approach. London: Sage. 
van Dijk, Teun, A. (2004). Discourse, knowledge and ideology: Reformulating old questions and proposing some new solutions. In M. Pütz et al. (Eds.), Communicating ideologies: Multidisciplinary perspectives on language, discourse, and social practice (pp. 5-38). Frankfurt am Main: Peter Lang.

van Dijk, T., et al. (2004). Introduction: Language, discourse and ideology. In M. Pütz et al (Eds.), Communicating ideologies: Multidisciplinary perspectives on language, discourse, and social practice (pp. xiii-xxxi). Frankfurt am Main: Peter Lang.

Wang, Cunhe (2005). Zhi dao bian ge yu fa jing shen zhuan xing (Governance reformation and the transformation of the spirit of law). Beijing: Fa lü chu ban she.

Wang, Hui (2003). China's new order. Cambridge: Harvard University Press.

Wang, Hui (2004). Xian dai zhongguo si xiang de xing qi (The rise of modern Chinese thought). Beijing: San lian shu dian.

Wang, Q. Edward (2001). Inventing China through history: The May Fourth approach to historiography. Albany: State University of New York Press.

Wang, Taixian, \& Ai, Ming (2001). Fa zhi de li nian yu fang lüe (The conception and strategy of the rule of law). Beijing: Zhongguo jian cha chu ban she.

Wang, Xuetai (2007). You min wen hua yu zhongguo she hui (Vagabond culture and Chinese society). Beijing: Tong xin chu ban she.

Wang, Yi (n.d.). Dong Zhongshu de "qu jun li xian" zhi (Dong Zhongshu's "constitutional system that restrains the monarch"). Retrieved July 2, 2009, from http://www.boxun.com/hero/wangyi/24_1.shtml

Wei shen me yao zheng feng (Why the rectification movement). (1957, May 2). People's Daily. Retrieved October 14, 2008, from National Cultural Information Resources Sharing Project.

White, H. (1973). Foucault decoded: Notes from underground. History and Theory, 12, 23-54.

White, H. (1979). Michel Foucault. In John Sturrock (Ed.), Structuralism and since: From Lévi-Strauss to Derrida (pp. 81-115). Oxford: Oxford University Press.

Wiedenhofer, S. (2006). Tradition - history-memory: Why do we need a complex theory of tradition? In T. Larbig \& S. Wiedenhofer (Eds.), Tradition and tradition theories (pp. 375-398). Münster: LIT.

Williams, R. (1977). Marxism and literature. Oxford: Oxford University Press.

$\mathrm{Wu}$, Guo (2006). Chan shi zhongguo de fan shi chong jian ji qi wen ti (Paradigm reconstruction and its problems in the narration of China). Zhongguo Shu Ping, 4. 
Retrieved May 7, 2007, from http://www.xschina.org/show.php?id=6936

Xia, Yong (1999). Fa zhi yuan liu: Dong fang yu xi fang (Origins and developments of the rule of law: From the oriental and Western perspectives). Beijing: Social Sciences Academic Press.

Xu, Bing, \& Min, Sheng (1998). "Lun 'ren quan' yu 'gong min quan"” yi wen de qian qian hou hou (Before and after the publication of the article "On 'human rights' and 'citizens' rights"'). In Guo Daohui, Li Buyun, \& Hao Tiechuan (Eds.), Zhongguo dang dai fa xue zheng ming shi lu (A record of contentions in contemporary Chinese legal studies) (pp. 172-182). Changsha: Hunan ren min chu ban she.

Xu, Xianming (1996). Lun "fa zhi" gou cheng yao jian - jian lun fa zhi de mou xie yuan ze ji guan nian (On the key components of the rule of law: And some thoughts on certain principles and conceptions of the rule of law). Cass Journal of Law, 18(3), $37-44$.

$\mathrm{Xu}$, Zhongming (2000). Si kao yu pi ping: Jie du zhongguo fa lü wen hua (Reflections and criticism: Understanding China's legal culture). Beijing: Fa lü chu ban she.

Ye, Yonglie (2000). Fan you pai shi mo (From the beginning to the end of the anti-rightist movement). Urumqi: Xinjiang ren min chu ban she.

Yu, Dunkang (2006). Zhongguo zhi hui zai Zhou Yi, Zhou Yi zhi hui zai he xie (Chinese wisdom can be found in $Z h o u ~ Y i$, the wisdom of Zhou Yi lies in the idea of harmony). Retrieved July 6, 2009, from http://www.tecn.cn/data/10953.html

Yu, Dunkang (2009). Yi xue de xian dai quan shi (The modern interpretation of Yi). The Century Forum. Video retrieved from http://ishare.iask.sina.com.cn/f/5373519.html

Yu, Yingshi (2004a). Fan zhi lun yu zhongguo zheng zhi chuan tong (Anti-intellectualism and Chinese political tradition). In Shen Zhijia (Ed.), Zhongguo si xiang chuan tong ji qi xian dai bian qian (Traditional Chinese thought and its modern transformations) (pp. 277-315). Guilin: Guangxi shi fan da xue chu ban she.

Yu, Yingshi (2004b). "Jun zun chen bei" xia de jun quan yu xiang quan (The power of the monarch and the prime minister under a system of "honorable monarch and humble subjects"). In Shen Zhijia (Ed.), Zhongguo si xiang chuan tong ji qi xian dai bian qian (Traditional Chinese thought and its modern transformations) (pp. 316-338). Guilin: Guangxi shi fan da xue chu ban she.

Yu, Yingshi (2004c). Qun ji zhi jian (Between collectivity and individuality). In Shen Zhijia (Ed.), Zhongguo si xiang chuan tong ji qi xian dai bian qian (Traditional Chinese thought and its modern transformations) (pp. 78-81). Guilin: Guangxi shi fan da xue chu ban she. 
Yu, Yingshi (2004d). Wu si yun dong yu zhongguo chuan tong (The May Fourth movement and Chinese traditions). In Shen Zhijia (Ed.), Zhongguo si xiang chuan tong ji qi xian dai bian qian (Traditional Chinese thought and its modern transformations) (pp. 82-91). Guilin: Guangxi shi fan da xue chu ban she.

Yu, Yingshi (2004e). Xian Dai Ru Xue Lun zhuo zhe xu (Author's preface to On Modern Confucianism). In Shen Zhijia (Ed.), Zhongguo si xiang chuan tong ji qi xian dai bian qian (Traditional Chinese thought and its modern transformations) (pp. 212218). Guilin: Guangxi shi fan da xue chu ban she.

Zhang, Jinfan (2005). Zhongguo fa lü de chang tong yu ji dai zhuan xing (The tradition and modern transition of Chinese law). Beijing: Fa lü chu ban she.

Zhang, Zhongqiu (1999). Zhong xi fa lü wen hua bi jiao yan jiu (A comparative study of the Chinese and Western legal cultures). Beijing: Nanjing University Press.

\section{Primary materials cited}

$1940 \mathrm{~s}-1960 \mathrm{~s}$

Ai sen hao wei er he Jiang Jieshi hui tan biao ming, meiguo qin lue zhe xu yi zhi zao jin zhang ju shi (The talk between Eisenhower and Jiang Jieshi shows that the American invaders create tensions on purpose). (1960, June 19). People's Daily, p. 4.

Ding, Liao (1957). Shanghai fa xue jie ji hui bo chi Wang Zaoshi Yang Zhaolong you pai miu lun (The assembly of the Shanghai legal studies circle to refute the rightist fallacious arguments of Wang Zaoshi and Yang Zhaolong). Xue Shu Yue Kan, 1957(8), 12.

Dong bei zao chuan suo jian li Han Yousan, wei fa da ren bei pan tu xing, dong bei ri bao hao zhao shu li fa zhi jing shen (Han Yousan, supervisor of the Northeastern vessel factory, sentenced for battery, Northeastern China Daily calling for the establishment of the spirit of the rule of law) (1948, August 15). People's Daily, p. 1.

Dong, Biwu (1954/1984). Guan yu dang zai zheng zhi fa lü fang mian de si xiang gong zuo: Jie lu (About the thought work of the Party on politics and law: Excerpt). In Sun Guohua (Ed.), Fa xue ji chu li lun can kao zi liao (Study material of basic legal theories) (pp. 72-88). Beijing: Zhong yang guang bo dian shi da xue chu ban she.

Dong, Biwu (1956/1984). Jin yi bu jia qiang ren min min zhu fa zhi, bao zhang she hui zhu yi jian she shi ye (Further strengthening people's democracy and legal systems, 
and safeguarding the cause of socialist construction). In Sun Guohua (Ed.), Fa xue ji chu li lun can kao zi liao (Study material of basic legal theories) (pp. 89-102).

Beijing: Zhong yang guang bo dian shi da xue chu ban she.

Dong, Biwu (1957/1984). Zai jun shi jian cha yuan jian cha zhang, jun shi fa yuan yuan zhang hui yi shang de jiang hua: Zhai yao (Speech at the meeting for chief prosecutors of military procuratorates and chief justices of military courts). In Sun Guohua (Ed.), Fa xue ji chu li lun can kao zi liao (Study material of basic legal theories) (pp. 103-114). Beijing: Zhong yang guang bo dian shi da xue chu ban she.

Dou zheng, dou zheng, zai dou zheng (Struggles, struggles, and more struggles). (1964, September 2). People's Daily, p. 4.

Du lu men jiao xiao ji xu qin lue chaoxian zhongguo (Truman clamored for continued invasion of Korea and China). (1951, April 20). People's Daily, p. 1.

Guan yu gan bu qin fan ren quan shi jian rong cheng xian fa xian wei zi wo jian tao (Selfcriticism of the government and Party committee of the Rong county for cadres' violation of human rights). (1950, August 11). People's Daily, p. 3.

Ha'erbin lin can hui re lie jian cha shi zheng gong zuo yi zhi tong guo shi zheng gang ling (The provisional senators of the Harbin city passionately inspect the work of the municipal government and unanimously approve its policy platform). (1946, July 23). People's Daily, p. 2.

Han, Youtong (1957, September 16). Fen sui fa xue jie you pai fen zi de fu bi qi tu (To crash the resurrection plot of the rightists in the field of legal studies). People's Daily, p. 7.

Kang yi mei ao fan dong zheng fu fei fa pan jue ge ming ling xiu, xin fa xue yan jiu hui fa biao sheng ming (To protest against the illegal convictions of revolutionary leaders by the counter-revolutionary governments of the United States and Australia: A statement by the Chinese New Legal Studies Institute). (1949, October 31). People's Daily, p. 1.

Ke, Yue (1957, September 7). Ye shi "liang zhong zhi shi fen zi" lun (On two types of intellectuals). People's Daily, p. 8.

Ken ni di "fa zhi" de biao zhun (The standards of "the rule of law" of the Kennedy administration). (1962, March 24). People's Daily, p. 5.

Li, Guangcan, \& Li, Jianfei (1952, August 22). Su qing fan ren min de jiu fa guan dian (To eliminate the anti-people viewpoints of the old laws). People's Daily, p. 3. 
Li, Qi (1956, November 6). Wei jian quan wo guo ren min min zhu fa zhi er dou zheng (To fight for the perfection of the people's democratic legal system of our country). People's Daily, p. 7.

Liu, Hong (1950, September 26). Zhonggong Anqing di wei gan xiao zheng feng ban, fen xi pi pan qiang po ming ling si xiang (The conduct rectification class of the cadre school of the Anqing Communist local committee: Analysis and criticism of coercion and commandism). People's Daily, p. 3.

Liu, Shaoqi (1954/1984). Guan yu zhong hua ren min gong he guo xian fa cao an de bao gao: Jie lu (The report about the draft Constitution of the People's Republic of China: An excerpt). In Sun Guohua (Ed.), Fa xue ji chu li lun can kao zi liao (Study material of basic legal theories) (pp. 26-61). Beijing: Zhong yang guang bo dian shi da xue chu ban she.

Quan shi jie ren min tong meiguo hei ren zhan zai yi qi (The people of the whole world stand on the side of African Americans). (1967, July 28). People's Daily, p. 6.

Rong cheng qu gan bu qin fan ren quan, xian fu xian wei bao bi gu xi ying jian tao (Cadres of Rong violated human rights, county government and Party committee should review their mistakes of cover-up and indulgence). (1950, July 12). People's Daily, p. 3.

Rui, Mu (1957, July 18). Fan dong jiu fa xue de "hun" zhao de hui lai ma (Can the "ghost" of the old laws be revived). People's Daily, p. 7.

Shanghai tan fan can an (The tragedy of Shanghai peddlers). (1946, December 5). People's Daily, p. 1.

Shen, Junru (1949/1994). Jia qiang ren min si fan jian she, gong gu ren min min zhu zhuan zheng (To strengthen the construction of the people's judiciary work and to consolidate the people's democratic dictatorship). In Zhou Tiandu (Ed.), Shen Junru wen ji (Collected essays by Shen Junru) (pp. 658-662). Beijing: Ren min chu ban she.

Shi, Liang (1952, September 23). San nian lai ren min si fa gong zuo de cheng jiu (The achievements of the people's judicial work in three years). People's Daily, p. 2.

Sun, Xiaolou (1957). Zhongguo gu dian fa xue de yi xie xian shi yi yi (Contemporary relevance of the classical Legalism of China). Fa Xue, 1957(1), 24-30, 9.

Tao, Xijin (1957, September 13). Fa lü jie de dou zheng (Struggles in the legal circle). People's Daily, p. 7. 
Wang, Zaoshi (1957). Jin yi bu jian li min zhu fa zhi zhi xu (To further establish an order based on democracy and legal systems). In Chinese Politics and Law Association (Ed.), Zheng fa jie you pai fen zi miu lun hui ji (Collection of the fallacious arguments of the rightists in the political and legal circles) (pp. 31-33). Beijing: Fa lü chu ban she.

Wu, Defeng (1957, October 4). Fa xue jie fan you pai dou zheng bi xu jin yi bu kai zhan (The anti-rightist struggles in the legal circle must be furthered). People's Daily, p. 3.

Xie, Juezai (1948/1984). Min zhu he fa zhi (Democracy and legal systems). In Sun Guohua (Ed.), Fa xue ji chu li lun can kao zi liao (Study material of basic legal theories) (pp. 115-128). Beijing: Zhong yang guang bo dian shi da xue chu ban she.

Yang, Zhaolong (1956). Fa lü de jie ji xing he ji cheng xing (The class nature and inheritability of law). Fa Xue, 1956(3), 26-34.

Yang, Zhaolong (1957a). Fa lü jie de dang yu fei dang zhi jian (Between the Party members and the non-Party members in the legal circle). In Chinese Politics and Law Institute (Ed.), Zheng fa jie you pai fen zi miu lun hui ji (Collection of the fallacious arguments of the rightists in the political and legal circles) (pp. 105-111). Beijing: Fa lü chu ban she.

Yang, Zhaolong (1957b). Wo guo zhong yao fa dian he yi chi chi hai wei ban bu (Why have important laws not yet enacted in our country). In Chinese Politics and Law Association (Ed.), Zheng fa jie you pai fen zi miu lun hui ji (Collection of the fallacious arguments of the rightists in the political and legal circles) (pp. 86-101). Beijing: Fa lü chu ban she.

Ye, Lan (1952, October 17). Bi xu che di gai ge si fa gong zuo, qing suan fan ren min de jiu fa guan dian (We must completely reform judicial work and liquidate the antipeople viewpoints of the old laws). People's Daily, p. 3.

Yi, Ershan (1962, September 24). Zui xu wei he huang tang de wen jian zhi yi (One of the most hypocritical and ridiculous documents). People's Daily, p. 3.

Yuan, Yuxiu, Qiu, Yanzhen, Wang, Fumin, \& Pan, Zhaoxin (1966, December 6). Yuenan xiong di gan de hao! (Good job for the Vietnamese brothers!). People's Daily, p. 6.

Yue han xun zheng fu shi meiguo ren min de si di (The Johnson administration is the deadly enemies of the American people). (1967, October 27). People's Daily, p. 5.

Zhong gong zhong yang guan yu fei chu guomindang liu fa quan shu yu que ding jie fang qu de si fa yuan ze de zhi shi (Instruction of the Central Committee of the Chinese 
Communist Party about the abolishment of the Kuomintang Six Codes and the establishment of the judicial principles for the liberated areas). (1949/1984). In Sun Guohua (Ed.), Fa xue ji chu li lun can kao zi liao (Study material of basic legal theories) (pp. 1-3). Beijing: Zhong yang guang bo dian shi da xue chu ban she.

Zhong gong zhong yang guan yu zheng feng yun dong de zhi shi (Instruction of the Central Committee of the Chinese Community Party about the rectification movement). (1957, May 1). People's Daily, p. 1.

Zhou, Enlai (1949/1980). Ren min zheng xie gong tong gang ling cao an de te dian (The characteristics of the draft common program of the Chinese People's Political Consultative Conference). In Zhou Enlai, Zhou Enlai xuan ji (Selected works of Zhou Enlai) (pp. 366-371). Beijing: Ren min chu ban she.

Zhu, Xingxi (1957). Bu yao bei you pai fen zi Yang Zhaolong de miu lun suo qi pian (Do not be blinded by the fallacious arguments of the rightist Yang Zhaolong). Fa Xue, 1957(6), 57-58.

1980 s

Ba fa lü jiao gei ren min (To put law in the hands of the people). (June 16, 1985).

People's Daily, p. 2.

Chen, Bohai (1986). Zhongguo she hui yu wen hua chuan tong de zai ren shi

(Reconsidering the Chinese society and its cultural tradition). Quarterly Journal of Shanghai Academy of Social Sciences, 1986(1), 3-?.

Chen, Zhengfu (1988). Ru xue yu xian dai hua (Confucianism and modernization). Journal of the Jiangxi University, 1988(3), 2-7.

Cui, Min (1981, October 12). Fa zhan min zhu, jian quan fa zhi (To develop democracy and to improve legal systems). People's Daily, p. 5

Dang yuan yao zuo zun shou xian fa de dian fan (Party members should be the model in observing the Constitution). (1983, January 24). People's Daily, p. 1.

Deng, Xiaoping (1978/1983). Jie fang si xiang, shi shi qiu shi, tuan jie yi zhi xiang qian kan (jie lu) (To liberate ideas, to seek truth from facts, and to look to the future with solidarity: Excerpt). In Deng Xiaoping, Deng Xiaoping wen xuan di er juan (Selected works of Deng Xiaoping, Vol. II) (pp. 140-153). Beijing: Ren min chu ban she. 
Deng, Xiaoping (1980a/1983). Dang he guo jia ling dao zhi du de gai ge (The reform of the leadership system of the Party and of the country). In Deng Xiaoping, Deng Xiaoping wen xuan di er juan (Selected works of Deng Xiaoping, Vol. II) (pp. 320343). Beijing: Ren min chu ban she.

Deng, Xiaoping (1980b/1984). Guan che tiao zheng fang zhen, bao zheng an ding tuan jie (To implement the adjustment guideline, and to ensure stability and solidarity). In Deng Xiaoping, Deng Xiaoping wen xuan di er juan (Selected works of Deng Xiaoping, Vol. II) (pp. 354-374). Beijing: Ren min chu ban she.

Deng, Xiaoping (1982/1983). Jian jue da jie jing ji fan zui huo dong (To strike sternly criminal activities in the economic realm). In Deng Xiaoping, Deng Xiaoping wen xuan di er juan (Selected works of Deng Xiaoping, Vol. II) (pp. 402-404). Beijing: Ren min chu ban she.

Fei guo min dang ji li fa wei yuan fa biao sheng ming, peng ji dang ju qiang xing tong guo jin ji ju ti quan tiao kuan (Non-Nationalist-Party legislators issue statement to criticize the authorities for enforcing emergency custody clause). (1982, August 20). People's Daily, p. 3.

Feng, Bing (1982, December 7). You "ren zhi" dal "fa zhi" (From "the rule of man" to "the rule of law"). People's Daily, p. 8.

Gao, Zihua (1985). Lüe lun jing ji li fa yu jing ji fan zui he jing ji gai ge (On economic legislation, criminal offences, and reform). Enterprise Economy, 1985(1), 60-61.

Gong, Ce (1981, June 8). Ren Zhongyi tan Guangdong zai dui wai jing ji huo dong zhong jin yi bu luo zhong yang zhi shi, xian tiao yi zhi gu li tou zi gu li chu kou (Ren Zhongyi speaking about the Guangdong province further implementing the instructions of the central committee of the Party in international economic activities, consolidating efforts to encourage investment and export). People's Daily, p. 1 .

Gu, Anliang (1980). Tao lun ren zhi, fa zhi wen ti de shi zhi he yi yi (The nature and implications of discussion about the rule of man and the rule of law). Tribune of Political Science and Law, 1980(1), 65-71.

Guo, Hua (1980). Tan tan ren zhi he fa zhi (Speaking about the rule of man and the rule of law). Academic Research, 1980(1), 87-90.

Jia, Jingping (1985). Zheng fa bu men ying wei pu ji fa lü chang shi duo zuo gong xian (Judicial and public security departments should make more contribution to the popularization of basic knowledge about law). Modern Law Science, 1985(3), 5-6. 
$\mathrm{Li}$, Shuyou (1988). Ru jia lun li si xiang de ji ben te dian (The basic characteristics of Confucian thought on morality). Academic Monthly, 1988(3), 31-38.

Li, Yizhe (1974/1985). On socialist democracy and the legal system. In A. Chan, S. Rosen, \& J. Unger (Eds.), On socialist democracy and the Chinese legal system: The Li Yizhe debates (pp. 31-86). Armonk: M. E. Sharpe Inc.

Liu, Shike (1985). Ti chang fa zhi, bing qi ren zhi (To promote the rule of law and to reject the rule of man). Journal of Huaihua University, 1985(2), 38-45.

Ma, Nan (1984). Kongzi fa lü si xiang ping yi (Comments on Confucius' thought about law). Journal of the Zhengzhou University, 1984(4), 98-104.

$\mathrm{Ni}$, Zhengmao (1986). Fa zhi guan nian gai ge de yi xiang zhong yao ren wu: Che di chan chu ren zhi guan nian (An important task in the reform of legal conceptions: To eradicate the mindset of the rule of man). Social Sciences, 1986(10), 14-17.

Ren da dai biao, zhong gong Jiangxi sheng wei di yi shu ji Bai Dongcai zhi chu, dang zu zhi yao zai xian fa fan wei nei huo dong (Bai Dongcai, people's delegate and first secretary of the Party committee of the Jiangxi province pointed out that the Party must act according to the Constitution). (1982, December 2). People's Daily, p. 3.

Ren ren xue xi xian fa, ren ren zhang wo xian fa (Everybody to study and master the Constitution). (1982, December 24). People's Daily, p. 1.

Tao, Zhuojie (1985). Qing nian he fa quan yi de qin fan yu bao zhang (The encroachment on and the protection of legal rights of the youth). Youth Studies, 1985(7), 38-39.

Wang, Guiwu (1981, March 10). Xue hui shi yong fa lü wu qi (To learn to use law as a weapon). People's Daily, p. 5.

Wang, Hongfu (1983). Ren zhi he fa zhi ti fa tan yuan (To search the origin of the notions of the rule of man and the rule of law). Political Science and Law, 1983(2), 100-102.

Wang, Jingrong (1981). Ru fa dou zheng shi ren zhi yu fa zhi liang zhong tong zhi fang fa de dui li ma? (Is the struggle between Confucianism and Legalism an antagonism between the rule of man and the rule of law as two modes of governance?). Journal of Graduate School of Chinese Academy of Social Sciences, 1981(2), 34-37.

Wang, Liming (1979, January 26). Ren zhi he fa zhi (The rule of man and the rule of law). People's Daily. Retrieved March 2, 2009, from the Database of the People's Daily.

Wu, Daying, \& Liu, Han (1980, March 21). Zheng que ren shi ren zhi yu fa zhi de wen ti (To correctly understand the issue of the rule of man and the rule of law). People's 
Daily. Retrieved March 2, 2009, from the Database of the People's Daily.

Wu, Shihuan (1989). Jian li "fa zhi ti zhi" shi zheng zhi ti zhi gai ge de di yi bu (To establish "the system of the rule of law" is the first step towards political reform). Journal of Gansu Political Science and Law Institute, 1989(1), 6-12.

$\mathrm{Wu}$, Wenhan (1980). Lun ren zhi yu fa zhi (On the rule of man and the rule of law). Gansu Social Sciences, 1980(4), 3-9.

Xie, Bangyu (1982). Jia qiang fa zhi yu dao de shi jian (To strengthen legal systems and moral practice). Law Science Magazine, 1982(3), 16-18.

Yang, Liuqiao (1983). "Wei zheng yi de": Kongzi de zheng shi lun li xue shuo ("To govern by virtue": Confucius' ideas about political morality). Morals and Civilization, 1983(4), 33-34.

Yang, Yonghua, \& Fang, Keqin (1984). Kang ri zhan zheng shi qi shan gan ning bian qu si fa gong zuo zhong guan che tong yi zhan xian zheng ce de ji ge wen ti (Several problems in implementing the united front policy in the judicial work of the shangan-ning region during the anti-Japanese war). Law Science, 1984(4), 67-72.

Ye, Jianying (1978/1984). Zai zhong yang gong zuo hui yi bi mu hui shang de jiang hua (jie lu) (Speech at the closing session of the central work meeting: Excerpt). In Sun Guohua (Ed.), Fa xue ji chu li lun can kao zi liao (Study material of basic legal theories) (pp. 190-191). Beijing: Zhong yang guang bo dian shi da xue chu ban she.

You, Junyi (1985). Jin nian lai fa xue jie dui ruo gan zhong da li lun wen ti de zheng yi (Debates on several important theoretical issues in legal studies in recent years). $F a$ Xue, 1985(11), 5-9.

Yu, Haocheng (1981). Lun fa zhi yu fa zhi gai nian zhi yi tong jian ji yi fa zhi guo de ti fa (On the similarities and differences between "legal systems" and "the rule of law" and on the notion of rule by law). Tribune of Political Science and Law, 1981(1), 912.

Yu, Ronggen (1984). "Ru jia ren zhi fa jia fa zhi dui li lun" zhi yi (Questioning the dichotomization between Confucian rule of man and Legalist rule of law). Modern Law Science, 1984(4), 60-63, 22.

Zai Taiwan "li fa yuan" ju xing de di liu shi jiu qi yuan hui shang, fei guo min dang ji li fa wei yuan peng ji dang ju (Non-Nationalist-Party legislators criticize the authorities at the $69^{\text {th }}$ session of the "Legislative Yuan" of Taiwan). (1982, April 23). People's Daily, p. 3. 
Zhang, Hao (1983). Lun jia qiang fa zhi he dao de jian she (On the strengthening of legal and moral construction). Tribune of Political Science and Law, 1983(3), 37-42.

Zhang, Jinfan (1984). Zhongguo fa zhi shi fa zhan gai lun (An overview of the development of Chinese legal history). Chinese Legal Science, 1984(2), 117-126.

Zhao, Shumin (1983). Dui fa zhi he ren zhi tao lun de ren shi (Understanding about the discussion about the rule of law and the rule of man). Journal of Social Sciences, 1983(5), 54-56.

Zhong gong zhong yang guan yu she hui zhu yi jing shen wen ming jian she zhi dao fang zhen de jue yi (Resolution of the central committee of the Party on the guidelines of constructing socialist spiritual civilization). (1986). Retrieved March 9, 2009, from http://www.people.com.cn/GB/news/6056/20011023/587955.html

Zhongguo gong chan dang zhong yang wei yuan hui guan yu jian guo yi lai dang de ruo gan li shi wen ti de jue yi (jie lu) (Resolution of the central committee of the Chinese Communist Party on several historical problems of the Party since the founding of the PRC: Excerpt). (1981/1984). In Sun Guohua (Ed.), Fa xue ji chu li lun can kao zi liao (Study material of basic legal theories) (pp. 9-13). Beijing: Zhong yang guang bo dian shi da xue chu ban she.

Zhongguo gong chan dang di shi yi jie zhong yang wei yuan hui di san ci quan ti hui yi gong bao (jie lu) (Communique of the third plenary meeting of the eleventh central committee of the Chinese Communist Party: Excerpt). (1978/1984). In Sun Guohua (Ed.), Fa xue ji chu li lun can kao zi liao (Study material of basic legal theories) (pp. 7-8). Beijing: Zhong yang guang bo dian shi da xue chu ban she.

1990s

Bo, Yibo (1993, July 5). Guan yu dang de jian she (About the construction of the Party). People's Daily, p. 5.

Cai, Daotong (1996). Fa lü guan nian de zhuan bian: Zhongguo fa zhi hua de guan jian (Shifts in conceptions of law: The key to the realization of the rule of law in China). Journal of Central Leadership Institute of Politics and Law, 1996(7), 16-18.

Chen, Chunlong (1994). Fa zhi she hui zheng zai dao lai: Zhongguo fa zhi jian she de hui gu yu zhan wang (The rule of law society is approaching: The past and prospect of China's legal construction). Bai Ke Zhi Shi, 1994(10), 3-5. 
Chen, Shuilin (1992, December 2). Shi chang jing ji gei fa zhi jian she dai lai le shen me? (What does market economy bring to the construction of legal systems?). Economic Daily, p. 1.

Cheng, Weili (1994, January 21). Shi chang jing ji xia jing shen wen ming jian she de san da wen ti (Three major issues in the construction of spirituality in market economy). People's Daily, p. 5.

Chi, Shugong (1996). Shandong sheng dang xiao xi tong '96 li lun yan tao hui guan dian zong shu (Summary of viewpoints expressed at the 1996 theoretical seminar of the system of the Party School of the Shandong province). Theoretical Front, 1996(14), 31.

Du, Gangjian (1993). Lun Hu Shi de zi you zhu yi ren quan si xiang (On Hu Shi's liberal thought on human rights). Lanzhou Academic Journal, 1993(6), 19-24.

Du, Gangiian (1994). Dong ou xian zheng gai ge yu ren quan jian she (Constitutional reforms and human rights construction in Eastern Europe). Lanzhou Academic Journal, 78(3), 33-35, 63.

Guo, Daohui (1994). Dui ren quan de fa zhe xue chen si (Considering human rights from the perspective of philosophy of law). Social Sciences in China, 1994(4), 190-193.

Guo, Fengzhi (1994). She hui zhu yi jing shen wen ming jian she yao de zhi yu fa zhi xiang jie he (The construction of socialist spirituality needs the combination of the rule of virtue and the rule of law). Journal of Northeast Normal University, 1994(5), 17-20.

Han, Baishun (1994). Jing ji shen pan gong zuo gong di fang bao hu zhu yi de cheng yin ji dui ce (Local protectionism in court trials of economic cases: Its formation and solutions). Journal of Zhejiang College of Politics and Law, 1994(2), 19-22.

Hao, Tiechuan (1996). Ru jia si xiang yu dang dai zhongguo fa zhi (Confucianism and contemporary Chinese rule of law). Exploration and Free Views, 1996(11), 25-27.

Hashimoto, T. (1995, December 29). Wai zi qi ye de ji dian xi wang (Some hopes of foreign-invested enterprises). People's Daily, p. 2.

Hong, Yaohui (1996, April 20). Shi lun shi chang jing ji de fa lü gui fan (On legal standards in market economy). People's Daily, p. 6.

Hu, Honggao. (1996). Xi fang fa lü wen hua ying xiang yu zhongguo dang dai jing ji fa zhi jian she (The influence of Western legal culture and contemporary economic law construction of China). Journal of Gansu Political Science and Law Institute, 
1996(4), 1-6.

Jiang, Liu (1996, September 28). Lun she hui zhu yi jing shen wen ming de ling hun (On the soul of socialist spirituality). People's Daily, p. 10.

Jin, Pengnian (1994). Lun she hui zhu yi shi chang jing ji tiao jian xia fa lü guan de shi da zhuan bian (On the ten transformations in legal conceptions under the conditions of socialist market economy). Journal of Hangzhou University, 24(4), 78-84, 87.

Li, Chen (1998). Quan li yi shi lun (On rights consciousness). Journal of Central Leadership Institute of Politics and Law, 1998(5), 3-5.

Li, Guoji (1993). Fan fu bai dou zheng de bi ran qu xiang shi "fa zhi" (The necessary solution to corruption is "the rule of law"). Chinese Cadres Tribune, 1993(12), 4445.

Li, Songling (1993). Bao hu xiao fei zhe quan yi, cu jin she hui zhu yi shi chang jing ji jian she (To protect consumer rights and to promote the construction of socialist market economy). Consumer Economics, 1993(Z1), 34.

Li, Yahong (1998). Xi fa zhong yi de wen hua kun huo (Cultural puzzlement in the Chinese transplation of Western laws). Peking University Law Journal, 1998(6), 110-116.

Lin, Ruo (1993). Tan ren da jian du yu fan fu bai de guan xi (On the relation between oversight of the People's Congress and anti-corruption). Theoretical Horizon, 1993(4), 33-35.

Liu, Jinguo (1993). Lüe lun fa zhi yu fa zhi (A brief discussion of legal systems and the rule of law). Tribune of Political Science and Law, 1993(1), 7-14.

Liu, Muyan (1998). Wang Hai xian xiang: Fa li ping shu yu fen jie (The Wang Hai phenomenon: Legal explication and analysis). Peking University Law Journal, 1998(2), 80-84.

Liu, Xinguo, \& Zhang, Jinxian (1994). Shi lun shi chang jing ji yu jing shen wen ming jian she (On market economy and the construction of spirituality). Journal of Hebei Normal University, 1994(supplement), 116, 72.

Liu, Yuanlongtao (1997, March 4). Wang Hai da jia bu bu gao (More progress in Wang Hai's fight against shoddy commodities). People's Daily, p. 10.

Ou, Guiying (1993, September 27). Guan yu fan fu chang lian de fa xue si kao (Thoughts about anti-corruption and the advocacy of integrity from the perspective of law). 
People's Daily, p. 5.

Peng, Chong (1994, September 4). Jia qiang fa zhi jian she shi ren min dai biao da hui de zhong yao zhi ze (It is an important duty of the People's Congress to strengthen the construction of legal systems). People's Daily, p. 3.

Peng, Hanying (1994). Zou xiang jie he: Guan yu zhi ce qu shi de si kao (Towards combination: Considering tendencies of governance strategies). Studies in Law and Market Economy, 1994(5), 93-95.

Qing, Xue (1993, December 6). Fan fu chang lian zhong heng tan (On anti-corruption and the promotion of integrity). Economic Daily, p. 2.

Qiu, Dunhong (1992). Lun "yao ren zhi, hai shi yao fa zhi" (On "whether the rule of man or the rule of law"). Social Sciences in Yunnan, 1992(3), 13-20.

Shen, Guoming (1995). Zhi fa zhong de di fang bao hu zhu yi tan yin (Explorations of the reasons behind local protectionism in the execution of laws). People's Procuratorial Semimonthly, 1995(12), 56-57.

Shen, Zheshou (1996, May 29). Jia qiang he gai shan dui jing shen wen ming jian she de ling dao (To strengthen and improve the leadership in the construction of spirituality). People's Daily, p. 9.

Su, Tianyu (1996). Zhan lüe di wei, he xin, guan jian: She hui zhu yi jing shen wen ming jian she li lun yan tao hui guan dian zong shu (Strategic position, the core, and the key: Summary of viewpoints expressed at the theoretical seminar on the construction of socialist spirituality). Theoretical Front, 1996(13), 30-31.

Tao, Wei (1994). Jia qiang dang de jian she bi xu shu li fa zhi quan wei (The authority of the rule of law must be established in order to strengthen the Party). Chinese Legal Science, 1994(6), 3-4.

Tian, Jingzhao (1995, March 25). Wei ming pai zao shi (To promote brand names). People's Daily, p. 2.

Wang, Dinghe (1995, February 24). Zai Meiguo zuo sheng yi xu "fa" zi dang tou (shang) ("Law" is of paramount importance for doing business in the United States: Part I). Economic Daily, p. 4.

Wang, Qiang (1997). Zhi shi fen zi she hui jue se zhuan huan lun (On the transformation of social roles of intellectuals). Mao Zedong Thought Study, 1997(3), 89-93.

Wang, Xiuqin, \& Wang, Xiufeng (1994). Guan yu ti zhi zhuan huan guo cheng zhong jia 
qiang dang de jian she de si kao (Thoughts about strengthening the construction of the Party in the process of restructuring). Theoretical Front, 1994(24), 5-7.

Wei, Zhanjie, \& Lei, Tang (1997). Zhongguo zhu zuo quan fa lü bao hu de ji dian si kao (Some thoughts on the legal protection of copyrights in China). Journal of Hebei University of Economics and Trade, 1997(4), 56-58.

Wu, Jie (1994). Di fang bao hu zhu yi zheng jie he zai (The reasons behind local protectionism). People's Procuratorial Semimonthly, 1994(7), 50-51.

Wu, Jun (1995, December 6). "Shang biao qiang zhu" shi yu fei (The rights and wrongs of "rushing to register trademarks"). Economic Daily, p. 1.

Xia, Jinwen, \& Cai, Daotong (1997). Lun zhongguo fa zhi hua de guan nian ji chu (On the ideational foundation of the rule of law in China). China Legal Science, 1997(5), 43-51.

Xiao fei zhe shi jia da jia da jia xing dong (Consumers get to know and fight against shoddy commodities: Action for all). (1996, January 18). People's Daily, p. 10.

Xiao, Sailiang (1996, February 13). Yao Wang Hai geng yao "wang fa" (We need state laws more than we need Wang Hai). People's Daily, p. 10.

Xie, Bangyu (1994). Shi chang jing ji shi "fa zhi" jing ji: Dui shi chang jing ji shi "fa zhi" jing zhi ti fa de zhi yi (Market economy is economy of "the rule of law": Questioning the notion of market economy as an economy based on "legal systems"). Theoreticael Front, 1994(10), 6-8.

Xie, Hui (1995). Fa lü gong ju lun: Fa zhi de li lun zhang ai (Legal instrumentalism: Theoretical obstacle to the rule of law). Gansu Li Lun Xue Kan, 1995(4), 50-55.

Xie, Pengcheng (1996). Ren quan yu she hui jin bu (Human rights and social progress). Journal of the Yantai University, 1996(4), 21-27.

Yuan, Yaping (1995, September 9). Hang cheng hu huan gong yi xin (The city of Hangzhou calls for public spirit). People's Daily, p. 5.

Zhang, Dainian (1994a). Zhongguo chuan tong wen hua yu xian dai she hui (Chinese traditional culture and modern society). Philosophical Research, 1994(4), 8-9.

Zhang, Dainian (1994b, December 15). Shi chang jing ji yu she hui zhu yi xin dao de jian she (Market economy and the construction of socialist new virtue). People's Daily, p. 5 . 
Zhang, Gangcheng (1995). Lun fa zhi de jia zhi (On the value of the rule of law). Law Science, 1995(2), 8-14.

Zhang, Hua (1994). Xin de dao de da sha he shi song li? (When will a new moral mansion be established?). China Youth Study, 1994(2), 7.

Zhang, Yunwen (1993, September 25). Hua shuo fa zhi he da jia (Speaking about the rule of law and cracking down on counterfeit commodities). People's Daily, p. 7.

Zhao, Ming (1992). Ru jia fa wen hua de kun jing (The dilemma of the legal culture of Confucianism). Du Shu, 1992(5), 98-100.

Zhong gong zhong yang guan yu jia qiang she hui zhu yi jing shen wen ming jian she ruo gan zhong yao wen ti de jue yi (Resolution of the central committee of the Party on several important issues in the construction of socialist spiritual civilization). (1996). Retrieved March 9, 2009, from

http://www.sirpa.fudan.edu.cn/CPsonline/data/dangdebaogao/forteenth/456601.html

Zhou, Xingwei (1993). Fa zhan shi chang jing ji de ji ge ren shi wen ti (Some conceptual problems in the development of market economy). Journal of Southwestern University for Nationalities, 1993(1), 24-28.

Zhu, Pangzheng (1995). "Fa zhi" yu "fa zhi”: Yi zhong fa lü wen hua xue tan tao ("Legal systems" and "the rule of law": Explorations from the perspective of legal cultures). Journal of Nanjing Normal University, 1995(4), 33-37.

Zhu, Yulong (1993, August 18). Hai shi yao yi fa zhi "zhi" (Law should be relied on for product quality control). Economic Daily, p. 2.

2000s

Dong, Yunhu (2003, July 3). Shi cu jin ren quan hai shi zhi zao dui kang? (Is it to promote human rights or to create confrontation?) People's Daily. Retrieved September 25, 2008, from China National Knowledge Infrastructure.

Dong, Yunhu (2004a, May 22). Ji duan wei shan de ren quan bao gao (The extremely hypocritical human rights report). People's Daily. Retrieved September 25, 2008, from China National Knowledge Infrastructure.

Dong, Yunhu (2004b, April 1). Ping zhong mei ren quan zhi zheng (On the human rights controversy between China and the United States). People's Daily, p. 7. 
Dong, Yunhu (2004c, March 15). "Ren quan" ru xian: Zhongguo ren quan fa zhan de zhong yao li cheng bei (The incorporation of "human rights" into the Constitution: An important landmark in the development of human rights in China). People's Daily. Retrieved September 25, 2008, from China National Knowledge Infrastructure.

Dou, Yongsheng (2001, December 12). Zhi xun: Ren da jian du de zhi ze (Interpellation: The responsibility of oversight by the people's congresses). People's Daily, p. 9.

Fa zhi de zhi, xiang fu xiang cheng (The rule of law and the rule of virtue: Supplementing and promoting each other). (2001, March 13). Guangming Daily, p. B02.

Fu, Dalin (2002, September 4). Rang ren da jian du gui fan hua (To standardize the oversight by the People's Congress). People's Daily. Retrieved September 25, 2008, from China National Knowledge Infrastructure.

Ge, Jiping (2003, December 3). Shi shi xian fa jian du, tui jin yi fa zhi guo (To implement constitutional supervision and to further the ruling of the country according to law). Legal Daily. Retrieved September 25, 2008, from China National Knowledge Infrastructure.

Gu, Yaochang, Gu, Ronghai, \& Dong, Lianxiang (2003). Jin yi bu gai ge he wan shan dang de ling dao fang shi he zhi zheng fang shi (To further reform and improve the leadership style and the mode of governance of the Party). Theory Front, 20, 8-10.

Guo, Xuede (2001). Shi lun zhongguo de "zheng fu tui jin xing" fa zhi dao lu ji qi shi jian zhong cun zai de wen ti (On China's "government-propelled" rule of law and the problems in its practice). Journal of the Zhengzhou University, 2001(1), 20-25.

Hou, Zhaoxun (2001, March 14). Fa zhi de zhi, bi yi shuang fei (The rule of law and the rule of virtue flying along side with each other). Legal Daily, p. 3.

Ji ji ping jia zhongguo ren quan (To praise China's human rights). (2003, April 2). People's Daily. Retrieved September 25, 2008, from China National Knowledge Infrastructure.

Jiang, Guanghui (2001, March 27). Ru jia "de zhi" si xiang de qi shi (Inspirations from the Confucian idea of "the rule of virtue"). Guangming Daily, p. B04.

Jiang, Wei (2003). Fa zhi yu she hui zhu yi zheng zhi wen ming jian she (The rule of law and the construction of socialist political civilization). Journal of the Party School of the Central Committee of the C.P.C., 7(3), 106-111.

Jiang, Zemin (2000). Zai zhongyang si xiang zheng zhi gong zuo hui yi shang de jiang 
hua (The speech delivered at the meeting of the Central Party Committee on ideological and political work). Retrieved June 6, 2009, from http://www.xj71.com/?action-viewnews-itemid-28607-page-2

Jie ren quan xing ba quan nan tao bai ju (It would not succeed to pursue hegemony in the name of human rights). (2001, April 19). People's Daily, p. 4.

Kan, $\mathrm{Ke}$ (2002, August 27). Jian du fa cao an: Shi qi nian feng yu li cheng (The oversight bill: 17 years of adventurous history). Legal Daily. Retrieved September 25, 2008, from China National Knowledge Infrastructure.

Lei, Gaoling (2001). Fa zhi yu de zhi you ji jie he: Guo jia chang zhi jiu an de gen ben da ji (To combine the rule of law and the rule of virtue organically: The primary strategy to ensure the long-term stability and security of the state). Theory Front, 2001(22), 27-38.

Li, Jinyan (2004). Xian zheng shi dai de guo jia quan li yu gong min quan li (State power and citizens' rights in the era of constitutionalism). Theory Front, 2004(23), 23-24.

Li, Jingying, \& Lin, Wei (2000, June 14). Ke shou di yi zhi wu: Guangdong ren da dai biao xing shi jian du quan ji shi (To perform diligently one's primary duty: A record of the members of the Guangdong People's Congress exercising oversight rights). China Youth Daily, p. 9.

Li, Junru (2006). She hui he xie shi zhongguo te se she hui zhu yi de ben zhi shu xing (Social harmony is the intrinsic nature of socialism with Chinese characteristics). Theory Front, 2006(21), 5-8.

Li, Peng (2002, February 11). Li Peng zhi xin zhongguo ren quan yan jiu hui, dui "ren quan" za zhi chuang kan biao shi re lie zhu he (Li Peng wrote to the China Society of Human Rights Studies, congratulating on the inauguration of the Ren Quan magazine). People's Daily, p. 1.

Liang, Cong (2007). Zhong xi fang chuan tong fa wen hua zhong de "fa zhi" ji qi ni xiang ("The rule of law" in traditionsl Chinese and Western cultures and their countercurrents). Guangdong Social Sciences, 2007(1), 161-167.

Liu, Hainian (2002, October 24). Wen hua zi jue yu ren quan bao zhang (Cultural selfconsciousness and human rights protection). Legal Daily. Retrieved September 25, 2008, from China National Knowledge Infrastructure.

Liu, Yuchun (2002, July 9). Shi chang jing ji tiao jian xia de fa zhi yu de zhi (The rule of law and the rule of virtue under the condition of market economy). Guangming 
Daily. Retrieved September 25, 2008, from China National Knowledge Infrastructure.

Lun de zhi he fa zhi de jie he (On the combination of the rule of virtue and the rule of law). (2001, March 27). Guangming Daily, p. B01.

Luo, Guojie (2001, February 22). Fa zhi yu de zhi: Xiang fu xiang cheng, xiang hu cu jin (The rule of law and the rule of virtue: Supplementing and strengthening each other). People's Daily, p. 9.

Ma, Zhenggang (2005). Lun quan li wen ming (On power civilization). Theory Front, 2005(11), 11-13.

Ma, Xiaohong, \& Yu, min (2002). Zhongguo chuan tong de zhi yu fa zhi de si kao (Reflections on Chinese traditional rule of virtue and rule of law). Fa Xue, 2002(9), $15-21,55$.

Pei, Zhiyong (2004, March 29). Qing xi ren quan yan jiu and jiao yu (Passions for the study of human rights laws and education). People's Daily. Retrieved September 25, 2008, from China National Knowledge Infrastructure.

Qi, Jianping (2006). Chuan tong fa lü wen hua ying xiang xia de zhongguo ren quan yi shi (Chinese human rights consciousness under the influence of traditional legal culture). Heilongjiang Social Sciences, 2006(6), 170-173.

Quan guo xuan chuan bu zhang hui yi zai jing zhao kai, Jiang Zemin yu chu xi hui yi tong zhi zuo tan bing zuo zhong yao jiang hua (The national meeting of Publicity Ministers convened in Beijing, Jiang Zemin talking to the comrade attendees and giving an important speech). (2001, January 11). People's Daily, p. 1.

Shen, Songlin, \& Zhou, Jianjun (2003, August 7). Ju ji ping yong zhe xue, da zao gang xing jian du (To fight against soft-line philosophy and to build hard-line oversight). Legal Daily. Retrieved September 25, 2008, from China National Knowledge Infrastructure.

Sun, Yuwei (2006). "He xie she hui fa zhi wen hua" ming ti de li lun yu shi jian (The theory and practice of the thesis of "the culture of the rule of law for a harmonious society"). Fa Xue, 2006(6), 18-27.

Tao, Yanhua (2006). She hui zhu yi he xie she hui yu zhongguo chuan tong wen hua jing shen (Socialist harmonious society and Chinese traditional cultural spirit). Social Sciences Journal of Colleges of Shanxi, 18(7), 4-6, 18.

Tian, Yongsheng (2001, April 3). Tan Mengzi de "de zhi” si xiang (On Mencuis' idea of 
"the rule of virtue"). Guangming Daily, p. B04.

Wang, Feng, \& Zhang, Guoqing (2004, March 9). Ren quan ru xian: Yi guan fang zhen, ben zhi yao qiu (The incorporation of human rights into the Constitution: A longterm guideline and the essential requirements). Legal Daily. Retrieved September 25, 2008, from China National Knowledge Infrastructure.

Wang Hai da jia 14 nian (Wang Hai fighting shoddy commodities for 14 years). (2008, November 13). Qi Lu Wan Bao. Retrieved March 8, 2009, from http://news.sina.com.cn/c/2008-11-13/175116648294.shtml

Wang, Huachao (2000, May 8). "Fa zhi" he "de zhi" ("The rule of law" and "the rule of virtue"). People's Daily, p. 4.

Wang, Qianhua (2001). Zhongguo fa zhi yu de zhi bian xi: Zai chuan tong yu xian dai yu jing zhi jian (An explication of Chinese rule of law and rule of virtue: Between the contexts of tradition and modernity). Journal of the Party School of the Central Committee of the CPC, 5(4), 92-96.

Wang, Taixian (2001). Lun zhongguo fa zhi de ren wen ji chu chong jian (On the reconstruction of the humanist foundation of the rule of law in China). China Legal Science, 2001(4), 7-19.

Wang, Zhenmin (2003). Mi shi de "fa zhi" (The lost "rule of law"). Chinese Cadres Tribune, 2003(10), 22-24.

Wang, Zhongfu (2001). Biao ben jian zhi, zheng dun he gui fan shi chang jing ji zhi xu (To treat the problems at both the surface and the root: To rectify and to standardize the market economy order). Chinese Cadres Tribune, 2001(6), 22-24.

Wu, Bangguo (2006, October 20). Gou jian she hui zhu yi he xie she hui de gang ling xing wen jian (The programmatic document on the construction of a socialist harmonious society). People's Daily, p. 2.

Wu, Guanzheng (2001). Ti gao nong cun gan bu su zhi, jie jue nong cun tu chu wen ti (To increase the caliber of village cadres and to solve major problems in villages). Seeking the Truth, 2001(8), 34-35.

Xie, Pengcheng (2007). Lun she hui zhu yi fa zhi li nian (On the socialist conception of the rule of law). Social Sciences in China, 2007(1), 76-88.

Xiong, Zelong (2003, September 4). Ren da jian du yao tuo zhan "chang kuan gao" (The dimensions of the oversight by the People's Congress should be expanded). Legal Daily. Retrieved September 25, 2008, from China National Knowledge 
Infrastructure.

$\mathrm{Xu}$, Aiguo (2002, November 7). Chuan tong yu fa zhi (Tradition and the rule of law). Legal Daily. Retrieved September 25, 2008, from China National Knowledge Infrastructure.

$\mathrm{Xu}$, Jian (2003, June 24). Qian tan de zhi yu fa zhi de guan xi (A brief comment on the relation between the rule of virtue and the rule of law). Guangming Daily. Retrieved September 25, 2008, from China National Knowledge Infrastructure.

$\mathrm{Xu}$, Xianming \& Song, Yunfeng (2005). Shi lun shi xian fa zhi mu biao de san da ji ben tiao jian (On the three basic conditions for the achievement of the goal of the rule of law). Dang Dai Shi Jie She Hui Zhu Yi Wen Ti (Issues of Contemporary World Socialism), 86, 19-23.

Xue, Weijiang (2006). She hui zhu yi he xie she hui de ke xue nei han (On the scientific meanings of a socialist harmonious society). Theory Front, 2006(19), 13-14.

Yin, Zhen (2004). Zhongguo te se she hui zhu yi min zhu zheng zhi jian she de yi ge zhong da ming ti (A major issue in the construction of democratic politics in a socialism with Chinese characteristics). Journal of the Party School of the Central Committee of the C.P.C., 8(4), 50-54.

Yin, Zhongqing (2004). Jian quan bao zhang zhi du, que bao xian fa shi shi (To strengthen Constitutional protection and ensure the implementation of the Constitution). Seeking the Truth, 2004(24), 43.

Yuan, Shuhong (2002, October 31). Bi xu qiang hua dui xing zheng quan li de zhi yue he jian du (The containment and supervision of the administrative power must be strengthened). Legal Daily. Retrieved September 25, 2008, from China National Knowledge Infrastructure.

Zha, Qingjiu (2002, March 11). Jin yi bu wan shan ren da jian du (To further improve the oversight by the People's Congress). Legal Daily, p. 1.

Zhang, Xiaoyan (2000). Lun yi fa zhi guo yu zhi zheng dang zhi zheng fa shi de bian ge (On governing the country according to law and the reform of the mode of governance of the ruling Party). Ren Da Fu Yin Zi Liao, 2000(4).

Zhao, Ming (2006). Xian qin ru jia lun he xie she hui de gou jian: Jian lun qi dui dang dai zhongguo he xie she hui fa zhi jian gou de jing shen yi yi (Pre-Qin Confucian way of constructing harmonious society: With special consideration to its theoretical implications for constructing legal system of a harmonious society in contemporary China). Journal of Xiangtan University (Philosophy and Social Sciences), 30(5), 
24-32.

Zhao, Wei, \& Xu, Junwei (2001, November 21). Zeng qiang di fang ren da jian du li du (To strengthen the oversight by the local People's Congress). People's Daily, p. 9.

Zheng, Shoucheng (2001, June 20). Jian du yu zhi chi (Oversight and support). People's Daily, p. 11.

Zhong gong zhong yang guan yu gou jian she hui zhu yi he xie she hui ruo gan zhong da wen ti de jue ding (The resolution of the Central Committee of the Party on several major issues in the construction of a socialist harmonious society). (2006).

Retrieved June 26, 2009, from http://news.xinhuanet.com/politics/200610/18/content_5218639.htm

Zhong gong zhong yang guan yu jia qiang dang de zhi zheng neng li jian she de jue ding (The resolution of the Central Committee of the Party on the strengthening of the Party governing capacity). (2004). Retrieved, June 27, 2009, from http://www1.china.com.cn/chinese/2004/Sep/668376.htm

Zhongguo ren quan yan jiu hui fa biao sheng ming zhi chu: Li yong ren quan fan hua bu de ren xin (The China Society For Human Rights Studies issues a statement: AntiChinaism in the name of human rights is unpopular). (2004, April 17). People's Daily. Retrieved September 25, 2008, from China National Knowledge Infrastructure.

Zhou, Hui (2002). Qian tan Deng Xiaoping fa zhi si xiang (On Deng Xiaoping's ideas about the rule of law). Theory Front, 17, 48.

Zhou, Yongkun (2002). Xun qiu xian fa yuan ze xia de de zhi (To seek the rule of virtue under the principle of the Constitution). Fa Xue, 2002(4), 3-8.

Zhu, Jimin, \& Chen, Bo (2001). Dao de jian she yu fa zhi (Moral construction and the rule of law). Theory Front, 2001(20), 13-14.

Zhu, Qunfang, \& Tong, Xu (2001). Ping heng xing zheng quan li yu gong min quan li de fa zhi jie xi (An explication of balancing administrative power and citizens' rights from the perspective the rule of law). Journal of the Party School of the Central Committee of the C.P.C., 5(2), 118-121. 